\title{
TWO POLITICAL WORLDS? RECONSIDERING VERTICAL PARTY INTEGRATION IN CANADA: EVIDENCE FROM ONTARIO
}

\author{
by
}

Scott Pruysers

\begin{abstract}
A thesis submitted to the Faculty of Graduate and Postdoctoral Affairs in partial fulfillment of the requirements for the degree of

Doctor of Philosophy

in

Political Science

Carleton University

Ottawa, Canada

(C) 2015
\end{abstract}

Scott Pruysers 


\begin{abstract}
The accepted view of contemporary federal-provincial party relations in Canada is one of independence, distance, and separation. Rather than creating vertical linkages that bridge the federal and provincial jurisdictions, parties are said to have created "two political worlds", each separate and distinct from the other. The primary purpose of this study is to challenge, or at the very least question, this conventional wisdom about Canadian politics: do parties truly inhabit two political worlds? This is particularly relevant given that there has been very little research on the subject of party integration in the last two decades. Emphasizing the informal, the human, and the local aspects of vertical party integration, this study demonstrates the considerable linkages that exist between federal and provincial parties in Ontario. The analysis presented here reveals a number of important multi-level connections including overlapping personnel, the provision of campaign endorsements, shared campaign teams, the sharing of party resources, and joint social activities and policy discussions in the inter-election period.
\end{abstract}

There is, however, considerable inter-party variation. Therefore, the second purpose of this study is to explain differences among parties. Not all parties respond to multi-level governance in the same way, and it is important to uncover the factors that lead to greater levels of cooperation and collaboration. In doing so, the study evaluates two possible explanations (one based on shared and consistent ideology and another based on formal organizational interconnectedness). While the organizational view tends to dominate the literature, this study demonstrates that organizationally truncated parties (those that operate only at a single level) can establish strong and meaningful multi-level linkages in the absence of any formal organizational connections if they have a coherent ideology that 
spans the federal and provincial realms. This coherent ideology helps to build informal norms of cooperation and collaboration and encourages individuals to participate for the same party at both levels. 


\section{Acknowledgements}

I would like to begin by thanking my committee members Jonathan Malloy and Jon Pammett for their thoughtful comments, time, and support. I couldn't have picked a better committee to work with. I would also like to thank my internal examiner Christopher Dornan and my external examiner Éric Bélanger for taking the time to read my dissertation and for being part of my committee. I am especially grateful to William Cross who has been a tremendous supervisor and mentor. The completion of this project would not have been possible without his ongoing encouragement and guidance. Thank you for encouraging me to publish my results, attend summer schools abroad, and to always consider the broader implications of my research.

Much of the data for this project were derived from a survey that I conducted of constituency association presidents at the federal and provincial levels in Ontario. Although they hold leadership positions within the party, these individuals are largely local volunteers who have their own careers and families outside of politics. I am truly grateful to everyone who took time to answer my emails, agreed to be interviewed, and completed my survey. Without their time and willingness to participate this study would not have been possible.

Throughout the course of my degree I have presented chapters of my dissertation at conferences and submitted papers to a number of journals for publication. The contents of this manuscript are undoubtedly stronger as a result of the thoughtful and thorough comments I have received from countless discussants, reviewers, and editors over the past five years. 
I would also like to thank my wonderful friends and family. My mom, dad, and brother have been a constant source of encouragement and support. To fellow grad students Tyson Flynn, Emmet Collins, Julia Calvert, and Kelly Holmes, you made the halls of Loeb far more pleasant and entertaining! Finally, to my wife Julie, you know more about party integration and multi-level party linkages than you should. Thank you for reading every draft, critiquing every argument, and joyfully telling me when something was "actually interesting". I couldn't imagine doing this without you. 


\section{Table of Contents}

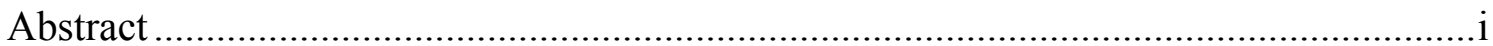

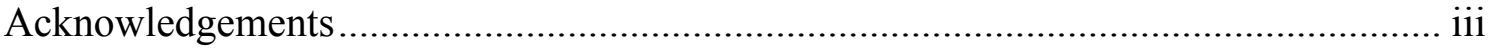

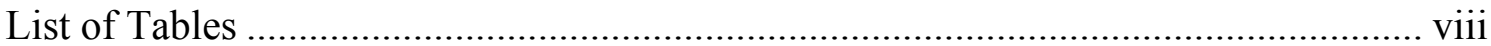

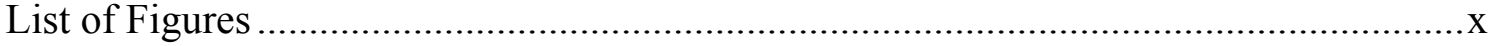

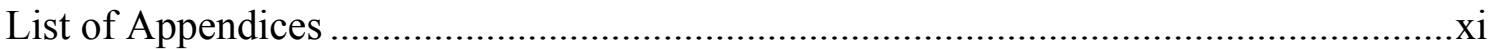

CHAPTER 1: Multi-level Governance and Party Integration ............................... 1

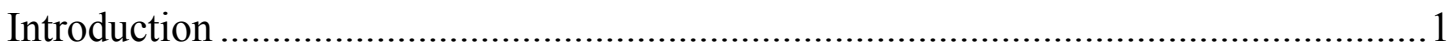

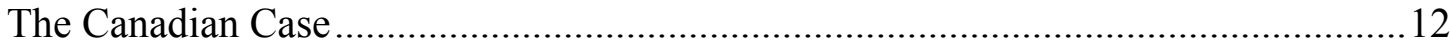

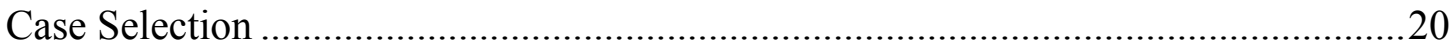

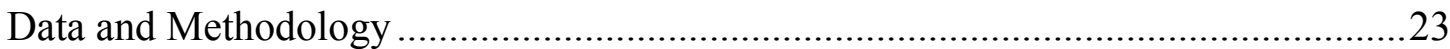

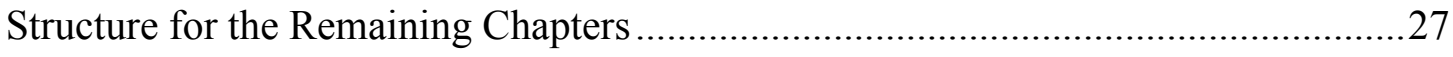

CHAPTER 2: Competing Explanations: Organization or Ideology? ...................... 31

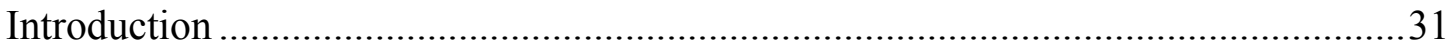

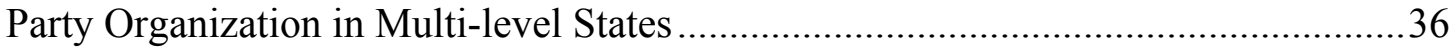

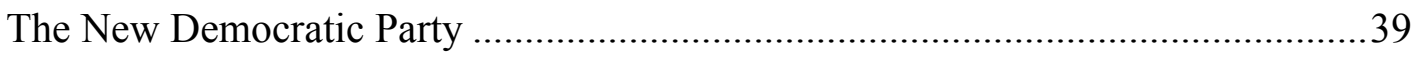

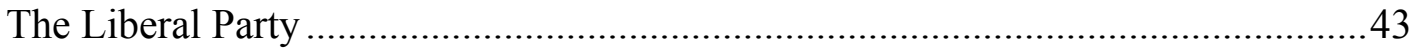

The Conservative Party .................................................................................... 47

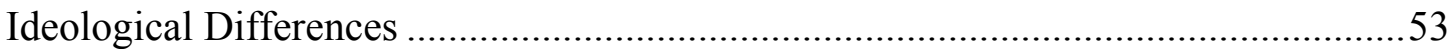

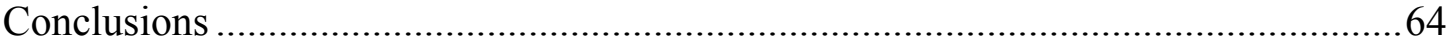

CHAPTER 3: Party Personnel in a Multi-level Context .........................................66

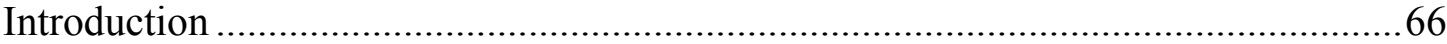

A Framework for Examining Party Personnel in a Multi-level Context......................68

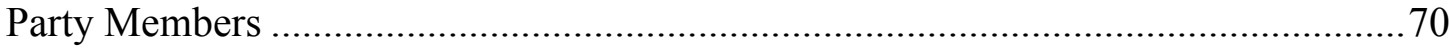

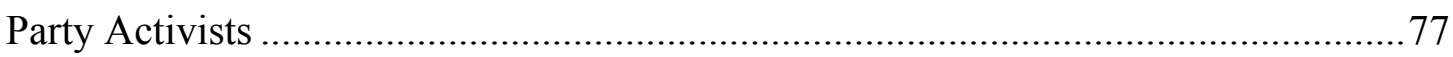

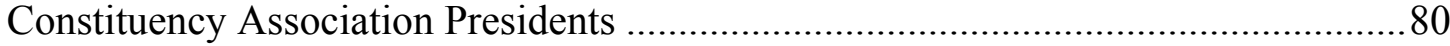

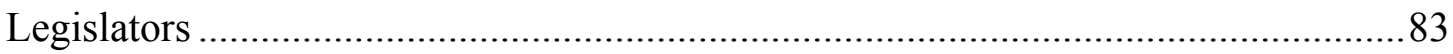

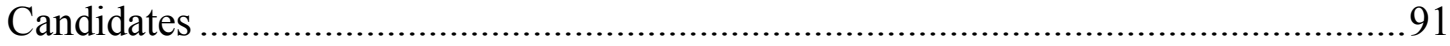

Inter-party Differences in Personnel Integration................................................... 97

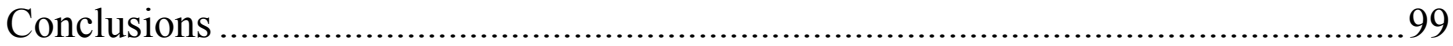

CHAPTER 4: Constituency Associations: A Possible Site for Integration? .......... 103

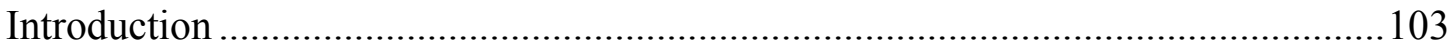

Constituency Associations and Party Integration at the Local Level........................ 104

Constituency Association Survey and Data Collection............................................ 113

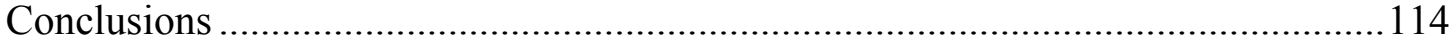


CHAPTER 5: Campaign Integration at the Grassroots ................................... 116

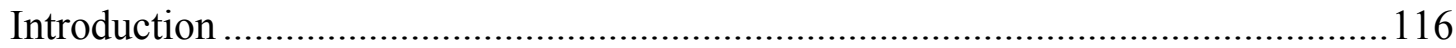

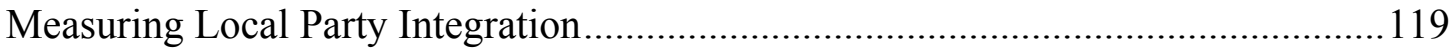

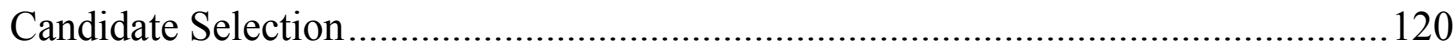

Resources: Volunteers, Data, and Activists ..................................................... 130

Endorsements and Support in Local Campaigns................................................. 138

Constituency Level Differences in Multi-level Campaigning ................................. 146

The General State of Local Campaign Integration................................................. 154

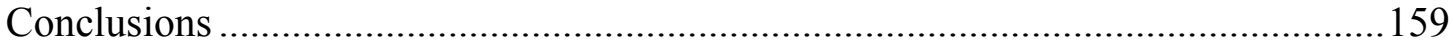

CHAPTER 6: Inter-election Integration at the Grassroots .............................. 160

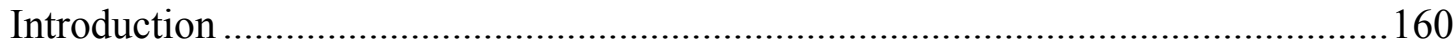

Overlapping and Common Constituency Associations.............................................. 166

Joint Multi-level Social Events and Recreational Activities.................................... 175

Joint Multi-level Policy Discussion and Formation ................................................ 183

Constituency Level Differences in Multi-level Inter-election Maintenance............... 187

The General State of Local Inter-election Integration.......................................... 190

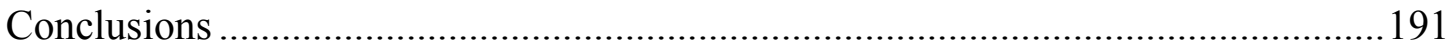

CHAPTER 7: Grassroots Party Integration: Completing the Picture .................. 195

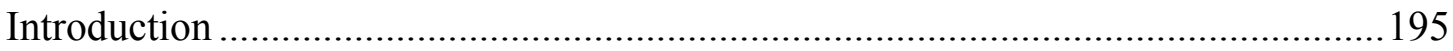

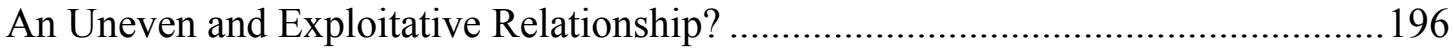

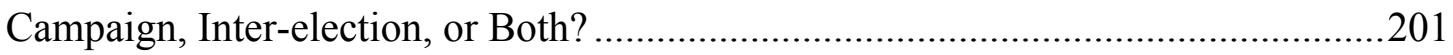

A Typology of Multi-level Constituency Associations...........................................202

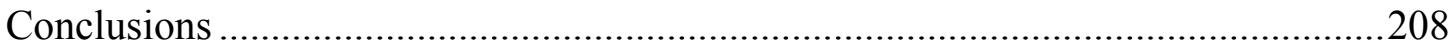

CHAPTER 8: The Province-wide Campaign .....................................................214

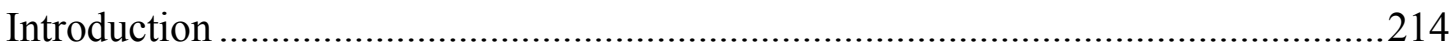

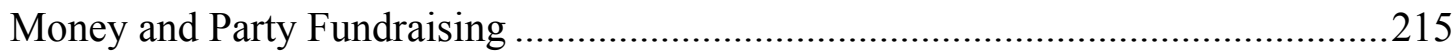

Campaigning: Multi-level Support and Endorsements .......................................220

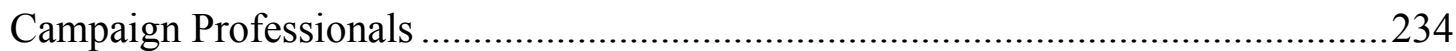

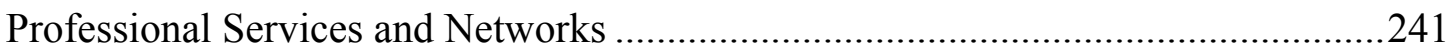

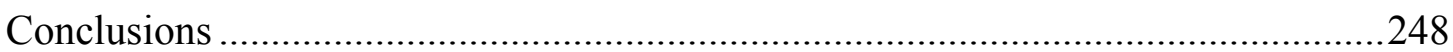

CHAPTER 9: Integration in the Electorate: Common Voters and Shared Partisanship

253

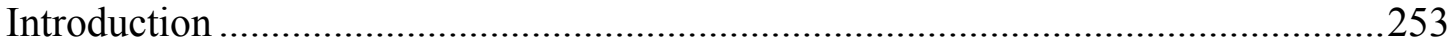

Aggregate Level Data: Cross-Jurisdictional Electoral Volatility............................263

Individual Level Data: Federal and Provincial Vote Intentions..............................268

The 2011 Ontario Provincial Election....................................................................22

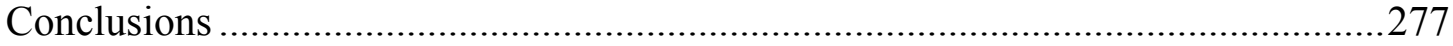




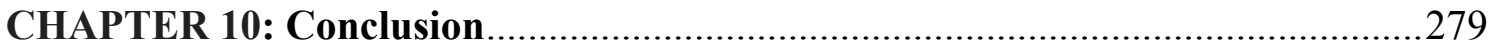

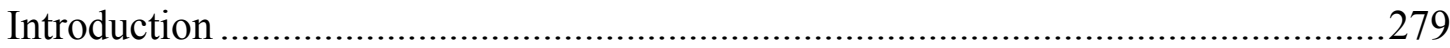

Towards an Explanation of Vertical Integration: Competing Hypotheses ...............285

Implications for Ontario Politics and Beyond ......................................................291

National Unity and Brokerage Politics ..........................................................2294

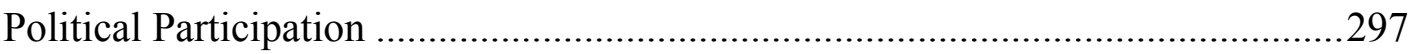

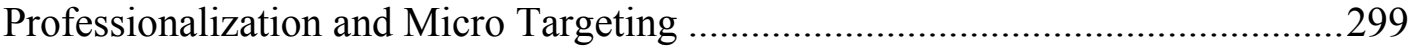

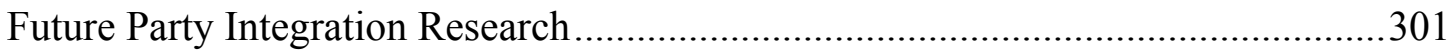

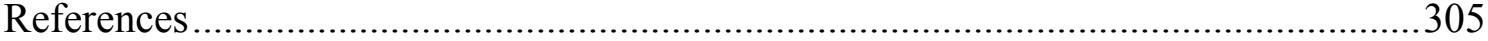




\section{List of Tables}

Table 2.1: Self-Perceived Multi-level Organizational Relationship by Party................52

Table 2.2: Federal and Provincial Right-Left Party Platform Scores Compared (2003-

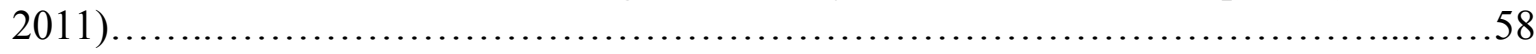

Table 3.1: Types of Party Members by Political Party.......................................74

Table 3.2: Types of Party Activists by Political Party ......................................78

Table 3.3: Membership by Level of Party Activity...................................... 80

Table 3.4: Multi-level Activities of Constituency Association Presidents by Party...........82

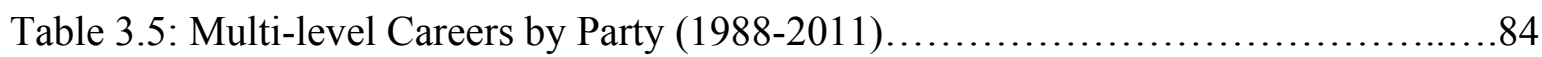

Table 3.6: Summary of Multi-level Personnel Linkages by Party............................99

Table 5.1: Degree of Multi-level Influence in Candidate Selection by Party................123

Table 5.2: Multi-level Campaign Labour and Coordination by Party ......................135

Table 5.3: Frequency of Multi-Level Campaign Visits by Party (2011)..................139

Table 5.4: Summary of Multinomial Regression Results...............................151

Table 5.5: Summary of Binary Logistic Regression Results.............................152

Table 5.6: Integrated Campaign Activities by Party .......................................155

Table 5.7: Degree of Multi-level Campaign Integration by Party ........................156

Table 6.1: Level of Multi-level Constituency Association Executive Overlap by

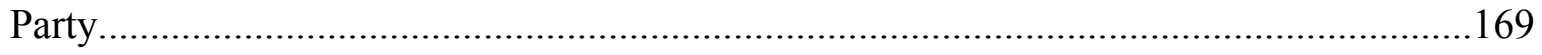

Table 6.2: Multi-level Makeup of Routine Party Meeting Attendance by Party............174

Table 6.3: Frequency of Multi-level Social Meetings by Party..............................179

Table 6.4: Frequency of Multi-level Policy Discussions by Party ...........................184

Table 6.5: Degree of Multi-level Influence in Policy Formation by Party..................187

Table 6.6: Summary of Binary Logistic Regression Results .............................188

Table 6.7: Integrated Inter-election Activities by Party .................................. 190

Table 6.8: Degree of Multi-level Campaign Integration by Party .............................191

Table 7.1: Degree of Campaign Integration (Federal and Provincial Parties

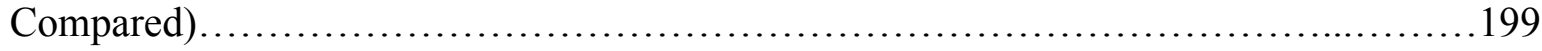


Table 7.2: Degree of Inter-election Integration (Federal and Provincial Parties Compared)

Table 7.3: Multi-level Constituency Association Type by Party............................206

Table 8.1: Federal-Provincial Competition for Funding by Party .........................219

Table 8.2: Shared Professional Services by Party ...................................242

Table 9.1: Federal-Provincial Electoral Dissimilarity (2003-2014) by Party..............267

Table 9.2: Federal and Provincial Vote Intentions (2000-2011) .........................269

Table 9.3: Vote Intention Across Six Elections (Column Percentages) by Party............272

Table 9.4: Multi-level Party Attachment by Party (Which Party do you Feel Closest

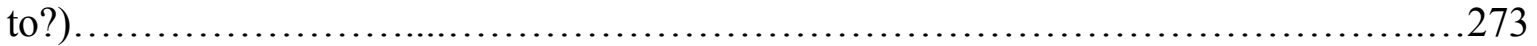

Table 9.5: Profile of Consistent Federal-Provincial Voters (Binary Logistic Regression)... 


\section{List of Figures}

Figure 2.1: Organizational Continuum of Political Parties in Ontario......................51

Figure 2.2: Liberal Platform Ideology Compared (2003-2014)........................59

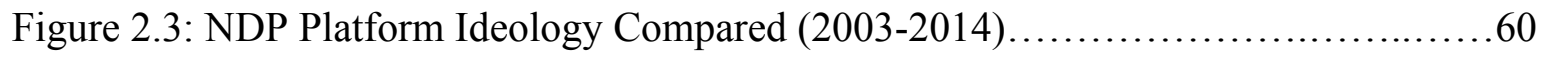

Figure 2.4: Conservative Platform Ideology Compared (2003-2014).....................61

Figure 2.5: Ideological Continuum of Political Parties in Ontario........................64

Figure 9.1: Federal-Provincial Vote Intention Consistency in Ontario (20002011).......270

Figure 9.2: Federal-Provincial Vote Intention Consistency in Ontario By Political Party

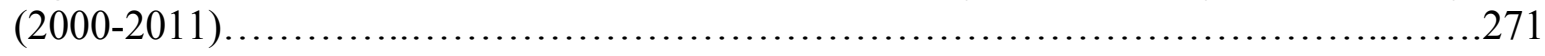




\section{List of Appendices}

Appendix 1: Survey Instrument...........................................327

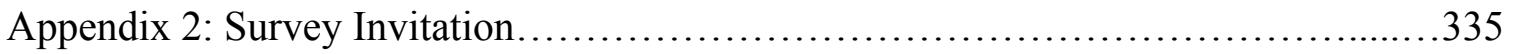

Appendix 3: Survey Reminder............................................ 337

Appendix 4: Survey Consent Form......................................... 338

Appendix 5: Interview Invitation......................................... 339

Appendix 6: Interview Consent Form...................................... 340

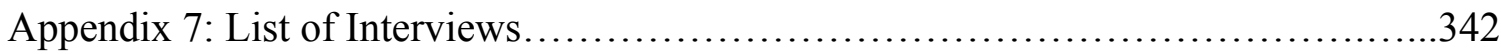

Appendix 8: Comparative Manifesto Left-Right Coding............................343

Appendix 9: McKay-Hunter BBQ Invitation................................. 344

Appendix 10: Midsummer Madness Event Invitation............................345

Appendix 11: Annual Joint BBQ Bruce Stanton, M.P and Garfield Dunlop, M.P.P....346

Appendix 12: Tim and Dean's West Niagara BBQ...............................347

Appendix 13: Provincial PC Announcement for Federal MP Peter Van Loan Event.....348 


\section{CHAPTER 1: Multi-level Governance and Party Integration}

\section{Introduction}

New forms of governance, Hooghe and Marks (2003) write, are dispersing decision-making authority away from the central state towards other governmental arenas in many countries around the world. There is, however, great variation in this dispersion of authority - both in terms of where the power is located (the regional, substate, local, or supra-national levels) and the extent of the division of powers. Despite considerable variation in this changing nature of governance, the dispersion of political authority in this manner is often referred to by a singular name: multi-level governance.

Although there are a variety of different definitions, the fundamental nature of this phenomenon remains the same. Marks, for example, defines multi-level governance as a "system of continuous negotiation among nested governments at several territorial tiers - supranational, national, regional and local" (1993: 392). Hooghe and Marks echo this conception and define it as the "the dispersion of authoritative decision-making across multiple territorial levels" (2001: xi). At its core, then, multi-level governance involves the decentralization of political authority to new locales and spread among different orders of government.

While multi-level governance is often portrayed as a new method of governmental organization (typically in reference to the European Union), it is a rather old phenomenon and can be seen in federal arrangements that have existed for hundreds of years. What is a relatively new phenomenon, however, is the process of regional devolution (Keating and Wilson, 2009; Marks et al., 2008). As Detterbeck (2012:14) 
notes, the traditional federal/unitary distinction is becoming increasingly blurred and less useful in recent decades as the process of electoral devolution has occurred in a number of states. While not a traditional federal state, these new arrangements (which can be seen in countries such as Spain) allow regionally elected governments and parliaments to represent citizens at the regional level and often have significant legislative authority and fiscal resources.

Whether it is electoral devolution in the United Kingdom and Spain, the supranational elections of the European Union, or the federal arrangements found in countries like Canada and Australia, multi-level governance is an increasingly common and widespread phenomenon. In fact, nearly two billion people worldwide live under some form of multi-level governance (Thorlakson, 2006: 37). In general, the institutional environment in which many elections are held and in which many political parties now compete is becoming increasingly multi-layered.

Despite its growing importance, we know very little about the ways in which multi-level governance impacts traditional political institutions such as political parties. While a great deal of attention has been devoted to understanding and classifying party models and the different types of party organizations (Carty, 2002; Duverger, 1954; Katz and Mair, 1995; Kirchheimer, 1966; Krouwel, 2006; Panebiancoo, 1988), emphasis in the party literature has focused on the party at the national level and the focus has tended to be on states that have a unitary structure. As a result, models of party organization rarely take into account the multi-level nature of modern politics. 
Describing what he calls the "national bias of traditional party research", Detterbeck argues that the literature is guilty of "taking the nation state as the ubiquitous institutional and social context shaping party politics" (2012: 2). Deschouwer makes a similar claim, noting that "the language used to analyse party behaviour is intrinsically single-level in nature" (2003: 213). Until very recently, little attention has been devoted to political parties that operate in different contexts. While interest in the European Union (Hix and Marsh, 2011; Poguntke et al., 2007; von dem Berge and Poguntke, 2013), Europarties (Bardi and Calosi, 2009; Ladrech, 2002) electoral devolution (Bradbury, 2006; Fabre, 2008; 2009; Hopkin and Bradbury, 2006), and multi-level governance (Deschouwer, 2003; 2006; Hooghe and Marks, 2001; 2003; Marks, 1993) has begun to redress this issue, there still remains a need to examine political parties in non-unitary states.

One way to study parties and party organization in a multi-level context is to examine the degree of vertical integration that exists between parties at the federal and sub-state level. That is, to study the relationship and linkages between parties at different levels of electoral competition (federal-provincial, European-national, etc.). Like other forms of party organization, the level of vertical organizational integration between parties in multi-level states is said to have important and profound consequences on the health, stability, and functioning of democracy. Indeed, vertical integration between parties in multi-layered systems has consequences for national unity and federal stability (Thorlakson, 2009: 158), the performance of democracy (Riker, 1964: 91), accountability (Dyck, 1996: 184), party strength (Koop, 2012: 4), and intergovernmental relations (Esselment, 2013: 1). 
Riker, for instance, argued that decentralized political parties and a lack of integration would be beneficial for the health and performance of democracy. The separation of federal and sub-state political parties would, he asserted, prevent federallevel political parties from encroaching on provincial or state-level jurisdiction (1964: 91). In this sense, a lack of integration would be best for democracy as the clear disconnect between federal and provincial parties would protect the constitutional division of powers and ensure the proper functioning of the democratic order:

The decentralization of the two-party system is sufficient to prevent national leaders from controlling their partisans by either organizational or ideological devices. As such, this decentralized system is the main protector of the integrity of states in our federation (Riker, 1964: 101).

Others, however, have suggested the contrary, that interdependent party linkages can create stability in a federal state (Filippov et al., 2004). Thorlakson, for example, emphasizes the stabilizing impact of consistent party identification/attachment and stresses how integrated parties can work together at multiple levels of government to create a strong and stable federation (2009: 158). This is of particular importance in large and diverse countries such as Canada where parties are often expected to broker between a number of conflicting and competing interests.

Having close ties between parties at the federal and provincial level can also allow for cooperation and accommodation. Esselment (2013) furthers this argument by demonstrating that the relationship between federal and provincial parties can help ease tensions in intergovernmental relations (IGR), especially when negotiating governmental agreements that span multiple jurisdictions and involve many 
governments of different political stripes. Examining the Meech Lake negotiations (1987-1990) and discussions around the Child Care Agreements (2004-2005), Esselment concludes that "where traditional factors fail to provide a reason for conflict or cooperation between governments, the partisan variable offers valuable explanatory power" (2013: 1).

Party scholars have also considered the impact integration can have on accountability. Some have suggested that decentralization enhances accountability as it allows provincial parties to be unburdened by unpopular federal governments (and vice versa). Others, however, have noted that even if the parties are distinct, voters may be unable to separate them (Dyck, 1996: 184). Given the high informational costs associated with attributing blame in a multi-level political system, Cutler writes that 'federalism and intergovernmental policymaking may reduce voters' ability to hold their governments accountable" (2004: 19; 2008a). When this is the case, accountability can be seriously undermined, as parties at one level can be held accountable for their counterpart's performance at the other level despite the lack of meaningful ties. Empirical evidence supports these claims. In the Canadian case, Gélineau and Bélanger (2005: 407) find that provincial incumbents are "punished for national economic deterioration when the incumbent federal party is of the same partisan family."1 Likewise, Land elections in Germany have historically been used as opportunities where citizens give their judgment on the functioning and performance of the parties at the federal level (Hough and Jeffery, 2006: 8).

\footnotetext{
${ }^{1}$ In fact, the authors go as far as to write that "subnational economic voting in Canada seems to function as a referendum on the federal government" (Gélineau and Bélanger, 2005: 423).
} 
Finally, integration has potential implications for the responsiveness of political parties. In particular, decentralization and disintegration provide provincial parties with more freedom and a greater ability to represent local or territorially defined political interests (Thorlakson, 2009). This is more difficult in an integrated and centralized political party where local branches may have little autonomy to challenge the decisionmaking forces of the centre. An integrated structure provides an incentive to downplay regional differences and stress national unity and the cohesiveness of the party as a whole. These, of course, are normative arguments between effective local representation on the one hand, and federal stability on the other. Neither is inherently better than the other, and both highlight the implications that integration (or lack thereof) can have on broader democratic norms. Examining and understanding the integration of parties in multi-level states is therefore a worthwhile endeavour as its consequences can be significant and far-reaching with implications extending well beyond the political party, impacting broader issues of responsiveness, accountability, and unity.

Despite the numerous and far reaching consequences, little work has been done to understand the causes of party integration or the reasons for differing levels of integration between parties that compete within the same jurisdiction, especially in Canada. While scholars of federalism (Barrie and Gibbins, 1989; Riker 1964; Smiley, 1987) began to explore multi-level linkages among Canadian parties in the 1970s and 1980s, experts of political parties did not enter the debate until the 1990s. Even with the entrance of party scholars, only a small number of studies have examined party integration in any meaningful way (Blake 1985; Dyck 1991; 1996; Esselment, 2010; Koop, 2011; Thorlakson, 2009; 2011). 
Although integration between parties can take a number of forms (ideological, behavioural, cognitive, etc.), organizational linkages dominate the party literature (Thorlakson, 2006). In his discussion of the relationship between provincial and federal political parties in Canada, Dyck suggests that "where a political party functions more or less successfully at both levels of government and where the relations between the two branches are generally close, it can be called an 'integrated' party" (1996: 186). ${ }^{2}$ Huckshorn et al. echo an organizational definition of integration similar to that of Dyck, noting that "Integration involves a two-way pattern of interaction between the national and state party organization" (1986: 978). Likewise, Thorlakson agrees with both Dyck and Huckshorn et al., defining party integration as "the organizational linkages, interdependence and cooperation between federal and state party organizations in both the parliamentary and extra- parliamentary arenas" (2007: 161). For these scholars, integration is first and foremost concerned with the formal structure and organization of political parties.

To study integration, these and most other scholars typically turn to party constitutions and statutes in order to identify and measure the vertical power relations and linkages between political parties at different levels. Does the federal party constitution provide explicit rules for provincial representation at the executive level? Do individual party members who join the party at one level automatically become members at the other level? Are there institutionalized forms of communication between the two levels? These are the indictors that much of the literature looks for when

\footnotetext{
${ }^{2}$ Although much of the focus is on party organization, it should be noted that Dyck does include non-organizational indicators such as policy disputes in his analysis of Canadian political parties.
} 
assessing the level of integration between federal and sub-state parties. What is important in this conception is the formal organizational relationship between federal parties and their counterparts in the provinces. Integration is first and foremost, therefore, an organizational phenomenon.

There are, however, a number of problems and shortcomings associated with this organizational definition of party integration. First, this conceptualization is too vague. What it means for two parties to be "close", for instance, is often unclear and the indicators of closeness are left unspecified. Second, it places too much emphasis on the electoral success of the party. A party that is unsuccessful in a province but shares both resources (capital and personnel) and ideology with its successful federal counterpart surely must be considered somewhat integrated. Indeed, it is unclear theoretically why success is part of a definition of integration at all.

Perhaps the biggest shortcoming associated with this view of party integration, and the literature that it has generated, is what this approach leaves out. The emphasis placed on codified and formalized organizational linkages overshadows other forms of integration such as consistent voter behaviour, shared and consistent ideology, campaign and election support, overlapping party memberships, jointly sponsored party events, local grassroots cooperation, and a number of informal practices and mechanisms that can link parties even in the absence of interconnected party structures. In many cases, these forms of integration are simply ignored in favour of a strictly organizational approach that only explores formal party structures as detailed in party constitutions and statutes (see, for example, Thorlakson, 2009). 
In contrast to the political party research, the organizational theory and management literature has long since recognized informal means of integration between firms. Integration in this domain no longer only focuses on formally connected organizational structures or direct ownership. Instead, this literature looks to partnerships between suppliers and manufacturers, information sharing between different business units, strategic alliances, and so on as evidence of vertical integration (Barrat, 2004; Schmitz et al., 1995). Despite the emphasis of formalism in the party research, other literatures that study a variety of different organizations have moved beyond a strictly formal understanding of what it means for two units to be integrated and connected.

In a similar fashion, the organizational sociology and psychology literature acknowledges the existence of "informal organizations". This literature clearly distinguishes between "formalization" - a term used to describe the degree to which an organization has official rules, regulations, procedures, and structures and other informal networks and norms. Professional networks, common organizational affiliations, and shared goals can shape how individuals work together. An organization may have a formal structure, however, this growing body of research demonstrates how organizations often operate informally (Cross and Prusak, 2002; Krackhardt and Hanson, 1993).

While formal integration is detailed in party constitutions and statutes, informal integration can develop out of the reality on the ground and the day-to-day interactions of the members of the various organizations. It is important to note that all organizations are made up of individuals - and political parties are no exception. Thus, while some 
organizations are economic, cultural, or political in nature, they are all social organizations as a result of the individuals who populate them (Bradley and McDonald, 2011). The social and human aspects of organizations, for example, allow political parties to be integrated through their members and other personnel even when formalization suggests that integration will not occur. Two party organizations, despite not being formally unified may nonetheless create norms of cooperation and collaboration that are transmitted through people rather than documents and structures. Although unofficial, a parallel structure can emerge that complements the existing formal organizational design.

A brief example using party membership will be illustrative of the problems associated with focusing exclusively on formal organizational structures. Due to the strict emphasis on official rules and party structures, federal-level and sub-state political parties that share party members as a result of an organizational requirement are considered to be integrated. By contrast, two parties that operate in the absence of organizational requirements regarding multi-level membership but still manage to achieve high levels of overlapping membership are not considered integrated. Despite the multi-level makeup of party membership in both parties in this example, one is considered vertically integrated while the other is not.

The political party literature must therefore reconsider what it means for two political parties to be integrated: is it the joint membership structure that integrates two parties or is it the members themselves? If it is the latter, if members are integrating agents, then the way two parties come to share members is less crucial than the extent of the common membership. What's more, overlapping and common members are likely to 
contribute to the informal integration of the two organizations in other aspects of party life as well. Given the common membership base, all of the activities that members engage in (personnel selection, campaign activism, etc.) become possible integrating activities between political parties. We should therefore not only look to organizations for measuring and understanding party integration but to individuals and informal practices as well.

As Moon and Bratberg (2010: 56) acknowledge, studying integration and multilevel influence should not only focus on "formal indicators" but must also take into account the "non-formal" behavioural and ideological linkages. ${ }^{3}$ Viewing integration this way recognizes that parties are more than formal rules, constitutions, and structures. At their core, parties are a collective of individuals, or "teams of men" as Downs (1957) defined them. Similarly, Schwartz (1990: 13) defines parties as "a network of actors individual or collective units sharing a party name whose activities have some recognized partisan purpose". Despite their great importance, those individuals who make up parties remain understudied and their role in party integration under-theorized. Indeed, the human element of political parties is often ignored in favour of a more structural/organizational approach. This broader view of what it means for parties to be integrated posits that party personnel, regardless of how or why they overlap, are an integrating force for parties.

Broadening our focus to include other aspects of parties in addition to the formal party organization should yield a much richer understanding of how parties operate in

\footnotetext{
${ }^{3}$ This piece of scholarship, however, is purely conceptual/theoretical and therefore does not implement its call for an examination of integration using informal measures.
} 
multi-level environments. Integration therefore not only involves the interactions and relationships between party organizations but also the formal and informal networks and linkages between other aspects of parties such as their personnel, campaign behaviour, shared voters, and inter-election activities.

\section{The Canadian Case}

Canadian political parties, like many around the world, do not exist in isolation. Rather, they exist and compete in the larger institutional framework of multi-level governance. Federal arrangements in Canada divide governmental jurisdiction between two levels of governance and therefore result in two distinct levels of electoral competition. That is to say, federalism creates two electoral arenas in which political parties can exist and compete for office: federally and provincially/territorially. The Canadian federation is comprised of ten provinces and three territories.

Knowing that a unitary state would not be possible given the regional diversity and the political climate of Canadian society at the time, the founding fathers (reluctantly) agreed upon the creation of a very centralized federation. Smith, for example, describes the fathers of Confederation as "reluctant federalists" (2005:41). Indeed, Macdonald sought such a centralized system that the provinces would be “glorified municipalities" (Knopff, and Sayers, 2005: 109). Upon Confederation, the central government retained considerable power and authority as evidenced by powers of reservation and disallowance, and the residual/reserve power found in the "peace, order and good government" section. 
Over time, however, the centralization of Canadian federalism began to wane and the power of the centre greatly diminished (Cairns, 1988). Largely as a result of a number of crucial judicial challenges during the period of 1890-1940, the powers and autonomy of the provinces grew at the expense of the federal government (Filippov et al., 2004; Gagnon, 2009). This evolution of the federal arrangements in Canada has resulted in one of the most decentralized federations in the entire world (Erk, 2008; Rocher, 2009). The practice of dual federalism (as opposed to cooperative federalism) defines the competitive and often antagonistic relationship between the federal government and the provinces.

This multi-level structure, especially the decentralized federalism found in the Canadian case, provides political parties with a number of opportunities and challenges. In terms of advantages, Canadian federalism provides a relatively simple and elegant framework for party organization: integrating party structures vertically across jurisdictions. Moreover, integration provides federal-level parties with the ability to use provincial parties to create a cohesive and consistent party across the country. Likewise, it provides parties at both levels the ability to draw on one another for capital, human resources, and support. This is especially important when a party at one level is weak or has suffered a recent electoral setback. Finally, this kind of vertical organization allows federal parties to remain connected to citizens and voters which are located in the provinces (Koop, 2011: 4).

Creating strong party linkages, however, also has a number of risks and challenges. Two levels of electoral competition can exhaust party members and activists and can risk dividing scarce resources between two political parties. As political parties 
find it increasingly difficult to attract enough volunteers to run effective local election campaigns (Carty, 1991), the possibility of dividing essential human resources between two levels can be highly detrimental for parties. Worse yet, the integration of two parties can create tension and policy disputes between local/provincial and national interests. This is especially relevant in the Canadian case where provincial parties have often been viewed as the defenders of provincial interests and are expected to take strong stands against the federal government, regardless of which party is in office (Bakvis, 1989; 1991). Finally, unpopular parties at one level can hamper the success of their counterpart at the other level (Koop, 2011: 4), obscuring accountability and creating unwanted electoral obstacles.

Given these different trade-offs, not all parties will respond the same way. Indeed, different parties are likely to adopt different strategies to address the challenges and benefits of federalism. As Chapter 2 illustrates, some parties may choose to establish integrated organizations that link vertically with their counterpart in another jurisdiction while others may decide to remain separate or focus on a single level of electoral competition. Finally, some parties may find it beneficial to link certain aspects of their organization and not others. As a result, federal arrangements provide political parties with a number of different organizational strategies.

Since Dyck's $(1991 ; 1996)$ pioneering work almost two decades ago, emphasis in the vertical integration literature has continued to have an almost exclusive focus on organizational indicators of party linkage such as unitary membership structures, common headquarters, joint representation on party executives, and so on. A narrow 
focus on organization has lead party scholars such as Thorlakson to conclude that Canadian parties are among the most weakly integrated in the world (2009: 169).

The traditional understanding of Canadian parties suggests that they were highly integrated and tightly knit groups in the first half of the twentieth century, but have since become increasingly disentangled as integration has weakened (Esselment, 2010: 871). During Canada's first party system, federal and provincial parties were highly integrated with little distinction between the two levels. Carty, for instance, has written that "local party organizations normally operated at both levels of competition, with members of constituency associations treating federal and provincial political activity as indistinguishable" (1988: 18).

Candidates during this time sought the nomination for election at both levels, often simultaneously, and the party apparatus served the party as a whole, without jurisdictional distinction. In times of electoral defeat, the federal party would fall back on the provincial parties for support as it prepared for the next general election (Koop and Sharman, 2015). During this time, the phrase "a Liberal is a Liberal is a Liberal" was true in both theory and practice. Ultimately, it did not make sense to distinguish between the federal and provincial realms as party organizations were not fully developed and the organizations that did exist worked for the party at both levels without distinction.

This highly integrated and close relationship was a defining characteristic of party organization during the first party system and remained in place until the third party system in which provincial governments emerged as the principal regional 
spokesmen for the provinces (Bakvis, 1989; Carty, 1988). As this period of provincebuilding occurred, provincial parties began aggressively articulating regional grievances and pressured the federal government more forcefully about local demands. The changing dynamics of Canadian federalism and the deteriorating relationship between the federal and provincial realms during this era ultimately resulted in the separation and formal distinction of federal and provincial parties of the same name.

Writing about the Liberals and Conservatives, Smiley noted that they "ceased to be instruments of federal-provincial integration" during this time (1976: 104). This became particularly evident in the 1960s when provincial Liberal parties in Canada's largest provinces (Ontario and Quebec), separated from the federal party. The separation of federal and provincial parties continued to occur in a number of other provinces in the following decades (Chapter 2 provides a more detailed history). The exception to this process of deintegration of party organizations is the New Democrats, a party that was established during this province building era and nonetheless designed strong federalprovincial organizational linkages.

The accepted view is that contemporary federal-provincial party relations are characterized by a high degree of independence, distance, and separation. Much of this work builds on the scholarship of Blake (1985) and Blake, Carty, and Erickson (1991) who concluded that British Columbians lived in bifurcated political worlds: one provincial and one federal, both separate and distinct from one another. As Blake and his colleagues (1991:31) write, "British Columbians exist in two political worlds. The federal world is inhabited by Conservatives, Liberals, and New Democrats; the provincial one largely by Social Crediters and New Democrats. Not only are these 
worlds asymmetrical but the overlap is neither clear nor predictable." However, while this bifurcation was true for voters, the authors noted that activists lived in a more "tightly integrated federal-provincial existence" (Blake, Carty, and Erickson, 1991: 33). Despite this divergent conclusion about activists, the phrase "two political worlds" has come to dominate the discourse around federal-provincial party integration.

Following this work, Stewart and Carty (2006: 107) describe a process whereby federal and provincial political parties in Canada are "becoming increasingly disentangled". Likewise, Bakvis has argued that:

Rather than bridging federal-provincial or interprovincial differences by providing informal avenues for cooperation and consensus building, or for representing regional interests directly in central institutions, the Canadian party system has served to segregate and sharpen conflict between levels of government (1994: 1-2).

Carty and Wolinetz echo this argument, writing that:

Over time, provincial parties and provincial party systems have become increasingly separate from federal parties and the federal party system... Most provincial parties are now organizationally distinct and feel no obligation to adhere to a common party line... The result is a series of federal and provincial party systems that are anything but congruent (2006: $54)$.

More recently, writing about the separation of federal and provincial party systems, Carty and Cross (2010: 199) note that:

Parties of the same name now have distinct and autonomous organizations within an individual province so that, for instance, in Ontario there is both a Liberal Party of Canada (Ontario) and an Ontario Liberal Party operating as quite independent political entities. 
The accepted conclusion has been, therefore, that Canadian parties have responded to the federal structure by opting out of integration. Rather than creating vertical links that bridge the federal and provincial jurisdictions, parties have created "two worlds", each separate and distinct from the other. More than simply opting out of integration, some scholars now view parties as agents of disintegration, acerbating federal-provincial tensions, and sharpening conflict between the two realms (see, for example, Bakvis, 1994).

These conclusions, however, may no longer be true, or at very least be overstated. One needs only to read the newspaper to get a glimpse of the widespread connections that exist between federal and provincial parties in Canada: "Federal Tories not worried about Ontario election results, vow not to repeat Hudak's campaign mistakes" (Abbas, 2014); "Liberal candidate in Toronto by-election gets shot of star power from Ontario premier" (Associated Press, 2014); "NDP MP says Tories, Libs going after NDP mailings to influence Ontario election, Grit calls claim 'absolute paranoid fantasy"” (Naumetz, 2014); "Clement keeps up federal pressure on Wynne" (CBC News, 2014a); "Wynne, Trudeau join campaign trail as by-election nears" (City News, 2013); or "Ontario election foreshadows 2015 federal race" (Herbert, 2014). These are but a few of the recent headlines that highlight the close relationship between federal parties and their provincial counterparts. Despite the behavioural connections, academics and scholars of Canadian party politics and federalism still proclaim the distinction and separation of federal and provincial parties in the country, reinforcing the two political worlds thesis. 
The purpose of this study is therefore threefold. The first is to challenge, or at the very least question, the conventional wisdom about Canadian political parties: do parties truly inhabit "two political worlds"? While there may be few formal connections between federal and provincial parties (Thorlakson, 2009), this does not demonstrate complete distinction and separation. A small but growing body of evidence is beginning to emerge which suggests that federal and provincial parties share important informal networks, human linkages, and behavioural connections (Esselment, 2010; Koop, 2011). Whether it is elite level cooperation among campaign professionals or local volunteers working at both levels, there is some evidence that federal and provincial parties are not as distinct as they are typically portrayed.

Applying the broader and more encompassing definition of integration outlined earlier, one that includes a wide range of informal mechanisms of cooperation as well as the networks of party personnel, this study builds on this emerging literature and demonstrates that federal and provincial parties share a number of important, yet often overlooked, linkages. From overlapping personnel (members, activists, etc.) and shared campaign teams to the provision of campaign endorsements and the sharing of party resources (data, volunteers, etc.) to joint activities and policy discussions in the interelection period, the analysis presented in the following chapters reveals a number of important multi-level connections.

There is, however, considerable inter-party variation in the practice of integration. The second purpose of this study is therefore to make sense of the differences among the various parties. Not all parties respond to multi-level governance in the same way, and it is important to uncover the factors that lead to greater levels of 
cooperation and collaboration. In particular, the next chapter highlights two possible explanations (one based on shared and consistent ideology and another based on formal organizational interconnectedness). While the organizational hypothesis tends to dominate the literature, this study demonstrates that organizationally truncated parties (those that operate only at a single level) can establish strong and meaningful multi-level linkages in the absence of any formal organizational connections if they have a coherent ideology that spans the federal and provincial realms. This coherent ideology helps to build informal norms of cooperation and collaboration and encourages individuals to participate for the same party at both levels.

This study, however, does more than simply examine the linkages between federal and provincial parties. Thus, the third purpose is to reveal something about the parties themselves and how they organize and operate. Given the extensive attention that this study devotes to grassroots party organizations, we are able to gain considerable information about these individual parties, what their operations and internal structures are like, the different activities they engage in (both during and outside of election campaigns), and how healthy and vibrant party life is at the local level (i.e., how many members and volunteers they can attract). While the primary focus is on the multi-level nature of Canada's parties, the following chapters reveal a great deal about Canadian parties more broadly. As the last surveys of local party organizations are now decades old, the data presented here represent an important empirical contribution to the study of Canadian political parties.

\section{Case Selection}


In order to provide a comprehensive examination of party integration and to question the conventional wisdom, this study focuses on Canada's largest province: Ontario. The province of Ontario offers the ideal Canadian case to study party integration for a number of reasons. First, while somewhat incongruent party systems are the norm in Canada (Wolinetz and Carty, 2006), Ontario is an important exception. Both provincially and federally the dominant political parties that capture all of the seats in Ontario consist of the Liberals, Conservatives, and New Democrats. While patterns of government formation have differed slightly (the NDP, for example, has never formed government federally while it has provincially), the major parties competing for office and their patterns of competition are the same. This, of course, is not the same in other provinces where the party systems have dissimilar players - either as a result of provincial specific parties (i.e., Wildrose, Saskatchewan Party, etc.) or different patterns of electoral competition (see, for example, Stewart and Carty, 2006).

Second, unlike many other provinces, Ontario provincial elections share the same electoral boundaries as their federal counterparts - with the exception of one northern federal riding being divided into two ridings at the provincial level. This congruence ensures that local party organizations have meaningful opportunities to forge cross-jurisdictional linkages as they operate in the same predefined electoral space. It also has the potential to create a greater sense of unity and solidarity among parties at different levels within the riding. Perhaps more importantly, however, this congruence holds some constituency level factors constant between the levels (i.e., the urban/rural location of the riding, the population, etc.). 
Third, recent Ontario provincial elections have occurred roughly at the same time as the Canadian federal elections. This includes federal and provincial elections in 2011, as well as federal and provincial elections only a year apart in 2003/2004 and 2007/2008. The close proximity of elections provides party personnel and local associations with sufficient opportunity to be engaged and involved with party politics both provincially and federally. Similarly, this proximity allows us to capture data more accurately and reliably as survey respondents, for example, only need to recall their activities in the year prior as opposed to four of five years.

Finally, as the next chapter illustrates, each of the multi-level party types (integrated, truncated, semi-integrated) is represented by one of the major parties in the province. In other words, there is great variation in terms of how the major parties have organized for multi-level politics in Ontario. This organizational diversity is what allows this study to examine the impact of party structures on the practice of vertical party integration in the Canadian case. Likewise, there is considerable diversity in terms of multi-level ideological consistency and saliency in the province as well, allowing ideological explanations to be compared against organizational ones.

In many respects, the congruence of electoral boundaries, overlapping party systems, and other factors make electoral and party politics in Ontario the best comparative Canadian case. Indeed, Ontario more closely resembles other European federations than it does other provinces in many ways. As such, the lessons learned from this particular Canadian case are likely to have the broadest set of implications for political parties competing in other multi-level states. 
Although exploring party integration in another province (or provinces) would certainly add to our understanding of multi-level party linkages, doing so would mean losing the depth that this analysis is able to offer. Indeed, by focusing on a single province, and all six major parties, this study is able to marshal a considerable amount of evidence from a variety of different sources that simply would not be possible with additional cases.

In terms of the parties to be analyzed, the focus is on the three major parties in Ontario (both federally and provincially) - the Liberals, the Conservatives, and the New Democrats. While there are a variety of other registered political parties that compete in the province, none have been able to capture any significant portion of the popular vote ${ }^{4}$, nor have they been able to win any seats in the provincial or federal legislature. The two elections of 2011 provide the perfect example with the three parties accounting for 96 percent of the popular vote at the provincial level, 95 percent of the federal vote in the province, and 100 percent of the seats at both levels. Thus, the analysis of the Liberals, Conservatives, and New Democrats captures those parties that receive the vast majority of the popular vote as well as those parties that represent all of the seats in the legislature from the province.

\section{Data and Methodology}

The data for this thesis are derived from a variety of sources, often marrying existing datasets and surveys with original data collection and analysis. This includes

\footnotetext{
${ }^{4}$ The fourth largest provincial party in Ontario, for example, received less than three percent of the popular vote in the 2011 election. Similarly, the fourth largest federal party in the province captured less than four percent during the 2011 federal election.
} 
existing survey data of party members (Cross and Young, 2002; 2004) ${ }^{5}$, candidates (Cross and Young, 2011; Cross et al., 2015), ${ }^{6}$ and voters (Canadian Election Study 2004-2011), as well as an original analysis of parliamentary careers, careful exploration of media reports, content analysis of party platforms, a survey of federal and provincial constituency associations, and interviews with party personnel. It is worth briefly expanding on the last three sources of data as this represents the major empirical contribution that this study offers.

Although the Comparative Manifesto Project (CMP) codes Canadian federal election platforms, provincial platforms are not covered in this or any similar database (the one exception is the recent work of Wesley, 2011). Given the traditional emphasis on federal politics, it should come as no surprise that provincial party ideology has not been on the research agenda. In order to remedy this and to compare federal and provincial party ideology for Chapter 2 to set up a baseline of multi-level ideological consistency, I have coded 12 provincial platforms $\left(2014,2011^{7}, 2007\right.$, and 2003 for each party) according to the CMP coding manual. These platforms are compared to federal party platforms issued during the same period $(2011,2008,2006,2004)$ that have already been coded by the CMP team. This original content analysis of campaign

\footnotetext{
${ }^{5}$ The Study of Canadian Political Party Members is a mail-back survey of randomly selected members that was conducted between March and May of 2000. The study includes five political parties (the Liberals, New Democrats, Progressive Conservatives, Canadian Alliance, and Bloc Quebecois) and the dataset includes 3,872 completed surveys, for a response rate of 36 percent. ${ }^{6}$ Federal data comes from a post election mail-back survey of Liberal and New Democrat candidates who contested the 2008 federal election. The dataset includes 170 New Democrat respondents and 168 Liberals, yielding a response rate of 55 percent. The provincial data come from a post election online survey of Liberal and New Democratic party candidates who contested the 2011 Ontario provincial election. The response rate for the survey was 40 percent and included 78 respondents.

${ }^{7} 2011$ platforms were coded as part of the Making Electoral Democracy Work (MEDW) project. See Blais (2010).
} 
manifestos appears to be the first attempt to quantitatively compare federal and provincial party ideology in a systematic and rigorous manner. While platforms are only one measure of party ideology, this represents a crucial step forward in our understanding of the relationship between federal parties and their provincial counterparts.

As already noted, the existing literature suffers from a "national bias" (Detterbeck, 2012; Deschouwer, 2006) and research has only just begun to consider the local level. The most extensive research on integration at the local level has been a small $n$ ethnographic study of 16 Canadian ridings (Koop, 2011). Building upon this in depth ethnographic research, this study provides original survey data of riding association presidents (both federally and provincially) in Ontario in order to truly quantify the relationship between parties at the grassroots level. The online survey, which was conducted in the summer of 2013, is divided into three fundamental modules: the first asks questions specifically about the activities and opinions of the riding association presidents as individual high level local party activists, the second asks a series of questions about the activities of the association as a whole, and the third module focuses on the environment in which the constituency is located.

The dataset consists of 273 responses, which represents an overall response rate of approximately 51 percent. As is often the case with survey research, response rate varied by party: 113 Liberal (53\%), 95 Conservative (45\%) and 64 New Democrat $(60 \%)$ constituency associations responded. While the Liberal and Conservative response rates include federal and provincial associations, the NDP response rate of 60 percent represents federal respondents only. As detailed in the next chapter, the NDP has 
adopted a unified and tightly connected federal-provincial organizational structure and as a result, many of the same individuals who serve as president federally also serve provincially. Attempting to survey both levels therefore became redundant as respondents replied that they had already completed a survey (albeit for the 'other' level). Not wanting to discourage participation by sending repeated mailings and causing confusion or frustration among potential respondents, it was decided to focus on federal associations alone in this case.

Finally, in addition to the content analysis of platforms and the survey of constituency associations, I have conducted semi-structured interviews (in person and via the telephone) with a variety of party officials at different levels of each party. This includes riding association presidents, members of parliament/provincial legislature, campaign professionals, and members of the central party executive. These individuals have provided valuable insight into the realm of federal-provincial party relations and are cited throughout the study. In many ways the interviews are not used for the purpose of 'fact-finding' but rather to provide context, examples, and to bring life to the findings of the more empirical survey evidence.

In particular, the interviews provide concrete examples for the more abstract survey data. While the survey can tell us the frequency in which federal and provincial associations meet with one another for social purposes, the amount of information provided in each observation is rather limited. What are these meetings like? What is their purpose? Who typically attends these events? Interviews help to find answers to these questions. Likewise, interviews help uncover the incentives and motivations for engaging in this kind of integrating behaviour. While the survey data make it clear that 
parties share data, for example, interviews with campaign officials help to corroborate this cooperation as well as uncover the reasons behind such cooperation.

Appendices 1-8 provide more detail on the original data collection that I have conducted. This includes the complete survey instrument, consent forms and invitations (for both interviews and survey respondents), list of interview subjects, as well as more detail on the Comparative Manifesto Project coding of policy positions.

As should be clear from the various sources of data, this study applies a multiple methods approach, combining quantitative survey analysis with qualitative interviews and content analysis. Combining the two approaches helps to "triangulate" results (Mays and Pope, 2000) in order to strengthen the validity and reliability of the claims and conclusions that are being made. As Jick (1979: 602) suggests, "multiple viewpoints allow for greater accuracy". Interviews not only provide greater context and meaning for the survey results, but they also provide legitimacy to the broader findings. Likewise, the appendix provides corroborating evidence from a variety of different sources (websites,

party flyers, social invitations, etc.) that helps to illustrate and strengthen the findings from the survey of constituency association presidents.

\section{Structure for the Remaining Chapters}

The focused examination of Ontario coupled with the extensive data collection and analysis allows for one of the most comprehensive examinations of party integration to date. Chapter 2 details the organizational and ideological differences between federal parties and their provincial counterparts through an examination of party constitutions and election manifesto data. Building on the work of Riker (1964), Smiley (1987), and 
Dyck (1991), the chapter classifies the major political parties in Ontario based on their level of formal organizational connectedness into a threefold classification scheme (integrated, semi-integrated/confederal, and truncated). Using the left-right platform data the parties are similarly classified based on the level of multi-level ideological consistency.

Chapter 3 examines multi-level party linkages from the perspective of party personnel. Adopting a framework from the partisan attachment literature (split, singlelevel, and consistent), the chapter uncovers high levels of consistent multi-level membership and activism among a variety of types of party personnel. This includes party members, activists, association presidents, candidates, and legislators. While there are differences between the parties, the chapter concludes that it is the norm for members and activists of each party to engage in party politics at both the federal and provincial level for the same party.

The next four chapters focus on multi-level linkages at the constituency association level. Chapter 4 highlights the importance of constituency associations as the fundamental building block of party life in Canada (Carty, 1991) and develops the theoretical expectations for the local level as a possible site for integration to occur. Emphasizing the stratarchical nature of Canadian parties and the autonomy of local associations to conduct local party affairs, the chapter offers a number of reasons why local party units might behave in an integrated fashion. This chapter also reviews the limited research on grassroots party integration and highlights the advancements that the following chapters make to this body of literature. 
Chapters 5 and 6 examine associations both inside and outside of election campaigns and explore the extent to which federal and provincial parties coordinate their efforts to win elections and also to satisfy party members. It is not uncommon for parties to hold joint policy discussions, to share election campaign volunteers, to work on coordinated social events, or to provide campaign endorsements for one another. Additionally, both of these chapters examine which types of constituency associations are the most likely to engage in integrated multi-level activities. The results of binary and multinomial logistic regressions reveal a number of important relationships between the level of integration and factors such as incumbency and electoral success.

Chapter 7 then combines the analysis of the election and inter-election period to offer a rich and complete understanding of party integration at the local level, examining questions such as the possibility of an uneven or exploitative relationship. Are federal parties, for instance, taking advantage of their provincial counterparts, ultimately receiving more support than they provide? Despite a history of "resting" on their provincial counterparts, the analysis finds no evidence of an exploitative relationship between federal and provincial parties in this regard. For as much support and resources that federal parties receive, they also provide.

Chapters 8 and 9 shift the attention away from the grassroots and focus on the state-wide campaign and the voters that parties compete for. While local campaigns are important in single member districts (Carty and Eagles, 2005), there are also centralized campaigns that focus on the leaders tour and debate. Chapter 8 considers vertical linkages from this state-wide perspective and examines multi-level party linkages in 
terms of funding/fundraising, campaign professionals, campaign endorsements/support, and shared professional services and networks.

Chapter 9 takes the analysis beyond the parties themselves and explores an often unexplored aspect of integration: shared voters. Using both aggregate and individual level data from a number of recent election campaigns, the chapter examines which parties are the most likely to have common voters and which kinds of voters are the most likely to cast their ballot in a consistent multi-level manner. Despite the tendency to focus on split or single-level identifiers, the chapter reveals considerable multi-level stability in Ontario over the past 15 years. What's more, this stability is a common feature of each of the major parties.

Chapter 10 offers a conclusion, which is divided into four parts. It begins by drawing the various findings together, highlighting and summarizing the level of integration that is found in Ontario. Next, the chapter offers an explanation of inter-party differences in the practice of vertical integration and an evaluation of the competing hypotheses. Third, this is where some of the broader democratic implications of multilevel party integration are revisited. Particular emphasis is given to issues of political participation, micro targeting and data sharing, campaign professionalization, and national unity. Finally, the chapter ends by suggesting new avenues for future research, highlighting the implications that this study has for parties in other multi-level jurisdictions (both other countries and provinces). 


\section{CHAPTER 2: Competing Explanations: Organization or Ideology?}

\section{Introduction}

Why are some political parties more integrated than others? Why do some parties, such as the Partido Popular in Spain, choose to create vertical linkages that connect party organizations across multiple jurisdictions while others, such as Partei Rechtsstaatlicher Offensive in Germany, choose to operate at a single level and eschew all multi-level organizational ties? One recent theory offered by Chhibber and Kollman (2004) suggests that the type of federalism is the answer to different organizational and behavioural responses taken by political parties.

In centralized federations, federal governments control key resources and are in command of important (and prestigious) policy jurisdictions. The result of this centralization is that the sub-state units (be they states, provinces, etc.) are weak by comparison, having limited resources and only controlling minor and less prestigious policy jurisdictions. If political parties at the sub-state level want access to crucial government resources, or at the very least more influence in how those resources are allocated or how policies are developed, they have an incentive to create strong vertical linkages with their party counterpart at the federal level. Therefore, in order to access federal resources, integration between the parties is maximized.

Conversely, where the federation is decentralized, provincial governments are likely to be strong and autonomous, controlling important policy jurisdictions and wielding considerable resources. The result of federal decentralization is that provincial parties have very little incentive to create vertical linkages as the federal party has little to 
offer. Ultimately, sub-state parties in this environment have an incentive to "split" from the federal party and create their own separate and organizationally independent party. ${ }^{8}$ This organizational separation frees the sub-state party from its federal counterpart and allows it to access and control the provincial realm and all of its resources on its own without interference. As Chhibber and Kollman (2004: 21) explain:

Party systems become more national as governments centralize authority; in contrast, there are more opportunities for regional, state, or provincial parties to thrive as provincial or state governments gain more authority relative to the national government.

Following the theoretical foundation of this work, Thorlakson (2009) also suggests that there is a strong and direct relationship between the type of federation and party organization. Examining 27 political parties in seven federations (Canada, Australia, Germany, Austria, Switzerland, the United States, and Spain), Thorlakson (2009: 157) writes:

Clear patterns emerge between the form of federal state design and the predominant form of party organization: in decentralized federations with low coordination requirements between federal and state-level governments, a tendency can be found towards highly autonomous state parties. Where resources are centralized and intergovernmental coordination requirements are high, integrated parties with low autonomy can be found.

There is, however, an important limitation with this theory. Namely, it is not able to offer any insight into why we might witness varying degrees of integration within a

\footnotetext{
${ }^{8}$ This, of course, is not an entirely new idea. Scholars of federalism have, for some time, argued something similar. Riker (1964) and Smiley (1987), for example, argued that federal arrangements were a reflection of the party system.
} 
single jurisdiction (i.e., country, province, etc.). As the previous chapter noted, Canadian federalism is often characterized as being highly decentralized (Erk, 2008; Erk and Swenden, 2010; Detterbeck, 2012; Filippov et al., 2004; Gagnon 2009; Knopff, and Sayers, 2005; Thorlakson, 2006), providing provincial governments with considerable power, resources, and autonomy that rival, if not surpass, those of the federal government. In fact, Rocher (2009: 78) has described the Canadian system as "one of the most decentralized federations in the world" from a comparative perspective.

Following Chhibber and Kollman's theory, we would expect all of the parties operating in Canada's highly decentralized form of federalism to fail to create any meaningful integrative multi-level linkages. With control over significant policy portfolios and resources, provincial parties are not expected to create vertical linkages with their party counterparts at the federal level. Even the limited existing research on the subject of party integration, however, demonstrates that this is not the case (Dyck, 1991; 1996). Canadian parties, both contemporary and historic, have engaged in vertical integration, albeit to differing degrees, despite the institutional incentives to create split or single level organizations. What then, if not the federal arrangement, explains differing levels of integration between political parties operating under the same institutional framework? In other words, what factors help to explain within country variation in the practice of vertical party integration?

When considering possible explanations for the divergent levels of party integration within a single country, two competing explanations can be identified. The first, and the most common view, is a structural perspective. This view of integration posits that interconnected organizational structures provide the channels and incentives 
necessary to promote vertical linkages between political parties in different jurisdictions. While the organizational focus of the existing party integration research is problematic for a variety of reasons, it remains the dominant framework for analyzing vertical party relations in multi-level states (Detterbeck, 2012; Dyck, 1996; Huckshorn et al., 1986; Thorlakson, 2009).

Moreover, despite the criticisms outlined in Chapter 1, the organizational approach has obvious merit. Rules matter, and how parties structure their organization will have clear consequences for their vertical relations. According to this body of literature, having interconnected organizations allows for, and even encourages, the flow of individuals and resources between parties. From this structural perspective, interconnected party organizations both facilitate and incentivize cross-jurisdictional partnerships and relations that extend beyond organizational requirements. In other words, the initial organizational connections foster an environment in which other forms of cooperation and collaboration are encouraged, and ultimately flourish. Where these inter-connected party structures are absent, resources and individuals remain, for the most part, separate and distinct.

H1: Those parties that are formally and organizationally connected will have the highest levels of vertical integration and personnel linkages. Due to organizational incentives, party personnel and party behaviour in interconnected parties will exhibit high levels of party integration and cooperation.

The second, and less common view of integration, suggests that ideology is a powerful force for integration. Tanguay (1992), for instance, has suggested that ideology is often meant for internal party consumption, and that a consistent ideology and a shared commitment to a common vision can create a unified and motivated electoral machine. While Tanguay is writing about party politics at the federal level, the same logic applies 
to multi-level politics. Where federal-level and sub-state political parties share a strong and consistent ideology, they are likely to also share members, resources, activists, and so on. This ideological dimension can help mobilize the same individuals at both levels and provides an incentive for parties that share an ideology to co-operate and co-ordinate their efforts to win elections, regardless of whether the party has formally connected party structures. In other words, ideology can help to create a unified and motivated multi-level electoral, political, and social machine.

Where parties are ideologically inconsistent, they will find it difficult to mobilize the same individuals to participate at both levels and will find little electoral benefit in providing campaign/election support. Activists, voters, and members who are interested in policy at one level are therefore not automatically directed to the party's counterpart at the other level when ideology and policy is inconsistent across levels. It is important to note that ideological consistency therefore not only applies across levels but also across time.

The importance of ideology, however, extends beyond consistency. While having the same ideology across levels is important, the saliency of ideology - how central and important ideology is to a party and its identity - is also critical. A federal-level and substate party may share an ideology, but if that ideology is not equally important to both parties and their members/activists, then this is unlikely to facilitate high levels of vertical party integration.

H2: Those parties with coherent and salient ideology that is consistent across multiple jurisdictions will have the highest levels of vertical integration and personnel linkages. Due to this ideological dimension, party personnel and party behaviour in ideologically coherent parties will exhibit high levels of party integration and cooperation. 
While interconnected party organizations and shared and consistent ideology are often used as the outcome variables in the party integration literature (Detterbeck, 2012; Dyck, 1991; Thorlakson, 2009), this study seeks to explore integration from a broader perspective using organization and ideology as potential explanatory variables. Applying the broader definition of integration that was developed in Chapter 1 (a focus on behavioural, human, local, and informal factors), the subsequent chapters question whether political parties with interconnected multi-level structures exhibit higher levels of multi-level linkages than parties without extensive structural connections. Likewise, the chapters explore whether parties that have a shared ideology that is consistent across multiple jurisdictions achieve higher levels of integration, independent of their organizational structure, than those parties that have inconsistent federal-provincial ideology.

\section{Party Organization in Multi-level States}

Given Canada's long history with federalism, it is not surprising to find that scholars of Canadian parties and federalism were once at the forefront of the party integration literature. In an effort to systematically categorize the different organizational strategies available to parties operating in a multi-level context, Dyck (1991) established a threefold typology of political parties. Building on the earlier work of Riker (1964) and Smiley (1987), Dyck's $(1991 ; 1996)$ analysis of the Canadian case classifies parties based on their level of vertical organizational integration. The three types of parties include integrated, confederal (semi-integrated), and truncated. As Koop (2011) reminds us, however, these party models are ideal types and serve as broad heuristic devices that can help us understand the various strategies parties employ when navigating multi-level 
politics. In practice, integration should be viewed as operating on a continuum with parties falling anywhere between integrated and truncated as some parties can be more or less 'integrated' than others. ${ }^{9}$

Each of the three types represents a different organizational response to the challenges and opportunities parties face as a result of multi-level politics. Integrated political parties have strong vertical linkages that connect federal-level and sub-state party organizations together. Unified membership structures, common personnel selection methods, common campaign teams, and shared party offices are common features of integrated political parties. Given the close organizational relationship, integrated parties typically provide representation on each other's executives and have shared decisionmaking bodies. Moreover, these organizational aspects are often governed by a collective constitution or common set of party statutes and bylaws. State mandated rules and regulations permitting, these parties engage in joint fundraising and have interconnected party finances as well. Likewise, policy disputes are often quite rare and ideological differences are minimal. Suffice it to say, these parties are highly connected in all aspects of party life.

By contrast, confederal (or semi-integrated) parties remain much more autonomous, discrete, and distinct. Despite having party branches that operate at multiple levels, confederal parties typically have single level membership, distinct offices,

\footnotetext{
${ }^{9}$ While the term 'truncated' may carry negative connotations of something that is incomplete or lacking in some sense, I use this particular term because it is well established and embedded within the existing literature on vertical party integration (both in Canada and in the larger comparative literature). Despite the potentially negative connotation, no normative claim is being made about single level parties by applying the label of 'truncated'. As the introduction makes clear, each of the various organizational responses that parties take to multi-level governance has its own set of costs and rewards both for the party itself and the democratic system more generally.
} 
independent personnel, separate campaigns, and so on. In their daily operation, these parties usually bypass each other, having relatively limited communication with one another. Election campaigns, including those individuals who staff them, are largely run independently of the other level. While policy may be similar across levels, this is not a result of considerable multi-level policy discussions or deliberate action. Minor organizational connections, either as a legacy from a more integrated past or purely by design, are likely to be found in these parties. While limited, communication between the different party branches does exist and these parties do have a relationship with each other.

Finally, truncated political parties are single level organizations, operating either at the federal or sub-state level, never both. With an exclusive focus at a single level, truncated parties do not have party branches at other levels and therefore cannot have any cross-jurisdictional formal organizational connections. While a party of a similar name may exist, membership is completely separate, party offices and resources are not unified, and policy can be varied.

Given the different organizational strategies and the variation that can exist, we have the important task of identifying where the major Canadian parties fall along this organizational continuum. Applying the threefold typology described above, the following section seeks to situate Canadian parties and identifies the dominant modes of organizing for multi-level party politics in the province of Ontario. Drawing on the approach used by Thorlakson (2009) and Fabre (2007), the constitutions of each party were carefully examined to uncover the formal organizational connections between each party and its multi-level counterpart. As Thorlakson (2009) suggests, party statutes, 
constitutions, and official party documents are the most readily available and reliable sources of information concerning the vertical relationships between parties. Detterbeck (2012: 131) takes a similar approach in his analysis of European parties in an effort to uncover what he calls the "vertical map of organizational power".

This kind of document analysis, however, is not without limitations. In particular, parties can act differently than the formal rules suggest they will. They can create informal rules and norms that either complement or contradict official party statutes. While parties may behave in a manner that is inconsistent with their own internal rules and statutes, an examination of party constitutions will nonetheless provide a baseline for the level of official formal integration that exists within the major Canadian parties that compete in Ontario. This, of course, also allows us to compare the level of actual integration (how parties truly behave), which is the subject of later chapters, to the level of integration that is outlined in official party documents.

\section{The New Democratic Party}

The New Democratic Party is Canada's most fully integrated multi-level political party. The NDP was set up with, and continues to use, a federated organizational structure that includes fully autonomous (yet organizationally linked) provincial parties. Article XII of the federal NDP Constitution states that "Each province of Canada shall have a fully autonomous provincial Party, provided its constitution and principles are not in conflict with those of the Federal Party" (NDP Constitution, 2013). ${ }^{10}$ The federal party does,

\footnotetext{
${ }^{10}$ This is the case in all provinces except for Quebec. As a result of policy disputes concerning sovereignty in the 1980s, the Quebec wing of the NDP split from the federal party. A majority of the three hundred delegates to the party's convention in 1989 voted to form a fully independent Quebec NDP with no affiliation to the federal party (Picard, 1989). After the federal NDP's
} 
however, retain the authority to determine whether a provincial party is in "good standing" with the party and therefore decides which provincial parties will be members of the broader federated party. In terms of organizational linkages, this ranges from overlapping party membership to shared decision-making.

One of the major distinguishing features of the New Democrats is its unitary membership structure. When an individual joins a provincial New Democratic party, a federal membership is granted automatically. Section 3.06 (1) of the Ontario NDP Constitution states that "each individual member shall be a member of one provincial constituency association and one federal constituency association" (Ontario NDP Constitution, 2014). Similarly, article 3.2 of the Federal NDP Constitution states "Applications for individual membership shall be dealt with in accordance with the constitution of the appropriate provincial Party and shall be subject to the approval of that provincial Party" (Federal NDP Constitution, 2013). It is also the provincial parties that set the price to the membership and the rules associated with party membership (i.e., members are not permitted to belong to another political party at another level).

Thus, those individuals who want to join the federal party must first join the provincial party in their province - at which time they become members of both the federal and provincial party. This multi-level membership ensures that the federal and provincial parties share the same membership in each province and provides a constant

historic breakthrough in Quebec during the 2011 election, the party reaffirmed its commitment to create a more unified provincial party. Federal NDP leader, Thomas Mulcair, asserted that "You can be sure that the NDP will be running in the next provincial election in Quebec" (CBC, 2012a). According to the federal NDP, the party plans to run candidates in each of the 125

ridings in the province during the next provincial election. 
and important human linkage between the two levels. It also means, however, that any issues surrounding provincial membership impact federal membership and vice versa.

As a result of this unified multi-level membership structure, the National President of the Canadian Auto Workers trade union was dismissed from the Ontario NDP due to comments that he made about strategic voting in the federal election. Given the integrated membership design, the only way to remove Hargrove from the federal party was to remove his provincial membership, thereby ejecting him from the federal party simultaneously. By endorsing certain Liberal candidates and encouraging strategic voting at the federal level, the executive of the Ontario wing of the NDP argued that Hargrove had violated the party's constitution and should be expelled from the party (CBC, 2006). Despite his comments having little to do with Ontario politics or his membership in the Ontario NDP, the integrated nature of membership linked the two parties together in a very powerful way.

The New Democratic Party's multi-level connectedness, however, does not stop with unified party membership. Indeed, this approach to organizing for multi-level politics is quite pervasive and influences a number of aspects of party behaviour and structure. Take, for example, the task of candidate selection, one of the most fundamental of all party tasks (Cross, 2004; Cross and Young, 2013). The federal party has not typically included in its Constitution robust rules regarding the selection process ${ }^{11}$; instead the federal party relies on the process outlined by the appropriate provincial party. While

\footnotetext{
${ }^{11}$ Only recently in anticipation of the 2015 federal election has the federal NDP established its own set of candidate selection rules to be applied uniformly across the country.
} 
the federal party retains the authority to intervene where necessary ${ }^{12}$, provincial parties essentially set the rules. Article XV of the 2011 federal NDP constitution states the following:

Subject to section 2 below, candidates shall be nominated in accordance with the procedures laid down in the constitution of the appropriate provincial Party (NDP Constitution, 2011).

Additionally, provincial party offices tend to provide administrative support and service both levels of the party, which ensures continued and frequent contact between the multiple branches and their staff (Dyck, 1991: 208; personal interviews). And where electoral boundaries permit, constituency associations are closely connected and individuals often serve as riding presidents for both the provincial and federal party, creating another human and structural linkage between the two organizations.

Beyond regular communication, the party also ensures multi-level representation on key decision-making bodies. As outlined in the federal NDP Constitution (article VIII.2), two officers from each provincial party have a seat on the federal council, safeguarding provincial representation at the federal level. It is important to note that this is not simply a symbolic gesture given to the provincial parties. Indeed, the federal council has significant authority, as it is the governing body of the party between party conventions. In a similar fashion, the provincial council provides federal representation in the form of "Two members elected by and from the federal caucus" (Ontario NDP Constitution, 2013).

\footnotetext{
${ }^{12}$ The federal NDP, for instance, is committed to ensuring that riding associations engage in a thorough search for women and ethnic minority candidates. In this sense the party has rules concerning candidate nominations. The provincial party, however, determines the more basic rules of the selection process.
} 
Additional evidence of the party's organizational integration can be seen in the fact that federal and provincial New Democratic parties alternate conventions so they do not occur in the same year; both allow elected members and former leaders to act as delegates to each other's party convention; and the ability for provincial parties to submit resolutions to be discussed at the federal NDP convention. Overall, federal and provincial New Democratic parties share a number of important organizational linkages that range from joint party membership and overlapping party staff to representation on party executives and shared office space.

\section{The Liberal Party}

The federal Liberal Party is a federation of provincial organizations. The Liberal Party of Canada (Ontario), for example, is the formal organization that the party has in the province of Ontario. Likewise, The Liberal Party of Canada (British Columbia) takes care of matters in that province, and so on. Taken as a whole, these regional branches of the federal party form a federated Liberal Party of Canada. These regional branches are, for the most part, distinct from the provincial Liberal parties in these provinces (i.e., the Liberal Party of Ontario). As we will see, however, some organizational connections remain, and in some provinces the organizational relationship is stronger than others.

Historically, the Liberals operated a unified multi-level party that was similar in structure to what the NDP currently practices. For nearly a century after Confederation, for example, federal and provincial Liberal parties remained organizationally connected, sharing resources, personnel, and supporting each other during election campaigns (Carty, 1988). This interconnected party structure and federal-provincial reliance, however, often 
resulted in tension between the different levels of the party. Writing about a public feud between Prime Minister King and Ontario Premier Mitch Hepburn, Whitaker (1977: 327) noted that:

The most immediate weapon which Hepburn could utilize was the control of the provincial leader over the party organization in the province, and the exclusion of the federal party from direct access to the party machinery. Since the Liberal party had never developed separate federal and provincial organizations to any extent, a strong provincial leader could squeeze the federal leaders out of the picture by the simple expedient of dominating the existing party machinery.

By ordering his provincial organization and activists to withhold any support from the federal Liberal Party and its candidates in the province, Hepburn significantly reduced the federal party's ability to run an effective election campaign in the province and demonstrated a potential cost of integrated multi-level party organization as King was deprived of the provincial party's electoral machinery. These tensions continued until the 1960s when provincial parties in Canada's two largest provinces split from the federal party and created their own, organizationally distinct and independent, provincial Liberal parties.

Thus, while there are contemporary provincial wings of the Liberal Party, unlike the NDP, each provincial wing retains autonomy and control over its own affairs. In Ontario, for example, party memberships are separate at each level and members must join each level individually if they desire to participate as a "Liberal" party member both federally and provincially. Like membership, the Liberal Party of Ontario has its own 
constitution and executive that is fully independent from the federal party. Moreover, unlike the NDP, there is no prohibition on differing party membership across levels.

This independence, however, has not prevented parties from remaining connected in many ways. Beyond sharing a name, the Ontario branch of the Liberal Party of Canada and the Ontario Liberal Party have shared a headquarters for nearly two decades (Esselment, 2010: 886) located at 10 St. Mary Street in Toronto. This, of course, is no accident. Despite the organizational separation, the two parties still have a close relationship. Being located in the same building helps to foster a sense of community and solidarity among federal and provincial Liberals in the province. Although staff for each party is distinct, this represents a formal and co-operative arrangement between the parties nonetheless. Moreover, as Dyck notes, "there is regular contact between national headquarters and the various provincial party offices" (1991: 190), an observation that is consistent with interviews with party personnel at both levels.

Furthermore, both the federal and provincial Liberal constitutions provide each other with delegates to party conventions (federal Members of Parliament or the Senate from Ontario, for instance, are invited to be voting delegates at the provincial Liberal convention) and other forms of representation (Liberal Party of Ontario, 2012). An important distinction, however, is that this representation does not go as far as what the NDP offers. The federal Liberal council, for instance, does not include representation from the Liberal Party in Ontario. ${ }^{13}$ Major decision-making bodies remain detached from the kind of multi-level influence that is so common in the New Democratic Party. This, of

\footnotetext{
${ }^{13}$ It should be noted, however, that the Liberals ensure provincial representation in their own way. Rather than a multi-level linkage, the federal party provides representation to its federal branches located in each of the provinces.
} 
course, is not to trivialize the fact that provincial Liberals are invited to act as delegates to federal conventions (and vice versa) which is still a sign of cooperation and collaboration. Rather it is meant to highlight the different approaches that the Liberals and New Democrats take to the issue of multi-level party politics.

Finally, the federal and provincial Liberals in Ontario have coordinated to create joint auxiliary units. The Ontario Young Liberals (OYL), for example, service the party at both levels. As the Ontario Young Liberals constitution states, the OYL are the "officially recognized youth organization for the Liberal Party of Canada (Ontario) and the Ontario Liberal Party" (OYL Constitution, 2014). Its membership is made up of the youth (i.e., those younger than 25) of both the Ontario Liberal Party and the Liberal Party of Canada (Ontario) and executive members of the organization are invited to both provincial and federal events.

The same is true for the Ontario Women's Liberal Commission (OWLC). The preamble of the OWLC constitution highlights the relationship, going as far as to refer to both parties as a singular 'Liberal Party':

Determined to preserve the basic principles of substantive equality and enhance the participation and role of women in, the political process at all levels within the structural context of the Ontario Liberal Party ("OLP"), the Liberal Party of Canada (Ontario) ("LPC(O)") and the Liberal Party of Canada (together referred to as the "Liberal Party") and in association with the NWLC, the Ontario Women's Liberal Commission exists to ensure equal participation and involvement by women in the political process (OWLC Constitution, 2009).

As a result of this independent yet connected organizational design, the Liberal Party in Ontario can be best understood as a semi-integrated party type. While this is true 
for Ontario, it should be noted that this is not the case for the Liberal Party in other provinces. In the Atlantic provinces (as well as Saskatchewan), for example, the Liberal Party remains organizationally integrated, typically having one constitution, shared headquarters, and integrated party memberships (Esselment, 2009: 96). In the western provinces, however, the relationship is characterized by a greater degree of separation and distinction. Here there are separate party memberships, distinct constitutions, and individual executives. ${ }^{14}$

\section{The Conservative Party}

The federal Conservatives have no formal organizational ties to their provincial counterparts in any of the provinces. ${ }^{15}$ When the federal Progressive Conservative Party, a party that had provincial wings across the country, and the Canadian Alliance, a party that existed only at the federal level, merged in 2003 to establish the new Conservative Party of Canada (CPC), the party had crucial organizational decisions to make. Confronted with the multi-level framework of Canadian politics, the newly formed CPC embraced a truncated organizational structure and made no effort to form provincial wings of the party. As such, the party operates at a single level and remains organizationally distinct from the existing PC parties in the provinces.

The Constitution of the federal Conservative Party makes it clear that it will continue to operate as a truncated party. Article 15, for example, states that "The Party

\footnotetext{
${ }^{14}$ The "splits" between federal and provincial Liberal Party's happened in the following order: Quebec (1964), Ontario (1976), Alberta (1977), British Columbia (1991), and Manitoba (2002). ${ }^{15}$ Minor courtesies, however, do occur. The Federal Conservative Constitution, for instance, allows the leaders of provincial PC parties who are federal party members to be voting delegates at the national convention. The Ontario PC Constitution includes a similar clause, extending the privilege to CPC candidates and Members of Parliament.
} 
shall not establish provincial political parties" (Conservative Party of Canada Constitution, 2011; emphasis added). This organizational separation, however, does not automatically rule out the possibility of informal cross-jurisdictional cooperation and collaboration. The federal Conservative Constitution, for example, notes that "The Party shall promote and maintain relationships with existing provincial conservative parties" (Conservative Party of Canada Constitution, 2011).

This constitutionally entrenched commitment to cooperate with 'conservative' parties allows the federal party considerable flexibility when choosing its multi-level partners. It does not, for example, rule out the possibility of working closely with the Saskatchewan party, the Wildrose, and the Progressive Conservatives simultaneously. Note that this constitutional commitment to cooperate with provincial parties is specifically based on a conservative ideology rather than a specific organizational and institutional structure.

This approach, collaborating with provincial parties rather than creating formal organizational linkages, comes more from the Reform roots than from the PCs. Prior to merging in 2003, the Reform/Alliance made a clear decision not to create separate provincial wings of the party. Instead, the party only operated at the federal level. In fact, the first Reform Party Constitution (1987) did not mention provincial politics at all - no mention of the possibility of creating its own provincial organizations, cooperating with existing parties, and so on. In this regard the Reform party began as the quintessential truncated political party: operating at and focused on a single level of jurisdiction. This of course, was in direct contrast to the Progressive Conservatives, a federal party with established provincial parties across the country. 
These different philosophies in terms of multi-level party organization naturally caused tension during the merger negotiations, as there was no clear or obvious way forward. To create new provincial wings would mean that the new parties would have to compete with the existing Progressive Conservative parties in the provinces, parties with well established grassroots organizations, members, volunteers, marketing/branding, committed voters, and so on. Moreover, to create new provincial wings of the federal party would simply re-create the vote splitting that occurred at the federal level during the 1990s between the Alliance and PCs. This, of course, would undermine the united conservative project that was the very basis for the merger in the first place.

On the other hand, to establish a formal organizational connection with the existing Progressive Conservative parties in the provinces would potentially undermine the organizational tradition of Reform - a party firmly focussed at the national level. Perhaps more importantly, this would undermine the Reform ideology, especially given that many provincial PC parties still emphasised and practiced the 'progressive' in their title. Thus, the promotion and maintenance of relationships with "existing provincial conservative parties" seems to be a compromise between the two different parties - one that allows for multi-level cooperation but does not force the party down any one path. ${ }^{16}$ Still, this constitutionally entrenched commitment to cooperate with existing conservative parties may come as a surprise to some given the complete truncation of the federal party.

Similar to the federal Conservatives, article 3 of the Ontario Progressive Conservative Constitution also highlights the possibility for both vertical and horizontal

\footnotetext{
${ }^{16}$ While the possibility of creating provincial wings of the federal Conservatives has been raised at convention, there have "never been any serious discussion or desire to do so" according to party officials (personal interview).
} 
linkages with other Conservative parties. According to the PC Constitution, one of the primary objectives of the party is "To cooperate with and assist Progressive Conservative Parties in other Provinces and Territories of Canada and the Conservative Party" (Ontario Progressive Conservative Constitution, 2009; 2013). Not only does this recognize the possibility of engaging in vertical integration (CPC - PC), but horizontal integration as well (i.e., PC parties in other provinces).

It is worth pointing out that this commitment to work with the federal Conservatives is found in a constitution that was amended in 2009, a number of years after the merger between the federal PCs and the Alliance. It is therefore unlikely that this is a relic of the past and seems to represent a real commitment to work together despite being organizationally distinct. As Esselment suggests in her analysis of cross-party cooperation in intergovernmental relations, such commitments are not "mere window dressing" (2010: 139) and can have significant implications for the functioning of intergovernmental relations.

When applying Dyck's threefold typology to the current slate of political parties competing in Ontario, we find considerable variation. Rather than acting in a universal fashion towards separation and independence (as Chhibber and Kollman might expect), political parties in Canada have adopted a number of different organizational strategies. In fact, the diversity is such that each of Dyck's party models is represented (see Figure 2.1). More than just diversity, each party has adopted its own unique approach to the challenges and opportunities that multi-level politics has to offer: the New Democrats are integrated, the Conservatives are truncated, and the Liberals find themselves in between these extremes as semi-integrated. 


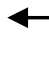

NDP

Liberals

Conservatives

Figure 2.1: Organizational Continuum of Political Parties in Ontario

It is also worth considering the view from the ground. That is, how local party presidents view their association in relation to their multi-level counterpart. In general the way that the major parties are organized along the continuum in Figure 2.1 and the narrative provided above is largely reflected in how parties view their own internal relationship with their multi-level counterpart. In the survey, constituency association presidents were asked which of the three statements listed in Table 2.1 best represented their party and its relationship to its multi-level counterpart. Although fewer than might be expected, nearly four-in-ten NDP associations describe their party as organizationally connected (i.e., the provincial party is an organizational component of the federal party).

By contrast, only two percent of Liberal and Conservative associations view their party this way. While considerably higher than the other parties, this score suggests less integration within the NDP that we typically associate with the party. This, however, is likely a result of the options afforded to respondents. That only 38 percent view the provincial party as an organizational component of the federal party may be a result of respondents viewing the federal party as a component of the provincial party. Nonetheless, the NDP is considerably more likely to view its organization as integrated than either of its competitors. 
Table 2.1: Self-Perceived Multi-level Organizational Relationship by Party

\begin{tabular}{|c|c|c|c|c|}
\hline & Liberal & PC & NDP & Total \\
\hline $\begin{array}{l}\text { A party of the same name exists at the federal level, } \\
\text { but it is not organizationally linked to the provincial } \\
\text { party. }\end{array}$ & $\begin{array}{l}37 \% \\
(42)\end{array}$ & $\begin{array}{l}52 \% \\
(49)\end{array}$ & $\begin{array}{l}8 \% \\
(6)\end{array}$ & $\begin{array}{l}35 \% \\
(97)\end{array}$ \\
\hline $\begin{array}{l}\text { The federal party collaborates with a party at the } \\
\text { provincial level, but the two are not organizationally } \\
\text { linked. }\end{array}$ & $\begin{array}{l}62 \% \\
(69)\end{array}$ & $\begin{array}{l}46 \% \\
(44)\end{array}$ & $\begin{array}{l}54 \% \\
(35)\end{array}$ & $\begin{array}{r}54 \% \\
(148)\end{array}$ \\
\hline $\begin{array}{l}\text { The provincial party is an organizational component } \\
\text { of the federal party. }\end{array}$ & $\begin{array}{l}2 \% \\
(2)\end{array}$ & $\begin{array}{l}2 \% \\
(2)\end{array}$ & $\begin{array}{l}38 \% \\
(24)\end{array}$ & $\begin{array}{l}10 \% \\
(28)\end{array}$ \\
\hline Total & 113 & 95 & 65 & 273 \\
\hline
\end{tabular}

"In your opinion, which of the following statements best describes the relationship between the provincial [Progressive Conservative Party] and the Federal [Conservative Party]?"

At the other end of the spectrum, the Conservatives are far more likely to (correctly) view their party as organizationally distinct and separate from their multi-level counterpart. More than half of Conservative constituency associations (52\%) view their party this way. This is compared to less than one-in-ten NDP associations and two thirds of Liberal associations. While Liberals also acknowledge their organizational distinctiveness, they are significantly more likely to also note the cooperative relationship that they have with their multi-level counterpart. More than six-in-ten Liberal associations describe their relationship this way. Table 2.1 provides the complete breakdown.

A similar pattern emerges when constituency association presidents are asked to place their association on a 10-point scale, where ten is highly organizationally integrated with the party's multi-level counterpart and zero is not at all integrated. Consistent with the above discussion, the New Democrats are considered the most integrated, as they have a mean self-placement integration score of 8.06. By contrast, the Conservatives are again the least integrated, with a mean score of 4.10. Finally, the Liberals are located between 
these two extremes with a mean score of 6.30. Again, the views from the ground are largely consistent with the formal organizational relationships detailed above.

A one-way-ANOVA demonstrates that the level of perceived integration differs significantly across the three parties, $F(2,269)=41.788, p<.001$. Moreover, the analysis of means shows that there are significant differences between each party, revealing that the NDP respondents view their party as significantly more integrated than both the Liberals and the Conservatives, and the Liberal respondents view their party as significantly more integrated than the Conservatives. This, of course, is consistent with both Figure 2.1 and Table 2.1.

Even a cursory examination of Canadian parties thus reveals a considerable degree of variation in terms of how they organize and how they view their multi-level party counterpart. In fact, the three major parties have each adopted their own strategy for competing in Canada's multi-level political landscape. Ultimately there is no quintessential "Canadian approach" to vertical party organization as the system is characterized by diversity rather than uniformity. This diversity, however, provides us with a unique opportunity to explore the role of organizational design in the practice of cooperative and collaborative vertical party integration. While the literature typically takes the behavioural aspects of integration as a given, examining integration this way will let us explore whether parties that are vertically connected in an organizational sense do in fact engage in more cooperative and coordinated behaviour.

\section{Ideological Differences}

In addition to differing on the organizational dimension, Canadian parties are typically viewed as also differing on the ideological dimension. Here we can differentiate 
two elements of party ideology. First, there is a consistency element. That is, to what extent does a political party share an ideology with its multi-level partner? The second component is that of ideological saliency. How important is this ideology to each party and does this differ across levels? While a party may indeed share an ideology that is consistent across levels, it may not hold the same importance at each level. Both consistency and saliency are therefore crucial to understanding multi-level political ideology.

When considering ideology, recent research has considered the difference between brokerage and ideological politics. Cross and Young's (2002) study of party members concludes that the post-1993 party system is much more ideological than its predecessors. The evidence presented by these authors suggests that the NDP and Conservatives are more consistent in their ideology and their members more coherent in their policy views compared to the Liberals.

As Cross and Young (2002: 876) note, "a key characteristic of ideological parties is the substantial agreement on important policy questions exhibited by their members, whereas members of brokerage parties are characterized by competing views on the principal issues". The need to broker and accommodate a variety of competing and often conflicting views is an important factor that prevents the Liberals from establishing coherent and consistent ideology and policies. As brokerage is much more of a Liberal Party phenomenon (Carty, 2013a), the need to be ideologically flexible does not press upon the Conservatives and New Democrats to the same degree. 
This, however, only points to ideological differences at a single level (the federal level). While this is useful, we are more interested in ideological differences between parties operating in different electoral arenas (e.g., the difference between the federal and provincial Liberals). Dyck (1991) requires that there be a "basic ideological similarity" between two parties if they are to be considered integrated. This, however, is rather unclear. What it means for two parties to be ideologically similar is largely impressionistic. Does it simply mean that two parties must be on the same side of the political spectrum? What is the maximum distance between two parties? A more precise and rigorous method of examining ideological integration between federal and provincial parties is therefore required if we are to conclude that two parties are integrated.

To date there has been very little research examining the ideological congruence of federal and provincial parties in Canada in any systematic way. Two studies, however, are worth highlighting. Comparing Progressive Conservative party workers in the provincial arena in Nova Scotia and in Alberta, as well as those active in the federal arena for the same provinces, Stewart and Stewart (1997) are able to contrast the political orientations and ideological congruence of party workers at multiple levels within the same party. Their examination concludes that "while there are clear provincial differences of opinion within the Tories, there exists an even greater attitudinal fault-line across orders of government" (Stewart and Stewart, 1997: 99). In other words, the authors find evidence of substantial federal-provincial ideological incongruence. Rayside (1978) also finds considerable ideological differences between the federal and provincial Liberals in Quebec in his survey of backbench MPs. While the research is limited, what little 
evidence we do have suggests that federal and provincial parties do not share a consistent ideology.

These studies, however, examine individual party activists and legislators, and not necessarily the party as an organizational whole. One way to examine party ideology in a multi-level system is to study the level of ideological consistency across jurisdictions. In this regard, party platforms are a useful source of information and can be used to quantitatively measure party ideology. As Wesley (2011: 253) suggests, election platforms, the most common of all party sponsored campaign material, serve as the most valuable and readily available source of information for determining party ideology.

Researchers in Western Europe have engaged in quantitative analysis of parties' election platforms in more than 50 countries since 1945. The Comparative Manifesto Project's (CMP) methodology codes platforms according to a set of 54 pre-defined policy categories. Based on the content of party platforms, the CMP coding provides an easy-tointerpret score on the left-right dimension ranging from -100 to 100 for each party. A party platform that is dedicated entirely to left-wing issues is coded as -100 whereas a platform entirely devoted to right-wing issues is coded as $100 .{ }^{17}$

Using this left-right score, we can compare federal and provincial party platforms to discover which parties are more consistent in their ideology. The CMP database, however, only includes the platforms of the federal parties. In order to compare party ideology across levels, I have coded 12 provincial platforms using the same coding scheme that can be compared to federal platforms in the CMP database during the same

\footnotetext{
${ }^{17}$ See Appendix 8 for a more detailed explanation of the CMP left-right coding including a list of the categories that make up each dimension.
} 
period. The smaller the federal-provincial difference, the more ideologically coherent the party is from a multi-level perspective. While there are limitations to these data ${ }^{18}$, the CMP is the most widely used source of data on party manifestos and has been used in a number of different countries for a variety of different analyses (Benoit and Laver, 2007; Budge, 2001; Cole, 2005; Pelizzo, 2003).

Table 2.2 provides the left-right platform scores for each of the parties in the past four federal and provincial elections, covering the period between 2003 and 2014. An easy way to make sense of the data presented in Table 2.2 is to compare "pairs" of elections and calculate the difference between the party's federal left-right score and the provincial left-right score. The 2003 Ontario election is paired with the 2004 federal election; 2007 Ontario with 2006 federal; 2011 Ontario with 2008 federal; and 2014 Ontario with 2011 federal. Pairing elections this way ensures that every federal election is paired with a unique provincial election and vice versa. Figures 2.2, 2.3, and 2.4 plot these election pairs on a line graph to visually highlight the differences and similarities between the CMP coded left-right scores at each level. When examining these pairs, the evidence supports the Cross and Young (2002) argument that the Conservatives and New Democrats are more ideologically consistent, even from a multi-level perspective, than the Liberals. $^{19}$

\footnotetext{
${ }^{18}$ Just as parties may behave differently than their constitution or rules suggest, a party's ideology may differ from that of its platform. CMP data should not be seen as definitive but simply a single measure of party ideology. While not adopted here, another possible approach to examining ideological congruence would be to explore the views of voters. Bélanger (2003) demonstrates that voters have clear views of the federal parties in terms of issue-handling capability and competency. It would be interesting to see whether the same views of competency and issue ownership transfers across jurisdictions.

${ }^{19}$ A curious reader may wonder why the two 2011 elections are not paired together given that they occurred in the same year. To pair the 2011 elections together would require us to pair individual elections more than once (i.e., the 2011 federal election would be paired with both the
} 
Table 2.2: Federal and Provincial Right-Left Party Platform Scores Compared (2003$2011)^{20}$

\begin{tabular}{llll}
\hline & Liberal & Conservative & NDP \\
\hline Federal 2011 & -7.8 & 26.3 & -27.9 \\
Federal 2008 & 5.2 & 9.1 & -20.7 \\
Federal 2006 & -12.1 & 16.2 & -21.7 \\
Federal 2004 & -12.2 & 14.4 & -17.6 \\
Ontario 2014 & -15.1 & 16.7 & -20.5 \\
Ontario 2011 & -22.9 & 6.4 & -17.9 \\
Ontario 2007 & -26.5 & 5.3 & -28.2 \\
Ontario 2003 & -33.1 & 10.5 & -22.4 \\
\hline
\end{tabular}

We can also take the mean score across the entire period and compare federal and provincial parties this way. Using this approach, we can see that the mean federal Liberal platform score during this period is -6.7 . By contrast, the mean provincial score is -24.4 (a difference of 17.7). While the Liberal Party in Ontario has been moving closer to the center with each election in the past decade (see Figure 2.2), this is not the case for their federal counterpart. It is clear that Liberal ideology is not consistent across the two levels as the federal and provincial parties do not share the same general trend and there are considerable differences between the election pairs.

2011 and 2014 provincial elections. Likewise the 2007 provincial election would be paired with both the 2008 and 2006 federal election). However, it is worth considering whether pairing elections to their most proximate election (regardless of duplication) changes the pattern of results. While there are some differences, the pattern is largely the same: the mean difference between proximate election pairs is 18 for the Liberals, 10 for the Conservatives, and 7 for the New Democrats. This is, for the most part, consistent with Figures 2.2, 2.3, and 2.4 and the discussion that follows.

${ }^{20}$ Federal platform scores were retrieved from the CMP database (Volkens et al., 2013) and provincial scores were calculated by the author using CMP coding instructions and guidelines. 2011 provincial scores were calculated for the Making Electoral Democracy Work project. 


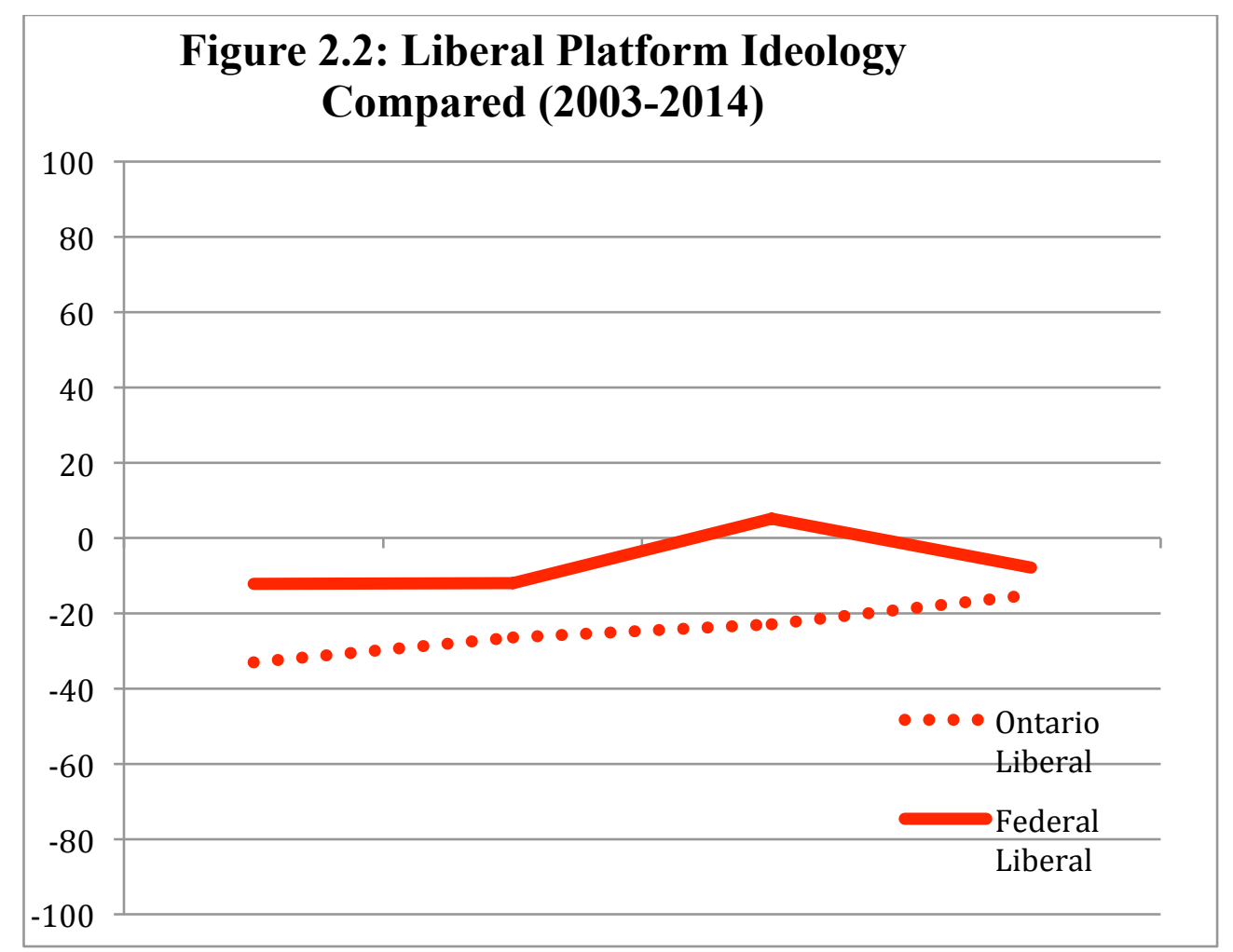

The NDP, by contrast, is considerably more consistent in terms of crossjurisdictional party ideology. The mean federal NDP platform score during this time is -22.25 while the mean provincial NDP platform score is only slightly different at -21.98 . Compared to the Liberal difference of 17.7, the federal-provincial NDP difference is a remarkably low 0.275 (see Figure 2.3). Based on CMP coding of platforms, there is very little difference between the ideology of the federal NDP and its provincial counterpart in Ontario. 


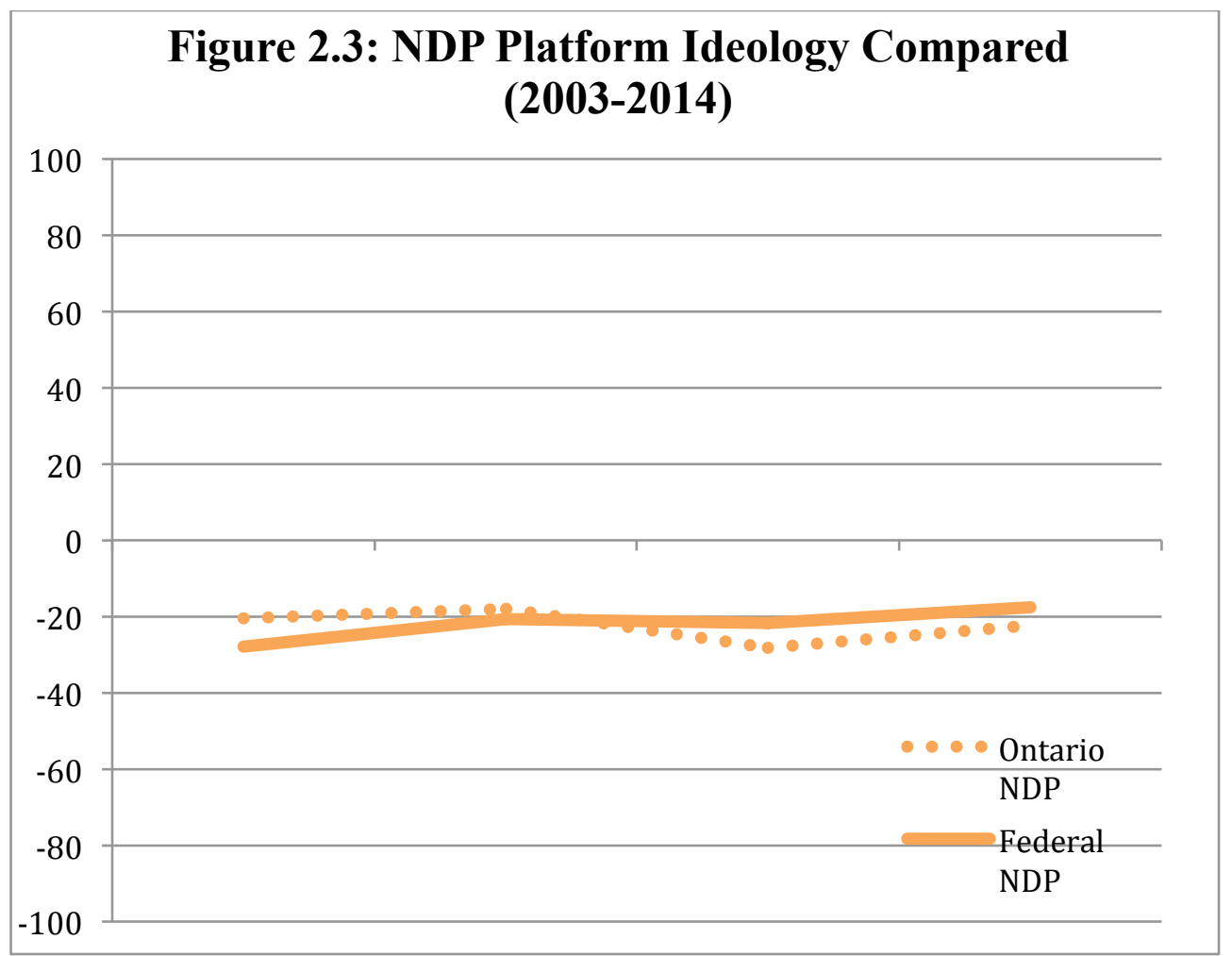

While not as coherent as the NDP, the Conservatives achieve much more ideological congruence than the Liberals are able to accomplish. While the federal Conservatives are further to the right of the spectrum than their provincial counterpart, the mean difference between federal and provincial platform scores is only 6.75 (see Figure 2.4). While this represents a greater difference than what the NDP parties experience, it is still less than half of the distance that the federal and provincial Liberal parties experience.

The difference between the federal and provincial Conservative parties, however, does highlight the "Progressive" element of the PCs in Ontario. Even the 2014 election, where the party has its highest right-wing score in the past decade, it is still 10 points closer to the centre than the most right-wing federal score. During the 1990s, the PCs at the federal level had scores much more similar to that of the PCs in Ontario currently (10.6, for example, in the 1997 election). The Reform, by contrast, had scores 
considerably farther to the right (40.4 in the 1997 election). The merger of these two parties has ultimately resulted in a delicate compromise between the two, resulting in an average platform score of 17 - further to the right of the spectrum than the old PCs but more left than the Reform. Despite this compromise, the party has been pushed further to the right than it's provincial counterpart and as a result, provincial scores are consistently more towards the centre.

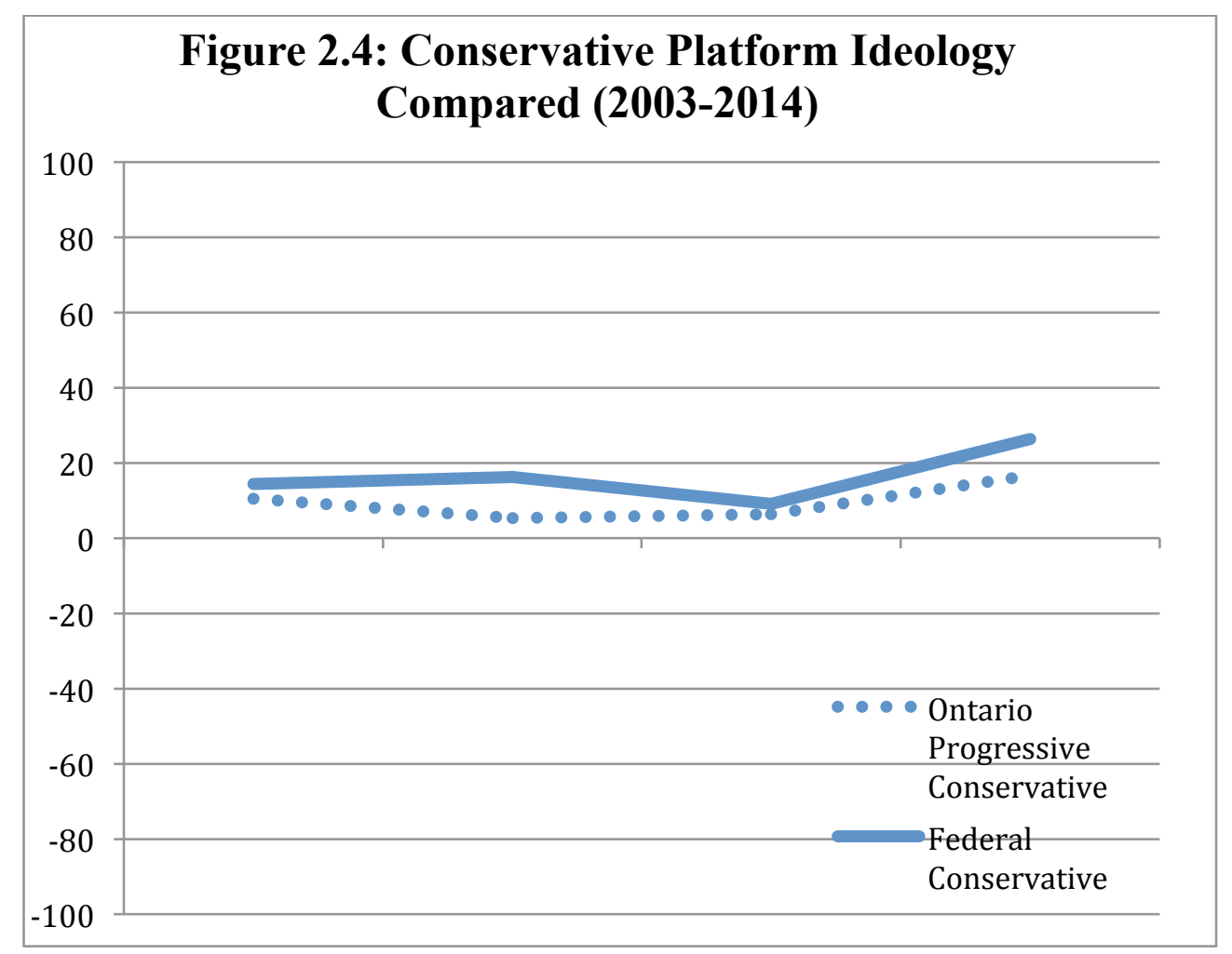

When considering the saliency of party ideology, we can explore the incentives to membership literature (i.e., Cross and Young, 2002), which explores how important ideology/policy is in the initial decision to join a political party. Survey data from party members highlights important ideological differences in this regard as well. In particular, it demonstrates that policy is more important for some parties than others. When Cross and Young asked how important believing in the party's policy was in terms of the initial 
decision to join the party, 92 percent of NDP members, 86 percent of Conservative members, and 71 percent of Liberal members reported "very important". This pattern of ideological saliency/importance largely fits the discussion above with the NDP being the most ideologically coherent followed by its competitors. ${ }^{21}$ Equally important, however, is the substantial gap that is found between the Conservatives and Liberals, with the Conservatives exhibiting higher levels of multi-level ideological consistency.

Finally, interviews with party personnel also fit this general pattern. Speaking with party insiders, it is clear that the NDP's ideology transcends jurisdictions, remaining consistent in the federal and provincial realms. Explaining how federal and provincial NDP parties share the same "ideological DNA", one NDP Member of Parliament stated that "Tommy Douglas is a hero for all of us in the NDP. Regardless of which province you are in, federal or provincial, the values remain the same" (personal interview). For those that are part of the NDP, the core values of social democracy are consistent regardless of which level you are considering (which is reflected in the analysis of party platforms).

Similarly, Conservatives openly stress their ideological similarities. Despite the "progressive" in the PC party at the provincial level, party personnel view the two parties as sharing similar policy goals and drawing upon the same ideological principles. In fact, party officials at both levels often speak of the "conservative movement" in Canada, not necessarily emphasizing the federal or provincial realms. One federal Conservative, for

\footnotetext{
${ }^{21}$ This only includes federal party members as a similar survey of provincial party members is not available. However, as Chapter 3 demonstrates, a majority of party members in Canada belong to parties at both levels and do so consistently. As a result, we can be relatively confident that these views are somewhat reflective of provincial party members as well.
} 
instance, described the "conservative mosaic" - an assortment of conservative organizations that includes both federal and provincial parties. Others noted that the cleavages/factions within each party are often far larger than the differences between federal and provincial conservative parties (personal interviews). Moreover, as a result of long periods of Liberal dominance (both federally and provincially), both parties not only define themselves by their conservative values but also by their positioning as an alternative to the Liberals (personal interview). This is particularly relevant given that these parties are the only viable right-of-centre option in the province.

In contrast to the NDP and Conservatives, many Liberals noted the differences, rather than the similarities, between the two levels and how it can be difficult to find meaningful policy overlap between the federal and provincial parties. Given their brokerage nature, what it means to be a Liberal can vary considerably from province to province and from provincial to federal politics. Furthermore, Liberal Party officials are keenly aware of the difference between their party and the competitors, noting that the coherency of PC and NDP platforms lends itself to easy coordination with their federal counterparts while the Liberals sometimes struggle to find common ground (personal interview).

Overall, the examination and analysis of recent party platforms combined with Cross and Young's (2002) observations about the ideological positions of grassroots party members, as well as interviews with party personnel provides convincing evidence that the NDP and Conservatives are more ideologically coherent than the Liberals. Despite both being much more coherent than the Liberals, the New Democrats also achieve greater multi-level ideological consistency than the Conservatives. Thus, we are 
confronted with a similar picture as to what is presented for organizational integration, except here the Liberals and Conservatives are interchanged on the continuum when it comes to ideological integration (Figure 2.5).

Consistent

NDP

Figure 2.5: Ideological Continuum of Political Parties in Ontario
Semi-Consistent

Conservatives
Inconsistent

Liberals

\section{Conclusions}

Canadian parties have not adopted a uniform approach to dealing with the obstacles, challenges, and potential benefits of multi-level politics. In fact, there is no single dominant approach to how parties organize across multiple levels nor is there a quintessential Canadian response. An examination of the federal and provincial parties in Ontario demonstrates a wide range of organizational possibilities, ranging from highly connected to distinct and separate. Given that each party in Ontario has adopted a unique organizational response to the question of multi-level governance, if the organizational hypothesis is correct we should expect to find a very clear pattern based on these different organizational designs. We should find evidence of a highly integrated New Democratic Party, a moderately integrated Liberal Party and a weak or non-integrated Conservative Party. 
These organizational choices, however, do not fully overlap with ideological consistency and saliency. The Conservatives, for example, are organizationally truncated yet ideologically coherent. This leads us to our second hypothesis. If ideology is the primary force behind integration, we should expect to see very different results. If this is the case, we should find an integrated New Democratic Party, a moderately integrated Conservative Party and a weakly integrated Liberal Party. 


\section{CHAPTER 3: Party Personnel in a Multi-level Context}

\section{Introduction}

Chapter 1 discussed the narrow definition of vertical integration that is commonly used in much of the literature and offered a more expansive alternative that captures informal means of cooperation, shared personnel, and actual party behaviour. This chapter applies this broader understanding of integration by focussing on party personnel and in doing so adds to the debate about multi-level political parties in a number of ways. Most importantly, the chapter explores how a variety of different types of party personnel have responded to the multi-level structure of Canadian politics. Are those party members and activists who are responsible for the machinery of elections and inter-election party maintenance at the provincial level the same as those at the federal level? Do these actors, constrained by the scarcity of resources, divide their time, capital, and loyalty among the different levels of government or do they instead devote their attention at a single focal point and arena? Ultimately, do these partisans live in two separate and distinct worlds of politics or are they connected to both in subtle and nuanced ways?

Although the relationship between voters and federalism has been examined in a number of cases (Clarke and Stewart, 1987; Blake, 1982; 1985; Perlin and Peppin, 1971), party members, activists, legislators, and other party personnel continue to be understudied in the political party literature. Although limited, recent research demonstrates that federal and provincial parties can often draw upon the same personnel. Esselment's (2010) analysis of recent election campaigns in Ontario, for example, 
highlights extensive overlap between central party campaign professionals and campaign workers operating at the provincial and federal levels. Similarly, Koop (2011) provides preliminary evidence to suggest that the same individuals may populate local Liberal constituency associations federally and provincially in certain ridings across the country.

Although preliminary, there are a number of shortcomings with this emerging literature. Both Koop (2011) and Esselment (2010), for example, exclude the NDP from their respective studies. Additionally, both rely on a small n qualitative approach, which raises concerns of generalizability (10 interviews for Esselment and 16 ridings for Koop). Chapter 4 provides a more detailed discussion of these concerns. However, this and subsequent chapters address these and other issues by including the NDP and by utilizing a much larger sample, alleviating concerns of generalizability.

This chapter extends this line of investigation further and looks for overlap and federal-provincial commonality in a wide range of other party personnel that are closely involved in the machinery of parties and elections. This includes party members, party activists, constituency association presidents, legislators, and legislative candidates (central party campaign professionals are dealt with separately in Chapter 8 and voters in Chapter 9). In addition to understanding how party personnel have responded to the structures of multi-level governance, this chapter seeks to understand the differences between the major political parties. In doing so the second section evaluates the two competing explanations of party integration that were highlighted in Chapter 2 and seeks to uncover whether differences in organizational design or ideological consistency best 
explain divergent levels of party integration as measured by overlapping party personnel.

Examining how party personnel respond to the multi-level nature of Canadian politics requires data about a wide range of individuals. As such, the data used throughout this chapter are derived from a variety of different sources. First, I collected information on the career paths of Members of Parliament (MP) elected in the province of Ontario between 2004 and 2011. Data were obtained from two sources: The Parliament of Canada and Legislative Assembly of Ontario websites. Each parliamentarian was coded for the direction of his/her career path (i.e., a transition from provincial to federal politics), party affiliation (at both levels if applicable), and inclusion in cabinet. Second, candidate information was gathered from a 2011 post election online survey of provincial New Democratic and Liberal candidates and a 2008 mail survey of federal New Democrat and Liberal candidates. Third, membership numbers come from a survey of federal party members that was conducted in the spring of $2000^{22}$. Finally, the author conducted an online survey of federal and provincial constituency association presidents in Ontario during the summer of $2013 .^{23}$

\section{A Framework for Examining Party Personnel in a Multi-level Context}

In order to create a theoretical framework for understanding how party personnel in Ontario have responded to the federal nature of Canadian politics, this chapter draws

\footnotetext{
${ }^{22}$ I am grateful to William Cross and Lisa Young for providing their survey data of party members and candidates.

${ }^{23}$ This includes 113 Liberal (53\%), 95 Conservative (45\%) and 65 New Democrat (59\%) respondents for an overall response rate of $51 \%$ and a total of 273 valid responses. Chapter 4 contains a more detailed description of the data collection procedure for the survey of constituency association presidents.
} 
on a number of theoretical insights and concepts from the party identification and voting literature. The concept of party identification (i.e., partisanship) is embedded within an established body of voting research and is often said to have four major components. This includes direction, intensity, durability, and consistency (Campbell et al., 1960; Clarke et al., 1979). Of particular importance for a discussion of party integration and federal-provincial party relations is the concept of partisan consistency. Consistency, however, is itself a multifaceted concept with a number of components. When considering the multi-level consistency of partisanship, there are typically three main types to consider: consistent, split-level, and single-level.

Clarke et al., (1980) add another dimension to this framework: intensity of the partisan attachment. Adding this dimension allows Clarke and his colleagues to further differentiate between fully consistent (those who are consistent in both partisanship and intensity) and partially consistent (those who are consistent in partisanship but not intensity). While a useful distinction, the lack of data on the intensity aspect of consistency for individuals other than voters makes its applicability less useful in a discussion of party members, activists, and so on. As a result, the original, albeit less complex, framework is used here.

Voters are considered consistent when they identify with the same political party both federally and provincially (i.e., federal Liberal and Ontario Liberal). By contrast, voters are considered to be split-level identifiers or inconsistent when they have completely different partisan affiliations at the federal and provincial levels (i.e., federal Conservative and Ontario Liberal). Finally, voters are considered to be single-level 
identifiers when they have a partisan attachment to a party at one level but no corresponding attachment at the other (i.e., federal NDP only). ${ }^{24}$

This threefold classification and framework from the party identification and voting literature can naturally be extended beyond partisanship and can be applied to a wide range of party personnel and how they affiliate with parties. In the remainder of the chapter this framework is adopted for an examination of how other party personnel such as party members and activists have responded to the multi-level nature of Canadian politics. Like voters, these individuals can affiliate at either the federal or provincial level, they can split their time between both levels consistently, or they may split their time at both levels in an inconsistent manner. Unlike voters, however, there has not been any systematic review of how these individuals behave in Canada's multi-level political environment.

\section{Party Members}

An examination of party members is warranted for a number of reasons. Chief among these reasons is that party members have been one of the most understudied aspects of political life in Canada (Cross and Young, 2004). Indeed, Cross and Young's 2000 study of federal party members represents the first truly comparative analysis of

\footnotetext{
${ }^{24}$ Given that the membership data used throughout this chapter come from a survey of federal party members, there are certain limitations concerning the conclusions that we can draw. While we can ascertain split and inconsistent party members, only federal single-level members can be identified. In other words, those individuals who only belong to political parties at the provincial level cannot be captured in this analysis due to the nature of the data. This points to the need for not only more studies of party membership but also studies that examine party membership from the provincial perspective as there continues to be a significant gap in the literature.
} 
party membership in Canada. ${ }^{25}$ Prior to this large-scale data collection, understandings of how members responded to the multi-level nature of Canadian politics were largely impressionistic and lacked any concrete empirical evidence (see, for example, Smiley 1976). While considerable attention has been devoted to surveying and studying party convention delegates (Perlin, 1980; Archer and Whitehorn, 1997), these samples can only be used as a proxy or estimate of the typical party member (delegates are more committed and active than a typical member, for example).

As a result of the lack of scholarship on the subject of party membership, it is still unclear whether party members engage in party politics at multiple levels or if they prefer to operate independently in their own political world. Although some parties have devised organizational strategies to ensure overlapping federal-provincial party membership (see Chapter 2), there is no clear evidence demonstrating whether other parties can achieve the same commonality without similar organizational structures in place.

If members choose (or are required) to participate in party politics at multiple levels, shared and common membership can provide a significant and continuous linkage between federal and provincial parties. Members are particularly relevant given that recent decades have witnessed a dramatic increase in intra-party democracy in many Western democracies (Cross and Katz, 2013; Pilet and Cross, 2014; Scarrow, 1999; Seyd, 1999). Canada is no exception. As political parties continue to provide members

\footnotetext{
${ }^{25}$ Clarke and his colleagues (1999) also examine party members, however, this is a single case study of the Reform Party. Likewise, Erickson and Laycock (2002) survey NDP party members only. By contrast, Cross and Young include all five major parties at the federal level in their survey of party members.
} 
with opportunities for greater and more meaningful participation within internal party affairs (Cross, 2004; Young and Cross, 2002b; Young, 2013), the role of ordinary grassroots members cannot be overlooked.

Members in the major Canadian parties now directly choose party leaders and nominate candidates for election, they volunteer their time and work on election campaigns, and they vote on policy at party conventions. Due to their increasingly crucial role in internal party decision-making, party members are an integral component of the party apparatus. Two political parties that have high levels of common membership will therefore share an important linkage that spans the jurisdictional divide.

Despite the potential reasons for single level or inconsistent membership ${ }^{26}$ (see, for example, Blake, 1982), a majority of party members in Canada's political parties hold memberships in both provincial and federal political parties. More than two-inthree party members at the federal level also report belonging to a political party at the provincial level. If we define consistency, as others have, as membership in two parties that does not cross partisan lines (Esselment, 2009:132), then those Canadians who hold memberships at both levels exhibit considerable consistency. Overall, 70 percent of federal party members from Ontario hold dual membership while 97 percent of those members hold consistent dual membership. The data reveal that the majority of party members in Canada routinely take advantage of the federal system by participating in politics at both the federal and provincial levels.

\footnotetext{
${ }^{26}$ Chapter 7, which examines integration through voters and shared partisanship in the electorate, provides a more detailed discussion of the reasons why individuals may hold single or inconsistent partisan attachments in Canada.
} 
When we turn our attention to the party level, we find interesting cross party differences. As illustrated in Table 3.1, all federal New Democratic party members from Ontario simultaneously belong to the Ontario NDP. This, of course, is an accomplishment that is due to the party's unified membership structure that does not allow party members to "opt out" of dual membership and prohibits members from belonging to any other political party. In joining the provincial party, members are automatically members of the federal party. By contrast, 68 percent of Liberal and 62 percent of Conservative federal party members report belonging to a provincial party in Ontario. $^{27}$

Not only are these numbers higher than we might expect given that federal and provincial party memberships are separate in these parties, it is surprising that there is only a minor difference between Liberal and Conservative party members in terms of the percentage who hold dual membership. The data reveal that dual membership does not differ significantly between Liberals and Conservatives, $\chi^{2}(1,967)=3.19, p=.07$, despite the Liberals opting for a semi-integrated organizational style compared to the truncated structure that the Conservatives have adopted. The difference between the New Democrats and its competitors, however, is significant (NDP vs. Conservatives: $p<.001 ;$ NDP vs. Liberals: $p<.001)^{28}$

\footnotetext{
${ }^{27}$ While party membership data is not available for the federal Conservative Party of Canada, we can collapse membership numbers from the Progressive Conservative Party and the Canadian Alliance into a single variable that will approximate the membership of the federal Conservative Party. While there are limitations to such an approach, it does provide the best estimate that is currently available.

${ }^{28}$ New Democrat cells for single level party members are empty because of the structure of party membership (i.e. all members belong to both parties simultaneously and therefore none are considered single level members). As such, NDP significance tests are calculated using Fisher's Exact Test rather than Chi square to account for the empty cells in the analysis.
} 
It is also worth noting that those party members that do belong to parties at both the provincial and federal level are remarkably consistent in their multi-level membership: members of the federal Conservatives migrate, almost universally, to the Progressive Conservatives in Ontario, and members of the federal Liberal Party join the Liberal Party of Ontario. The evidence in Table 3.1 suggests that the majority of party members in Ontario are consistent and not split-level or single level members. In fact, less than five percent of party members that have decided to engage with party politics at multiple levels in the province do so in a split or inconsistent manner.

Table 3.1: Types of Party Members by Political Party

\begin{tabular}{lcccr}
\hline & Single & Split & Consistent & Total \\
\hline Liberal & $32 \%(85)$ & $3 \%(8)$ & $65 \%(171)$ & 264 \\
Conservative & $38 \%(270)$ & $2 \%(17)$ & $60 \%(416)$ & 703 \\
NDP & $0 \%(0)$ & $0 \%(0)$ & $100 \%(198)$ & 198 \\
Total & $30 \%(355)$ & $2 \%(25)$ & $68 \%(785)$ & 1165 \\
\hline
\end{tabular}

While Table 3.1 combines the Canadian Alliance and Progressive Conservatives so that we can approximate the Conservative Party in which they merged, it is worth examining the two parties separately. In fact, doing so provides us with a unique opportunity to more precisely examine the role of ideology and organization. When we do, we find that members of the federal PCs are far more likely to belong to a provincial party compared to members of the Canadian Alliance. Whereas eight-in-ten federal PC members belong to a provincial party, approximately one-in-three Canadian Alliance members hold a provincial party membership. As a truncated party, the Alliance had no formal connections to any provincial party. By contrast, the federal PCs had a long history with the provincial Conservatives and shared a number of minor organizational linkages (Dyck, 1991), including a name and overarching party brand. What this 
suggests is that multi-level party membership is perhaps driven more by organizational connections between parties than a similar ideology.

When examining consistency of membership, however, there is very little difference between the two parties. More than nine-in-ten multi-level party members in both parties belong to the provincial Progressive Conservatives. Moreover, the data reveal that the Liberals are more likely to have dual members but no more likely to have consistent dual members than either the PCs or Alliance. In other words, Canadian Alliance members who belong to a party at both levels are just as likely to join the provincial PCs, as members of the federal Liberals are to join the provincial Liberal Party in Ontario. Thus, while direct organizational connections appear to incentivize multi-level party membership, ideology likely plays a role in ensuring multi-level consistency.

It is also worth noting that while the organizational model adopted by the NDP ensures that the federal and provincial wings share the same party members, it cannot guarantee the quality of participation. More than twice as many members of both the Conservatives and the Liberals report spending five or more hours per month on federal party activity than NDP party members. This may be a result of the different organizational designs that each of the parties have adopted. Since provincial members of the Progressive Conservatives and Liberals in Ontario are not automatically members of their federal counterpart, their joining a federal party is a deliberate decision that demonstrates their commitment to party politics at both the provincial and federal level in Canada. These members have chosen to be active in both federal and provincial party politics without any organizational requirements. 
New Democrat party members, however, cannot make such a choice. As such, members who are interested in provincial politics alone have no choice but to become members of the federal party as well. Likewise, members interested only in federal politics must become provincial members. Overall, more than one-in-three New Democratic Party members from Ontario report being more active in provincial politics compared to a mere five percent that report being more active at the federal level. Although this question was not asked to members of other parties, we can assume that the deliberate act of joining two separate political parties represents a more balanced commitment to each.

Given the high levels of common members it should be clear that membership acts as a significant linkage between provincial and federal parties in Canada. Take the Liberals as an example. They were reported to have approximately 120,000 members in Ontario alone after the 2000 election (Toronto Star, 2003). Despite only being semiintegrated organizationally, the federal and provincial parties still operated on a common base of membership with tens of thousands of common members connecting the two parties.

Overall, a majority of party members in Ontario have responded to the multilevel nature of Canadian politics by opting to participate in party politics at both levels. What's more, the vast majority of these party members have done so consistently, despite the institutional challenges associated with federalism. Rather than opting out of integration, party members represent a significant linkage between federal and provincial parties in Ontario. 


\section{Party Activists}

More than the general membership, active party members are those individuals who provide the machinery for election campaigns and actively participate in party affairs on a regular basis. While membership as a whole can act as an integrating link because of the quantity of overlap (potentially tens of thousands of common members), party activists represent a linkage because of the quality of their participation and their commitment to the party. Writing about party activists, Blake et al. noted that "it is their commitment to democratic participation that sustains electoral politics in contemporary liberal democracies" and that "Canadian political science has too often ignored them" (1991: ix). Little has changed in the two decades since Blake and his colleagues wrote of the importance of party activists. Although activists are the lifeblood of electoral politics, we know very little about them, especially about how they respond to the two political worlds created by the federal structure (for an exception see Jacek et al., 1972).

As electoral machines, political parties require a large body of active and committed individuals to achieve their goals. Despite significant advances in communications technology and sophisticated campaign techniques (Norris, 2002; 2005), parties still require boots on the ground and a committed activist base to engage in party activities (Carty and Eagles, 2005). Party activists mobilize voters, recruit new supporters, contribute to election campaigns, raise funds and perform a number of administrative tasks (i.e., manage phone banks, etc.) that are required for the efficient management of party affairs. As Blake and his colleagues note, "even with modern party campaigns organized and run by paid professions, without some network of local activists a party has little chance of victory" (1991: 17). Given their role in the 
successful functioning of Canadian parties, a common pool of party activists represents a strong linkage between federal and provincial parties.

In order to identify activists, party members can be categorized based on their level of activity and time commitment to the party. Based on the number of hours party members report spending on party activity in an average month, party members can be separated into three groups: those members who are active (3+ hours/month), moderately active (1-3 hours/month), and inactive (less than 1 hour/month). Categorizing members this way allows us to capture party activists separately from the broader party membership.

One-in-five party members from Ontario fall into the category of activist, devoting three or more hours per month to party activity. When we examine active party members, the trends are similar to that of the party membership as a whole. Again, as a result of the organizational structure, fully 100 percent of those active members of the federal NDP are also members of the Ontario NDP. Liberal cross membership, however, increases from 68 percent of the membership as a whole to 80 percent when we focus our attention on active members. Similarly, cross membership for the Conservatives rises from 62 to 72 percent (Table 3.2). In both cases, dual membership witnesses an increase of more than 16 percent when examining the more committed and active members of the party.

Table 3.2: Types of Party Activists by Political Party

\begin{tabular}{lccrc}
\hline & Single & Split & Consistent & Total \\
\hline Liberal & $20 \%(12)$ & $0 \%(0)$ & $80 \%(45)$ & 57 \\
Conservative & $28 \%(42)$ & $2 \%(3)$ & $70 \%(103)$ & 148 \\
New Democrat & $0 \%(0)$ & $0 \%(0)$ & $100 \%(22)$ & 22 \\
Total & $24 \%(54)$ & $1 \%(2)$ & $75 \%(170)$ & 227 \\
\hline
\end{tabular}


While the percentage of federal party members who also belong to provincial parties increases for both the Liberals and the Conservatives, the gap between the two parties and the New Democratic party persists. Like the general membership, there continues to be no meaningful statistical difference in the level of common membership between Conservative and Liberal party activists, $\chi^{2}(1,205)=1.13, p=.29$. The gap between the NDP and the others, however, continues to endure (NDP vs. Conservatives: $p<.001 ;$ NDP vs. Liberals: $p=.01)$.

The analysis above demonstrates that party activists in Ontario, even more so than party members, live in an integrated and singular political world. Overall, more than three-in-four (76\%) active federal party members from Ontario also belong to a political party at the provincial level. Like the broader party membership, these individuals are remarkably consistent in their dual memberships and do not cross partisan lines when joining a political party at another level of electoral politics. In total, 100 percent of active federal Liberal and New Democrat party members and 98 percent (103 of 105) of active federal Conservative members are consistent in their dual party memberships.

Table 3.3 demonstrates that the likelihood of dual level membership increases the more active a member is with the party. Nearly nine-in-ten active Liberal members are dual members compared to just over 50 percent of inactive members. While slightly lower, the numbers for the Conservatives are not that dissimilar, with three-in-four active members belonging to the party at both levels. With every increase in level activity we find an increase in the propensity for dual membership. The NDP is excluded here because multi-level membership is automatic. 
Table 3.3: Membership by Level of Party Activity

\begin{tabular}{lcccc}
\hline & \multicolumn{2}{c}{ Liberal Party } & \multicolumn{2}{c}{ Conservative Party } \\
\hline & Dual level & Single level & Dual Level & Single level \\
Inactive & $55 \%(52)$ & $45 \%(42)$ & $52 \%(123)$ & $48 \%(115)$ \\
Moderately active & $71 \%(95)$ & $29 \%(38)$ & $65 \%(227)$ & $35 \%(123)$ \\
Active & $88 \%(29)$ & $12 \%(4)$ & $73 \%(67)$ & $27 \%(25)$ \\
\hline
\end{tabular}

Note: Inactive $=$ less than 1 hour/month; moderately active $=1-3$ hours/month; active $=3$ or more hours/month

As the next chapters demonstrate, these individuals play an important role in linking federal and provincial parties in Ontario. Beyond their overlapping party membership, these activists volunteer for election campaigns at both levels, they host lawn signs, they canvass neighbourhoods and mobilize voters, they attend routine party meetings, and so on. In a very meaningful sense, these individuals make parties work at both levels: they are the machinery of election campaigns both federally and provincially. While there are single level activists, it is the consistent dual level activists that are the most common and active. Through their activities on the ground, parties share an important resource and linkage. Moreover, the federal arrangement (two sets of elections, two parties, etc.) offers these individuals more opportunities to participate with their democracy and the ability to gain additional electoral experience.

\section{Constituency Association Presidents}

While the riding association is a central component of Canada's electoral system, it has been suggested that "political scientists know little about constituency association executives" (Koop, 2010: 894). Exploring the activities of constituency presidents not only helps us in our quest to understand multi-level parties, but it also provides us with further insight into an often ignored aspect of Canadian party life. Besides the local candidate, the constituency president is often the most central and authoritative figure of 
the party in the riding. These individuals are not only party activists - volunteering their time and energy to head the local executive - but they also hold a leadership position within the party tasked with the grassroots maintenance of the party during and between election campaigns. Although the role of local constituency association executives is examined in more detail in later chapters, it is worth briefly highlighting some of the multi-level characteristics of constituency association presidents here as well. ${ }^{29}$

According to Carty $(2002 ; 2004)$ and Carty and Cross (2006), one of the defining features of Canadian parties is the stratarchical relationship between the party on the ground and the party in public office. The bargain provides constituencies with considerable autonomy over the management of local affairs, effectively allowing individual ridings to organize and conduct their business without interference from the central party. Given this autonomy and the uniformity of electoral boundaries in Ontario, riding presidents that are committed to the party at both levels have the ability to forge considerable, although informal, connections between local associations in the same riding. ${ }^{30}$

Table 3.4 highlights a number of key multi-level activities that riding presidents can engage in that have the ability to link federal and provincial parties together. This includes their vote choice, party membership, and multi-level volunteer activity during election campaigns. Like party members and activists, the Conservative numbers are surprisingly high given the party's organizational design. Nearly eight-in-ten

\footnotetext{
${ }^{29}$ Chapter 5 and 6 examine the constituency association executives more broadly and are less concerned with individuals. By contrast, the discussion here examines constituency association presidents as individuals and separates them from the broader party executive and riding association as a whole.

${ }^{30}$ The stratarchical nature of Canadian parties and the implications of this design on party integration are considered more fully in the next two chapters.
} 
Conservative constituency association presidents have consistent dual party membership, and the vast majority (93\%) voted consistently in the last election.

Furthermore, despite the absence of organizational incentives, more than six-inten Conservative riding presidents frequently volunteer on election campaigns at the other level. While the percentage of frequent Liberal volunteers is higher $(73 \%$ compared to $63 \%)$, it does not differ significantly from the Conservatives, $\chi^{2}(1,208)=$ 2.10, $p=.15$. Like their Conservative counterparts, high levels of consistent dual membership and voting behaviour characterize Liberal constituency association presidents.

Continuing the trends identified for party members and activists, New Democrat constituency association presidents are significantly more likely to volunteer in a multilevel manner than either the Liberals or Conservatives with nearly nine-in-ten federal riding presidents volunteering to help the provincial NDP during recent election campaigns. Similarly high levels of dual membership and electoral behaviour are also evident in the New Democrats.

Table 3.4: Multi-level Activities of Constituency Association Presidents by Party

\begin{tabular}{lcccc}
\hline & $\begin{array}{c}\text { Consistent } \\
\text { Membership }\end{array}$ & $\begin{array}{c}\text { Consistent } \\
\text { Vote Choice }\end{array}$ & $\begin{array}{c}\text { Frequently Volunteer for } \\
\text { Party Counterpart }\end{array}$ & Total \\
\hline Liberal & $85 \%(96)$ & $91 \%(103)$ & $73 \%(82)$ & 113 \\
Conservative & $77 \%(73)$ & $93 \%(88)$ & $63 \%(60)$ & 95 \\
NDP & $100 \%(62)$ & $92 \%(57)$ & $87 \%(54)$ & 62 \\
Total & $86 \%(231)$ & $92 \%(248)$ & $73 \%(196)$ & 270 \\
\hline
\end{tabular}

Note: Those individuals who voted in only one of two elections are considered single-level voters. Only those individuals who voted both provincially and federally and for the same party are considered consistent voters. 
Regardless of party affiliation, a majority of constituency association presidents are engaged with party politics at multiple levels: the vast majority vote for and belong to their multi-level party counterpart and a sizeable majority frequently volunteer their time cross-jurisdictionally to help during election campaigns. Like party members and other party activists, riding presidents serve as an important human linkage between federal and provincial parties. The role of riding presidents in facilitating and encouraging party integration is examined further in Chapters 4 and 5, which focus on party integration at the grassroots level between federal and provincial constituency associations.

\section{Legislators}

Writing about the migration of party politicians from one level to another, Detterbeck notes that these individuals "will bring in experience and personal contacts from their prior position" (2011: 250). Due to the relationships and networks that they bring, those individuals who have been elected at both levels of government can create a significant linkage between parties. Previous research on the subject has demonstrated that very little provincial-federal migration takes place in the career paths of Canadian legislators (Barrie and Gibbins, 1986; Docherty, 2005). In their study of parliamentary careers in Canada, Barrie and Gibbins found that only seven percent of federal members of parliament had previously been elected at the provincial level.

In total, 187 unique individuals were elected to the House of Commons from Ontario between 2004 and 2011 (Table 3.5). Of these, 13 have previous elected experience in the Ontario legislature. Consistent with earlier research, this analysis 
confirms that less than one-in-ten Members of Parliament elected in Ontario have previous provincial experience over the past decade. The low levels of career transition become more apparent when compared to the career paths of legislators in other federal states. In Switzerland, for instance, 68 percent of federal members are ex regional members and in the United States this figure is one third (Stolz, 2003: 228).

Table 3.5: Multi-level Careers by Party (2004-2011)

\begin{tabular}{lccc}
\hline Party & $\begin{array}{c}\text { Federal and Provincial } \\
\text { Elected Experience } \\
\text { (Dual Level) }\end{array}$ & $\begin{array}{c}\text { Federal Elected } \\
\text { Experience Only } \\
\text { (Single Level) }\end{array}$ & Total \\
\hline Liberal Party & $6 \%(5)$ & $94 \%(80)$ & 86 \\
Conservative Party & $7 \%(5)$ & $91 \%(68)$ & 75 \\
New Democratic Party & $12 \%(3)$ & $88 \%(23)$ & 26 \\
Total & $7 \%(13)$ & $90 \%(171)$ & 187 \\
\hline $\mathrm{N}=187$ & & &
\end{tabular}

The findings also demonstrate that the direction of the career path is exclusively in a single direction. Not one individual between 2004 and 2011 began with a career at the federal level and later moved to provincial politics in Ontario. While limited, all of the transitions during this period are from provincial to federal politics. We also find that, like other party personnel, provincial Members of the Legislative Assembly are, for the most part, consistent in their multi-level activities. With only two exceptions, all provincial MLAs that went on to federal politics became members of their federal counterpart.

That only two members (15\% of the total) switched parties in their transition, and that both migrated to the Liberals, a party that has historically been in government at the federal level, demonstrates the consistent nature of parliamentary career transitions. Take, for example, Bob Rae's transition to federal politics. The former leader of the 
Ontario New Democrats and Premier of Ontario sought the leadership of the federal Liberal Party before he was elected as a Liberal Member of Parliament.

A desire to govern, especially after serving as Premier of Canada's largest province, is likely the reason Rae switched from the NDP to the Liberals in his transition to federal politics. As the NDP has never formed a government at the federal level, the Liberals provided the only centre/left-of-centre governing alternative. This desire to be part of government should come as no surprise. Downs (1957: 30-31), for example, writes that "...politicians are motivated by the desire for power, prestige, and income...their primary objective is to be elected."

A more recent example not included in Table 3.5 is Sudbury NDP MP, Glen Thibeault, who resigned in order to run as the provincial Liberal candidate in a 2015 provincial by-election. In one sense this move is surprising: the transition from federal to provincial politics is very rare, as any movement in a multi-level career trajectory typically moves in the other direction. In another sense, however, the move is not that surprising at all. The Liberals have been in government for more than a decade at the provincial level in Ontario and their strength does not appear to be diminishing (in fact they increased their seat and vote share in the previous election). To be a provincial Liberal candidate typically has a much higher success rate to be included in government than a federal NDP candidate.

While not the focus of this chapter, it is interesting to note that former federal Liberal leader and Prime Minister, Jean Chrétien, actively endorsed Thibeault's bid to become the next MPP of Sudbury (subsequent chapters examine more fully the multi- 
level dynamics of campaigning and endorsements). Despite only joining the party to seek the nomination, and despite his history with the New Democrats, federal Liberals were eager to provide campaign support for their new provincial colleague as soon as he became a Liberal (Northern Life, 2015).

More important than the broader party caucus, however, is cabinet. Not only is cabinet where effective power resides (Savoie, 1999), but historically it has been a body where strong regional ministers could represent the provinces (White, 2005). Moreover, a cabinet position is a prestigious appointment and a significant dimension to the career paths of MPs. In the 1970s, Smiley wrote that so far "as federal-provincial relations is concerned, ministers deal with one another in the absence of either personal experience or personal ambition related to the other order of government" (1976: 98). As he noted in his own analysis, federal cabinets typically had three or fewer ministers with provincial experience.

In contrast to Smiley's observations, today we find that a number of federal cabinet and shadow cabinet ministers do have personal experience with their counterparts at the provincial level. In fact, ministers with previous provincial experience are typically overrepresented in federal cabinets. Although MPs with provincial experience constitute less than 10 percent of all members, they make up a much higher percentage of cabinet ministers. While in government between 1993 and 2006, Liberal MPs with previous elected experience in provincial politics constituted 24 percent of all Ontario MPs appointed to cabinet. 
Likewise, between 2006 and 2011, Conservative MPs with previous elected experience in Ontario constituted a slightly higher 26 percent of all cabinet ministers appointed from Ontario (this includes high-profile ministries such as Finance, Foreign Affairs, and President of the Treasury Board). Moreover, this number increases to onein-three for the Conservatives when high-level non-elected positions in the provincial party are included. Federal cabinet minister Peter Van Loan, for instance, was previously the president of the Ontario Progressive Conservative Party. ${ }^{31}$ Despite its truncated nature, the Conservatives offer a career path that is very similar to that of the Liberals.

Since the NDP has never formed a government at the federal level, we do not have comparable data on the number of cabinet positions held by members with previous provincial experience. In Westminster tradition, however, the opposition creates its own shadow cabinet - an alternative cabinet with critics for all government portfolios. While in Opposition from 2006 to 2011, 17 percent of NDP shadow cabinet members from Ontario had been previously elected provincially. We should be careful in interpreting this figure given the unusual makeup of NDP shadow cabinets. With one exception, all members of the NDP caucus in 2006 and 2008 were given a critic position. With that said, one-in-six Ontario NDP shadow cabinet ministers has been previously elected at the provincial level in Ontario. While the NDP caucus has a

\footnotetext{
${ }^{31}$ In fact, past presidents of the Ontario Progressive Conservative Party are well represented in the Conservative Party at the federal level, especially in cabinet. In addition to Peter Van Loan, current federal cabinet minister, and former provincial cabinet minister Tony Clement, served as president of the Ontario PC party in 1990. Clement therefore represents not only a connection between the federal and provincial parties in public office but central office as well.

Additionally, federal MP Patrick Brown served as vice president of the Ontario PC party for a number of years. Brown has since left his position as a federal Conservative MP and is now the leader of the Ontario Progressive Conservatives.
} 
greater percentage of MPs with previous provincial experience than either the Liberals or Conservatives, due to the unique nature of its shadow cabinets the multi-level linkage in cabinet becomes muted.

The extent of overlapping legislators in the federal cabinet is more impressive when placed in a comparative context. In Germany, for example, 23 percent of German cabinet ministers have been previously elected at the state level (Fischer and Stolz, 2010: 7). This is remarkably similar to the 24 and 26 percent of federal Liberal and Conservative ministers who have previous provincial experience. We find this similarity at the cabinet level despite the fact that Germany has seen a greater degree of multi-level political career transitions overall than Canada (Stolz, 2003).

While Smiley found that three ministers with provincial experience was the ceiling for the entire cabinet in the 1960s and 70s, this analysis demonstrates that there are routinely three or more cabinet ministers with provincial experience from Ontario alone. ${ }^{32}$ The Conservative cabinet of early 2014 , for instance, had three senior ministers who served in PC cabinets in Ontario: John Baird (foreign affairs), Tony Clement (treasury), and Jim Flaherty (finance). What's more, each of these individuals was a cabinet colleague of (former) provincial PC party leader Tim Hudak. If similar patterns are found in other provinces, we can expect to find cabinets with a considerable degree of provincial experience and networks. Rather than working in the absence of personal

\footnotetext{
${ }^{32}$ The size of cabinet, however, has changed over time. It is therefore worth examining not only the raw number of ministers but also the proportion. The average size of cabinet during the 1960s and 1970s was 27.1. With 3 ministers with provincial experience, this represents approximately 11 percent. The average size of the current Conservative cabinet has been remarkably similar, 26.6. Without taking into account any of the other provinces, Ontario ministers with previous experience account for 11 percent of the entire cabinet. Once other provinces are included, the proportion of cabinet with provincial experience should be substantially higher than it was only a few decades ago.
} 
experience, a number of federal cabinet ministers from Ontario have worked with and have close personal ties to their counterparts at the provincial level.

The change over time may be a result of different patterns of intergovernmental relations. Historically, strong regional ministers often had a considerable influence on cabinet and even intergovernmental relations (Bakvis, 1991; White, 2005). During the second party system, for example, regional chieftains emerged to link the federal and provincial worlds in an era of unprecedented brokerage and regional accommodation (Carty, 1988). As provincial autonomy grew and province-building occurred, these ministers lost much of their authority and their role as representatives of their province was greatly reduced. Likewise, as executive federalism took hold, provincial Premiers usurped the traditional role of regional ministers.

Bakvis (1989), however, argues that the reversal of this trend of weak regional ministers was evident in both Mulroney governments. By the end of the 1980s, constitutional talks and a tenuous regional coalition reinforced the need for strong regional ministers. The findings presented here concerning the makeup of cabinet likely represent a continuation of that trend. Those individuals with previous electoral experience at the provincial level are excellent candidates for a strong regional minister for a number of reasons: not only have they been electorally successful in the province at both the provincial and federal level but they are likely to retain relationships and networks at the provincial level. These individuals can therefore serve as both a regional minister and as an integrating agent. 
The potential for increased and enhanced federal-provincial communication is one of the most important benefits that vertical party integration may have on the practice of democracy in a federation (Esselment, 2013). The implications of integration, however, are not always positive and beneficial for both parties. The Ontario Progressive Conservatives, for instance, lost a great deal of cabinet depth and experience in 2004. Three senior ministers, a previous party president, and countless other campaign professionals and administrative staff migrated from Ontario provincial politics to make their entrance into the federal arena.

While this transition was undoubtedly a good thing for the newly formed Conservative Party of Canada, a party that desperately needed experienced politicians in the House of Commons, it left a mark on the provincial party. This was especially difficult for the provincial party as no federal politicians migrated to the provincial level in Ontario during this time. While integration does not have to be a zero sum game, in this particular instance it was: the multi-level migration of politicians was a net gain for the federal Conservatives and a net loss for the provincial PCs.

In this sense, integration can have negative consequences for political parties if its practice is severely one sided and uneven. Although only occurring at modest levels, the migration of legislators from provincial to federal politics may ultimately act as a "brain drain" of sorts. Successful provincial politicians leave to support the federal counterpart while the federal party provides nothing to the provincial party in return. Furthermore, if successful politicians are seen to have been "stolen" or "poached" from the provincial level, this can create further tensions between the parties. Not only will brain drain ensue, but public conflict may also erupt between the federal and provincial 
branches of the party. ${ }^{33}$ Such conflict will likely impact other aspects of the federalprovincial relationship, and it would not be surprising to see cooperation and collaboration decline as a result.

There is, however, a trade off. As later chapters clearly demonstrate, the federal Conservatives offer the provincial PCs in Ontario a considerable amount of campaign support and endorsements. Moreover, the main providers of this support appear to be those very individuals who were previously elected at the provincial level and then moved on to federal politics. Jim Flaherty, John Baird, Tony Clement and others with personal ties to the provincial PCs are constantly on the front lines of provincial election campaigns in Ontario, providing their support and endorsements wherever and whenever possible (Ladurantaye, 2011; McHahon, 2011; Taber, 2011b). While the party lost cabinet depth, it gained multi-level campaign partners for future elections.

\section{Candidates}

Thus far we have examined federal-provincial overlap of party members, activists, riding presidents, and elected legislators. Candidacy for election, even when the seat is not won can also represent an important linkage between parties. Like legislators, those candidates with previous involvement at another level of government will bring contacts, experience, and networks to their current position. Shared

\footnotetext{
${ }^{33}$ The potentially uneven or exploitative relationship between federal and provincial parties is explored more fully in Chapter 7 where rates of support and cooperation are broken down by level and examined.
} 
candidates can therefore represent a unique linkage between federal and provincial parties. $^{34}$

As is the case for elected politicians in Ontario, there is modest evidence of a multi-level dimension to the candidates of the major parties as well. When federal candidates were asked if they had ever sought a nomination at the provincial level, twice as many federal New Democrats reported previously seeking a provincial nomination compared to their Liberal counterparts (30\% compared to $14 \%)$. That nearly one-inthree federal NDP candidates have previously sought a provincial nomination demonstrates how close the parties truly are. While less likely than their federal counterparts, it is not uncommon for provincial candidates to have already sought a federal nomination as well (10\% of Liberal and $21 \%$ of NDP). Like the federal level, twice as many NDP candidates report seeking a nomination than do Liberals.

The differences between the two parties, however, become even more apparent when candidates are asked which party they had sought to be nominated by. For New Democrats the answer is simple: 100 percent of provincial candidates and 94 percent of federal candidates who have previously sought nomination at another level have done so for the NDP. The Liberals, however, are not as consistent. More than 20 percent of Liberal candidates who have sought a nomination at the other level have done so for a different political party.

\footnotetext{
${ }^{34}$ Unfortunately no candidate data is available for the provincial or federal Conservative parties. While both have been asked to participate in previous surveys, the parties have declined to participate. As such, emphasis in this section is on the Liberals and New Democrats. Where possible, however, data from other sources have been used to provide the Conservative perspective.
} 
The higher inconsistency of Liberal candidates is a somewhat surprising finding for a number of reasons. The NDP has always had considerably greater electoral success in the provinces, establishing provincial governments across the country. Federally, however, the party has never formed a government and has only recently earned the status of the official opposition. In the remainder of its federal history, the party has been relegated to third place or worse. In fact, Stewart and Carty have described the federal NDP as a party that has often rested on its provincial machines (2006: 101). If any party's candidates would be expected to switch at the federal level it would certainly be the NDP since that is where the party's electoral fortunes are weakest. The fact that candidates are consistent likely demonstrates the role of consistent ideology in ensuring consistent multi-level behaviour.

There have been, however, a number of high profile exceptions, both in Ontario (i.e., Bob Rae, Glenn Thibeault) as well as other provinces such as British Columbia (i.e., Ujjal Dosanjh). Despite different circumstances, each of these individuals transitioned to a different party that had a far better chance of forming the government at the other level. Nevertheless, these are exceptions, and the vast majority of NDP MPs and candidates are consistent in their multi-level activities.

This also tells us a great deal about the Liberal Party. Given the fact that Liberals have experienced widespread success at both the provincial and federal level, we would expect Liberals to be the most consistent, maximizing their chances for office by holding on to the Liberal Party label regardless of jurisdiction. The fact that many Ontario Liberal candidates who had previously sought a federal nomination did so for another party illustrates the consequences of the confederal structure. The survey data show that 
federal Liberals, while mostly drawn to the NDP when they switch parties, have also sought political candidacy for the Progressive Conservatives.

This difference in consistency likely speaks to the ideological differences of the two parties. Without coherent and consistent policy and ideology, Liberal candidates are less constrained and are freer to move across party lines when transitioning from one order of government to another. Since the party lacks ideological consistency, individuals interested in policy at the provincial level are not inherently directed to their party counterpart at the other. Recall Figure 2.2, which highlighted the considerable differences between federal and provincial Liberal ideology as coded according to the Comparative Manifesto Project. By contrast, the coherent ideology of the NDP ensures more consistency when moving across the jurisdictional divide.

While some candidates are inconsistent in terms of their office seeking behaviour, they are more consistent in other aspects of their political life. Like other party personnel, candidates are consistent in their multi-level party memberships. Fully 75 percent of federal Liberal candidates belong to a political party at the provincial level. Of these candidates, more than 90 percent are consistent in their dual membership. This is consistent with the 79 percent of provincial Ontario Liberal candidates who report that they belong to the federal Liberal Party.

In contrast to the Liberals, 80 percent of federal and 91 percent of provincial New Democratic candidates claim to belong to a provincial party. This is somewhat surprising given that the NDP does not allow individuals to opt out of dual party membership. In actuality, 100 percent of NDP candidates belong to the party both 
federally and provincially. However, it is interesting that between 10 and 20 percent clearly do not consider themselves to be dual members of the party. While the NDP may officially engineer 100 percent membership overlap, the perceptions of members and candidates are not always consistent with the official rules. Nonetheless, more than seven-in-ten federal candidates belong to a provincial party and of these, the vast majority are consistent in their dual level activities.

Additionally, it is worth noting that one-in-five federal Liberal candidates and nearly one-in-three federal New Democrat candidates report being previously elected to their provincial party executive. What is particularly striking is that despite seeking a federal nomination, federal candidates in both parties are more than twice as likely to have been previously elected to the provincial executive of their party than the federal executive. In this regard, the provincial executive appears to be somewhat of a career ladder for would-be-candidates and federal party elites. Overall, one-in-four federal Liberal and New Democrat candidates have provincial experience either as a candidate or as a member of their provincial party's executive.

Beyond being active at both levels, the candidates themselves view the parties as being connected to one another. Provincial candidates in Ontario were asked the following question in a 2011 candidate survey (Cross et al., 2015): How did the recent federal election affect your campaign? A majority of provincial candidates in both parties believed that their electoral fortunes were tied to the success and failure of their federal counterpart in the most recent federal election. According to provincial New Democratic candidates, the success that the federal party enjoyed six months prior to the provincial election had a positive impact on their own campaign. This is not surprising 
given the tremendous breakthrough that the federal party had just enjoyed: earning the title of Official Opposition for the first time and winning more seats than the party had in any previous election.

Likewise, Ontario Liberal candidates viewed the poor performance of the federal Liberals - the worst election in the party's history - as an obstacle in their campaign that had to be overcome. As the provincial Liberals are now the unpopular party in 2015, there are accounts of federal candidates "coming back from canvasses complaining about their provincial cousins being a drag on them" (Radwanski, 2015a). It is therefore evident that this works both ways, and that the perceptions of a provincial party can impact the federal party's brand and reputation.

In total, more than 70 percent of NDP candidates believed that the federal results helped them in their campaign compared to 67 percent of Liberal candidates who felt that the federal results hurt their chances. In other words, the majority of provincial candidates in both parties felt that the federal election campaign and results had a significant impact on their own provincial election.

While comparable data for Progressive Conservative candidates is not available, Progressive Conservative constituency association presidents were asked the same question for this study. Nearly two-in three (63\%) reported that the 2011 federal election results had a positive impact on their own provincial election campaign and results. The fact that the federal Conservatives had gained more than 20 seats in the province since the 2008 election was perceived as a benefit to the provincial party's campaign. Consistent with the provincial candidates in the Liberal and new Democratic parties, 
federal performance was viewed as having a meaningful impact on the provincial campaign by the PCs.

Beyond the party, it is also worth considering which types of candidates are the most likely to engage in multi-level politics (i.e., seek a candidacy at another level). Interestingly, men seeking a federal party nomination are significantly more likely than women to have already sought a nomination at the provincial level in the past. Given what we know about political ambition (Bledsoe and Herring, 1990; Carroll, 1985; Costantini 1990; Elder, 2004; Lawless and Fox, 2010), this is perhaps not that surprising. Men have consistently been shown to exhibit higher levels of political ambition and this would explain why they have sought nominations at the provincial level, likely using it as a launching pad for their career in federal politics. While gender produces significant differences, other possible factors like constituency location do not. Those candidates located in rural ridings do not differ from their urban counterparts in this regard and are no more likely to have sought a provincial nomination previously in their political career.

\section{Inter-party Differences in Personnel Integration}

Given the evidence presented in this chapter, it should be clear that party personnel link federal parties and their counterparts in Ontario in a number of ways. Put simply: people matter. Rather than opting out of integration, those individuals who are closely involved in party politics have responded to federalism by participating at multiple levels. The parties examined here share a majority of their members and 
activists while also exhibiting modest connections between their candidates and elected officials.

To use the language of Katz and Mair (1993), party personnel on the ground appear to be highly integrated whereas personnel in public office remain modestly integrated. The evidence presented here suggests that Canadian parties may be more integrated than previously thought. When we work with a broader definition of integration - one that includes people as well as structures - it is clear that Canadian parties share a number of important linkages. Table 3.5 provides a summary of the multi-level nature of party personnel in Ontario.

It should also be clear that the parties examined in this chapter do not enjoy the same levels of cross membership and overlap of party personnel. For each of the types of personnel that this paper has examined the NDP tends to stand apart from its rivals. In each of these dimensions the NDP has more overlap and shares a greater percentage of its personnel than either the Liberals or Conservatives. In this regard, the NDP appears to confirm the hypothesis that organizationally connected parties will foster the highest levels of party integration. The relatively high levels of integration that can be found within the Conservatives, however, cast doubt on the notion that integration is only an organizational phenomenon. The role of ideology in mobilizing the same individuals to participate at both levels appears to play a significant role here as well. 
Table 3.6: Summary of Multi-level Personnel Linkages by Party (Columns reporting dual level or previous provincial experience)

\begin{tabular}{lccccc}
\hline & $\begin{array}{c}\text { Party } \\
\text { Members }\end{array}$ & $\begin{array}{c}\text { Party } \\
\text { Activists }\end{array}$ & $\begin{array}{c}\text { Constituency } \\
\text { Presidents }\end{array}$ & $\begin{array}{c}\text { Cabinet } \\
\text { Ministers }\end{array}$ & $\begin{array}{c}\text { Candidates } \\
\text { (Federal) }\end{array}$ \\
\hline Conservative & $62 \%$ & $72 \%$ & $77 \%$ & $26 \%$ & - \\
Liberal & $68 \%$ & $80 \%$ & $85 \%$ & $24 \%$ & $14 \%$ \\
NDP & $100 \%$ & $100 \%$ & $100 \%$ & $17 \%$ & $30 \%$ \\
\hline
\end{tabular}

\section{Conclusions}

This chapter raised two questions in the introduction that we have sought to answer. First, how do party personnel respond to multi-level governance? In other words, are these individuals single level actors or do they engage with politics in multiple jurisdictions? And if they engage in party politics at multiple levels, are they consistent in their multi-level activities? The evidence presented here suggests that the "two political worlds" (Blake, 1985) argument may no longer be true, or at the very least does not apply in the province of Ontario when considering party personnel.

In total, 70 percent of party members, 76 percent of activists, and 86 percent of constituency association presidents engage with party politics at multiple levels and do so consistently without crossing partisan lines. This is in addition to the modest linkages that can be found between candidates and cabinet ministers. If anything, the analysis presented in this chapter demonstrates that party personnel, for the most part, live in an integrated and coherent political world. Consistent with Koop (2011), the data from a wide range of party personnel supports the claim that in the eyes of individual activists "a Liberal is a Liberal is a Liberal". Extending the analysis beyond the Liberal Party, this chapter demonstrates that 'a Conservative is a Conservative is a Conservative' and that 'a New Democrat is a New Democrat is a New Democrat'. While the party label 
may change slightly in the move from federal to provincial politics, it is clear that party personnel are not discouraged by the (mostly) formally distinct nature of multi-level politics in Canada.

The second question the chapter sought to answer centered on possible explanations for differing levels of personnel/human integration. Is integration a product of organizational design or does integration rely on a coherent and consistent ideology? The answer to the second question, as demonstrated above, is somewhat mixed. As the case of the NDP demonstrates, organizational design can ensure overlapping party personnel. By design, federal and provincial NDP share a common party membership base. The Conservatives, however, demonstrate that a lack of organizational networks does not automatically result in a complete absence of vertical integration. Despite having no organizational incentives or cooperative structures in place to facilitate their integration, Conservative party personnel have responded to multi-level governance in a similar way as the Liberals. The party's coherent ideology serves to create its own incentives and opportunities for integration and in many ways offsets the party's truncated organizational design. Both ideology and organization, therefore, are crucial in understanding divergent levels of personnel integration between parties.

The findings presented in this chapter have a number of important implications for the functioning of democracy in Canada's multi-level environment. In a recent article Esselment (2013) demonstrates the powerful role that partisanship can play in intergovernmental relations (IGR). Like partisanship, overlapping personnel is likely to have important consequences for IGR for at least two reasons. First, as Truman noted in his work on interest groups a number of decades ago, those groups with high levels of 
overlapping membership would be pressured to temper their arguments and claims visa-vis other groups and the state (Truman, 1951).

Following Truman's logic, two parties that share members, candidates, activists, legislators, and other party personnel will have a strong incentive to cooperate in the intergovernmental arena. Otherwise, political parties risk alienating key party personnel who belong to the party at both levels. In order to keep their members satisfied, parties will be pressured to find delicate multi-level compromises. Although this needs to be empirically tested, we may discover political parties with high levels of overlapping personnel to be more collaborative and cooperative in the inter-governmental arena.

Second, as Putnam notes, membership in a community or group has the impact of increasing trust and creating norms of reciprocity. The end result, Putnam argues, is that these groups and individuals can solve collective action problems as they are encouraged to cooperate with one another (Putnam et al., 1993). When working with their former colleagues, the stockpile of social capital and social trust that these individuals have accumulated is expected to improve IGR and incentivize cooperation. As it will be clear in later chapters, those individuals with close personal ties to the other level are often the very individuals who are the most engaged in multi-level activities. This is likely a result of the social capital that has been accumulated.

In a decentralized and competitive multi-level governance context such as Canada, those mechanisms that can reduce conflict, even informal ones such as overlapping party personnel, may contribute to the health and stability of the broader 
democratic state. As these are only theoretical expectations, further work on the subject is necessary. 


\section{CHAPTER 4: Constituency Associations: A Possible Site for Integration?}

\section{Introduction}

As the previous chapters illustrate, there are a number of theoretical and empirical challenges that the current integration literature faces. Chapter 1, for example, outlined some of the issues that arise when integration is examined from an exclusively organizational perspective. Moreover, Chapter 3 highlighted the need to include party personnel in the analysis. This, however, is not the only concern with the party integration literature or how integration is typically portrayed. What little we do know about party integration also tends to suffer from an equally troubling exclusive focus of the state-wide and province-wide party organizations.

As Detterbeck explains, "for many studies, the state-wide level of party systems and party organizations has provided the sole unit of analysis" (2012: 2). Deschouwer $(2006 ; 2003)$ makes a similar argument, noting that a major (albeit incorrect) assumption embedded in the party literature is to take the national state as the primary institutional context shaping party politics. Parties, however, are themselves multi-level institutions (i.e., local activists vs. central party elites) and as such the national or state-wide level should not be our only focal point. This national bias in party research overlooks other arenas in which political parties operate.

Much of the Canadian party integration research has typically ignored the interaction and relationship between parties at the grassroots or local level (for some exceptions see Koop, 2011 and Jacek et al., 1972). The multi-level and stratarchical nature of political parties in Canada, however, suggests that the local level may be an 
important site where meaningful integration can occur. As the previous chapter challenged the formal and organizational approach to the study of party integration, the following three chapters challenge the focus on the state-wide level and suggest that the grassroots is an important site where integration may occur.

The next section begins with a discussion of the place of constituency associations in Canadian party politics. Additionally, this section provides a justification as to why the constituency association is a worthwhile unit of analysis when studying party integration. The chapter then ends with a discussion of the constituency association survey and the methodology used in the data collection process.

\section{Constituency Associations and Party Integration at the Local Level}

Canada's single member plurality (SMP) electoral system divides the country into 308 (soon to be 338) distinct 'electoral districts' (sometimes referred to as constituencies or ridings). Given that electoral victory is achieved by winning individual districts, and not necessarily the most votes, Canadian parties have always had an incentive to create active and strong local grassroots party organizations (Carty, 1991; Carty and Eagles, 2005; Carty, Cross, and Young, 2000; Sayers, 1999). As Koop suggests, "An impressive national campaign is useless if the party cannot win in more ridings than the other parties, and doing so requires both competent candidates and local organizations to support them" (2011: 9).

Constituency associations (also known as Electoral District Associations [EDA]) are the organizational response to state-wide (national) political parties seeking to have a formal presence across the country in each of the single member districts. Federal parties 
establish associations in each of the country's electoral districts in order to remain connected to local members and to support local candidates in the general election. Taken together, these individual associations makeup the fundamental building blocks of party life. As Carty and Eagles (2005: 2) write, "Constituencies and the political organizations and processes that they frame, stand at the very core of Canada's political life".

For much of Canada's electoral history, local constituency associations were outside the purview of state regulation. These local organizations were viewed as private associations that had no reporting obligations and no requirement to be registered with state agencies (unlike the federal or provincial branch of the party). While local candidates have been subject to spending limits and other requirements for decades (campaign spending limits, for example, were introduced in 1974), constituency associations did not become legally recognized entities until 2004 with the introduction of Bill C-24. This new legislation requires local associations to register with Elections Canada, it limits who can contribute and how much, and it obliges proper financial reporting and transparency.

While these associations serve as the fundamental organizational building blocks for all Canadian parties, and while all federal associations are subject to the same legal requirements, not all associations function the same. While they all typically share a similar organizational structure with three major components (membership, executive, and president; Koop, 2010; 2011), they vary considerably in wealth, size, health, and vibrancy. Carty (1991), for example, finds that the number of members in local associations ranges from 2-3 in some small ridings to 13,000 regular members in others. 
Additionally, some local associations have "virtually no money" while others have incomes of "over $\$ 40,000$ and nest eggs approaching $\$ 100,000 "$ (Carty and Eagles, 2005: 17-18).

Given the vast differences in available resources (human and capital) as well as differences in local electoral support, we might expect some associations to be better equipped to engage in coordinated and sometimes costly multi-level activities than others. However, this still begs the question: why should we expect local associations to be agents of integration in the first place? What is it about local associations that might make them an important site for integration to take place?

While we know there is little formal organizational integration between federal and provincial parties with the exception of the NDP (see Chapter 2), we do not know to what extent Canadian parties actually behave in an integrated fashion. In other words, while party statutes highlight the absence of formal integration, parties may nonetheless act in an integrated manner. In fact, there is good reason to believe that the experience of political parties at the grassroots level may differ considerably from that of parties at the federal/provincial level. Katz and Mair (1993) convincingly argue that political parties are not completely coherent and unified actors, but instead have three important, and often competing components. This includes the party in public office, party in central office, and party on the ground. The identification of these three competing "faces" of political parties challenges the conventional view of parties as hierarchical and unified organizations. 
As Carty (2004: 6) explains, the traditional conception of a political party as "as a single identifiable organization that some group can capture and command" may no longer accurately describe how parties actually organize. While parties were once hierarchical, stratarchy is a more apt description of how many modern parties organize. The defining features of a stratarchical design are multiple sources of power and a number of mutually autonomous organizational sub-units with considerable independence within their own sphere of authority. Perhaps the first to recognize the stratarchical nature of parties, Eldersveld (1964:10) has written that:

Contrary to the bureaucratic and authoritarian models of social organization, the party is not a precisely ordered system of authority and influence from the top down, though as a 'paper' structure it may give this appearance. The organization does not function through the issuance of directives from the top which are obeyed without question. Rather, there is a tolerance of autonomy, local initiative, local inertia.

Developing this argument further and applying it to the Canadian case, Carty (2002; 2004) and Carty and Cross (2006) suggest that stratarchy is an organizational bargain that is made between the competing faces of the party. In the Canadian case, the stratarchical bargain provides the party on the ground (local constituency associations) with a significant degree of autonomy and independence over the management and direction of local party affairs. This bargain therefore allows the local party apparatus to organize and conduct their business without interference from the central party. In exchange for this autonomy, the party in public office is provided disciplined support and the freedom to develop policy and manage the party's brand (Carty and Cross, 2006: 97). 
The stratarchical bargain has also been referred to as the "franchise" model of party organization (Carty, 2002): constituency organizations act as franchisees where the central organization establishes the brand, manages the marketing campaign, provides leadership, and determines policy. Despite central party oversight, the local "franchise" retains autonomy over local affairs and exercises local decision-making authority. As a result of the stratarchical bargain, some branches of the party may be more integrated than others since each component of the party has the autonomy and independence to engage in different behaviour, utilize different strategies, and forge different relationships and networks.

Given the considerable autonomy afforded to constituency association executives to control and direct local party business, the responses parties take towards multi-level politics at the grassroots level may be quite different than the response adopted by the central party's formal vision as laid out in party statues and constitutions. Therefore, as a result of the stratarchical bargain we cannot assume that party behaviour on the ground will follow the same path as it does between central party structures. Instead we must empirically examine how local party organizations respond to the federal nature of Canadian politics.

Although limited, there is preliminary empirical evidence to suggest that the dynamics of party life at the grassroots level differ considerably from that of the politics at the center, especially as it relates to party integration. Jacek, McDonough, Shimizu, and Smith (1972), for instance, examined the federal-provincial campaign activities of 180 campaign workers in two Hamilton ridings. The authors uncovered considerable 
multi-level involvement and found that a majority (58\%) of campaign activists were actively involved with both provincial and federal election campaigns.

Similarly, in a survey of constituency associations following the 1988 federal election, Carty (1991) found that two-thirds of federal constituency associations (64\%) focused their attention and efforts not only on federal politics but on provincial politics as well. This level of federal interest in provincial affairs highlights the fact that political parties do not limit themselves to their own jurisdiction, nor do they seek to live in separate and distinct political worlds. Instead, parties are interested in other jurisdictions, and when possible, will make an entrance into multi-level politics. Moreover, data from this particular survey demonstrate that a majority of federal constituency associations describe their local membership as being joint with the provincial party rather than completely federal $(\mathrm{NDP}=73 \%$; Liberals $=50 \%$; Progressive Conservatives $=23 \%){ }^{35}$

More recently, Koop's (2011) analysis of a number of Liberal Party constituency associations from across the country demonstrates that it is not uncommon for local Liberal Party activists to forge informal relationships that result in cooperation and coordination between provincial and federal constituency associations. Such informal cooperation is often based on personal relationships and involves sharing resources with one another, promoting each other's events, attending meetings, and so on.

Overall, preliminary evidence from the existing research suggests that political parties at the local level (1) care about multi-level politics and dedicate their time and

\footnotetext{
${ }^{35}$ I am grateful to Ken Carty for sharing this survey data from The Royal Commission on Electoral Reform and Party Financing.
} 
attention to multiple jurisdictions (2) draw upon the same pool of campaign labour during elections, and (3) often engage in informal cooperation and coordination with their multi-level counterpart. While these and other studies certainly contribute to our understanding of multi-level party politics, they are not without limitations.

First, both Koop and Jacek et al. examine only a small number of electoral districts (16 and 2, respectively). As a result, it is unclear how representative the findings truly are. It may be the case, for example, that there is something unique about Hamilton ridings that provided an incentive for integration and therefore limited the generalizability of the Jacek et al. (1972) findings. Similarly, while Koop (2011) finds enough variance to create a four-fold typology of constituency associations based on their level of integration, it is unknown how common each type of constituency association really is given that the evidence is derived from a single party. While the conclusions drawn from these two studies are interesting, the findings must be replicated more systematically across a much larger set of constituencies. Only then can we make generalizations about the state of party integration in Canada.

Second, very little work on the subject of Canadian party integration has examined all three of the major Canadian parties simultaneously. Because of the time and resources necessary to conduct in depth ethnographic research based on participant observation, Koop (2011) omits the Conservatives and New Democrats from his analysis and focuses exclusively on the Liberals. Although not interested in the local level, Esselment (2010) also excludes the New Democratic Party from her analysis of multi-level campaign behaviour of political parties in Ontario. Justifying the NDPs exclusion from the analysis, Esselment writes that "suffice it to say that by virtue of its 
integrated structure, the federal and provincial wings of the New Democratic party engage in intense electoral collaboration" (2010: 889).

This, however, tells us very little about the New Democrats beyond the formal organizational structure. Despite being organizationally connected, it is still worthwhile to study federal and provincial New Democratic parties and uncover the extent to which they behave in an integrated manner. Notwithstanding the party's organizational design, it is possible that the party may exhibit very little campaign integration, instead choosing to divide its personnel and resources and focus on one single level. It seems that the last truly comparative piece of scholarship focusing on party integration in Canada is nearly two decades old (Dyck, 1991; 1996) and focused much of its analysis at the national level.

Finally, studies have rarely attempted to capture both the formal and informal practices of political parties, often focusing exclusively on formal organizational indicators. Thorlakson (2009), for instance, adopts a strictly organizational and formal approach to the study of integration that examines Canada in a comparative study of 27 parties across seven different federations (Canada, Spain, Germany, Australia, Austria, Switzerland and the United States). To assess the state of party integration, Thorlakson uses data from party statutes and constitutions. Although acknowledging that there are considerable shortcomings with this approach (parties can act quite differently than their constitutions would suggest), Thorlakson argues that party documents are the most reliable source of information available for comparative study. This analysis, however, focused exclusively at the national level and did not examine the constitutions or rules of local constituency associations. As Chapter 6 details, local associations have their own 
constitutions and these often include clauses that relate to issues of multi-level party integration.

More recently, Thorlakson (2011) has refined her organizational approach to include aspects that go beyond the use of party statues alone. Surveying party elites between 2005-2008 in eight countries, Thorlakson has compiled a dataset that attempts to capture the "soft" practices of parties. Thus, departing from her earlier work, Thorlakson's recent scholarship examines shared goals, identity, and cooperation. ${ }^{36}$ In addition to Koop's examination of informal and personal linkages, this represents the only Canadian scholarship that devotes considerable attention to the soft and informal means of party integration.

By utilizing a unique dataset constructed from a survey of federal and provincial constituency associations and their presidents, the next three chapters seek to address a number of the limitations of previous research on the subject of party integration. These chapters do so by examining all three major Canadian parties simultaneously, by using a much larger sample of constituencies, and by taking into account both formal and informal forms of vertical party integration. Ultimately, the following chapters build on previous integration research, systematically and empirically testing a number of findings that have been derived from case study research (i.e., Koop, 2011; Esselment, 2010). This approach offers a much more rich and complete understanding of multilevel politics in the province.

\footnotetext{
${ }^{36}$ While including non-organizational indicators in the study of integration is indeed an important advancement, the focus on national party elites falls into the same national bias trap that Detterbeck warns against. A similar level of attention on local party activists and campaign teams must therefore compliment the study of central party elites.
} 


\section{Constituency Association Survey and Data Collection}

The main source of data for Chapters 5, 6, and 7 were collected using an online survey tool administered to constituency association presidents of federal (Liberal, Conservative, and New Democrat) and provincial (Liberal and Progressive Conservative) parties in the province of Ontario. The survey was administered between April and May 2013 for the two provincial parties and June and August 2013 for the three federal parties. Approximately two weeks after initial email requests for participation were sent, a physical postcard reminder was mailed to constituency associations to collect additional responses and to invite those associations where an email invitation could not be previously sent.

Kaplowitz et al. (2004) find that this type of hybrid survey design can achieve comparable response rates to traditional mail surveys. Moreover, the survey literature has tended to suggest that using web-based surveys for populations that regularly use the internet can be a useful means of reducing the level of non-respondents (Kaplowitz et al., 2004: 2). Given that constituency associations have their own websites and emails, it is safe to assume that this particular population uses the internet on a regular basis and would therefore be comfortable with a web-based approach to completing their survey.

The dataset consists of 273 valid responses, for an overall response rate of 51 percent. This is consistent with previous attempts to survey Canadian constituency associations (see, for example, Cross, 1996). The overall response rate is slightly higher if we do not include those constituency associations in which there was a vacancy at the time of the survey (at least 10 constituency associations advised the author of a vacancy 
and therefore did not participate). While contact information for each association was obtained from Elections Ontario and Elections Canada, some information was nonetheless out of date. As a result, a number of requests went undelivered as either physical mailing addresses or constituency email addresses were no longer valid at the time of the survey. While an attempt to contact every constituency association was made, in the end some were missed due to a lack of contact information.

As is often the case with survey research, response rate also varied by party. The 273 responses include 113 Liberal (53\%), 95 Conservative (45\%) and 65 New Democrat $(60 \%)$ constituency associations. While the provincial NDP in Ontario was initially contacted to participate in the survey, it quickly became clear that the integrated nature of the party's organizational structure would make surveying both federal and provincial associations difficult. Because electoral boundaries are the same provincially and federally in Ontario, and because the party is organizationally unified, many of those individuals who serve as the federal riding president simultaneously serve as the president for the provincial party as well. In most instances, the provincial association replied to the survey request by indicating that they had already completed the federal survey. As a result, the universe of unique provincial NDP presidents (those who only serve the provincial party) is rather small and therefore not included.

\section{Conclusions}

Constituency associations are a fundamental, yet often ignored, component of Canada's party democracy. Their loose organizational structure combined with a stratarchical design that provides considerable local autonomy suggests that these party 
organizations are in a unique position to engage in multi-level activities with their counterparts in the riding. Moreover, given their franchise nature, these local party units have the ability to engage in behaviour that is outside of formal party rules codified in party statutes. Despite some notable exceptions, the possibility of the grassroots as a meaningful site for multi-level linkages to occur and the role of constituency associations in facilitating and furthering party integration have largely been ignored.

Using this unique data source, the next three chapters explore party integration at the grassroots level. Focusing on federal and provincial constituency associations, Chapter 5 examines multi-level politics during election campaigns. Here the focus is on the provision of campaign endorsements, influence in candidate selection processes, and the sharing of resources (both human and otherwise). Chapter 6 extends the examination of party integration at the local level beyond the campaign, exploring how parties remain connected during the inter-election period. Finally, Chapter 7 combines both campaign integration as well as inter-election integration in order to obtain a richer and more complete picture of party integration. 


\section{CHAPTER 5: Campaign Integration at the Grassroots}

\section{Introduction}

In a recent news interview the Liberal Member of Parliament for ScarboroughGuildwood, John McKay, explained the close relationship between federal and provincial parties at the constituency level. In particular, the MP detailed how the federal party would build on the provincial party's success: "given that federal and provincial Liberal parties and riding associations work very closely in Ontario, the relationship will help the federal Liberals in the next federal election in the province" (Rana, 2014). While McKay's statement about local Liberal cooperation is presented as common practice, the extent of such cooperation at the constituency level is largely unknown. In fact, as detailed in the introduction to this thesis, the academic portrayal of Canadian parties is that of distinction and separation rather than cooperation and collaboration.

The purpose of this chapter is to add to our understanding of party integration in Canada in two ways. First, the chapter begins by examining a typically unexplored aspect of party integration: party linkages at the local level. In doing so, this chapter shifts our focus away from an exclusive emphasis on parties at the national level and examines multi-level politics at the grassroots. Of particular interest in this chapter is the extent to which local parties provide their multi-level party counterpart with campaign support and the degree to which they share resources and information during the election period. In other words, are Liberal MP John McKay's observations about Liberal cooperation at the constituency level true for most ridings and most parties or is this unique to his own particular circumstance? 
Second, the chapter also examines different types of local constituency associations in order to determine which are the most likely to engage in integrated campaign activities. Although exploratory, four hypotheses (focusing on issues of electoral strength, incumbency, the urban/rural divide, and the presence of cabinet representation) may help account for differing levels of party integration in Ontario constituency associations. It is expected that constituency associations will be more integrated in ridings where the party is electorally strong, where there is an incumbent, in rural ridings, and where a cabinet minister is present.

While detailed in greater length later in the chapter, it is worth briefly elaborating on these hypotheses here. First, electoral strength is typically accompanied by greater access to resources (both human and capital). As a result, local associations in these ridings are more vibrant and have the ability to engage in cross-jurisdictional activities. An alternate hypothesis, however, might be that a lack of resources leads to integration out of necessity. In order to achieve any sense of organizational strength these associations may work across levels to ensure there are enough volunteers, data, and so on. Second, incumbency also tends to produce a more active local association. Additionally, incumbents have an incentive to protect the party brand in the riding. As such, it is expected that incumbents will devote resources to multi-level activities in order to manage and cultivate the party's image. Third, rural life is often described as having more face-to-face interaction and higher levels of social capital. This is expected to facilitate a greater sense of solidarity and therefore cross jurisdictional cooperation. Finally, cabinet ministers wield considerable power in Canadian governments: they are part of a small court of individuals who have access to the Prime Minister. Beyond 
potential policy implications, these individuals can easily raise funds for upcoming elections and attract countless volunteers. In order to gain access to these benefits, associations are expected to cooperate more closely in ridings represented by a minister.

Overall, the purpose of this section is not to determine causal relationships but instead to create a profile of the constituency associations that are the most likely to engage in integration campaign behaviour and activities. This will help us determine which factors help explain why some associations or parties are more integrated than others.

Employing a number of indicators of local campaign integration this chapter demonstrates that federal and provincial parties at the local level share a number of important linkages during election campaigns: parties at the grassroots routinely cooperate and share resources, coordinate their efforts during elections, and provide support to one another throughout the campaign period. What's more, these linkages are found to be present in all of the major parties, even in parties that are formally and organizationally distinct from one another. This is consistent with the conclusions in the previous chapter that found significant personnel linkages to be present even in truncated and semi-integrated parties.

While there are clear differences at the level of the political party - the New Democratic Party exhibits higher levels of integration than its competitors - the chapter concludes that cross-jurisdictional electoral collaboration is by no means an uncommon occurrence at the constituency level in Canada. Furthermore, the results of the multinomial and binary logistic regressions highlight the potential for non-party based 
factors. The results demonstrate that constituency associations in electoral districts where the party is electorally viable are significantly more likely to engage in integrated campaign behaviour than those constituencies where the party is electorally weak.

\section{Measuring Local Party Integration}

Constituency associations ${ }^{37}$, while often overlooked, are fundamental to Canadian party democracy. These local party branches engage in a number of important party activities that can be divided into two broad categories. First, there are those activities that focus on inter-election grassroots party maintenance in the riding. This includes activities such as policy study and formation, fundraising, social events and public meetings, membership recruitment, and election planning (Carty, 1991; Carty and Eagles, 2005; Koop, 2011). This set of local party activities is examined in more detail in the next chapter.

The second category of functions involves those activities directly related to elections and campaigning. This includes activities such as candidate recruitment and training, information dissemination, managing local volunteers and party activists, mobilizing the vote, and supporting the local candidate during the election campaign. As elections continue to be "party-centered" events, the campaign function of local parties is of considerable importance. For the purpose of this chapter we are particularly

\footnotetext{
${ }^{37}$ The unit of analysis for the next two chapters is the constituency association. To be clear, it is not individual ridings/electoral districts. Since integration can be one sided (for example, a federal association provides support to its provincial counterpart but receives none in return) we cannot draw conclusions about an individual riding as a whole unless we have responses from both provincial and federal constituency associations in the electoral district. While interesting, such an analysis would significantly reduce our sample size and limit analysis. Additionally, not all associations provided their riding location. As such, we focus here on individual constituency associations instead of electoral districts.
} 
interested in this latter category of activities and focus on multi-level cooperation and coordination during election campaigns as this represents the arena in which local associations arguably have the most independence. As Carty and Cross write, "local autonomy for the party on the ground means that the local association is free to run its own affairs as it sees fit. The most important of its activities are choosing its candidates for public office and organizing and managing campaigns on their behalf" (2006: 97).

To assess the extent to which grassroots parties engage in coordinated and integrated campaign behaviour during elections a number of different activities directly related to elections are considered. First, the degree of multi-level involvement in the candidate selection processes is considered. Given that candidate selection is the quintessential party activity, constituency associations that allow multi-level influence in the selection of their local candidates share an important linkage. Second, the extent to which parties share information about activists and voters in their electoral district and coordinate volunteers jointly with their multi-level counterpart is assessed. Finally, the extent to which parties received/provided direct campaign support in the form of local campaign endorsements from their multi-level counterpart in the 2011 election is examined.

\section{Candidate Selection}

Before local constituency associations can engage in election campaigns they must first conduct a search for and nominate a local candidate to carry the party label in the upcoming general election. Of the long list of functions that political parties perform there is widespread agreement in the literature that the selection of party personnel is 
among the most important (Cross, 2008; Kirchheimer, 1966; Ranney, 1981; Sartori, 1976). This function is so consequential that Schattschneider once wrote that "he who has the power to make nominations owns the party" (1942: 100). Likewise, American politician William M. Tweed, famously remarked, “I don't care who does the electing, so long as I can do the nominating" (Stewart and Archer, 2002: 3).

Control over this process provides local constituency associations with a "pivotal role" in Canadian political parties (Sayers, 1999) as they can influence the direction and character of the party through the selection function. While there may be national guidelines and occasional interference ${ }^{38}$, local activists have historically been charged with the nomination of legislative candidates (see, for example, Scarrow, 1964). Over a century ago, for example, Siegfried noted that "five or six weeks before voting-day the candidates are nominated by a local convention held in each constituency" (1966: 119). Likewise, Cross and Young write that "one of the distinctive characteristics of Canadian political parties is the autonomy local party associations enjoy in the selection of candidates to stand for elected office" (2013: 24). Given the importance of candidate nomination, local constituency associations guard this right tightly from outside intrusion, especially from the central party apparatus (Carty, 1991; Sayers, 1999). ${ }^{39}$ In fact, there is even some evidence suggesting that local executives may punish central

\footnotetext{
${ }^{38}$ New Democrat constituency associations, for example, are tasked with ensuring that there has been an adequate search for female and minority candidates before the selection process can continue.

${ }^{39}$ Cross (2006: 177), however, writes of increasing central party involvement in the candidate selection process. In 2006, for example, Liberal and Conservative party leaders unilaterally reappointed a large number of candidates without a proper local nomination contest. This is not necessarily a new development either. As early as 1935, Social Credit candidates in Alberta were chosen by the local associations, however, the party leader first screened all potential candidates (Smiley, 1987: 106). It is not uncommon to have these attempts to interfere in local affairs be resisted vigorously by the local association.
} 
party interference by withholding local resources during the campaign (Carty and Eagles, 2005).

While candidate selection is typically viewed as a solitary event, there is certainly room for multi-level involvement in the selection process. Until now, however, no research has examined the informal aspects of multi-level influence in candidate nomination. While scholars have often included candidate selection as an indicator in their analysis of integration (Dyck, 1991; 1996; Smiley 1976; 1987; Thorlakson, 2009), this line of research has always examined the formal role that parties detail in their constitutions and statutes. In other words, do federal parties provide formal mechanism for provincial parties to participate in the selection process and vice versa? The answer to this question has largely been no.

This, however, ignores the possibility that parties influence candidate selection outside of formal mechanisms - either during the selection process or the search for candidates. To capture the extent of the cross-jurisdictional involvement, constituency association presidents were asked to identify how influential their multi-level counterpart is in the selection of their own local candidates ("In your opinion, to what extent does the federal [Conservative Party] influence the provincial [Progressive Conservative Party's] actions in the choice of candidates for provincial elections"). Table 5.1 provides the responses to the question of multi-level involvement in the candidate selection process.

It is interesting that only a plurality of riding associations describe their multilevel counterpart as being "not very influential" in the selection of candidates. Given the 
conclusions in the literature we would expect the vast majority of constituency associations to report that their provincial or federal cousins have absolutely no influence in the selection of their local candidates. Instead we find that one-in-four Ontario constituency associations (25\%) report that their multi-level counterpart plays an influential role in the selection of local candidates for election. What's more, only a third of Ontario constituency associations describe their multi-level counterpart as being "not at all influential" in the selection of local candidates for election. This suggests that in nearly two thirds of Ontario constituency associations there is at least some multilevel involvement in the candidate selection process.

Table 5.1: Degree of Multi-level Influence in Candidate Selection by Party

\begin{tabular}{lcccc}
\hline Party & Influential & $\begin{array}{c}\text { Not very } \\
\text { Influential }\end{array}$ & $\begin{array}{c}\text { Not at all } \\
\text { Influential }\end{array}$ & Total \\
\hline Liberal & $25 \%(29)$ & $39 \%(44)$ & $35 \%(40)$ & 113 \\
Conservative & $17 \%(16)$ & $40 \%(38)$ & $43 \%(41)$ & 95 \\
NDP & $34 \%(22)$ & $44 \%(28)$ & $22 \%(14)$ & 64 \\
Overall & $25 \%(67)$ & $40 \%(110)$ & $35 \%(95)$ & 272 \\
\hline
\end{tabular}

"In your opinion, to what extent does the federal [Conservative Party] influence the provincial [Progressive Conservative Party's] actions in the following areas: Choice of candidates for provincial elections."

This kind of multi-level influence in candidate selection can take a number of forms. The most common way in which this influence is exercised is through overlapping party personnel. That is, the same individuals being involved in both provincial and federal politics at the party level. As Chapter 3 demonstrates, 70 percent of party members and 76 percent of activist party members in Ontario belong to parties at both levels. The selectorate responsible for choosing federal and provincial candidates therefore overlaps considerably in the province. Political parties can therefore exert 
influence on each other by having their members turnout and vote in the candidate nomination process for their multi-level counterpart.

Cross and Young (2013) demonstrate that local associations are not only active in selecting candidates but recruiting them as well. Their study of federal Liberal and New Democratic party candidates from the 2008 election reveals that a majority (60\%) of candidates were approached by a member of the local constituency executive (2013: 39). Like overlap in the selectorate can allow for multi-level influence, overlapping recruiters allows for influence as well. According to the survey, more than 50 percent of the constituency associations report significant linkages between their local executive and their multi-level counterpart (see Chapter 6 for further analysis of these executive linkages). In some cases, many of those individuals involved in the candidate search federally are often the same people responsible for the candidate search provincially and vice versa. Thus, both the selectors (party members) and the search committees (local party executives) often have a considerable degree of commonality between federal and provincial parties that can allow for multi-level influence in a number of ways.

In other cases, multi-level influence is not a result of overlapping party personnel (members or executives) but instead cooperation in candidate selection serves as a strategic decision. In these instances, coordination is more active and federal and provincial constituency association executives work together to find suitable candidates at both levels. This form of cooperation ensures that prospective candidates are not "poached" by a party's multi-level counterpart. Follow up interviews with constituency association presidents confirms that local executives often work together to ensure that federal and provincial parties are not courting the same "star" candidate in the riding. 
This kind of coordination can help reduce conflict and competition between parties of the same label operating in a single riding (personal interviews). The federal and provincial Conservatives in Ontario, for example, have a relatively longstanding, albeit informal, agreement where each party agrees not to poach candidates from one other (Esselment, 2010: 882; personal interview).

When candidates are poached, however, a rift in the party (either publicly or privately) can emerge. A number of party officials recounted stories of "underhanded" behaviour, which ultimately soured the relationship between the two local associations. In some cases, events like this have created a history of distrust and separation between the parties in the riding. Despite no recent developments to make the relationship worse, these parties have cultivated a culture of not cooperating with one another. One constituency association president described his riding association as having a "long standing beef with the provincial bunch" after a candidate for the provincial election was wooed to seek the candidacy of the federal party instead (personal interview). Like the discussion in Chapter 3 concerning integration "brain drain" with elected officials moving from the provincial level to the federal level, cases of candidate poaching such as this can prevent integration from occurring in the future and can have negative implications for other aspects of local party integration.

Finally, some influence is less strategic but equally as overt as above. There have been a number of recent cases of federal candidates attending a nomination meeting and nominating an individual to be the provincial candidate or vice versa. Isabel Cisterna, for example, the provincial NDP candidate in Kitchener-Waterloo, was nominated to run in the 2011 election by federal NDP candidate Bill Brown (Daily Exchange, 2011). This 
is especially common in the NDP, where the local constituency association often services both the federal and provincial parties.

Additionally, it is not uncommon for politicians at one level to make phone calls and suggest candidates for the party at the other level (personal interviews). When this is the case, incumbent candidates at one level can use their position and standing in the riding to influence the choice of candidate at the other level, or at very least influence the pool of candidates from which party members will choose. As incumbents typically work hard to create a vibrant local association, they prefer a counterpart that they can work with. While boundaries must be respected (MPs will not demand that a particular individual be chosen as the provincial candidate, for example), multi-level participation in the selection process does occur. This is consistent with Koop's analysis of Liberal constituency associations, which demonstrates a strong personal component to certain forms of vertical integration (2011: 188) where established incumbents seek out likeminded individuals who will fit in to the dynamic and culture that the riding has worked to cultivate.

A recent example of an incumbent getting involved in the selection of candidates at the other level can be seen in the aftermath of the defection of MP Eve Adams. After leaving the Conservatives and joining the Liberals, Adams announced that she would be seeking the federal Liberal nomination in the riding of Eglinton-Lawrence. The provincial Liberal MPP in the riding, Mike Cole, immediately expressed his dissatisfaction: "I mean, that a Harper Tory from Mississauga all of a sudden is going to run here in the middle of Toronto with no connections and no awareness? You know, it's a real insult to the local Liberals in this community" (Canadian Press, 2015). Not only 
did the provincial MPP become publicly involved, his statement highlights the perceived linkage between federal and provincial Liberals in the riding. Rather than speaking of 'federal Liberals' or 'provincial Liberals', Cole speaks of 'local Liberals' as a single coherent group that does not seem to distinguish the two levels.

Not all parties, however, experience the same level of cross-jurisdictional involvement in candidate selection. Multi-level involvement within the New Democrats, for instance, is twice as prevalent as it is within the Conservatives when it comes to the nomination of candidates (34\% compared to $17 \%$ ). By contrast, the Liberal figures are in line with the overall average in each category.

Evidence from a recent survey of provincial candidates provides further support to the observation that there is a modest degree of multi-level involvement in local candidate selection. According to the candidate survey one-in-five provincial New Democratic candidates considered running for office due to encouragement from the national party. This, of course, provides evidence that federal involvement in candidate nomination is more widespread than previously thought. What this demonstrates is that the federal party can often have a vested interest in the provincial election and have particular candidates in the race.

Furthermore, in the case of the NDP, fully 25 percent of those candidates approached by the federal party went on to win their seat in the provincial election. The presence of MLAs in Queens Park that have connections with and received support from the federal party highlights important linkages between the federal and provincial NDP parties. The numbers for the Liberals, while less striking, are important nonetheless. 
More than one-in-ten Liberal candidates ran for provincial office due to federal party influence and encouragement.

While the level of influence should not be overstated, Table 5.1 provides some interesting evidence to suggest a modest degree of federal-provincial coordination when it comes to the recruitment and nomination of local party candidates. Despite having formal authority over the selection of their own local candidates, party counterparts in other jurisdictions exert at least some influence nonetheless. Rather than living in their own political world, parties are willing to engage with party politics in jurisdictions other than their own. While candidate selection is sometimes considered the raison d'être of local associations, parties appear willing to tolerate and allow this type of intrusion into their own sphere of influence from their multi-level counterpart. Indeed, it is rare to hear about local constituency associations protesting the involvement of their multi-level counterpart in the candidate selection process. This is particularly surprising given that local riding associations often fight, typically quite vocally and publicly, against the central apparatus of their own party when there is any hint of interference. ${ }^{40}$

While the focus here has been on the process of candidate selection, it should be noted that multi-level influence in the selection of party personnel is not limited to the selection of legislative candidates. Indeed, parties routinely get involved with leadership selection politics as well. The 2015 leadership contest within the Ontario PCs to replace

\footnotetext{
${ }^{40}$ A recent example can be seen in the Conservative electoral district of Mississauga-Brampton South. After interference from the National Director to ensure to reselection of Eve Adams, the constituency association executive fought back against the central party, contacting the prime minister and creating a media firestorm (Wingrove and Chase, 2014). Similarly, Liberal leader Justin Trudeau's decision to block a local candidate from seeking the Liberal nomination in Trinity-Spadina was met with widespread criticism from the local executive who condemned the move as being undemocratic and inconsistent with the party's principles (Delacourt, 2014).
} 
Tim Hudak is a telling example. During the leadership election, federal Conservative backbench MP Patrick Brown not only came forward as a candidate for the provincial party position but he was also actively rounding up support from the federal party, claiming to have the support of more than 40 federal MPs. Additionally, a number of high profile ministers such as Peter MacKay and Maxime Bernier supported his candidacy and attended fundraising events for the Brown leadership campaign. Interestingly, these cabinet ministers are from outside of the province. In a recent interview, Brown stated that he was "honoured with the heavy federal involvement and support of my campaign" (Fekete, 2015). Brown, of course, went on to win the leadership of the Ontario Progressive Conservatives.

Nor is this unique to Brown's campaign. Indeed, similar multi-level campaigning can be seen among the other candidates as well. Longtime provincial PC MPP Christine Elliott campaigned for federal party support, securing endorsements from numerous Conservative MPs and cabinet ministers such as Rob Nicholson and Kellie Leitch. More than just an endorsement, federal Conservative MP Erin O'Toole organized a questionand-answer session where federal MPs could meet and discuss issues with the provincial leadership candidate (Fekete, 2015).

Multi-level involvement in leadership selection is not confined to the Conservatives. The 2012 federal NDP leadership race, in which Tom Mulcair was selected as party leader, witnessed dozens of provincial legislators providing endorsements for their preferred candidate. Indeed, each of the leadership frontrunners secured endorsements from a variety of provincial legislators across the country. At least four British Columbia MLAs (Austin, Coons, Donaldson, and Macdonald), for example, 
endorsed federal MP Nathan Cullen to lead the federal party (Cullen, 2011). Similarly, MLAs in Nova Scotia, British Columbia, Manitoba, and Ontario endorsed Paul Dewar for the leadership (Dewar, 2012). One MP noted that this kind of provincial support is incredibly valuable to leadership contenders as it demonstrates an ability to extend beyond an individual riding and create relationships and support across the entire country (personal interview). In other words, it highlights some of the qualities that are needed in a party leader that do not necessarily apply to being a good MP.

Nor is this behaviour limited to elected officials. As Chapter 8 highlights, campaign professionals from other levels can also get involved in leadership politics. Take the 2013 Liberal leadership election as an example. In preparation of his leadership campaign, Justin Trudeau began assembling a team of campaign experts, many of who had previous experience provincially, particularly in Ontario (Delacourt, 2012). Key Trudeau leadership campaign individuals such as Gerard Butts and Katie Telford have a long history with the Liberal party in Ontario and were brought on board at the federal level to secure the party leadership.

\section{Resources: Volunteers, Data, and Activists}

Campaigning is a labour intensive activity that requires a great deal of human capital. A major task for constituency associations is to mobilize local party members and supporters to volunteer their time and energy during election campaigns. Although the media tends to focus on the leader's tour and the national (or province-wide) campaign, much of the election campaign actually occurs at the local level in each of the country's 308 constituencies. As Carty, Cross, and Young explain, "It is on the ground 
in the constituencies, that much of the hard work of Canadian party politics takes place, for, at the end of the day, winning constituencies is more important than winning votes in the quest for power" (2000: 154). Local volunteers and party activists canvass ridings and knock on doors, mobilize supporters to turnout to vote, provide voters with valuable information, host lawn signs to make the party's presence in a riding known, work phone banks, contribute money, help sway swing voters, and take care of a variety of other tasks essential to modern election campaigns.

These active and committed individuals, however, are often in short supply. In his study of constituency associations, Carty (1991) finds that local campaigns need an average of 150 campaign volunteers to run an effective campaign. Despite their importance, less than one-in-five local campaigns reported having enough volunteers in the 1988 election (Carty, 1991: 167). The parties in the current sample reported having an average of 105 volunteers during their last election campaign (2011). ${ }^{41}$ Given high demand and short supply of campaign volunteers, one way parties in a multi-level environment can cooperate with one another is to coordinate volunteers jointly, share information about activists across levels, and ultimately draw upon the same active and engaged individuals to volunteer during campaigns.

Koop's (2011) study of grassroots constituency associations finds that Liberal constituency associations are typically willing to provide their counterpart with lists of those individuals who have hosted a lawn sign during a previous campaign. This type of cooperation can provide integrated parties with a considerable head start and advantage

\footnotetext{
${ }^{41}$ It should come as no surprise that this is lower than the 1988 figure given the trends towards less labour intensive campaigns and towards more capital intensive ones as well as overall declines in membership and activism.
} 
once an election is called, as they will begin the campaign with a large list of potential supporters to immediately contact. This is particularly important in the era of voter surveillance (Bennett, 2013) where parties are keeping increasingly detailed lists of eligible voters.

In fact, each of the parties have and routinely use sophisticated software that stores the names, addresses (physical and email), vote intentions, intensity of party support, history of party activism, and other relevant information of individual voters in the riding. The Conservatives use the "Constituent Management System" (CIMS), the Liberals use "Liberalist" and the New Democrats use a database called "NDP Vote". The Liberalist database, for instance, contains the following lists of detailed information: member renewal, active member, expired member, lawn sign request, potential volunteer, vote history, supporter, phone, and email (Liberal Party of Canada, 2012). More recently a group of Conservative Members of Parliament have been developing software for federal and provincial parties alike to use in upcoming elections (Millar, 2014). C-Vote, computer software that is set to replace CIMS is reported to have cost more than $\$ 7$ million to develop (Funke, 2014).

Garth Turner, a former Conservative Member of Parliament, revealed the extent of the information that can be found in these databases. Writing in his personal blog, Turner described his experience with CIMS as follows: "When I went to bang on doors in a neighbourhood, my team dug into CIMS, and printed out a walk list for the poll. It told me who lived in each house on each street, along with any known information on what party they support. Every name was followed by a bar code. After talking to each person, I assessed their political leaning and marked it on my sheet. Back at the 
campaign office, teams of people keyed in the data while using bar code readers to match it up with voters' names" (Turner, 2007).

Access to this detailed voter information can be incredibly valuable for political parties for obvious reasons. These data collection efforts and predictive analytics shape the character and content of modern campaigns. They inform campaign managers as to where their limited resources should be allocated and help make decisions about which ridings to target, where to place party advertisements (online, television, mailing), and how to contact potential voters (McGregor, 2014).

This information from each provincial and federal election can be pooled together to create a more robust and more complete database to use in the next election. The pooling of such data allows parties to more accurately target ridings and have up-todate and detailed information about the voters in their constituencies. The sharing of this kind of information is further incentivized by the congruence of electoral boundaries in Ontario. Given the potential benefits that this type of cooperation can produce for local associations in their election preparedness, to what extent does this kind of electoral coordination regularly occur on the ground during election campaigns?

Table 5.2 reveals that more than half (56\%) of riding associations in Ontario share information concerning local voters and party volunteers with their multi-level counterpart in the same riding. This level of multi-level campaign cooperation at the local level is perhaps surprising given the tension that often occurs between parties in central office concerning the use of party data. Indeed, parties tend to guard their data tightly, rarely revealing how many members or volunteers that they have. The federal 
and provincial Conservative parties, for example, were recently in a dispute concerning the use of lists of party members. During the 2009 Ontario Progressive Conservative leadership race the National Director of the federal Conservatives sent letters to four PC leadership contenders alleging misuse of Conservative Party data. The letter stated the following:

It has come to our attention that at least one leadership campaign team has been using Conservative party lists in an effort to recruit new members to the Progressive Conservative Party of Ontario...I would like to remind all campaign teams that Conservative party data is the property of the Conservative Party of Canada and is not to be used by any of the leadership campaign teams in any form... We will continue to monitor the situation and will take the necessary action to ensure compliance (Benzie, 2009).

Despite the tensions that can erupt between the federal and provincial Conservatives in central office, party organizations at the local level appear willing to provide this kind of support to one another. ${ }^{42}$ In fact, nearly half of Conservative constituency associations (44\%) report sharing voter and activist information with their multi-level counterpart in the same riding. Not only does this illustrate the party's commitment to informal means of local party integration, but this example further demonstrates the considerable autonomy that constituency associations have in managing their own organizations and local party affairs. Although central party officials want to tightly guard this type of party information, local parties understand the

\footnotetext{
${ }^{42}$ It is also unclear how much tension there really was around this issue. The Federal Conservatives only sent the letter two days before the end of the leadership election. This suggests that the party was either unaware that provincial candidates were using federal lists throughout the campaign or that the party did not care and waited until the end of the campaign in an attempt to demonstrate that they take the privacy of their members seriously while not interfering with the leadership contest. Given that it was widely known that the provincial candidates were using the federal data, the latter is more probable.
} 
benefits that can emerge from forging relationships with their local multi-level counterpart.

Table 5.2: Multi-level Campaign Labour and Coordination by Party

\begin{tabular}{lccc}
\hline & $\begin{array}{c}\text { Share lists of } \\
\text { voters/activists }\end{array}$ & $\begin{array}{c}\text { Dual Level } \\
\text { Volunteers }\end{array}$ & $\begin{array}{c}\text { Dual Level } \\
\text { Campaign Teams }\end{array}$ \\
\hline Liberal & $47 \%(53)$ & $93 \%(86)$ & $60 \%(50)$ \\
Conservative & $44 \%(42)$ & $78 \%(56)$ & $68 \%(49)$ \\
NDP & $90 \%(55)$ & $98 \%(61)$ & $100 \%(60)$ \\
Total & $56 \%(150)$ & $90 \%(203)$ & $74 \%(159)$ \\
\hline
\end{tabular}

"Does your local party association and the federal [Conservative Party] association in the same riding share lists of members, activists, or supporters?" "Does your local association and the federal [Conservative Party] association in the same riding coordinate volunteers jointly?" "Most campaign teams (office manager, campaign manager, etc.) in this association have also served on campaign teams for the federal [Conservative Party] in the same riding".

As noted above, these collaborative relationships can provide a significant advantage once an election is called as the constituency association now has access to multiple sources of data (federal and provincial) and can multiply the number of committed volunteers that the party has access to. Given that parties often struggle to find enough bodies to run effective campaigns (Carty, 1991), access to more potential volunteers, donors, and voters is an incredibly valuable resource for parties. Moreover, despite the recent tension between Conservatives at the center, local Liberal constituency associations only provide this form of multi-level support at a slightly higher rate $(47 \%)$. While this type of cooperation is not uncommon for either the Liberals or Conservatives, it is the norm for the New Democrats. The data reveal that 90 percent of NDP associations report engaging in this kind of cross-jurisdictional cooperation (nearly twice as many as the Liberals or Conservatives). 
It is also worth noting that while federal and provincial campaigns are formally separate from one another, the individuals involved in the machinery of elections are largely the same at both levels. In addition to sharing information concerning voters and volunteers in their riding, parties also rely on the same individuals during the campaign. As Table 5.2 makes clear, parties that share a label draw upon the same pool of labour during elections. Nine-in-ten constituency associations report that a majority of those individuals in the riding who volunteer for their party during election campaigns also volunteer for their party's multi-level counterpart. Rather than living in two separate political worlds, party activists at the local level live in a single unified and integrated political world. This finding is consistent with the evidence provided in Chapter 3 that demonstrates the commonality of other types of party personnel such as members, candidates, and legislators.

In the lead up to the 2006 federal election, for example, the federal Conservative campaign director called upon his provincial counterparts across the country to provide support during the election:

Every province where there's a Tory Premier and some that don't - including Ontario - will send provincial workers to help out with the federal campaign...It's going to be a big difference. Our on-the-ground troops are solid right across the country (Galloway, 2005).

When taken as a whole, the amount of overlap between party personnel inside and outside of election campaigns is impressive and points to a clear and stable linkage for federal and provincial parties. A recent example from the 2014 provincial election in Ontario highlights the close relationships that can be forged at the local level. After 
winning the riding of Trinity-Spadina in the provincial election, the Liberals viewed this victory as evidence that they would also win an upcoming federal by-election in the riding. Liberal leader Justin Trudeau stated: "We're taking it as a very positive sign". Moreover, it was widely known that federal and provincial constituency associations in the riding worked together to ensure the victory: "During the provincial election Adam [the federal candidate] and Han Dong, who's now the MPP for [the riding], worked very, very closely, combining volunteers, working to help each other out and to make sure that Trinity-Spadina turns red...Obviously there is a continuation of that relationship" (Campbell, 2014).

While campaigns are becoming less labour intensive and more capital intensive (Norris, 2002), there is still a great need for human labour nonetheless. In addition to the amateur party volunteers who can canvass the riding, manage phone banks, engage in get-out-the-vote efforts, and put up lawn signs throughout the constituency, another resource that can be shared between federal and provincial parties are the campaign teams and volunteers that work behind the scenes. These individuals support local candidates during their campaign, creating local advertising, arranging speaking opportunities, and so on.

When turning our attention to these individuals, we find that in all three parties, key local party professionals migrate seamlessly from one level to the other during elections (Table 5.2). Three quarters (74\%) of constituency associations report that they witness considerable overlap between the campaign teams in their constituency association and those individuals who have worked with their multi-level counterpart. Like common campaign labour, this form of personnel integration is not limited to a 
single party: a majority of constituency associations in each party report substantial campaign team overlap.

The results of my survey of constituency association presidents is consistent with a 2011 survey of provincial candidates (Cross et al., 2015) which finds that there is a clear perception that the electoral results of the party at one level influence the results at the other. Where the federal Conservatives and New Democrats performed well in Ontario, their counterparts believed that this had a positive impact on their own provincial campaign. Conversely, as the federal Liberals performed quite poorly, provincial Liberals viewed this as a drag on their campaign. Given the perception that integration influences election results, it should not be surprising to find volunteers and organizers working at both levels.

\section{Endorsements and Support in Local Campaigns}

The logic and nature of the Single Member Plurality (SMP) system dictates that local campaigns matter, as parties fight to win individual constituencies and not simply a percentage of the popular vote. In this sense there is not a single large-scale election but instead 308 smaller elections. Recent research demonstrates that while the province or nation-wide campaign matters, local candidates and campaigns can have an impact on the vote (Carty and Eagles, 2005; Coletto, 2010).

Once the local candidate has been selected and volunteers amassed, constituency associations engage in their own local campaigns. They do so by providing support and resources to their candidate throughout the election period. As Esselment has convincingly argued, the ways in which multi-level parties contest elections is one of the 
most important informal connections that can exist between parties in federal states (2010: 872). While Esselment's work examines party elites (national campaign managers, pollsters, advertisers, etc.), the results provided here lend further support and evidence to the argument that parties that share a label provide support for one another during election campaigns. One of the principal ways in which this kind of support can manifest is through local endorsements and having prominent party officials make campaign visits in support of the local candidate during the election campaign.

Table 5.3 demonstrates that more than half of the constituency associations surveyed report receiving direct campaign support from their multi-level counterpart during the 2011 election campaign. This includes a campaign visit from a sitting legislator (either a Member of the House of Commons or Provincial Legislature from the riding or outside of the constituency), party leader, or other prominent non-elected party notable. Furthermore, of those constituency associations that did receive support, 62 percent received campaign support on multiple different occasions throughout the campaign. In total, 21 percent report receiving a single campaign visit, and 33 percent report receiving multiple visits.

Table 5.3: Frequency of Multi-Level Campaign Visits by Party (2011)

\begin{tabular}{lccc}
\hline Party & One Campaign & Multiple Campaign & No Campaign \\
& Visit & Visits & Visits \\
\hline Liberal & $19 \%(21)$ & $30 \%(34)$ & $51 \%(58)$ \\
Conservative & $26 \%(25)$ & $37 \%(35)$ & $37 \%(35)$ \\
NDP & $16 \%(10)$ & $34 \%(22)$ & $50 \%(32)$ \\
Total & $21 \%(56)$ & $33 \%(91)$ & $46 \%(124)$ \\
\hline
\end{tabular}

"During the 2011 [Provincial] election campaign, did any of the following campaign in your constituency? Federal [Conservative Party] leader; Federal [Conservative Party] MP from your riding (if you have one); Any other Federal [Conservative Party] MP; Any other prominent federal [Conservative Party] figures." 
Examples of federal campaign support from the 2011 provincial election are abundant. ${ }^{43}$ Despite the Prime Minister issuing a memo about the appropriate role of federal-provincial campaigning, many federal Conservatives provide support to their provincial counterparts ${ }^{44}$. Prime Minister Stephen Harper's chief of staff, for instance, hosted a \$250-a-ticket wine and cheese fundraiser for Trinity-Spadina's provincial Progressive Conservative candidate Mike Yen (Ladurantaye, 2011). Likewise, federal New Democrats Paul Dewar, Thomas Mulcair, and Nycole Turmel, attended a campaign rally for Ottawa-Centre provincial NDP candidate Anil Naido (McHahon, 2011).

At the party level, half of New Democrat and Liberal constituency associations report receiving at least one form of campaign support from their counterpart at the other level during the 2011 election. The Conservatives stand apart from the Liberals and New Democrats in this regard, with nearly two thirds of constituencies reporting that they received some form of multi-level campaign support in the 2011 election. While the difference between the Conservatives and their competitors only approaches statistical significance, the Conservatives appear to be behaving qualitatively different than their competitors in this regard nonetheless.

This difference may speak to the electoral professionalization of the Conservative parties. The Conservatives have often been portrayed as being more professionalized and election ready than their other federal counterparts in recent years. Woolstencroft and Ellis, for instance, suggest that the Conservatives have evolved from

\footnotetext{
${ }^{43}$ The campaign itself is the focus of Chapter 7. Using the two elections of 2011 as a case study, Chapter 7 details the integrating links that bind parties during election campaigns: endorsements, shared professional services, fundraising, etc.

${ }^{44}$ The Prime Minister's memo and the activities of federal MPs are more closely examined throughout Chapter 8 (The Campaign).
} 
a "makeshift collection of amateurs" in 2004 into "the most well-funded, well-oiled machine in federal politics" (2008: 29). While all parties target certain ridings, the Conservatives have created an entire unit devoted to these potential swing ridings. The 'Target Seat Management' unit, led by Mark Spiro, identifies specific swing districts, creates strategies, and monitors the party's electoral progress. The sophisticated nature of the Conservative campaign machine, as well as the interpenetration of campaign professionals, helps to explain why this party is able to achieve higher levels of campaign integration than even the New Democrats despite the truncated nature of the Conservative Party.

Although developed more fully in Chapter 8, the interpenetration of Conservative campaign professionals is clear. Spiro himself has worked closely with the federal and provincial Conservatives, not only running the 'Target Seat management' unit for the federal party but also serving as campaign manager to provincial party leader Tim Hudak. Commonality among key members of the campaign teams like this, in addition to regular meetings between various members of the federal and provincial campaign teams, allows for easy access to multi-level data and encourages further cooperation.

While 54 percent may not seem like a high degree of multi-level campaigning, when put in proper context the extent to which parties engage in this type of multi-level campaign behaviour becomes apparent. Given that resources are limited and not all ridings can be a priority, parties target their time and resources on those local constituency campaigns that have a real chance of yielding results and winning a seat (Denver and Hands 2004; Eagles, 2010; Flanagan, 2010; Denver and Hands 2004). In 
other words, not all ridings can expect to receive campaign support and resources during the course of the election campaign. Interviews with provincial campaign managers in Ontario suggest that anywhere between $20-40$ percent of ridings can be targeted in a given election (personal interviews). However, this number can, and is likely to shrink or expand during the course of the election (Johnston and Pattie, 2006).

Take, for example, the riding of Oakville. The Liberals hold the riding provincially while the Conservatives do federally. Liberal officials at the federal level are already planning to have the provincial incumbent attend rallies for the federal candidate during the 2015 election as the riding could swing back to the Liberals with some help (personal interview). Given that the provincial Liberal MPP is a cabinet minister, this is expected to help draw crowds for the federal candidate as well as help the federal party raise money in the riding. The New Democrats and Conservatives engage in this type of targeting as well, identifying key ridings where their multi-level counterpart could help the local election effort and make a strategic difference (personal interviews).

This kind of targeting is consistent with the findings of Esselment (2010). After winning in 2003, the provincial Liberals had the local infrastructure in place to provide the federal party considerable support in their 2004 campaign. According to one campaign organizer:

We went out and supported, at first, 25 ridings where we put out full-time people. We put out our outreach staff and field workers on the road for them and we adapted what we did in 2003 into their campaign. By the end of the campaign we had 98 people working full time on the federal campaign and on Election Day there were hundreds because we just cleared out our offices. 
And the federal Liberals knew that and they were extremely happy (quoted in Esselment, 2010: 885).

According to Cross' 2011 survey of provincial Liberal and New Democrat candidates in Ontario, 51 percent of their campaigns received a campaign visit or endorsement from their own party (campaign visit from a party leader, MP, or other notable). That is, provincial candidates receiving campaign support and endorsements from their own provincial party. In this regard, local candidates and party campaigns are actually slightly more likely to receive campaign support from their multi-level counterpart (54\%) than they are from their own party (51\%). When put into this context, the extent of multi-level campaign support should become abundantly clear.

Multi-level endorsements, however, do not just differ by party. Indeed, clear constituency level differences are also evident in the provision of local campaign support. Of those associations that provided or received a campaign endorsement, for instance, six-in-ten were located in ridings where the party had an incumbent. In other words, those ridings where the party performed well enough to win the seat in the previous election, appear significantly more likely to engage in multi-level campaigning in the form of local endorsements compared to associations located in ridings where the party was unable to win one of the two seats.

Why do parties or candidates take the time to offer endorsements or attend campaign rallies for a party at another level? Why would an incumbent Member of Parliament allow his campaign team or staff members to focus their attention at an entirely different electoral jurisdiction? To be sure, such campaign support and assistance that is provided to their multi-level counterpart is not a completely selfless 
endeavour. While associations and their MPs/MPPs certainly care about the broader party brand in the riding and are eager to see their multi-level counterpart enjoy electoral success, there is a very clear element of self-preservation as well. While the benefits of receiving campaign support are obvious and have been addressed above, interviews with a number of Members of Parliament reveal a variety of benefits to providing multi-level campaign support (whether it is sharing staff, providing endorsements, etc.).

One MP, for example, noted that helping out on provincial campaigns is "good practice for the real show" (personal interview). Using an analogy from hockey, an MPP described multi-level campaigning as "more time on the ice", allowing staff to hone their craft (personal interview). Other party officials provide similar sentiments. Getting out on the campaign trail (despite being for a different level) provides campaign teams the ability to gain additional (and practical) experience, it allows the other party to connect with voters, and it facilitates the building of the local party organization. Without the multi-level dynamic of Canadian federalism and two arenas for elections, these opportunities would be far less frequent and campaign staff would become restless.

At the most basic level, then, multi-level campaign engagement allows incumbents and constituency associations to remain sharp and active in between their own elections, providing real world experience and excitement to those activists and professionals who are interested in campaigns. In other words, such actions are not completely altruistic, but offer very clear benefits to those receiving the support as well of those providing it. This is in addition to the practical benefits of receiving campaign 
support such as additional media attention, access to a larger pool of volunteers, exposure to experienced campaigners, and so on.

MPs and MPPs also believe that the optics of cooperating in a multi-level fashion is good for winning votes. One MPP, for example, stated that "voters like to see us getting things done and cooperating with the guys in Ottawa" (personal interview). Another MP said that "its an easy way to show voters that we can work together" (personal interview). When a party controls both seats in the riding, there is a readily available opportunity to demonstrate this cooperation to voters on a regular basis. Going door knocking, providing an endorsement, or jointly hosting a social/recreational event signals to voters that these individuals, and the broader party, can work with one another despite being located in different electoral jurisdictions. Whether this actually influences vote choice is a different matter. Nonetheless, party personnel perceive value in this type of cooperation.

While there are obvious benefits to multi-level collaboration, some associations also pointed out practical barriers to integration. In a riding where the party is not particularly vibrant and thriving, the association can often have real difficulty engaging in its own activities and cannot devote resources to its multi-level counterpart (personal interviews). This is especially true for the manpower and human capital that is required to run an efficient election campaign. Many struggling associations do not have enough volunteers to adequately carry out party business at a single level, and therefore cannot easily share their scarce resources with their multi-level counterpart. 
The average constituency association in this study, for example, had 103 volunteers during the last election campaign. There is, however, great variation among the different associations. Some ridings reported having as few as five volunteers during their 2011 election campaign whereas some large Toronto ridings reported having as many as 600 volunteers throughout the campaign. As noted earlier, Carty (1991) estimates that approximately 150 campaign workers are needed to run an effective campaign. Clearly, those associations with only a handful of volunteers cannot offer the same assistance to their multi-level counterpart as other, more healthy and wellresourced, associations. While these associations may be the target of integration, they have very little to offer in the way of campaign support.

\section{Constituency Level Differences in Multi-level Campaigning}

By now it should be clear that local politics is often more integrated than previously thought. Not all constituency associations, however, engage in integration to the same extent. While the previous section examined vertical integration at the party level, it is also important to consider constituency level differences as well. Four hypotheses - relating to electoral strength, incumbency, the urban/rural divide, and the presence of a cabinet minister - have been formulated that may help explain why some constituency associations are more integrated than others.

To explore these hypotheses both multinomial and binary logistic regressions are conducted. Both methods of multivariate analysis allow us to narrow the profile of the types of constituencies most likely to engage in integrated campaign behaviour and also identify the different levels of integration. In this sense we are not attempting to 
determine causation but instead compare different types of constituencies in order to establish which types of constituency associations are more likely to engage in coordinated and cooperative campaigning.

Constituency associations are expected to be more integrated in ridings where they are electorally strong (H1). Local associations that perform well during elections differ from other associations in a variety of important ways. For example, these associations are typically well resourced (both in terms of human and financial capital) and more professionalized than others (Carty, 2002; Koop, 2010). Additionally, constituency associations in which the party has a realistic chance of electoral success tend to be more vibrant and active during election campaigns (Cross and Young, 2011).

Integration, while beneficial, has real costs for the parties involved. Multi-level election campaigning, for example, requires time, energy, and capital. It also risks creating fatigue among key party volunteers working on both campaigns. More experience, resources, professionalization, and vibrancy suggest that these associations will be more equipped to engage in integrated and coordinated campaign behaviour with their multi-level counterpart than the less resourced and inexperienced associations where the party is electorally weak. Additionally, electoral strength and the possibility of winning a seat speaks to the need for parties to prioritize ridings and target their resources on constituencies that are likely to produce a victory.

Similar to the expectations concerning electoral strength, I also expect constituency associations to be more integrated in ridings with an incumbent (H2). While incumbency is similar to electoral strength, the expectations are theoretically 
different. Incumbents spend a significant amount of time and energy cultivating a local brand and image in the riding. As a result, they have an incentive to protect and manage this image, especially if they are seeking re-election in the near future. An association of the same party label in the riding that is sparsely attended, has few members, and does not perform well during elections may ultimately reflect poorly on the successful candidate at the other level. Given that incumbents are typically well staffed and well resourced, it is expected that these associations will be able, and have incentive to, devote resources to multi-level activities.

Rural constituency associations are expected to be more integrated than their urban counterparts (H3). Rural ridings are more likely to have face-to-face interactions and have a greater sense of community, both of which are expected to incentivize multilevel cooperation. Sayers (1999: 6), for instance, suggests that "close-knit rural communities may rely much more heavily on personal networks than suburban associations". Additionally, there is evidence that demonstrates higher levels of social capital among rural communities (Hofferth and Iceland, 1998). Social capital increases trust and encourages cooperation between individuals and groups (Putnam et al., 1993). As such, a higher level of social capital is expected to facilitate local party integration between federal and provincial parties. Using a framework provided by Elections Ontario, Ontario ridings were classified into the following four categories: urban, urban/fringe, urban/rural, and town/rural. These ridings were then dichotomized urban (urban and urban/fringe) and rural (urban/rural and town/rural) constituencies for the purpose of analysis. 
In recent decades there has been a trend towards concentrating power at the centre, in the hands of the PM and his inner circle (Martin, 2011; Savoie, 1999; 2008). Rather than the broader caucus, power now rests with the prime minister and his/her cabinet members according to the 'court government' theory. Electoral districts represented by a cabinet minister are therefore expected to potentially reap more electoral benefits and have a more effective say in the government. As such, it is expected that if parties are going to create vertical linkages, they will do so in ridings where the most political power resides. Thus, constituency associations in ridings represented by a cabinet minister are expected to be more integrated than those ridings that have no representation in cabinet (H4). This hypothesis builds on recent work found in the federalism and party system literature that suggests that vertical linkages are often created in order for parties at one level of government to access the power of the other level (Chhibber and Kollman, 2004).

The dependent variables for the multivariate analysis are comprised of the individual campaign integration indicators examined throughout the chapter. This includes multi-level involvement in candidate selection, the provision/receipt of campaign support, and the sharing of resources (both human and informational) during elections. These indicators are examined collectively in the multinomial logistic regression (Table 5.4) and individually in the binary regression (Table 5.5).

A number of potential explanatory variables derived from the series of hypotheses outlined above have also been included in the model. Electoral strength is coded in a dichotomous fashion $(0=$ weak; $1=$ strong $)$ where 0 indicates the party did not win a seat at either the provincial or federal level in the riding and 1 is where the 
party won the seat at both levels. While a more accurate indicator of electoral strength may in fact be measured by vote share, this requires the ability to identify each association in the dataset to their constituency. While many respondents offered this information, it is far from complete. Questions on past electoral performance, however, have a much higher response rate. Similarly coded variables are also included for whether there is an incumbent in the riding (i.e., the party won the 2008/2007 election; 0 $=$ no; $1=$ yes); whether the constituency association is located in a rural or urban electoral district (as coded by Elections Ontario guidelines; 0 = urban; 1 = rural); and whether the constituency association is represented in cabinet (at either the provincial or federal level). The analysis also controls for party using dummy variables for the Conservatives and New Democrats with the Liberals as the omitted reference category.

We begin with the multinomial logistic regression. Based on the three indicators examined throughout this chapter (influence in candidate selection; sharing of resources [either human or informational]; and the provision of endorsements) an integration score has been calculated which simply sums the number of multi-level activities that a constituency association engages in (ranging from 0 to 3 ). If an association exerts influence in candidate selection processes but does not share resources or engage in multi-level campaigning, it scores a 1. If, on the other hand, an association does all three - exerts influence in the nomination process, shares resources, and campaigns for its counterpart -then it scores a 3. Each association was coded in this fashion. Examining integration from this perspective highlights the factors that influence the overall level of integration in a riding. 
Of the potential explanatory variables included in the analysis, only one is significant in the final model. Table 5.4 provides a summary of the multinomial logistic regression results. Only belonging to the New Democratic Party helps us to predict the overall level of integration in the riding. In fact, membership in the NDP is significant across each of the different degrees of campaign integration. A constituency association that engages in all three forms of campaign integration, for example, is 23 times more likely to be a New Democrat association compared to an association that does not engage in any of the three indicators of campaign integration. Thus, the overall level of integration (regardless of the specific activity) is explained only by the party variable. ${ }^{45}$

Table 5.4: Summary of Multinomial Regression Results (Campaign Activities)

\begin{tabular}{|c|c|c|c|c|c|c|}
\hline \multirow[t]{2}{*}{ Variables } & \multicolumn{2}{|c|}{$\begin{array}{l}\text { One multi-level } \\
\text { activity (1) }\end{array}$} & \multicolumn{2}{|c|}{$\begin{array}{l}\text { Two multi-level } \\
\text { activities (2) }\end{array}$} & \multicolumn{2}{|c|}{$\begin{array}{c}\text { Three multi-level } \\
\text { activities (3) }\end{array}$} \\
\hline & B & ExpB & B & ExpB & B & ExpB \\
\hline Cabinet & .028 & 1.028 & -.888 & .411 & .369 & 1.466 \\
\hline Urban & -.234 & .791 & .031 & 1.03 & .903 & 2.468 \\
\hline Incumbent & -.003 & .997 & .750 & 2.11 & 1.093 & 2.984 \\
\hline NDP & 2.607 & $13.56 * *$ & 3.066 & $21.45 * *$ & $3.147 * *$ & 23.270 \\
\hline $\mathrm{PC} / \mathrm{CPC}$ & .590 & 1.805 & .190 & 1.209 & .277 & 1.320 \\
\hline $\begin{array}{l}\text { Won seat at both } \\
\text { levels }\end{array}$ & -.059 & .943 & .405 & 1.499 & .161 & 1.175 \\
\hline $\begin{array}{l}\text { Nagelkerke's } \\
\text { pseudo } \mathrm{R}^{2}\end{array}$ & .186 & & & & & \\
\hline
\end{tabular}

Note: ${ }^{* *} \mathrm{p}<.01 ;{ }^{*} \mathrm{p}<.05$; Reference category for party is 'Liberal'; Reference category for integration score is ' 0 ' (no multi-level campaign activities).

It is also worth examining each of the multi-level activities separately. It may be the case, for example, that our predictor variables, such as riding location, have an influence on certain types of integration activities despite having no significant effect on the overall level of integration that the association experiences. Using the same

\footnotetext{
${ }^{45}$ Even the party variable, however, only accounts for approximately 20 percent of the total variance.
} 
variables, Table 5.5 highlights the importance of our independent variables on each of the types of campaign integration that has been examined.

Table 5.5 offers a somewhat different story when each different campaign activity is examined individually. We see that the presence of an incumbent, for example, is relevant for two distinct types of integration: campaign endorsements and candidate selection. As the analysis demonstrates, associations located in ridings where there is an incumbent are significantly more likely to exert multi-level influence in the candidate selection process and are significantly more likely to provide multi-level endorsements. Given the resources that these kinds of associations have coupled with the incentive to protect the carefully cultivated local brand, it makes sense that this is where incumbents would focus their attention. Recruiting like-minded quality candidates and helping to secure their election will help to enhance the party's overall brand in the district. This also speaks to the personal relationships that develop over time at the local level. Given their history in the riding, incumbents appear more likely to develop ties with their multi-level counterparts compared to relative newcomers.

Table 5.5: Summary of Binary Logistic Regression Results (Campaign Activities)

\begin{tabular}{|c|c|c|c|c|c|c|c|c|c|c|}
\hline \multirow[t]{2}{*}{ Variables } & \multicolumn{2}{|c|}{$\begin{array}{l}\text { Candidate } \\
\text { selection }\end{array}$} & \multicolumn{2}{|c|}{$\begin{array}{c}\text { Campaign } \\
\text { teams }\end{array}$} & \multicolumn{2}{|c|}{ Volunteers } & \multicolumn{2}{|c|}{ Share party data } & \multicolumn{2}{|c|}{$\begin{array}{l}\text { Campaign } \\
\text { endorsement }\end{array}$} \\
\hline & B & ExpB & B & ExpB & B & ExpB & B & ExpB & B & ExpB \\
\hline Cabinet & .753 & 2.124 & -.504 & .604 & -.704 & .494 & -714 & .490 & .004 & 1.004 \\
\hline Urban & .794 & $2.213^{*}$ & -.493 & .611 & .156 & 1.169 & .077 & 1.080 & .234 & 1.263 \\
\hline Incumbent & 2.354 & $3.874 *$ & .413 & 1.511 & -.103 & .902 & .077 & 1.080 & .873 & $2.393 *$ \\
\hline NDP & 1.064 & $2.898 *$ & 3.74 & $42.1 * *$ & 2.343 & $10.41 *$ & 2.66 & $14.40^{* *}$ & .281 & 1.324 \\
\hline $\mathrm{PC} / \mathrm{CPC}$ & .500 & 1.649 & .162 & 1.176 & -.664 & .515 & -.094 & .910 & .485 & 1.624 \\
\hline $\begin{array}{l}\text { Won seat } \\
\text { at both } \\
\text { levels }\end{array}$ & -1.13 & .320 & -.064 & .938 & .973 & 2.645 & .476 & 1.609 & -.230 & .795 \\
\hline $\begin{array}{l}\text { Nagelkerke's } \\
\text { pseudo } \text { R }^{2}\end{array}$ & \multicolumn{2}{|c|}{.135} & \multicolumn{2}{|c|}{.251} & \multicolumn{2}{|c|}{.146} & \multicolumn{2}{|c|}{.180} & \multicolumn{2}{|c|}{.078} \\
\hline
\end{tabular}

Note: ${ }^{*} \mathrm{p}<.01 ;{ }^{*} \mathrm{p}<.05$; Reference category for party is 'Liberal' 
Unlike incumbency, examining multi-level campaigning among urban and rural constituencies and those represented by a cabinet minister did not reveal significant differences. While it was hypothesized that the rural setting would encourage integration as a result of higher levels of social capital, constituency associations in urban and rural ridings do not differ in terms of the frequency of resource sharing, the extent to which the ridings received campaign support during the most recent election or exerted influence in the candidate selection process. The same is true for the expectations concerning cabinet representation.

It is possible that the enhanced social capital and reciprocal trust aspects of rural constituencies are offset or undermined by the large geographic distance that some of Ontario's rural constituencies span. The riding of Timmins-James Bay, for instance, is 246,275.67 square kilometers. In a riding this large, it may be difficult to cooperate and coordinate campaign activities effectively. This is especially true if the federal and provincial riding associations are located in different regions or towns within the riding.

In such a case there may be hours of travel distance separating the two constituency association offices. By contrast, the small geographic size of many urban ridings may compensate for lower levels of social capital. The ease of cooperation that is facilitated by a small and densely populated constituency likely provides an incentive for integration that is not available in large rural ridings. Combined, this may explain why both urban and rural ridings experience similar levels of grassroots integration despite their differences. 
The size of some electoral districts in Ontario may also help explain the differences between parties. For Liberal and Conservative parties, constituency associations may be located kilometers away, making it difficult and time consuming to coordinate their efforts or share valuable information. Not so for the New Democrats. Given that New Democrat associations are often physically housed in the same location, the party's organizational structure easily facilitates this type of electoral cooperation. Having federal and provincial parties working in the same office allows greater access to one another and their resources. In this way, integration for the NDP tends to have very few barriers or added costs. The integrated nature of the NDP's organizational structure helps to create a culture and atmosphere of vertical integration: promoting and encouraging cooperation and collaboration even when such behaviour is not formally mandated. Such a design also mitigates against large and expansive electoral districts that make coordination and cooperation difficult.

Consistent with the multinomial logistic regression results, the party variable for the NDP remains highly significantly for every indicator of integration with the exception of campaign endorsements. This is unsurprising given the bivariate results presented earlier in the chapter, which almost universally emphasized high levels of multi-level campaign integration among New Democratic Party associations.

\section{The General State of Local Campaign Integration}

The stratarchical design of political parties in Canada provides riding associations with considerable autonomy to control local party business. This is especially true for those functions that relate to elections and campaigns. As a result of 
this considerable local freedom, this chapter questioned whether grassroots organizations would follow the same path as their central party counterparts and opt out of multi-level party integration. While federal and provincial parties in central office have often focused on their own political world, the evidence presented in this chapter suggests that local constituencies are embracing party integration rather than turning away from it.

As Table 5.6 illustrates, the vast majority of ridings (92\%) report engaging in at least one of the three indicators of local campaign integration previously discussed (share resources, influence candidate selection, provide campaign endorsements). By contrast, less than one-in-ten ridings $(8 \%)$ report that they do not cooperate with their multi-level counterpart on any of the three measures. Furthermore, a majority (55\%) of constituencies report cooperating on multiple campaign activities. At least as it relates to election campaigns, party politics on the ground is much more integrated than previously thought.

Table 5.6: Integrated Campaign Activities by Party

\begin{tabular}{lcccc}
\hline Party & $\begin{array}{c}\text { Zero multi- } \\
\text { level activities }\end{array}$ & $\begin{array}{c}\text { One multi- } \\
\text { level activity }\end{array}$ & $\begin{array}{c}\text { Two multi-level } \\
\text { activities }\end{array}$ & $\begin{array}{c}\text { Three multi- } \\
\text { level activities }\end{array}$ \\
\hline Liberal & $9 \%(10)$ & $43 \%(49)$ & $31 \%(35)$ & $17 \%(19)$ \\
Conservative & $13 \%(12)$ & $28 \%(27)$ & $45 \%(43)$ & $14 \%(13)$ \\
NDP & 0 & $38 \%(24)$ & $44 \%(28)$ & $19 \%(12)$ \\
Total & $8 \%(22)$ & $37 \%(100)$ & $39 \%(106)$ & $16 \%(44)$ \\
\hline
\end{tabular}

While political parties of all stripes engage in multi-level campaign activities to some extent, there are clear differences at the individual party level. None of the New Democrat constituency associations, for example, reported participating in no multilevel campaign activities. By contrast, the percentage of Conservative and Liberal 
associations that did not engage in any of the three multi-level campaign activities is 13 and 9 respectively.

Table 5.7 summarizes the information presented throughout the chapter and categorizes campaign activities by the degree of multi-level involvement. The degree of campaign integration considers the number of local associations that engage in these activities. When a third or less of a party's associations report engaging in an activity it is coded as representing a low degree of integration whereas between a third and twothirds is coded as medium and more than two-thirds is coded as high (the same approach is applied in the next chapter).

Table 5.7: Degree of Multi-level Campaign Integration by Party

\begin{tabular}{|c|c|c|c|c|}
\hline Party & $\begin{array}{l}\text { Campaign } \\
\text { Labour }\end{array}$ & $\begin{array}{c}\text { Riding } \\
\text { Information }\end{array}$ & $\begin{array}{l}\text { Candidate } \\
\text { Selection }\end{array}$ & Campaigning \\
\hline Liberal & High & Medium & Low & Medium \\
\hline Conservative & High & Medium & Low & Medium \\
\hline NDP & High & High & Medium & Medium \\
\hline
\end{tabular}

Overall the NDP scores as high or higher on all of the indicators of campaign integration than either the Liberals or Conservatives (not surprising given the results presented in Table 5.4). The gap is likely a result of the party's unified organizational structure. Since federal and provincial branches are organizationally connected, the sharing of information and human labour is easily facilitated and even incentivized and encouraged. The Liberals and Conservatives, however, face organizational challenges when confronted with multi-level politics. Without interconnected party structures in place, cooperation between these parties and their multi-level counterparts is much more difficult. 
Perhaps the most surprising party finding, however, is the degree of campaign integration that can be found between the federal Conservatives and the provincial Progressive Conservatives given their complete organizational truncation and independence. While lower than the NDP, the Conservative parties achieve significant levels of integration despite not even sharing a name. Overall, the Conservatives exhibit a number of integrating links that are consistent with the levels of integration found between federal and provincial Liberal parties. Notwithstanding a number of organizational connections (the provincial and federal Liberals share a name, history, and a headquarters in Toronto) the Liberals do not engage in multi-level cooperation and coordination at a higher rate than the organizationally truncated Conservatives.

Consistent with the observations and conclusions made in Chapter 3 concerning party personnel, local campaign integration does not appear to be restricted to organizationally integrated parties alone. If this were the case, the Conservatives would exhibit very little integrated campaign behaviour. However, nearly nine-in-ten Conservative constituency associations report engaging in at least one of the integrated campaign activities discussed above (influence in candidate selection, providing campaign support, sharing voter/activist information). This is not all that dissimilar to the 91 percent of Liberal constituency associations that do so. In fact, the number of constituency associations that engage in multi-level campaign activities and those that do not does not differ significantly between the Liberals and Conservatives, $\chi^{2}(1,208)=$ $0.432, p=.511)$.

These findings add further evidence to the argument that ideologically coherent multi-level parties, such as the Conservatives, can achieve moderate levels of integration 
even in the absence of cooperative and connected party structures. Importantly, however, the difference between the Conservatives and New Democrats remains statistically significant, $\chi^{2}(1,160)=7.149, p=.008$. Like Chapter 3 , this demonstrates that a consistent ideology is not enough to ensure the highest levels of vertical party integration. Organizational connectedness still appears to add to the level of integration as the New Democrats continue to exhibit the highest levels of integration of the three parties being examined.

Table 5.7 also reveals that some types of campaign integration, regardless of party, are more common that others. Shared campaign labour, for instance, is common across all parties whereas the degree of integration in candidate selection is much lower. In between these two ends of the spectrum, campaign endorsements and support, and sharing of riding and voter/volunteer information is relatively common across each of the parties.

Finally, besides party level differences, we also find variance at the constituency level. In particular, parties are significantly more integrated in ridings where they are electorally viable compared to those ridings where the party is weak or has suffered an electoral setback. This is likely a result of the resources that incumbents bring to election campaigns. Incumbents and their inner entourage tend to be successful fundraisers, effective campaigners, and experienced networkers. The result of electoral success is the development of professional riding associations that have the ability, resources, and manpower to engage in coordinated multi-level campaigning. Conversely, we find no evidence to suggest that levels of integration differ along the urban and rural divide. Although the evidence is mixed, these findings suggest that there may be non-party 
based determinants to integration that extend beyond organizational design and ideological consistency.

\section{Conclusions}

This chapter has explored how, and to what extent local associations cooperate with their multi-level partners. Questions surrounding local party integration, however, still remain. Although this chapter has focused on party behaviour during the campaign period, political parties and their local apparatus's continue to operate in the months and years in between elections. Analysis of local party activities in the inter-election period is therefore required. Areas in which local parties can coordinate during the interelection period include policy formation, membership recruitment, fundraising, and so on. These aspects of political parties have been largely unexplored and deserve close attention. Coordinated multi-level activities in the inter-election period are the focus of the following chapter. 


\section{CHAPTER 6: Inter-election Integration at the Grassroots}

\section{Introduction}

Consistent with Esselment (2010) and Koop (2011), Chapter 5 provides compelling evidence to suggest that political parties, at least in Ontario, are much more linked during election campaigns than previously thought. Resource and information sharing between local executives, campaign endorsements, and a common pool of party activists and volunteers connect federal and provincial parties together during the campaign period at the grassroots level. In general, it can be said that the majority of individuals responsible for management and conducting of election campaigns at the constituency level are the same both provincially and federally.

For these individuals, it matters very little that parties are said to occupy their own political world. Whether it is an ideological incentive, an organizational imperative, or some combination of both, partisans at the grassroots in Ontario tend to be dual members who participate and contribute to party politics and election campaigns at multiple levels.

In this chapter the focus remains on the grassroots level, however, emphasis is placed on the activities of political parties outside of election campaigns. While many view running election campaigns as the raison d'être of political parties ${ }^{46}$, local constituency associations engage in a number of other important tasks that are essential to the functioning and survival of political parties. In particular, political party

\footnotetext{
${ }^{46}$ Parties themselves often feel this way as well. Cross, for instance, has written that "Canadian parties have long seen their primary role as being that of electoral machines. The extraparliamentary parties exist to choose candidates and leaders and to help them get elected to the provincial and federal legislatures" (2007: 425).
} 
executives at the local level perform a number of functions that relate to the interelection maintenance of the party. Inter-election maintenance includes activities such as policy study and formation, fundraising and financial maintenance, hosting social events, engaging in public meetings, recruiting new party members, election planning and preparation, and supporting incumbent Members of Parliament (Carty, 1991; Carty and Eagles, 2005; Koop, 2010; 2011).

This entire set of activities, however, has largely been ignored in the literature. While there has been widespread research on the election activities of constituency associations (Carty, 1991; Carty and Eagles, 2005), Members of Parliament (Docherty, 1997), legislative candidates (Erickson, 1997), delegates to party conventions (Archer and Whitehorn, 1997; Perlin, 1988), and even party members (Cross and Young, 2004) very little work has examined constituency associations during the inter-election period. ${ }^{47}$ Despite being often overlooked, the activities of parties outside of the campaign period are important nonetheless and can have serious implications for the health, legitimacy, and success of political parties.

The primary purpose of inter-election maintenance activities is, for the most part, to keep the grassroots party members engaged and active in between election campaigns and to build a vibrant and energetic local base of support in anticipation for the next general election. Additionally, constituency associations serve as the "eyes and ears" on the ground for elected members of the legislature. As the local agents of elected

\footnotetext{
${ }^{47}$ There are, of course, some notable exceptions. Cross (1996), for example, surveyed Canadian constituency associations to better understand the participatory mechanisms available for ordinary grassroots party members. Likewise, while the focus of Carty's 1991 survey is on the election activities of local associations, the inter-election aspects are not completely overlooked. These studies, however, are now two decades old and renewed attention is required.
} 
representatives in Parliament, constituency associations can act as a feedback mechanism for legislators, communicating the preferences and demands of their constituents (Koop, 2012). ${ }^{48}$ In order to perform this feedback function, constituency associations need to keep in close contact with members, activists, and even the general constituents of the riding in between elections in order to effectively act as a conduit for the local Member of Parliament or Legislative Assembly.

Three trends in party membership and the internal dynamics of modern Canadian parties have made these activities take on additional significance in recent decades. First, in the past twenty years there has been a significant decline of party membership and activism in most western democracies (Mair and van Biezen, 2001; Scarrow and Gezgor, 2010; van Biezen, Mair, and Poguntke, 2012; Whiteley, 2010). Canada, of course, is no exception to this trend and has also experienced widespread decline (Cross and Young, 2004). Consistent with earlier studies (see, for example, Carty, 1991), Cross and Young's study of Canadian party members in Canada estimates that only two percent of Canadians are party members at any given time (2004: 430). While the golden age of the mass party with enormous membership rolls may have been exaggerated (Scarrow, 2002), it is clear that parties typically have fewer members today than they did even a decade ago.

\footnotetext{
${ }^{48}$ Community and social events also let parties connect with potential voters in the riding and as such can have an impact on future elections. As the Liberal University handbook states, one of the main purposes of community engagement is "to gather data about members of the community. This information becomes especially useful for election campaigns and microtargeting" (Liberal Party, 2012). As illustrated in the previous chapter, parties collect significant amounts of data about potential voters in their ridings and often share this information freely with their multi-level counterpart. Cooperating outside of the campaign period provides parties with more opportunities to collect greater amounts of voter and volunteer data.
} 
Second, while parties have been on the decline, there has been a simultaneous rise in unconventional forms of participation such as political consumerism (Stolle, Hooghe, and Micheletti, 2005) and demands for direct democracy (Donovan and Karp, 2006). Indeed, as Katz (2013) suggests, long-term societal changes in the attitudes and behaviours of citizens represent significant challenges for modern political parties. At the same time, many Canadians, youth in particular, are increasingly sceptical of political parties (Cross and Young, 2008) and criticize them for being too hierarchical and impenetrable. In fact, recent survey and public opinion data demonstrate that Canadian citizens are largely distrustful and dissatisfied with their political parties (Samara, 2012). Canadian parties therefore face challenges from within (declining membership and activism) and from outside (declining trust and satisfaction among ordinary citizens and a rise in other forms of political participation that bypass parties altogether).

The final trend concerns the nature of party membership in Canadian parties. For the most part, membership in the major Canadian parties tends to ebb and flow with the opportunity for participation in important intra-party events (Carty, 2013b). Thus, while an overall decline is occurring, membership remains fluid and in constant flux. When parties nominate candidates and select party leaders, membership increases dramatically. During the most recent federal leadership elections, for example, party membership increased by 131, 55, and 64 percent for the Liberals (2013), New Democrats (2012), and Conservatives (2004) respectively. After these events, however, party membership drops once again until the next high profile intra-party event. This is not a new occurrence. In a study of constituency associations, Carty (1991: 38) discovered a clear 
pattern where the Liberal and Conservative parties' membership numbers fluctuated significantly between years in which there was an election and years in which there was not. $^{49}$

As a result of these three inter-related trends, the inter-election activities have become increasingly relevant to the survival and health of political parties in Canada. As parties continue to struggle with membership growth year-after-year, keeping existing members enrolled and active, as well as incentivizing new members to join, are crucial tasks that political parties at the local level must continuously engage in. Here the incentives to membership literature offers important insights concerning what benefits and opportunities parties can offer their members in order to keep them engaged in party affairs (Clark and Wilson, 1961; Seyd and Whiteley, 1992; Ware, 1996; Young and Cross, 2002a).

One way that parties encourage new members to join the party is by hosting recreational and social events in the community. Barbeques and other community gatherings allow local constituency associations to meet a number of new potential members while also providing existing members with a reason to remain engaged between the excitement of election campaigns. Similarly, holding social events and other public meetings also allows the local constituency association to measure public opinion and get feedback from the locals that can then be communicated to the riding's Member of Parliament. Thus, there is a representational element to such activities as well.

\footnotetext{
${ }^{49}$ Also see Sayers (1999) for a discussion of these kinds of local party membership trends.
} 
Parties may also use policy study and formation as a means of retaining party members and encouraging new members to join. This is especially important for those individuals who are less interested with the social and recreational aspects of parties and more interested in the ideological or policy objectives of parties. For these individuals the opportunity to participate in policy discussion may act as an incentive to membership even when there is no immediate election to prepare for. As the numbers from recent leadership elections demonstrate, Canadians are willing to join political parties when there are meaningful opportunities to participate in the internal decisionmaking process. Opening up the policy process offers potential party members with another way of taking an active role in their democracy. Moreover, this offers parties an avenue to be participatory institutions outside of the election period.

Combined, policy study and social events are fundamental ways in which parties can remain relevant in the inter-election period. What's more, engaging and recruiting new members in the "off season" provides parties with a strengthened core and activist base to draw upon come election time. The activities of parties in the inter-election period can therefore have a meaningful impact on the health, vibrancy, and quality of their election activities during the campaign.

The remainder of this chapter examines these inter-election activities of parties at the grassroots. It does so, however, through the lens of federalism and party integration. Thus, the first section examines the extent to which these types of inter-election activities occur in a multi-level manner. It begins by examining the frequency in which parties meet to formulate and discuss party policy. Next, the chapter examines the influence that parties exert on their multi-level counterpart in this regard. Jointly 
discussing policy can demonstrate a strong linkage between parties, however, exerting influence in policy decisions is important as well. Parties may not meet often for policy formation reasons, but may still exert influence nonetheless. Therefore, both frequency and influence are examined. This is followed by a discussion of multi-level social gatherings. Do federal political parties, for instance, meet with their provincial counterparts in a recreational capacity when there is no immediate election to prepare for? Finally, the chapter also examines the makeup of local constituencies (executives and members) in order to ascertain the extent to which the same individuals populate federal and provincial parties at the local level.

This discussion of the inter-election activities of parties is followed by an examination of constituency level differences. The hypotheses tested in Chapter 5 are replicated here and this section explores the extent to which electoral strength, party, urban and rural differences, and other local factors are related to the level of integration that a constituency association engages in.

\section{Overlapping and Common Constituency Associations}

In addition to exploring party activities such as policy discussions and social/community events, it is worth considering the extent to which the same individuals populate each party at the association level. Smiley, for example, has written that "There have not been, so far as I know, any systematic studies of the degree to which there is overlapping membership in the federal and provincial constituency organizations of the parties" (1987: 106). The following section addresses this gap by focusing on commonality at the level of the constituency association. 
Chapter 3 provides a compelling look into the personnel aspect of integration as members, activists, association presidents, candidates, and legislators were examined for their dual membership and participation in other multi-level activities. Here the focus is on association as a whole rather than the individual riding presidents. In order to provide a more complete picture of the local constituency association, the riding executive, broader party membership, and active membership are examined for commonality and overlap between the federal and provincial branches.

Constituency association executives are the small governing bodies that manage the routine and daily operations of the party at the grassroots level. The officers of the executive include a president, vice-president, secretary, treasurer, membership chair, and policy chair and are typically elected at the Annual General Meeting (AGM) by the party membership (Koop, 2010). While membership in Canadian parties is fluid, largely depending on the timing of the next intra-party election, the composition of local executives tends to be much more stable. Koop, for example, notes that "members of the association executive lend stability to the association through their long-term involvement" (2011: 74).

Unlike many members who often join the party for transient reasons like participating in a leadership election ${ }^{50}$, members of the executive tend to have a long history of membership and activism with the party. The mean length of membership for existing constituency association presidents, for instance, is 13.8 years. Length of

\footnotetext{
${ }^{50}$ The 1998 Progressive Conservative leadership election is a telling example. During this election David Orchard, a candidate with no meaningful ties to the party, entered the leadership race (LeDuc, 2001). His entry into the race prompted the frontrunner, Joe Clark, to describe newcomer Orchard and his supporters as nothing more than "tourists" with no attachment or history with the party (Carty and Stewart, 2002).
} 
membership does vary by party: Liberal (12.86 years), Conservative (13.66 years) and New Democrats (15.5 years). However, a one-way ANOVA demonstrates that length of membership does not differ significantly between parties, $F(2,266)=1.322, p=.268$. Furthermore, the average president has served in that leadership role for more than three years. This is combined with years of experience with other positions on the executive and their activities as party activists and volunteers prior to being elected to the executive.

Commonality between executives of federal and provincial constituency associations therefore provides a more stable linkage than connections between other types of party personnel. While overlapping party members may come and go, integration at the executive level is more long-term as a result of the commitment of constituency association presidents and their fellow executive members. The commitment of these individuals, their longstanding attachment to the party, and their leadership roles provides ample opportunity to forge meaningful connections in the ridings that can span a number of years and elections.

As you may recall, the vast majority $(86 \%)$ of constituency association presidents in Ontario hold consistent and dual party memberships. Moreover, three quarters frequently volunteer for their multi-level counterpart during elections, and more than nine-in-ten voted for their federal or provincial cousin in the last election. As activists with a leadership role in the party, their commitment to integration and multilevel politics acts as a significant linkage between federal and provincial parties at the local level. To what extent can we find similar levels of commonality between the other members of the local executive more broadly? 
Consistent with the findings presented in Chapter 3, there is considerable overlap and commonality between local executives and active members at the constituency level in Ontario. Table 6.1 provides the breakdown of linkages between local riding executives. Constituency association presidents were asked to identify the level of overlap between their executive in the riding and the executive of their multi-level counterpart. That is, whether members of the executive are, or have in the past been, members of the local executive of the party's multi-level counterpart.

As Table 6.1 demonstrates, a majority of constituency association executives in Ontario are classified as having high levels of federal-provincial linkage in this regard. What's more, only one-in-four constituency associations reports experiencing low levels of executive commonality. Perhaps more importantly, not a single association reported that their executive had no commonality with its multi-level counterpart.

Table 6.1: Level of Multi-level Constituency Association Executive Overlap by Party

\begin{tabular}{llll}
\hline Party & High & Medium & Low \\
\hline Liberal & $40 \%(46)$ & $30 \%(33)$ & $30 \%(33)$ \\
Conservative & $45 \%(43)$ & $19 \%(18)$ & $36 \%(34)$ \\
NDP & $93 \%(59)$ & $3 \%(2)$ & $3 \%(3)$ \\
Total & $54 \%(148)$ & $20 \%(53)$ & $26 \%(70)$ \\
\hline
\end{tabular}

"Most members that sit on the executive in this association have also served on the local executive of the federal [Conservative Party]".

This, however, is somewhat inflated by the remarkably high level of commonality that is found between federal and provincial New Democrat constituency associations (93\% of NDP associations report having high levels of overlap between local executives). This, of course, is not surprising given the organizationally integrated nature of the party structure. A result of the unified party organization is that many 
provincial New Democrat executives simultaneously serve as federal executives as well. It can be estimated that between one third and one half of all NDP constituency associations in the province are dual associations (servicing both levels simultaneously with a unified executive).

According to records provided by Elections Ontario and Elections Canada, 35 of the 106 federal NDP association presidents act as president for the provincial riding as well. Upon conducting the survey of constituency associations, however, a number of additional dual associations were also identified. While organized in a manner that services both the federal and provincial levels, many of the dual associations do have additional executive officers that focus on a single level. The electoral district of Kingston is one such example. The NDP association in this riding has a single executive with a single association president that services both the federal and provincial parties but has distinct federal and provincial vice presidents.

These kinds of formal and organizational connections between federal and provincial constituency associations, however, are not limited to the New Democrats. The constitutions of Liberal constituency associations, for example, provide clear provisions for coordinated local integration between executives. Section 4.4 of the model constitution for federal Liberal constituency associations in Ontario states the following:

The Presidents of those Provincial Liberal Associations whose boundaries overlap those of this EDA shall be non-voting, exofficio members of the EC [Executive Committee] (Liberal Party of Canada, 2010). 
Section 15.13 of the Ontario Liberal Party constitution provides federal riding association presidents with the same ex-officio privileges. The section of the constitution states the following: "The President of a federal Liberal Riding Association for a federal electoral district that shares territory with a constituency association shall be an exofficio member of the constituency association's Executive Committee" (Liberal Party of Ontario, 2012). As ex-officio members, Liberal riding association presidents are invited to attend and take part in the executive meetings of their multi-level counterpart. Attending these meetings as an ex-officio provides constituency associations with a means of ensuring that communication between the federal and provincial parties remains open and frequent.

According to the survey of constituency associations, the Liberals hold executive meetings once a month on average. Meeting at this frequency provides an opportunity for riding presidents to debrief with their multi-level counterpart in the riding on a regular basis, notifying each other of recent developments, upcoming events, and so on. Constant federal-provincial communication in this sense is formalized and institutionalized in party statutes. Moreover, this multi-level aspect to executive meetings also provides riding presidents with an opportunity to meet potential new members who are already engaged with the party at another level. ${ }^{51}$

Unlike the Liberals and New Democrats, the Conservatives in Ontario do not provide their multi-level counterparts with any form of ex-officio status at the local

\footnotetext{
${ }^{51}$ While not all constituency associations make their constitutions available for public viewing, those that are available confirm the institutionalized ex-officio status. Of all those made available online, the ex-officio rule has been adopted. Burlington, Beaches-East York, Ajax Pickering, Don Valley East, and a number of other ridings, for example have their constitutions available and all have included the ex-officio rule in their own constitution.
} 
level. Despite this lack of formal agreement that is found in other parties, more than sixin-ten Conservative constituency associations describe their executive as having at least moderate levels of commonality between the members on their executive with those of their multi-level counterpart. Without the institutionalization that the Liberals have adopted or the organizational unification of the NDP, the Conservatives still achieve integration between local executives. In fact, the percentage of Conservative associations that report high or moderate levels of executive commonality (64\% combined) is only slightly smaller than the percentage of Liberal associations that reported the same ( $70 \%$ combined).

However, it is worth noting that in other provinces the Conservatives have some informal measures in place to ensure integration between local executives. Until recently in Alberta, for example, federal Conservative constituency associations in the province were allowed to send 15 delegates to provincial Progressive Conservative events, the same number of delegates that provincial PC riding associations are allocated to send (Walton, 2012). While this has recently changed, federally elected Conservatives are still invited to provincial party functions and are still afforded their vote.

As the body that is tasked with governing the local branch of the party, association executives have a leadership role in the party. This group of local party activists search for potential candidates, manage election campaigns, study policy, and maintain the party's health on the ground in between election campaigns. Their long history with the party and their leadership role combined with the autonomy that is afforded to them through the stratarchical bargain allows local executives to forge 
longstanding and cooperative relationships with their multi-level counterpart in the riding.

The considerable linkage between the members of local executives helps to explain why parties routinely take advantage of opportunities to cooperate and coordinate with their multi-level counterparts. This commonality is a crucial factor in explaining why parties engage in joint multi-level endeavours, share resources, and work with one another both inside and outside of election campaigns. When working with their former colleagues from other constituency executives, the stockpile of social capital and social trust that these individuals have accumulated results in integration in other aspects of party life as well. It should not be surprising, therefore, that parties engage in coordinated and cooperative campaign activities during elections given the relationships that are present at the local leadership level.

In addition to the executive body, it is also worth examining the commonality of party membership in routine party meetings. Chapter 3 demonstrated that party members who are active within the party are more likely to have dual membership than those members who are relatively inactive. Here it is worth considering whether the same individuals are active at both levels and attend meetings for both the provincial and federal parties. This is done in two ways. First, riding presidents were asked whether or not they had personally attended a party meeting of their multi-level counterpart in the 
past year. Second, of those who had attended, we asked what the attendance of the meeting was like compared to their own. ${ }^{52}$

More than eight-in-ten riding association presidents have attended a meeting for their multi-level counterpart in the last year. What's more, the high levels of integrated behaviour are not limited to the New Democrats as it might be expected. More than three-in-four Liberal and Conservative riding presidents reported attending one such meeting in the past year as well. Perhaps more important, however, is the composition of those in attendance. Seven-in-ten constituency association presidents report that those individuals who attend their local association meetings are mostly, if not completely, the same as those individuals who attend the local association meetings of their multi-level counterpart in the riding. Furthermore, only two percent describe the attendance as being comprised of a completely different set of individuals. Table 6.2 provides the complete breakdown.

Table 6.2: Multi-level Makeup of Routine Party Meeting Attendance by Party

\begin{tabular}{lllll}
\hline Party & $\begin{array}{l}\text { Completely the } \\
\text { same }\end{array}$ & $\begin{array}{l}\text { Mostly the } \\
\text { same }\end{array}$ & $\begin{array}{l}\text { Mostly } \\
\text { different }\end{array}$ & $\begin{array}{l}\text { Completely } \\
\text { different }\end{array}$ \\
\hline Liberal & $3 \%(3)$ & $56 \%(50)$ & $41 \%(36)$ & $0 \%(0)$ \\
Conservative & $0 \%(0)$ & $63 \%(46)$ & $30 \%(22)$ & $7 \%(5)$ \\
NDP & $50 \%(29)$ & $45 \%(26)$ & $5 \%(3)$ & $0 \%(0)$ \\
Total & $15 \%(32)$ & $55 \%(122)$ & $28 \%(61)$ & $2 \%(5)$ \\
\hline
\end{tabular}

"In the past year have you attended a federal [Conservative Party] riding association meeting? If yes, how would you describe the people in attendance compared to those that attend the provincial [Progressive Conservative] riding association meetings in the same constituency?"

Not only do the same individuals volunteer for elections and act as shared campaign labour for federal and provincial parties (see Chapter 5), but Table 6.2 reveals

\footnotetext{
${ }^{52}$ According to this sample, associations have an average of 292 members. Of these members, routine party meetings have an average of 19 members in attendance.
} 
that it is largely the same group of individuals who are responsible for inter-election party maintenance as well. That is, it is the same people who attend meetings and participate in routine monthly party activities. With the same members attending meetings at both levels, and with parties sharing a long history between those in leadership positions, coordination and cooperation becomes possible even outside of parties that have adopted formally unified party structures.

Again, we find stark party differences. Nearly every NDP president describes his/her membership as being completely or mostly the same (95\%). While this should come as no surprise given the multi-level nature of NDP party membership, membership at both levels does not require participation at both levels. That is, members do not have to attend meetings at both levels. Nonetheless, with the ability simply choose a preferred jurisdiction and devote attention to a single level, the vast majority of members attending meetings attend both levels. Here we also find similarities between the Liberals and Conservatives with only slightly more Conservative associations describing their attendance as at least mostly the same. This supports the hypothesis concerning the role of ideology, as despite being truncated organizationally, the Conservatives are able to attract nearly two-third of the same members.

\section{Joint Multi-level Social Events and Recreational Activities}

Beyond taking part in a general election and similar activities discussed in Chapter 5, there are a variety of reasons why an individual would join a political party. Here it is worth considering the incentives from the party membership literature. The conventional wisdom about party membership is that friends and family recruit potential 
members for the singular purpose of participating in an intra-party election: candidate nomination contest or a leadership election. Despite this longstanding conclusion, there is now considerable evidence that demonstrates other incentives to party membership. Clark and Wilson (1961), for instance, provide a threefold typology of incentives to membership. This includes material, solidary, and purposive (or ideological) incentives.

First, material incentives offer members with the possibility of a reward or benefit in exchange for their membership. Typical forms of material rewards or incentives for joining a political party include career advancement, patronage appointments, government contracts, and so on. This is especially true for the party that is in control of the governing apparatus. In short, material incentives offer tangible or material rewards that tend to have some degree of monetary value for the member.

While material incentives for membership are typically inward looking (or individualistic), solidary incentives tend to be much more communal in their nature. Parties have a recreational or social component to them as they engage in activities in the community, incentivizing membership through barbeques and other events. Solidary incentives allow members to meet like-minded people and engage in the social and recreational events that political parties routinely offer. These rewards for membership are intangible and offer no monetary value for the member.

Purposive incentives, like solidary ones, offer members no monetary or tangible rewards in return for their membership. However, unlike solidary incentives, the goals of the organization are more important; being a member and engaging in recreational activities is not enough for these individuals. Those motivated by purposive incentives 
are, for the most part, interested in the outcomes of their participation (Newman et al., 2004). For parties, purposive incentives provide individuals with the opportunity to discuss and debate policy and to aide the party in achieving its public policy objectives.

There is considerable agreement in the literature that the first two types of incentives have declined in importance over the past few decades (Young and Cross, 2002a; Ware, 1996). Yet, while it is true that solidary incentives have diminished over time, Seyd and Whiteley (1992: 74) do find that solidary incentives were the second most common reason for joining the British Labour and Conservative parties. The same, according to Young and Cross (2002b), is true for Canadian party members. In their study of party members, Young and Cross find that 48 percent of Liberal party members report that solidary aspects of the party are the best thing about membership. Similarly, 36 and 20 percent of Conservative and NDP members reported the same (Young and Cross, 2002b: 567). The survey data from the UK and Canada demonstrate that parties clearly engage in recreational activities that ordinary party members enjoy.

The solidary benefits to membership and the sense of community that social events can create are not lost on political parties. The Liberal University Handbook, for instance, reminds newly selected association presidents to get to know those individuals who routinely attend party meetings and party functions: "Invite them out for a drink or bite to eat after each meeting" (Liberal Party, 2012). Similarly, this particular section of the handbook ends with a reminder to pay attention to the social aspects of the party so that the riding can develop and cultivate a "sense of friendship and a team" (Liberal Party, 2012). 
When thinking of the solidary benefits of party membership, the first image that comes to mind is the excitement that engaged members and volunteers feel during election campaigns. Clarkson (2005: xxi) has written of the solidary benefits to fighting election campaigns as follows:

While elections are historical events pregnant with serious implications for the country, they can also be hugely exciting experiences for the combatants. When teams of volunteers, many of whom have worked in campaign after campaign, get back together to do political battle, they manage the tremendous tensions by developing an esprit de corps and enjoying the intense experience.

Likewise, Koop captures the solidary nature of local politics through interviews with local party activists. One activist, for example, described her time with the party in the following way:

We had a great team in that [campaign] office. We had lots of fun. We had all sorts of inside jokes. You know, we're very supportive of one another. I think we were all kind to one another. We looked out for one another, and that's what kept us going ... I just think that that helps. When you have a group of people that like each other and have a common goal and are going to be supportive of one another (2011: 71-72).

Parties, however, do more than simply fight election campaigns. As such, constituency associations offer other means of achieving the solidary benefits to membership. Social and recreational events coordinated in a multi-level manner have the ability to create lasting relationships between individuals at the federal and provincial level. To what extent, then, do federal and provincial constituency associations hold joint social events such as community picnics and barbeques with 
one another during the inter-election period? Riding association presidents were asked the frequency to which they met socially with their multi-level counterpart in the previous year. Table 6.3 shows the responses.

Table 6.3: Frequency of Multi-level Social Meetings by Party

\begin{tabular}{llll}
\hline Party & Frequently & Occasionally & Never \\
\hline Liberal & $45 \%(51)$ & $35 \%(40)$ & $20 \%(22)$ \\
Conservative & $29 \%(28)$ & $21 \%(20)$ & $50 \%(47)$ \\
NDP & $80 \%(51)$ & $17 \%(11)$ & $3 \%(2)$ \\
Total & $48 \%(130)$ & $26 \%(71)$ & $26 \%(71)$ \\
\hline
\end{tabular}

"How often does your provincial riding association host joint social events with the federal [Conservative Party] association in the same riding?"

Although the frequency differs by party, there is clearly a multi-level social aspect to political parties in Ontario. The majority of constituency associations meet socially on a number of occasions throughout the year. Nearly half of all constituency associations frequently meet socially with their multi-level counterpart. In fact, only a quarter of constituency associations report that they never meet socially with their federal or provincial counterpart.

Unlike other forms of integration that have been discussed in the previous chapters, differences between the Liberals and Conservatives are beginning to emerge. While Conservative constituency associations are evenly divided between those who meet socially (50\%) and those who do not (50\%), eight-in-ten Liberal associations meet at least occasionally throughout the year for multi-level recreational activities and events. The difference between the Liberals and Conservatives is statistically significant in this regard, $\chi^{2}(1,208)=19.628, p<.001$. In fact, the Liberals are nearly four times as likely to take part in multi-level social events than the Conservatives (odds ratio $=3.98$ ). 
The Scarborough-Guildwood Annual Community BBQ is a good example of this kind of multi-level and jointly coordinated social event. John McKay has been the Member of Parliament in this electoral district since 1997 and has been hosting the community social event for a number of years. When the provincial Liberals have had an MPP in the riding - as they have since 2013 - the event has been hosted jointly (see Appendix 9 for the 2013 flyer that was used to advertise this event). Both McKay (the federal Liberal MP) and Hunter (the provincial Liberal MPP) and their staff work together to create an event that will bring together both provincial and federal Liberals in the riding in a social setting.

The annual Liberal Don Valley East picnic is another example of a jointly coordinated social event. Each year the federal and provincial executives in the riding coordinate their efforts and host a picnic and barbeque for Liberal activists and supporters in the community at Broadland Park (Koop, 2011: 86). These types of events provide local federal and provincial Liberals in the riding an opportunity to see one another outside of the traditionally busy and stressful electoral cycle and get to know one another better.

These multi-level social events are not, of course, limited to the Liberals. An example from the New Democrats can be found in London where the federal and provincial NDP hold their annual "Midsummer Madness". This particular social event is jointly hosted by the two NDP riding associations in the area and all interested individuals (members, activists, and ordinary citizens alike), regardless of jurisdictional preference, are asked to attend. The last event, which was held in August 2014, was 
hosted by MPP Teresa Armstrong and MP Irene Mathyssen (see Appendix 10 for an invitation to the event).

These events are not uncommon among Conservatives either. In the riding of Simcoe North, for example, MP Bruce Stanton and MPP Garfield Dunlop have jointly hosted an annual community BBQ together for nearly a decade (see Appendix 11 for the 2015 event information). Similarly, MPP Tim Hudak and MP Dean Allison have been holding a joint BBQ in the Niagara region for more than a decade (see Appendix 12 for the 2013 invitation to this annual event). Like the Liberal and New Democrat examples outlined above, this kind of multi-level event is meant to bring together partisans from both the provincial and federal realms and to create a greater sense of unity in the riding.

Coordinated social events like the Don Valley picnic, the ScarboroughGuildwood Annual Community BBQ, the Midsummer Madness, and the Simcoe North Annual BBQ can have a number of important benefits for parties. Providing solidary incentives and involving activists and members in a recreational manner helps to ensure that local party personnel are engaged with the party even when there are no exciting elections to fight. By doing so, parties increase the chances that these members will renew their membership and participate in future election campaigns in the riding. Moreover, jointly hosting these events widens the pool of individuals who will be attending. This provides parties with an excellent forum to recruit new members to join the party at their level. Multi-level social events can therefore turn into recruitment drives. This extends beyond membership and applies to other areas as well. Joint federal-provincial events give parties access to more people in the constituency and as a 
result parties have easier access to raising funds and recruiting volunteers for upcoming election campaigns.

Table 6.3 highlights the extent to which formal coordination occurs in hosting social events throughout the year. However, social events can also have an informal element to them. In many cases local party events are exclusively federal or provincial events, however, behind the scenes there is considerable support from the other level. A number of riding association presidents described how in addition to their formal multilevel events, they would also coordinate their schedules to ensure that each level was not holding party events around the same time as each other. While social events are enjoyable for party members, too many events in close proximity to each other run the risk of having low turnout and exhausting party members since both parties draw from the same crowd. The last thing a party wants is to compete with their multi-level counterpart for attendance at party functions. As such, parties will often communicate with each other to ensure that their upcoming event does not conflict with functions that have already been planned, another practical reason for representation on one another's executive (personal interviews).

Likewise, it is not uncommon for federal parties to encourage their members to attend and participate in provincial party affairs and vice versa. Monthly executive meetings, for instance, can serve as an excellent forum to announce upcoming events for a party's multi-level counterpart. In this way federal and provincial parties can maximize the success of their own events. This is particularly true for the Conservatives. While only 50 percent of Conservative riding associations actually meet for joint multilevel social activities, officials inside the party described informal discussions and 
liaisons between the two levels to ensure that events are both well attended and staffed (personal interview). The Ontario Progressive Conservative events webpage, for instance, recently promoted a meet-and-greet with federal Conservative MP Peter Van Loan (see Appendix 13 for the event details). Although the events are not hosted together per se, many of the same individuals turn out to both and many of the individuals behind the scenes doing the planning are the same as well. While the extent of this informal type of cooperation is not empirically captured in the Table 6.3, interviews with party officials in all three parties reveal that it is not an uncommon occurrence.

\section{Joint Multi-level Policy Discussion and Formation}

Policy study is not a function that Canadian parties are particularly well known or praised for. Cross (2007: 425), for example, maintains that Canadian parties are not effective vehicles for policy development: "they neither offer voters meaningful opportunity for involvement in the policy-making process nor do they regularly generate policy alternatives for consideration". In fact, a survey of constituency associations after the 1993 federal election found that 31 percent of associations did not meet at all during the year to discuss policy. At the other end of the spectrum, only 14 percent reported that they met a number of times that year to discuss policy (Cross, 1996). ${ }^{53}$

This does not mean, however, that party members are uninterested in policy development. Cross (1996) and Cross and Young (2002) demonstrate that a majority of party members in all of the major Canadian parties desire to play a greater role in the

\footnotetext{
${ }^{53}$ These numbers, however, are not completely comparable as a different composition of parties are included in each analysis.
} 
study and formation of party policy. In fact, the latter study demonstrates that existing party members are largely dissatisfied with the minimal role that they are able to play in the realm of party policy. More than three-quarters of party members in the major federal Canadian parties feel that they should be provided with a greater role in studying and developing party policy (Cross and Young, 2002).

At the local level in Canada, the "small core of active members" (Gauja, 2012) who dominates policy discussions tends to be the constituency association executive. While local constituency associations devote a considerable amount of their time, resources, and attention to the selection of party personnel (candidates and leaders) and the administration of election campaigns, these local organizations also play a role in the study of party policy.

What is unclear, however, is the extent to which there is any joint coordination or multi-level aspects to these meetings. Table 6.4 reveals the extent to which constituency associations coordinate policy discussions. Six-in-ten associations meet at least occasionally throughout the year to engage in joint multi-level policy discussions $(30 \%$ frequently and 30\% occasionally). A sizeable minority, four-in-ten associations, however, do not meet at all throughout the year.

Table 6.4: Frequency of Multi-level Policy Discussions by Party

\begin{tabular}{llll}
\hline Party & Frequently & Occasionally & Never \\
\hline Liberal & $27 \%(30)$ & $37 \%(42)$ & $36 \%(41)$ \\
Conservative & $4 \%(4)$ & $29 \%(27)$ & $67 \%(64)$ \\
NDP & $75 \%(48)$ & $20 \%(13)$ & $5 \%(3)$ \\
Total & $30 \%(82)$ & $30 \%(82)$ & $40 \%(108)$ \\
\hline
\end{tabular}

"How often does your provincial riding association hold joint policy discussions with the federal [Conservative Party] association in the same riding?" 
It is on the question of policy that we find the biggest interparty differences. Like meeting socially, there is a significant difference between Liberal and Conservative associations when it comes to multi-level policy discussion and formation, $\chi^{2}(1,208)=$ $18.726, p<.001$. Fewer than one-in-ten Conservative associations meet with their multilevel counterpart to discuss policy frequently and the majority (67\%) do not meet at all. The divide between the Conservatives and the New Democrats is particularly large in this regard as three quarters of NDP associations frequently meet with their multi-level counterpart to discuss policy. Put differently, New Democrat constituency associations are nearly 20 times more likely to meet frequently to discuss policy than the Conservatives.

It is unclear, however, whether this is truly a party difference or whether it is a result of the Conservatives being in government for so long. Perhaps as a governing party, the Conservatives simply meet less to discuss policy than they otherwise would if they were in opposition. And indeed there is evidence of this among other parties. Clarkson (2005), for example, notes that the longer the federal Liberals were in government, the less inclined they were to meet and discuss policy. ${ }^{54}$

In addition to knowing how often parties meet to discuss policy, it is also worth considering the influence these meetings have on the outcome of the policy formation process. In other words, parties may meet to discuss policy with one another but at the same time they may exert very little influence on each other. As a result, it is important to know not only how often parties meet to discuss policy but also how much influence they are exerting. As such, the following question was also asked: "In your opinion, to

\footnotetext{
${ }^{54}$ Government status is therefore an interesting variable to consider in future research.
} 
what extent does the federal [Conservative Party] influence the provincial [Progressive Conservative Party's] actions in the creation of content of party platform and policy".

Despite only four percent of Conservative constituency associations reporting that they meet frequently to discuss policy, one-in-four associations describe their multilevel counterpart as being influential in their own formation of policy (see Table 6.5). This is remarkably similar to the 26 percent of Liberal associations that suggest that their multi-level counterpart exerts influence on their policy formation. Despite not meeting nearly as often, Conservatives exert the same level of multi-level influence in policy formation as their Liberal counterparts. This suggests that although infrequent, when multi-level policy discussion does occur within the Conservatives it is important and influential.

Despite not being afforded a lot of opportunities for engagement and participation, ideological, or purposive, incentives are among the most important reasons for joining a political party. Young and Cross' survey of Canadian party members, for instance, found that 84 percent of respondents indicated that policy reasons were very important to their original decision to join the party (2002: 558). Likewise, 68 percent of party members said that ideological or policy reasons (purposive incentives) are the best thing about being a party member (Young and Cross, 2002a: 567). Given that party members are drawn to membership because of ideological reasons, it is important that parties engage in these discussions as a means of recruiting new members and keeping existing members satisfied. 
Table 6.5: Degree of Multi-level Influence in Policy Formation by Party

\begin{tabular}{llll}
\hline Party & Influential & Not very Influential & Not at all Influential \\
\hline Liberal & $26 \%(29)$ & $52 \%(59)$ & $22 \%(25)$ \\
Conservative & $25 \%(24)$ & $41 \%(39)$ & $34 \%(32)$ \\
NDP & $83 \%(53)$ & $11 \%(7)$ & $6 \%(4)$ \\
Total & $39 \%(106)$ & $39 \%(105)$ & $22 \%(61)$ \\
\hline
\end{tabular}

"In your opinion, to what extent does the federal [Conservative Party] influence the provincial [Progressive Conservative Party's] actions in the following areas: Content of party platform and policy."

\section{Constituency Level Differences in Multi-level Inter-election Maintenance}

The previous chapter examined four hypotheses relating to the strength of campaign integration at the local level. The first posited that rural constituency associations would tend to be more integrated than urban ones. The second expected constituency associations in ridings where the party is electorally strong to be more integrated than associations in ridings where the party is electorally weak. Similarly, the third suggested that incumbency would also lead to higher levels of integration as incumbents have an incentive to protect their brand and image in the riding. Finally, the fourth proposed that constituency associations in ridings that were represented in cabinet would be more integrated than those associations located in ridings without any cabinet representation. Each of the three hypotheses is re-examined here as they relate to interelection campaign integration.

The same explanatory variables are included in the analysis as the previous chapter: party, urban/rural, electoral strength, incumbency, and the presence of a cabinet minister. This time, however, the model is attempting to predict inter-election integration (meeting socially, meeting for policy, member/executive overlap). As was the case in Chapter 5, the only significant variable for the multinomial analysis (the 
overall level of integration that an association experiences) is membership in the New Democratic Party. Associations in the NDP are significantly more likely to engage in more inter-election activities than the other parties, even when controlling for a variety of other variables.

Table 6.6, however, examines each indicator individually. The results of the binary logistic regressions highlight important differences between the types of integrating inter-election activities.

Table 6.6: Summary of Binary Logistic Regression Results (Inter-election Activities)

\begin{tabular}{|c|c|c|c|c|c|c|c|c|}
\hline \multirow[t]{2}{*}{ Variables } & \multicolumn{2}{|c|}{$\begin{array}{c}\text { Joint } \\
\text { Social Events }\end{array}$} & \multicolumn{2}{|c|}{$\begin{array}{l}\text { Joint Policy } \\
\text { Discussions }\end{array}$} & \multicolumn{2}{|c|}{$\begin{array}{c}\text { Shared Party } \\
\text { Members }\end{array}$} & \multicolumn{2}{|c|}{$\begin{array}{c}\text { Common Executive } \\
\text { Members }\end{array}$} \\
\hline & $\mathrm{B}$ & ExpB & $\mathrm{B}$ & ExpB & $\mathrm{B}$ & ExpB & $\mathrm{B}$ & ExpB \\
\hline Cabinet & .616 & 1.852 & .093 & 1.098 & .780 & 2.181 & .152 & 1.164 \\
\hline Urban & .511 & 1.667 & .437 & 1.548 & .360 & 1.433 & .157 & 1.171 \\
\hline Incumbent & $1.122 *$ & 3.326 & -.157 & .854 & .373 & 1.453 & .563 & 1.756 \\
\hline NDP & $1.668^{*}$ & 5.304 & $2.337 * *$ & 10.354 & $3.122 *$ & 22.695 & $2.724^{*}$ & 15.236 \\
\hline Conservative & -.759 & .468 & -1.181 & .307 & .211 & 1.235 & .183 & 1.201 \\
\hline $\begin{array}{l}\text { Won seat at } \\
\text { both levels }\end{array}$ & $1.354 *$ & 3.875 & .040 & 1.041 & -.371 & .690 & -.880 & .415 \\
\hline $\begin{array}{l}\text { Nagelkerke's } \\
\text { pseudo } R^{2}\end{array}$ & \multicolumn{2}{|c|}{.225} & \multicolumn{2}{|c|}{.334} & \multicolumn{2}{|c|}{.233} & \multicolumn{2}{|r|}{.145} \\
\hline
\end{tabular}

Note: ${ }^{*} \mathrm{p}<.01 ;{ }^{*} \mathrm{p}<.05$; Reference category for party is 'Liberal'

The results presented in the table above are remarkably similar to those presented in the previous chapter. Like campaign integration, Table 6.6 demonstrates that the presence of electoral strength is related to levels of inter-election party integration. Constituency associations that engage in joint social events are significantly more likely (nearly four times) to have won both the federal and provincial seats in the riding compared to constituency associations that do not engage in joint social events. That those associations with an incumbent are more likely to engage in joint social events also makes sense and fits with the expectation that incumbents care about the party brand in the riding, irrespective of jurisdiction. 
Also similar to campaign integration, there is no meaningful difference between urban and rural ridings in any of the inter-election indicators. As suggested in the previous chapter, the size of some Ontario constituencies may contribute to a lack of significance when considering urban and rural differences. One provincial Liberal official, for example, noted that he would like to engage in more joint social events with the federal party but the distance would place too much of a burden on party members in the riding. When party members in a riding already have to travel for routine party events and meetings, asking them to travel further for social events may be too cumbersome. This is likely more of a problem in large rural ridings than it is in the more dense urban ones.

Likewise, the presence of a cabinet minister in the riding did not add anything to the overall model shown above. This is somewhat surprising given that inter-election activities such as policy development and policy study may be perceived to carry more weight in ridings with cabinet representation. However, the stratarchical bargain that puts policy development within the purview of the central party and not the locals, may ultimately negate any benefit derived from having cabinet representation at the constituency level.

Finally, as was the case with integration during the election period, the party variable is highly significant. Constituency associations that engage in any of the integrated inter-election activities are significantly more likely to belong to the New Democratic Party. This is consistent with the evidence presented in both Chapters 3 and 5. New Democratic associations are five times more likely to host joint social events, 10 times more likely to discuss policy with their multi-level counterparts, 15 times more 
likely to have high membership overlap, and 20 times more likely to have the same members attend both the federal and provincial party meetings.

\section{The General State of Local Inter-election Integration}

It is also worth examining the range of integration at the local level. Table 6.7 provides the breakdown of constituency associations by party and level of integration. Associations that meet frequently to discuss policy, have high personnel overlap, and meet frequently for social and recreational events have an integration score of three, associations that do none of these have a score of zero, and so on.

Table 6.7: Integrated Inter-election Activities by Party

\begin{tabular}{lllll}
\hline Party & $\begin{array}{l}\text { Multi-level } \\
\text { Activities (0) }\end{array}$ & $\begin{array}{l}\text { Multi-level } \\
\text { Activities (1) }\end{array}$ & $\begin{array}{l}\text { Multi-level } \\
\text { Activities (2) }\end{array}$ & $\begin{array}{l}\text { Multi-level } \\
\text { Activities (3) }\end{array}$ \\
\hline Liberal & $21 \%(23)$ & $36 \%(40)$ & $24 \%(27)$ & $20 \%(22)$ \\
Conservative & $28 \%(27)$ & $48 \%(46)$ & $20 \%(19)$ & $3 \%(3)$ \\
NDP & $0 \%(0)$ & $13 \%(8)$ & $25 \%(16)$ & $63 \%(40)$ \\
Total & $19 \%(50)$ & $35 \%(94)$ & $23 \%(62)$ & $24 \%(65)$ \\
\hline
\end{tabular}

The majority of constituency associations, 80 percent, engage in at least one form of inter-election integrating activities. By contrast, fewer than one-in-five constituency associations do not engage in any inter-election integrating activities. Differences at the party level, however, remain significant. Almost two thirds of New Democrat constituency associations have high levels of personnel overlap (executive and membership) and meet frequently for both multi-level policy discussions and recreational events. By contrast, this figure is one-in-five for the Liberals and considerably lower for Conservative associations ( $3 \%)$. 
Unlike in Chapter 5 where it was demonstrated that all parties scored 'High' on certain aspects of campaign integration (i.e., shared campaign labour), none of the integrating activities in Table 6.8 enjoys the same support across all three of the parties in Ontario.

Table 6.8: Degree of Multi-level Campaign Integration by Party

\begin{tabular}{llll}
\hline Party & Meet Socially & Policy Discussions & Executive Overlap \\
\hline Liberal & Medium & Medium & Medium \\
Conservative & Low & Low & Medium \\
NDP & High & High & High \\
\hline
\end{tabular}

\section{Conclusions}

Although often overlooked, the activities and efforts of constituency associations during the inter-election period are of great significance and have consequences for the health and success of political parties. Without barbeques, community events, policy discussions, and other social and recreational events, parties would find it more difficult than they currently do to enrol new members and keep existing members satisfied. While elections are undoubtedly exciting events, parties need to keep members engaged in the months and years in between elections. The question relevant to this chapter is the extent to which parties engage in these types of activities in a coordinated multi-level fashion.

A major conclusion of this chapter is that integration is not simply an electoral phenomenon: parties do participate in integrating activities outside of election campaigns. In fact, a majority of constituency associations meet at least occasionally throughout the year to discuss party policy and host joint social and recreational events in the riding. These coordinated and cooperative activities are in addition to the 
extensive human linkages that can be found at the constituency executive and membership level. Seven-in-ten riding presidents describe the members who attend their party meetings as mostly the same as those who attend the party's multi-level counterpart's meetings; a majority of local executives are characterized as having significant multi-level linkages (having members that either currently or have in the past been an executive member at the other level); and the vast majority of riding association presidents belong to and frequently volunteer for election campaigns at both levels.

Substantial inter-party differences, however, are beginning to emerge. Conservative and Liberal parties have shown very little difference in terms of their integration up to this point. In terms of a broad range of party personnel the Liberals are not able to attract higher levels of dual membership than the Conservatives (see Chapter 3). Similarly, in terms of local election campaign integration, the Conservatives offered their multi-level counterparts just as much support and shared similar levels of resources as Liberal parties offer to one another (Chapter 5). We find these similarities despite the stark differences in both organizational design and ideological consistency.

However, the preceding discussion reveals that there is a considerable gap between the Liberals and Conservatives during the inter-election period. This inter-party gap is particularly stark on the question of policy formation where only 4 percent of Conservative associations report meeting with their multi-level counterpart frequently to discuss policy. This is compared to nearly 30 percent of Liberal associations that frequently do so. Similarly, we find a comparable gap between the Liberals and Conservatives in terms of how frequently these parties meet with their multi-level counterparts for social reasons. 
In this regard, integration during the inter-election period appears to follow more of an organizational logic and may be primarily the result of organizational rules and procedures and the signals that they send. The different levels of organizational connectedness directly correspond to the degree to which parties cooperate and coordinate with their multi-level counterpart in the riding. Overall, the New Democrats (unified organizational structure) are significantly more integrated than the Liberals (semi-integrated organizational structure) and the Liberals are significantly more integrated than the Conservatives (truncated organizational structure).

Despite the potential for a shared and consistent ideology to make up for a truncated organizational design (as was the case in the previous two chapters), there appears to be a clear pattern based on the level of organizational connectedness and the amount of inter-election integration. Once again, however, when we examine personnel (members and members of the local executive), this chapter demonstrates that the Conservatives achieve similarly high levels of multi-level commonality as the Liberals (consistent with Chapter 3 and 5). The difference appears to be limited only to interelection activities rather than the composition of party personnel during the interelection period.

This chapter, however, tells us more about parties than just their multi-level activities. The frequency at which parties are meeting socially and discussing policy in a multi-level manner reveals a great deal about their overall levels of activity and role in the community. While we do not have data, we can safely assume local organizations carry out many of their activities in an isolated single-level manner (i.e., without their federal/provincial counterpart). That 75 percent meet at least occasionally throughout 
the year with their counterpart to engage in recreational activities and 60 percent do so for policy suggests that riding associations in Ontario are perhaps more active than typically thought. Combined with their own single level activities, constituency associations appear to offer their members a number of opportunities throughout the year to engage with their party at the local level outside of election campaigns. 


\section{CHAPTER 7: Grassroots Party Integration: Completing the Picture}

\section{Introduction}

The previous two chapters have highlighted the extent to which federal and provincial parties at the grassroots level cooperate and coordinate both inside and outside of election campaigns in the province of Ontario. While this is a crucial first step for our broader understanding of party integration, separating the different types of party linkages apart like this provides a somewhat incomplete picture of how integration is practiced. Indeed, distinguishing between election and inter-election party integration has left a number of important questions unanswered.

For example, do federal and provincial constituency associations provide support to one another at the same rate or are the relationships between the two levels of government somewhat uneven and unequal? In other words, is integration practiced in an exploitative way or is the relationship relatively even and reciprocal? Another question that has yet to be addressed is whether the same constituency associations that engage in campaign integration also participate in inter-election integration or whether it is largely two separate groups engaging in unique sets of activities. Also left out of these discussions has been whether existing frameworks and typologies can be used to make sense of integrated constituency associations in Ontario.

Combining the data from Chapters 5 and 6 therefore allows us to have greater insight into party integration at the local level and allows us to answer the questions listed above. The first section explores the possibility that federal parties are exploiting their provincial counterparts. Here the emphasis is on federal-provincial differences in the provision of multi-level support and in the sharing of resources and personnel. This 
is followed by a discussion of the extent to which the same associations engage in both inter-election and campaign integration. Next, the chapter applies an existing typology of local integration to the 273 cases in the dataset, categorizing constituency associations into four main types. Not only does this provide a test of existing frameworks, but it also provides a more complete picture by revealing the extent to which constituency associations engage in integrating activities as a whole. The chapter then ends with a number of observations that we can make about local party integration when the findings about parties during elections are combined with the findings about parties during the inter-election period.

\section{An Uneven and Exploitative Relationship? Federal and Provincial Linkages Compared}

As you may recall, in Chapter 3 the career paths of legislators in Ontario were found to be unidirectional in nature. Although only modest levels of multi-level career transitions take place in Canada (approximately 7\% of all MPs in Ontario have had parliamentary careers at both levels), the vast majority of cross-jurisdictional movement is from the provincial level to the federal level. Although these multi-level politicians act as an integrating linkage between the federal and provincial realms by creating personal networks and relationships between the parties (especially when they are included in cabinet), the process of integration can be uneven nonetheless.

The provincial Progressive Conservatives experienced this uneven relationship

first hand as a number of prominent provincial cabinet ministers and other party officials left the party in favour of seeking candidacy in the federal party during the 2004 election. During this time, however, there was no migration from federal to provincial 
politics to help offset the loss. This political 'brain drain' of sorts provided the newly formed federal Conservatives with experienced politicians and veteran campaign staff and organizers while simultaneously weakening the provincial Progressive Conservatives.

It is therefore worth disaggregating the survey data of constituency associations presented in the previous chapter in order to examine the differences between federal and provincial parties in this regard. Are federal parties simply resting on the organizations of the parties in the provinces? It is clear that federal parties are often guilty of poaching talented and experienced legislators from the provincial level while providing nothing in return. However, it is unclear if federal parties provide their provincial counterparts with other types of support (e.g., sharing activist data, providing endorsements, etc.) to the same extent as they receive. In her examination of Canada, the United States, Germany, Austria, Switzerland, Spain, the UK, and Australia, Thorlakson (2011: 9) finds that the most common pattern of party linkage is an "upward flow of resources and services to the federal party from the state party units". Is that the case in Ontario? Or, perhaps the relationship is uneven in the opposite direction: are provincial parties in fact benefiting more from their federal cousins despite what we witness with multi-level careers?

Understanding the direction and relative symmetry of integration is important because if integrated and cooperative behaviour is not reciprocated there may be negative consequences for integration and federal-provincial relations more broadly. Perhaps most importantly, integration is not likely sustainable in such a one-sided environment. If a provincial party, for example, shares election information with its 
federal counterpart, lends its staff to help during federal elections, and provides campaign endorsements but receives no such support in return, it is unlikely that the provincial party will continue to be so cooperative and forthcoming in the future.

While there are benefits to providing support, there is a clear expectation that it will be returned. This extends beyond individual constituency associations and applies to the aggregate level more broadly as well. If a provincial or federal party in general is known for its uncooperative nature, this may foster a culture where parties do not even attempt to engage in integrated behaviour. If, however, the relationship between federal and provincial parties is reciprocal and mutually beneficial, then party integration can be more sustainable over the long term.

Uneven and unsustainable forms of integration are of particular importance given that vertical integration in multi-level systems has consequences for national unity and federal stability (Thorlakson, 2009), the performance of democracy (Riker, 1964), accountability (Dyck, 1996), party strength (Koop, 2011) and intergovernmental relations (Esselment, 2013). Ensuring that integration is balanced and reciprocal is therefore important to the health and stability of the federal system. The following section investigates the possibility of an exploitative federal-provincial relationship. Rather than look at individual parties as a whole (federal/provincial parties combined), here the focus is on federal and provincial differences in the extent to which they each engage in both campaign and inter-election integration.

In order to examine the extent to which parties at both levels are engaging in a reciprocal relationship, Tables 7.1 and 7.2 compare across jurisdictions rather than across parties. Recall, however, that the NDP sample is largely federal respondents. As a 
result, this particular analysis focuses on the Liberals and Conservatives. Table 7.1 demonstrates that federal and provincial parties do not differ significantly in terms of the amount of campaign support they offer.

Far from simply taking advantage of their provincial counterparts for election support and information, federal parties provide just as much support as they receive. ${ }^{55}$ The percentage of federal constituency associations, for example, that engage in two of the three forms of multi-level campaign activities (29\%) does not differ significantly from the 28 percent of provincial constituency associations that do so. The same is true for all other degrees of campaign integration as well. Not only do the figures not differ significantly, but they are remarkably similar as well - never more than a three percent difference.

Table 7.1: Degree of Campaign Integration (Federal and Provincial Parties Compared)

\begin{tabular}{lllll}
$\begin{array}{l}\text { Level of } \\
\text { government }\end{array}$ & $\begin{array}{l}\text { Multi-level } \\
\text { Activities (0) }\end{array}$ & $\begin{array}{l}\text { Multi-level } \\
\text { Activities (1) }\end{array}$ & $\begin{array}{l}\text { Multi-level } \\
\text { Activities (2) }\end{array}$ & $\begin{array}{l}\text { Multi-level } \\
\text { Activities (3) }\end{array}$ \\
\hline Provincial & $22 \%(20)$ & $41 \%(38)$ & $28 \%(26)$ & $9 \%(8)$ \\
Federal & $23 \%(26)$ & $38 \%(44)$ & $29 \%(34)$ & $10 \%(12)$ \\
\hline
\end{tabular}

Note: Liberal and Conservative parties only.

It is also worth noting that the reciprocal relationship holds true for individual indicators of campaign integration as well. Take, for example, the question of campaign endorsements. While not shown in Table 7.1, federal and provincial parties do not differ in the extent to which they campaign for one another: 56 percent of federal constituency

\footnotetext{
${ }^{55}$ Here we are not interested in all of the different types of multi-level linkage. Instead, we are interested in those active linkages that parties engage in. Overlapping human labour and party personnel are therefore excluded from the analysis, as this is a linkage that parties have little control over. By contrast, sharing information, exerting influence, and campaigning for one another are more active linkages that the parties can choose to engage in (or not). This analysis focuses on these types of activities as the purpose is to uncover whether one level is actually providing more support than the other.
} 
associations and 54 percent of provincial associations received multi-level campaign endorsements and support at some point during the 2011 election campaign.

A similar pattern is found when federal and provincial inter-election activities are compared. ${ }^{56}$ Despite occurring less frequently than campaign integration, there continues to be no significant difference between federal and provincial parties in this regard. Like campaign integration, federal parties are just as likely as their provincial counterparts to engage (or not) in integrating activities during the inter-election period such as studying and discussing policy, meeting socially, and having significant linkages at the executive level (Table 7.2). Here too we find no significant differences and similar to the above, the federal-provincial difference is at most 4 percent.

Table 7.2: Degree of Inter-election Integration (Federal and Provincial Parties Compared)

\begin{tabular}{lllll}
\hline $\begin{array}{l}\text { Level of } \\
\text { government }\end{array}$ & $\begin{array}{l}\text { Multi-level } \\
\text { Activities (0) }\end{array}$ & $\begin{array}{l}\text { Multi-level } \\
\text { Activities (1) }\end{array}$ & $\begin{array}{l}\text { Multi-level } \\
\text { Activities (2) }\end{array}$ & $\begin{array}{l}\text { Multi-level } \\
\text { Activities (3) }\end{array}$ \\
\hline Provincial & $39 \%(36)$ & $34 \%(31)$ & $21 \%(19)$ & $7 \%(6)$ \\
Federal & $38 \%(44)$ & $31 \%(36)$ & $25 \%(29)$ & $6 \%(7)$ \\
\hline
\end{tabular}

Note: Liberal and Conservatives parties only.

While the relationship between federal and provincial parties is uneven in regard to career transitions, this is not the case for local party integration. Both during election campaigns and in the inter-election period, federal and provincial parties engage in what appears to be a mutually beneficial and reciprocal relationship. Rather than resting on the provincial organization, as might be expected, federal constituency associations provide their local provincial counterparts with a considerable degree of support. In fact, throughout all of the follow up interviews conducted with riding presidents and

\footnotetext{
${ }^{56}$ Again, the focus here is on multi-level activities (rather than all linkages). This includes policy discussion, social events, etc.
} 
members of their executives, not one suggested that their multi-level counterpart was taking advantage of their association (personal interviews). Although some would like to see more cooperation in the future, there were no serious complaints of an uneven or exploitative relationship. This, of course, bodes well for the future and continued strength of local party integration in the province.

\section{Campaign, Inter-election, or Both?}

While we know that integration occurs both inside and outside of election campaigns, we do not yet know if the same constituency associations engage in both types of integrated local behaviour. It could be, for instance, that those associations that engage in election integration are entirely and fundamentally different from the associations that engage in inter-election integration. On the other hand, it may well be the case that the same associations are integrated, regardless of whether they are fighting elections or hosting barbeques.

In general, it is largely the same associations that engage in both types of grassroots integration. A majority of constituency associations that have the lowest interelection integration score also have the lowest campaign integration score. In other words, a majority of constituency associations that do not engage in any integrating activities in between elections (policy discussion, social events, etc.) also do not participate in any integrating activities during election campaigns (endorsements, sharing riding information, and so on). Overall, one-in-ten constituency associations fall into this category of not exhibiting any campaign or inter-election integrating indicators. Similarly, half (49\%) of associations that scored the highest on inter-election integration 
scored equally high during the election campaign period. ${ }^{57}$ In contrast to those that do not exhibit any integrating qualities, 16 percent of associations engage in all of the indictors of integration, regardless of whether it is during the campaign or not.

Despite campaign integration being more common, it appears as though the same constituencies are likely to engage in both types. Rather than a dichotomy of those associations that are integrated during elections and those that are integrated during the off seasons, there is considerable overlap between the two. This is hardly surprising given that inter-election activities tend to enhance the electoral activities of the party and vice versa. A vibrant and engaged multi-level activist and membership base that is cultivated during the inter-election period through barbeques, community events, and policy debates provides a strong base of support for the party to call upon during the next general election. Likewise, multi-level cooperation during election campaigns provides parties with a sense of solidarity and unity that is likely to continue well after the election campaign has concluded.

\section{A Typology of Multi-level Constituency Associations}

Combining the data from the election and inter-election period also provides us with an opportunity to examine associations in their totality, not simply during election periods or not. Moreover, this also allows us to explore how well the narrative provided in the previous two chapters maps on to recent conceptions of multi-level party politics in Canada. Koop (2011), for instance, has created a four-fold typology of constituencies

\footnotetext{
${ }^{57}$ This is also reflected in a moderate correlation between the two types of integration. The Spearman correlation is $0.40(p<.01)$.
} 
based on their level of grassroots party integration (one political world; interconnected political worlds; distinctive political worlds; two political worlds).

In the first type, which Koop terms one political world, federal and provincial party organizations are fully integrated with one another. Federal and provincial associations in these electoral districts share members of their executive councils, engage in ongoing communication, and create singular auxiliary units that work across jurisdictions. As it would be expected, campaigns in these ridings are also highly integrated: the inner circle of a candidate's campaign team typically work at both levels and campaign resources are openly and freely shared. Finally, party members in these ridings identify with the party in a broad sense (rather than at a single level) and engage in politics at both levels on a regular basis. In other words, the commitment is to the party as a whole irrespective of multi-level jurisdiction or formal rules outlined in party statutes. For the activists and members on the ground in these ridings it means very little that the party is "officially" distinct. The fact that the same individuals populate the executive of each branch, communicate with one another, and volunteer at both levels meaningfully links the two organizations despite possible formal organizational separation (Koop, 2011: 182).

The second type of constituency is the interconnected political world. This type can be best understood as a mixed constituency association. While structural linkages are typically absent, a modest level of integration is achieved through common party activists, campaign teams, and volunteers. As Koop explains: "even when there are few formal linkages between the national and provincial association executives, local activists drive integration between the two levels, making little attempt to distinguish 
between the inter-election maintenance events and campaigns of national and provincial parties" (2011: 186). What distinguishes this type from the first is two-fold. First, overall integration in these constituencies is somewhat weaker and second, what integration does occur tends to be more informal and less coordinated.

The third type of local constituency is that of distinctive political worlds. Like the second type, integration in these ridings is largely personality driven. With no meaningful structural linkages (few or no common executive members, for instance), the limited integration and multi-level cooperation is the result of committed activists. Unlike the second type, however, these ridings tend to have fewer common members and activists and therefore even the informal aspects of integration are relatively weak. According to Koop, "local cooperation comes neither naturally nor easily in these ridings... Lacking local administrators willing to build relationships with any associations at the other level, these constituency associations have remained singlelevel loners" (2011: 186). In other words, while we might find some evidence of integration in political life in these kinds of associations, it is anything but the norm.

Finally, Koop's fourth type, two political worlds, is characterized by highly differentiated local organizations and campaigns. In these ridings local associations do not engage in communication nor do they host events or create auxiliary organizations jointly. Likewise, members and activists in these ridings tend to focus on a single level and rarely participate in party politics at both levels. Unlike the first type, the grassroots in these ridings is committed to the party at a single jurisdiction. The result is that campaign teams and local executives remain distinct with little overlap, and although capital resources may be shared, personnel are not. Provincial party supporters 
contribute their time and money to the provincial organization whereas federal party supporters devote their attention to the federal party (Koop, 2011: 188).

Based on this four-fold typology, Koop classified each of the ridings in his analysis. Five (31\%) were classified as belonging to the one political world type, four (25\%) were characterized as being in interconnected political worlds, five (31\%) were distinctive political worlds, and two ridings (13\%) lived in two political worlds. It is important to remember, however, that this typology was established based on observations from Liberal associations in 16 electoral districts and has yet to be empirically verified using a larger sample.

Using this typology as a framework and the indictors of integration discussed in the previous chapters (sharing human and other resources during campaigns, exerting influence in the candidate selection process, providing campaign endorsements/visits, meeting for policy discussions, meeting for social events, and personnel overlap in the inter-election period), the classification of constituency associations has been expanded from Koop's original 16 ridings to each of the 273 constituency associations in the dataset. Table 7.3 extends the application of the typology beyond the Liberals to include both the Conservatives and New Democrats. In doing so, the following analysis more systematically and empirically tests the representativeness and usefulness of Koop's typology of local associations.

Based on these six indicators, an association can have a total integration score ranging from 0-6 which allows every constituency association for which there is data to be classified into one of the four types. Those associations that score zero on these 
indicators are classified as living in two political worlds whereas those associations that have a six are classified as living in one political world. In between we find the classifications of interconnected (a score of 3-4) and distinctive (1-2) political worlds.

Overall, the results are not that dissimilar to what has already been noted. Whereas Koop found that approximately 56 percent of ridings fit into the first two categories (2011:183), Table 7.3 estimates that approximately two thirds of constituency associations can be included in the first two types. ${ }^{58}$ This difference, however, should not be surprising given that the application of this typology has been extended to include the New Democrats, a party that is considerably more integrated than the Liberals. Moreover, that this particular analysis is limited to Ontario may also account for the higher levels of integration in Table 7.3. Despite some variation, the results presented here are consistent with Koop's conclusion that a majority of local Liberal constituency associations engage in integrated behaviour and live in political worlds that are linked together rather than worlds that are isolated from each other.

Table 7.3: Multi-level Constituency Association Type by Party

\begin{tabular}{lcccc}
\hline Party & $\begin{array}{c}\text { One Political } \\
\text { World }\end{array}$ & $\begin{array}{c}\text { Interconnected } \\
\text { Political } \\
\text { Worlds }\end{array}$ & $\begin{array}{c}\text { Distinctive } \\
\text { Political } \\
\text { Worlds }\end{array}$ & $\begin{array}{c}\text { Two Political } \\
\text { Worlds }\end{array}$ \\
\hline Liberal & $10 \%(11)$ & $46 \%(52)$ & $30 \%(34)$ & $14 \%(16)$ \\
NDP & $44 \%(28)$ & $53 \%(34)$ & $3 \%(2)$ & $0 \%(0)$ \\
Conservative & $4 \%(4)$ & $53 \%(50)$ & $31 \%(30)$ & $12 \%(11)$ \\
Total & $16 \%(43)$ & $50 \%(136)$ & $24 \%(66)$ & $10 \%(27)$ \\
\hline
\end{tabular}

That only one-in-ten constituency associations live in what we can characterize as completely isolated political worlds demonstrates the strength of the linkages that

\footnotetext{
${ }^{58}$ While Koop classified 16 entire electoral districts (i.e., both associations in the constituency) the focus here is on individual constituency associations. Thus, the application of the typology is slightly different than the original. Despite this, the results are largely the same.
} 
exist at the local level in the province. Not surprisingly, none of the New Democratic constituency associations examined fit into this category. What some may find surprising, however, is the relative integration of the federal and provincial Conservatives. A majority (57\%) of Conservative associations live in political worlds that we can say are at least interconnected federally and provincially. Despite low levels of integration during the inter-election period, the Conservatives do not differ from the Liberals in terms of the distribution of constituency associations into the four types.

It is also interesting that two NDP constituency associations fall into the classification of distinctive political worlds. While this is a very small minority, it is interesting nonetheless. Despite all of the organizational linkages and requirements, there are some, albeit only a few, NDP associations that prefer to live in a distinctive political world that has very little contact with party politics at the other level. This highlights the importance of the individuals who are involved at the local level. Despite the prevalence of integrating party rules, local associations can eschew integration and still live in their own political world.

While membership is obligated to overlap, and while a physical space may be shared, local party associations, even in the NDP, are free to establish independent single level campaign teams, to keep resources and data at a single level, or to campaign only at a single level. Despite this freedom, the culture within the NDP, the ideological congruence across levels, combined with the organizational incentives that encourage integration tends to ensure that parties cooperate with one another in a variety of different ways both during and in between election campaigns. Beyond party, however, no clear pattern emerges to explain the pattern of results. 


\section{Conclusions}

As the series of chapters on the grassroots come to a conclusion, we can make a number of specific observations about party integration at the local level in Ontario. Four of these conclusions directly relate to the state of party integration at the grassroots in a more general sense and one concerns the differences between the Liberals, Conservatives, and New Democrats.

First, there is clear evidence to support the claim that integration is present at the local level. Far from inhabiting "two political worlds", constituency associations in Ontario (and those individuals who populate them) exhibit a number of integrating linkages with their multi-level counterparts. In fact, it is safe to say that integration may be stronger at the grassroots level than anywhere else. The stratarchical bargain that defines Canadian parties provides local riding associations with the freedom and autonomy to forge their own networks and connections. Parties at the constituency level have chosen to use this freedom to create meaningful local connections with their multilevel counterpart in the riding.

This is true for both the campaign and inter-election periods. The majority of riding associations in each of the main political parties in Ontario engage in cooperation and collaboration inside and outside of election campaigns. This ranges from simple tasks such as meeting socially or sharing party members to more labour intensive forms of integration such as providing election endorsements and arranging for campaign support throughout the campaign. This high level of cooperation is captured in Table 7.3, which demonstrates that fully two thirds of constituency associations in Ontario 
operate, or live in, an interconnected or unified political world. This is compared to the ten percent of associations that live in completely isolated political worlds. While more research and empirical data is needed for the remaining provinces, it is clear that parties practice integration at the local level in the province of Ontario.

Second, the same factors that are related to local campaign integration are also significant for integration during the inter-election period. The results of the logistic regressions presented in Chapters 5 and 6 reveal that constituency associations that engage in multiple forms of coordinated and cooperative behaviour are significantly more likely to belong to the New Democratic Party than any of its competitors. Additionally, the analysis demonstrates that incumbency (and to a lesser extent electoral strength) is significantly related to certain types of integrated behaviour (i.e., joint social events, multi-level influence in candidate selection, and campaign endorsements). In each case, being located in a district that won a seat in the previous election corresponds with greater levels of local integration. Surprisingly, the urban or rural location of the constituency is not significantly related to either campaign or inter-election grassroots integration nor is having a cabinet minister (or shadow cabinet minister) present in the riding.

Third, parties practice integration more in certain times than others. In particular, integration during the campaign period is more common than integration during the inter-election period. Whereas less than one-in-ten constituency associations did not engage in any of the three forms of campaign integration that were examined, this figure rises to two-in-ten for inter-election forms of integration. Although non-election integration is still relatively common, occurring in a large majority of associations, it 
does not occur as frequently as campaign integration. Despite this gap, the two are related. Parties that engage in multiple forms of multi-level inter-election activities are, for the most part, the same associations that participate in multiple forms of multi-level campaign activities. In this regard, the associations opting for integration are doing so in a number of aspects of party life during and between election campaigns.

Follow up interviews with a number of constituency association presidents offers a potential explanation for divergent levels of integration in the election and interelection periods. Perhaps most importantly, constituency associations and executives that engage in campaign integration can clearly identify the immediate benefits of working with their multi-level counterpart. While difficult to quantify, many of those associations that are integrated believe that sharing election information, receiving campaign endorsements, and building on each other's best practices can have a positive impact on their own election results (personal interviews). In other words, there is a view that integration helps parties win elections, or at very least increase their vote share. This is consistent with survey results, which demonstrate that local candidates and party presidents believe that their multi-level counterpart's campaign affects their own electoral chances (Cross et al., 2015; Chapter 3). The benefits of campaign cooperation and collaboration, whether real or only perceived, provide a meaningful incentive for local campaign integration.

Parties, however, do not witness the same immediate benefits from cooperating outside of election campaigns. While inter-election maintenance is certainly important for parties, carrying out these activities in a coordinated multi-level fashion does not obviously or inherently add to their success. Whether a party meets to discuss policy on 
its own or with its federal or provincial counterpart often makes little difference in the final outcome. In fact, the latter often involves more planning, more resources, is more time consuming, and so on. It is therefore easier for parties to engage in these types of activities on their own at a single level.

This, however, is not to say that there are no benefits for inter-election integration. Meeting socially, for example, can often yield future benefits. And indeed a number of executive presidents noted that meeting socially outside of the campaign period allowed the federal and provincial executives to create relationships and networks that would carry forward (especially in the next election; personal interviews). The interelection comradery was therefore expected to result in benefits during the campaign such as sharing resources and volunteers. Likewise, meeting socially in a multi-level manner in between elections allows parties to easily recruit new members who are likely to be sympathetic to the party's goals. Thus, while there are benefits to local interelection integration, these benefits are more clearly identified when they relate to tangible electoral outcomes. This, however, may be years away. Without immediate benefits, inter-election integration is less incentivized by the party. The delayed value of inter-election integration appears to be one of the primary reasons that integration at the local level is more prevalent during the campaign period.

Fourth, the relationship between federal and provincial parties at the grassroots level cannot be characterized as uneven or exploitative. While federal parties have often been accused of "resting" on their provincial machines (Stewart and Carty, 2006: 101), this is not the case when it comes to local party integration. In fact, federal parties are just as likely to provide support to their counterpart as provincial parties are. In this 
sense, both federal and provincial parties appear to understand the benefits of a cooperative and reciprocal relationship. Unlike other aspects of federal-provincial relations (e.g., career transitions), local cooperation at the constituency level is reciprocal. This is a positive sign and suggests that the current practice of local integration in Ontario is sustainable. Although provincial parties like the Ontario PCs suffered considerable brain drain, losing a number of cabinet ministers to the federal party, similarly uneven trends are not evident when considering a number of other aspects of integration such as the provision of campaign endorsements, the sharing of lists/party data, or the lending of personnel.

Finally, consistent with the findings that have been discussed in Chapters 3, 5, and 6, the New Democratic Party is by far the most integrated party. Whether it is through their personnel, their campaign cooperation, or their inter-election activities, federal and provincial New Democrats are consistently more integrated than the other parties in the province. Indeed, the multinomial and binary logistic regression results presented in previous chapters demonstrate that, of the variables examined, membership in the NDP tends to be the most influential. Being part of the New Democratic Party means that a constituency association is significantly more likely to be integrated than either the Liberal or Conservative constituency associations, even when controlling for a number of other explanatory variables.

To summarize the above, there are five broad observations about local integration that we can make:

1. Integration does occur at the grassroots level and a majority of constituency associations live in interconnected political worlds. 
2. Incumbency is related to differences in both campaign and inter-election integration after controlling for factors such as party while other factors such as the urban/rural location of the riding or the presence of a cabinet minister is not.

3. The same associations responsible for high levels of inter-election integration are largely responsible for campaign integration as well. However, campaign integration is more common than integration during the inter-election period.

4. Party integration at the local level does not occur in a unidirectional nature. In other words, it is reciprocated.

5. The New Democrats are consistently more integrated than their competitors across a wide range of indicators. At the same time, the Liberals and Conservatives demonstrate considerable similarities despite their organizational and ideological differences.

The next two chapters move away from the grassroots and examine the province wide aspects of vertical party integration in Ontario. Chapter 8 examines linkages that can be found at the nationwide (or province-wide) level during election campaigns. Focusing on recent elections, Chapter 8 details how federal and provincial parties coordinate campaign strategies and examines the linkages that can be found between campaign professionals. This is followed by Chapter 9, which provides a discussion of the role of voters in linking federal and provincial parties together. 


\section{CHAPTER 8: The Province-wide Campaign}

\section{Introduction}

Chapter 5 examined the potential for integrated election campaigns from the perspective of the party on the ground. Throughout that chapter the focus was on the electoral activities of constituency associations and those individuals who populate them (members, executives, presidents). This included an examination of endorsements for local candidates, multi-level involvement in candidate nomination procedures, the sharing of constituency-level data (including information about voters and activists), and overlapping local campaign workers and volunteers. In general, the data and story presented in Chapter 5 demonstrate a high degree of local campaign integration across a wide range of activities and indicators. While there are differences between the parties, it is clear that local campaign integration is a common feature of local constituency campaigns in the province of Ontario.

Although individual local campaigns are undoubtedly important, especially given the nature and logic of the single member plurality electoral system (Carty and Eagles, 2005; Coletto, 2010; Denver et al. 2003; Johnston and Pattie 2006), they are only one aspect of a much larger and more complex election campaign that is itself multi-leveled. In addition to the 107 smaller constituency level campaigns in Ontario (106 at the federal level) there is also a single state-wide component to election campaigns in Canada and the provinces. While the local campaign typically involves individual candidates, their campaign teams, and the supporting constituency executive, the broader campaign has a different set of actors (Cross, 2004). In particular, the 
province-wide (or nation-wide) campaign tends to revolve around central party figures such as party leaders and their campaign tours.

Focusing primarily on the federal and provincial elections of 2011 as well as the 2014 provincial election, this chapter moves beyond the grassroots and explores the more province-wide aspects of election campaigns as they relate to party integration. This includes looking for similarities in the professional services that the parties use, overlapping and joint campaign fundraising, multi-level endorsements and campaign support from party leaders and senior party officials, and commonality among central party campaign professionals. While additional details from the constituency level are included in this chapter (especially as they relate to money and fundraising), the local level is not the focus as it has been in previous chapters.

\section{Money and Party Fundraising}

Although Canadian parties have received generous state funding during recent elections, election campaigns are increasingly expensive endeavors. The transition from modern to post-modern campaigns and the level of professionalization this necessarily entails has made campaigns far more capital intensive (Norris, 2005). Political parties routinely spend millions of dollars throughout the course of the campaign, producing radio and television advertisements; purchasing broadcast time; creating campaign materials such as platforms, partisan mailings, and party pamphlets; traveling across the country (or province) to meet with potential voters; setting up campaign offices; paying for campaign professionals such as pollsters, stylists; and so on. 
According to documents filed with Elections Canada, for instance, the major federal parties spent an average of more than $\$ 19$ million during the 2011 campaign (Elections Canada, 2011). Likewise, only competing in a single province, the provincial parties in Ontario spent nearly $\$ 5$ million each during their 2011 campaigns (Elections Ontario, 2011). The large amounts of money that parties spend on elections provide us with another opportunity to look for integration.

Different rules in each jurisdiction make coordinated multi-level fundraising difficult for Canadian political parties. Most notably, campaign finance rules at the federal level prohibit donations from corporations and trade unions while such donations are acceptable at the provincial level. In this regard, provincial parties in Ontario have somewhat of an easier access to potential funding sources. Moreover, while donations are limited to $\$ 1,500$ federally (indexed for inflation), contributors can contribute up to $\$ 9,975$ provincially.

More problematic for integration, however, are rules at both levels that explicitly prohibit parties from transferring and sharing resources across levels. Ontario's Election Finances Act, for instance, states that "no political party, constituency association, candidate or leadership contestant registered under this Act shall accept funds from a federal political party registered under the Canada Elections Act..." (Election Finances Act, 1990). Thus, not only do state regulations prevent the outright sharing of resources, but also donation limits and eligibility requirements differ from one level to the next, making financial coordination difficult. Given that there is evidence of horizontal transfers between constituency associations at the same level (Burgess, 2015; Cross et 
al., 2015), if not for clear electoral financing legislation this might also be the case vertically as it has been in the past (Carty, 1988).

Despite these challenges and obstacles, numerous party officials reiterated that coordination on the ground does occur when it comes to fundraising efforts (personal interviews). In particular, at the provincial level where corporate or union donations are still allowed, federal parties are often given more room to solicit donations from individuals. Conversely, since there are strict limits at the federal level, the provincial party may often attempt to solicit fewer donations from individuals but instead focus on business and corporations. This allows each party to maximize their fundraising given the different restrictions in each jurisdiction. It also prevents parties of the same family from competing with one another for increasingly scarce resources and donations.

While this cooperative multi-level behaviour is not codified in any party statutes or constitutions, it is informal and implicit. One constituency association president, for example, described the informal fundraising relationship between the federal and provincial Liberals in the following manner:

Even when we have shared donors, the federal association always solicits a personal contribution by the individual whereas the provincial party will more often seek a contribution from that person's business and or an organization they are affiliated with (personal interview).

This kind of cooperation is not unusual for Canadian political parties and is echoed by officials from other parties as well. Similar strategies have been documented in Quebec, where the Bloc Québécois (BQ) and the Parti Québécois (PQ) often coordinate their fundraising efforts to ensure that each party is adequately financed. It is 
well known, for example, that in the past the Bloc would often forgo intense fundraising efforts because it could rely on a steady flow of funding from the generous per vote subsidy that was offered to federal political parties (Young et al. 2007: 346). As these subsidies become phased out, however, it is unclear how the Bloc, or any of the federal parties, will respond to the new realities of election financing. It will be interesting to see if these parties adopt strategies similar to that of Ontario - where federal parties target individuals - or if a more competitive multi-level fundraising environment will emerge.

While informal arrangements define this domain, many federal party insiders are unsatisfied with the loose nature of the arrangement and feel that the provincial parties sometimes "protect their resources" too forcefully (personal interviews). Indeed, there appears to be some jealousy here as the provincial parties have fewer restrictions. A number of federal NDP MPs expressed this as an area where the party could enhance cooperation and establish more explicit operating procedures. Although formalizing and codifying such an informal arrangement is unlikely, even within the NDP, more discussion around the topic of financial cooperation seems warranted.

Federal and provincial parties not only rely on the same individuals for campaign labour (see Chapters $3,5,6$ ), but Table 8.1 demonstrates that they also rely on the same individuals for capital and fundraising as well. A majority of constituency associations in each of the three parties report that their financial donors overlap considerably with their multi-level counterpart (the question asked was as follows: "In recent elections the provincial and federal party compete for campaign funding from the same donors"). This ranges from 70 percent of Liberal and Conservative associations to 84 percent of 
New Democrat constituency associations. What's more, on average, fewer than 10 percent of constituency associations report that they do not share a common donor base with their multi-level counterpart.

In fact, cooperation is such a norm that parties can sometimes take this relationship too far. Despite being very complicated to do in accordance with electoral financing legislation, 63 (or one-in-four) constituency associations reported holding joint fundraising events with their multi-level counterpart in the riding in the past year. While there are ways of fundraising together that comply with electoral financing legislation, they require close attention to detail.

Table 8.1: Federal-Provincial Competition for Funding by Party

\begin{tabular}{llll}
\hline & Agree & $\begin{array}{l}\text { Neither Agree } \\
\text { or Disagree }\end{array}$ & Disagree \\
\hline Liberal & $69 \%(78)$ & $25 \%(28)$ & $6 \%(7)$ \\
Conservative & $70 \%(66)$ & $18 \%(16)$ & $12 \%(12)$ \\
NDP & $84 \%(54)$ & $13 \%(8)$ & $3 \%(2)$ \\
Total & $73 \%(198)$ & $19 \%(52)$ & $8 \%(21)$ \\
\hline
\end{tabular}

"In recent elections the provincial and federal party compete for campaign funding from the same donors."

Given the amount of data that is shared between federal and provincial parties (see Chapter 5), it should not be surprising to find the same individuals donating to parties at both levels. By sharing data with one another, the federal Conservatives, for example, know who the provincial PC supporters in the riding are. Knowing this allows the federal party to quickly solicit donations from individuals who are more likely to be sympathetic to their direct mailings and phone calls. 


\section{Campaigning: Multi-level Support and Endorsements}

Consistent with Esselment (2010), a close following of recent election campaigns as well as interviews with campaign and party officials reveals considerable multi-level campaign involvement from all of the major political parties in Ontario. While the examples and evidence provided in this chapter draw upon the experiences of parties in the province of Ontario, there is evidence that coordinated multi-level campaign behaviour at the central party level occurs in a number of other provinces as well (Esselment, 2008; personal interviews).

Perhaps one of the most telling examples from the 2011 Ontario provincial election comes from federal Conservative Member of Parliament, and Prime Minister Stephen Harper's then parliamentary secretary, Dean Del Mastro. After being unsatisfied by the results of a local Peterborough telephone poll of 629 eligible voters, Del Mastro commissioned and paid for his own poll of 1,000 Peterborough voters (McMahon, 2011). The original poll suggested that the local provincial Liberal candidate enjoyed a 17 percent lead over the PC candidate in the riding. Del Mastro's poll, however, put support for the Liberals and Conservatives at 34 percent a piece.

Justifying his entrance into the provincial election, Del Mastro wrote on his website that the previous results "were not consistent with my sense of what was going on in the riding and not consistent with polls of larger sample size in depicting the provincial mood" (Ladurantaye, 2011). This, however, was not the first time during the provincial election that Del Mastro had become the spotlight. A number of weeks earlier the MP criticized the provincial Liberal platform as being "outrageous" (Taber, 2011a). 
After these events, the provincial Liberal campaign chair accused the federal Conservatives of interfering with provincial politics in order to help their provincial PC cousins: "It is another sign that Harper and the Conservatives are increasingly concerned about Hudak's disorganized campaign and are prepared to intervene" (Ladurantaye, 2011).

Even the Prime Minister provided his endorsements and support to fellow conservatives while at Toronto Mayor Rob Ford's home. At the event Harper openly mused that the PC's needed to "complete the hat trick" and form the government in Ontario (McHahon, 2011). The Prime Minister's full comment: “We've started cleaning up the left-wing mess federally in the area. Rob's doing it municipally and now we've got to complete the hat trick and do it provincially as well" (Galloway, 2011). Interestingly, the nature of the comment suggests that cooperation and support is less of a party issue and more of an ideological one. Indeed, Harper's remarks on the "left-wing mess" suggest that his endorsement is ideologically motivated.

Overall, a number of high profile Conservative cabinet ministers provided support for their provincial cousins, attending campaign rallies and providing supportive sentiments in the media during the 2011 election. This included the minister of Immigration, Labour, Justice, Finance, Foreign Affairs, and the Treasury board president (McHahon, 2011). While providing a glowing endorsement of PC leader Tim Hudak, for example, Minister Flaherty, borrowing a line from PC advertising, told a Toronto audience that Ontario "can't afford four more years of the same Dalton McGuinty government” (Ladurantaye, 2011). 
What is interesting about these campaign events is that they are not spontaneous endorsements with little planning or thought. Campaign documents leaked months prior to the 2014 provincial election in Ontario, for example, demonstrate that the provincial Tories had planned and confirmed to meet with federal cabinet minister Jim Flaherty on day six of the election campaign (Brennan, 2013). Likewise, the party had already arranged a number of other multi-level campaign opportunities (personal interview).

Given the fixed election dates in the province, members of the two parties were able to coordinate their strategies months in advance of the actual start of the campaign. In many cases, federal MPs played a more prominent role in the province-wide campaign than did local candidates who were actually seeking election. Hudak, for example, often opted to have federal cabinet ministers such as John Baird introduce him at campaign events rather than the local PC candidate from the riding where the event was taking place. Interviews with party officials suggest that multi-level preparation for the 2015 federal election is already underway as well.

It is important to note that this multi-level campaign cooperation among the Conservative parties is not a completely recent development. During the 2006 federal election, for example, the Ontario PC leader, John Tory, conducted a "mini tour" across the province endorsing the Harper Conservatives (Esselment, 2010). Tory went canvassing with federal candidates, attended local campaign announcements, and helped to secure significant media attention for the party. Harper responded with his own show of support for the Ontario PCs in 2007, introducing John Tory as the "next premier of Ontario" at a PC campaign rally (CBC, 2006). After the provincial Conservatives lost the 2007 election, Tory met with the federal party's Ontario caucus. The provincial PC 
leader also met with Ian Brodie (Harper's chief of staff) and Doug Finley (the federal campaign director) to share "best practices for winning elections" and to learn from the federal party's "strategic expertise" (Benzie, 2007).

This close relationship, however, has not always been the case. One long serving Progressive Conservative MPP noted that prior to the merger that resulted in the current federal Conservatives, the Ontario PCs were put in an awkward position with regards to multi-level campaigning. The MPP described the situation as akin to having "divorced parents". With two conservative options at the federal level, Ontario PC leader Mike Harris directed his caucus not to take part in the 1997 and 2000 federal elections since it would only serve to create further tension between conservatives in the province and create unneeded tension (personal interview). There was a real sense of uneasiness during this time and very deliberate attempts were made not to alienate any conservatives (at either level, regardless of party affiliation). Only after the merger did the Ontario PC party begin to openly campaign for its federal counterpart once again. A similar directive was made more recently regarding the Toronto mayoral election. Since the contest involved two prominent conservatives (including a former PC party leader), the provincial Progressive Conservative Party was advised not to take sides during the election (personal interview).

This suggests that multi-level party support is not automatic or inherent. We see similar, albeit different, tensions in other parties as well. The Liberals, for example, have often appeared to avoid overt multi-level campaigning to some extent. Interviews with provincial campaign officials in the Liberal Party confirm that multi-level campaigning has not been a central component of the Liberal Party strategy in the past. The provincial 
Liberal campaign team, for instance, did not attempt to coordinate an endorsement from the federal Liberals or their leader during the 2011 campaign (personal interview). In fact, the provincial campaign team was skeptical about benefit of multi-level endorsements, suggesting that there is no empirical polling evidence that these kinds of endorsements have any impact on the results of elections or the perceptions of voters.

As a result of this view, there has been little overt and public cooperation and coordination between the central campaigns of the federal and provincial Liberals during recent elections. During the 2011 federal election, for example, Ontario Liberal leader Dalton McGuinty made it publicly known that he would not be campaigning on behalf of the federal Liberal Party. Reminding the media that he had his own election only a few months later, McGuinty stressed the need to focus on his re-election. He did, however, campaign on behalf of one Liberal candidate in particular: his brother, David McGuinty. As McGuinty explained, "if I do any campaigning it will be with my brother, and undoubtedly he will ask..." (CBC, 2011a). ${ }^{59}$

Despite the distance between Liberal parties at the province-wide level, campaign officials recognize that coordination does take place between federal and provincial parties at the local level. Unlike their views of party leader endorsements, the provincial campaign team also acknowledged the benefits that coordination can have for the local level. While the central party apparatus targets a small number of ridings that will yield the greatest return, a party's multi-level counterpart is free to provide support to local candidates in ridings that are sometimes ignored. In this sense, integration can

\footnotetext{
${ }^{59}$ A similar situation occurred during the 2008 federal election when McGuinty made it clear that he had no intention of endorsing Stéphane Dion (Paikin, 2008).
} 
help "pick up the slack", providing exposure to certain ridings that would normally not receive any endorsements or attention (personal interview).

While there appears to be a disjuncture between integration at the local level and the national level within the Liberal Party, the New Democrats are much more consistent. The same level of integration appears to be present regardless of the level of analysis. Interviews with campaign officials, for instance, reveal that the majority of individuals who worked on the federal campaign also worked on the provincial campaign in 2011. This, of course, is consistent with the view of NDP election campaigns that is presented in Chapter 5 .

While the leaders bring their own entourage (Cross, 2004; Esselment, 2010; Noel, 2007), many of the other players tend to be the same regardless of the level. Similarly, while material resources are technically prohibited from being shared, campaign officials note that information, best practices, and data are routinely shared across the two party levels. This was particularly evident in 2011 due to the close proximity of the federal and provincial elections.

In addition to sharing resources and personnel, the NDP frequently provides endorsements and coordinates with one another during elections similar to the Conservatives. Mid way through the 2011 campaign, for example, Ontario NDP leader Andrea Horwath met with 21 of Ontario's federal NDP MPs in Toronto. The goal of the meeting, as Horwath told the media, was to "discuss the future of the province and their shared goals" (New Democratic Party, 2011). The fact that Horwath spent time on a meeting with federal MPs in the middle of a busy election campaign demonstrates the 
strength of the relationship between the two parties. Moreover, it highlights that Horwath believed that the connection was important and that it was likely to have a positive impact on the campaign. The federal NDP was at its peak in terms of popularity, and reminding voters of the federal party was a strategic and calculated decision. Beyond Horwath's meeting, high profile NDP MPs also provided their support throughout the provincial campaign.

In fact, cooperation is such the norm that it can sometimes create controversy. During the 2011 provincial election, for example, federal NDP MP Mike Sullivan used his parliamentary resources to mail a pamphlet to members of his constituency. Although these mailing are commonplace, this particular pamphlet included a photograph of the provincial NDP candidate in the riding, as well as a signed letter calling for the removal of the HST from essentials such as electricity and home heating, a key platform plank of the Ontario NDP (CBC, 2011b).

Nor was 2011 unique in the amount of multi-level campaigning that could be observed. Indeed, the recent 2014 provincial election in Ontario also witnessed each of three of the federal parties lending support to their provincial counterparts. One news story, for instance, wrote that the 2014 provincial election in Ontario was "starting to feel like a warm-up to the 2015 federal vote as more national politicians and their staff are becoming involved on the campaign trail" (CBC, 2014a).

It was only a few hours into the 2014 provincial election that a number of prominent federal Conservatives were already taking interviews, supporting their provincial cousins in Ontario. The Conservative prime minister, for example, described 
the provincial Liberal pension plan as nothing more than an "unnecessary tax hike" while Finance Minister Joe Oliver called the Liberal budget "the route to economic decline" (CBC, 2014b). The campaign support continued throughout the campaign with cabinet ministers such as John Baird and Tony Clement attending provincial PC events, introducing Tim Hudak at campaign rallies, endorsing local PC candidates, and attacking the Liberal platform and campaign in general.

The NDP continued its practice of multi-level campaigning as well. Members of Parliament such as Andrew Cash, Paul Dewar, and others were campaigning for their provincial counterparts in their local riding on a number of occasions. Central party figures were also involved. Federal NDP leader, Thomas Mulcair, "headlined" an Ontario NDP fundraising event (CBC, 2014c), drawing a significant crowd and heightened media attention for Horwath's campaign. Anne McGrath, the federal NDP's Executive Director, promoted the provincial NDP in a message to supporters in the middle of the 2014 provincial election. Drawing parallels between the federal and provincial NDP, McGrath wrote:

People are telling you that you have to accept Tim Hudak killing 100,000 front-line jobs or you have to support Kathleen Wynne wasting billions of dollars. In 2011, Jack Layton showed Canadians that they didn't have to choose the red door or the blue door. And today in Ontario, Andrea Horwath is doing the same: telling people they don't have to choose between bad math and bad ethics. This election, you can vote to improve healthcare, clean up government, create jobs, and make life more affordable. You can vote for Andrea Horwath - and get a Premier who will deliver change that you deserve (NDP, 2014).

The federal NDP continued to provide support for its provincial counterpart in Ontario even after the election was over. More than 500 federal NDP parliamentary 
staffers left the union that represents them "after it refused to unequivocally endorse the NDP" in the 2014 Ontario election and instead encouraged strategic voting (Bryden, 2014). While not an example of direct campaign support, it was an impressive show of multi-level solidarity nonetheless.

With new leaders at both levels, the Liberals appeared much more open to the notion of multi-level campaigning than they had been in previous elections. Prior to the election, Wynne enlisted the help of experienced federal Liberals to run her campaign team. Federal Liberal leader, Justin Trudeau, attended campaign events for two provincial by-elections in Niagara Falls and Thornhill in February of 2014 (Radia, 2014). Given his celebrity status, Trudeau's appearance at campaign events like these helps the provincial party draw a much larger crowd than they would be able to mobilize on their own.

Additionally, both Trudeau and former Liberal Prime Minister Paul Martin joined Wynne to promote her party's proposal for a provincial pension plan, a move that provided much needed credibility to the plan. Trudeau continued to provide his support to the provincial Liberals, attending campaign events and introducing Wynne at party rallies throughout the campaign. Moreover, the federal party leadership sent out specific directives encouraging members to cooperate with the provincial Liberals and to provide support wherever possible (personal interview). One Liberal MP described the new relationship between the federal and provincial Liberals as a "substantive embrace" both literally as Wynne and Trudeau have been engaging in photo opportunities where they hug and shake hands and figuratively as a result of their newfound cooperation and commitment to one another (personal interview). 
This new relationship appears to be extending to the upcoming 2015 federal election. Recent accounts of the federal Liberal campaign preparation have been littered with headlines such as "Trudeau turns to provincial Liberals for help" describing how the federal and provincial Liberals are planning to work more closely in the upcoming election. After witnessing the high levels of federal Conservative influence in the 2014 provincial election in Ontario, the president of the Liberal Party of Canada (Ontario), Tyler Banham, vowed to unite the federal and provincial Liberal parties in "One Big Red Machine" (Werner, 2014).

Given how close Trudeau worked with the provincial campaign (attending rallies and by-elections), it would not be surprising to see the provincial party return the favour and provide its own endorsement and support during the federal campaign. In fact, central party personnel at the federal level have a clear expectation that this will be reciprocated. Wynne is expected to be on the campaign trail in 2015 for the federal Liberals and to deliver staff and cabinet ministers to help local Liberals raise both money and awareness (personal interview).

It is worth noting that parties can help their multi-level counterpart in other ways. Indeed, multi-level party support does not always have to be a direct endorsement or attendance at a local rally/event. There is evidence that MPs and MPPs frequently use their status and position inside the legislature to promote their multi-level cousins (see, for example, Waters, 2009). Answering a question in the Ontario Legislature, for example, provincial Liberal cabinet minister Marie Bountrogianni used the opportunity to attack the federal Conservatives while simultaneously providing an endorsement of the federal Liberals: 
Mr. Harper's Conservatives seem as ideologically bent as the Harris-Eves Conservatives... In contrast to the federal Conservatives, Mr. Martin's Liberals get it. They know that childcare is important and I applaud their new child care initiative, and I look forward to working with the municipalities in spending the monies... (quoted in Waters, 2009:7).

We can also find examples of similarly partisan multi-level rhetoric from the other parties. Taking advantage of the weak Liberal brand at the federal level (primarily as a result of Dion's low approval rating), Ontario Progressive Conservative MPP, John O'Toole, used his position in the legislature to promote the federal Conservatives while launching an attack on the entire Liberal brand, characterizing both the federal and provincial parties as tax-and-spend Liberals:

Who would you sooner have their hand on the tiller? Stéphane Dion, who's going to increase taxes, or Stephen Harper, who's going to steady as she goes? That's what the question should be about, and Mr. Harper should have a strong minority government and have to work co-operatively in these troubled times. I would be satisfied with that outcome, but to swing right over and bring in another taxing-and-spending Liberal-I don't think so (quoted in Waters, 2009:13).

There are, of course, limitations to how much multi-level participation is permitted in general elections. While this is not codified anywhere, political norms dictate that parties must find a delicate balance between supporting their multi-level counterpart while still being professional. This is especially relevant for those parties that find themselves in government. Federal governments of all political stripes must continue to work with provincial governments after the election, regardless of which party is ultimately elected. 
Overt partisanship and interference in provincial or federal election campaigns can therefore have negative implications and adversely impact the working of intergovernmental relations (IGR) after the campaign has been completed. This practical concern can act as a significant barrier to multi-level campaign cooperation in Canada. Liberal MPs, for example, noted that cooperation between the federal and provincial Liberal parties seemed to be at its lowest when both parties were in government during the early 2000s (personal interviews). The competitive relationship that defines Canadian federalism can make this a very uneasy relationship at times, especially when federal transfers and money is involved. ${ }^{60}$

Surveys and interviews with federal and provincial Liberals in the 1970s reveal a similar tension in Quebec. According to Rayside, "being in power accentuates the sense of responsibility felt by parties holding provincial power to represent provincial interests, and it accentuates the personal gain in prestige that comes of success in presenting regional concerns and in increasing provincial autonomy" (1978: 527). The need to act as regional representatives can create conflict between those parties operating in Ottawa and those in the provinces - even when the parties share the same label. Although discussed at greater length in Chapter 9, Danny William's "Anything But Conservative" (ABC) campaign against the federal Conservatives in 2008 is perhaps the most visible example of this kind of multi-level tension within the same party family in recent memory.

\footnotetext{
${ }^{60}$ While a similar partisan affiliation can often help intergovernmental relations (Esselment, 2013), the competitive nature of federal and provincial governments can create complications for the practice of integration and create an otherwise uneasy relationship.
} 
In 2011 there were a number of provincial campaigns underway. This included general elections in Prince Edward Island, Manitoba, Ontario, Newfoundland and Labrador, Saskatchewan and the Northwest Territories and a leadership primary in Alberta. The almost unprecedented extent of provincial electoral activity prompted the Prime Minister's office to send out a two and a half page letter to federal Conservative Members of Parliament warning them to "not become the story" in any provincial campaign. The memo went on to tell Conservative MPs not to do anything that would impair the party's "ability to maintain appropriate federal-provincial relations" with the eventual winner (McMahon, 2011).

Despite this warning, the memo did not prohibit providing endorsements or campaigning for provincial Conservatives. In fact, the memo encouraged this kind of cooperation so long as it was done in a manner that complied with the two ground rules noted above. For example, the introduction to the memo noted the following: "In provinces where there is only one 'conservative' option, we may all make efforts as individuals on private time to assist the election of that option - provided that we comply with this policy." Additionally, the memo ended: "A degree of support for provincial and territorial conservative counterparts is expected and will be accepted by their opponents and the public" (Taber and Curry, 2011).

This insight into the multi-level dynamics of Canadian elections demonstrates a number of points worth discussing further. First, it highlights the importance of ideological consistency. In this example it does not matter that federal and provincial Conservative parties are organizationally truncated and distinct from one another. Despite this separation, it is automatically assumed that if the Federal Conservative 
Party will support anyone, it will be a provincial conservative party. Related to this, it reveals the challenges that organizationally truncated parties face when engaging in cross jurisdictional campaigning. As the memo states, in provinces where there is only "one conservative option", the party can and should offer its support. When there is more than one conservative option, however, the decision to become involved is less obvious. While this does not apply in Ontario, it has clear implications for other provinces such as Alberta (where both the Wildrose and Progressive Conservatives compete provincially).

When there is more than one conservative option at the provincial level, the federal Conservatives have deliberately tried to remain neutral. During a recent Conservative Party convention in Calgary, for example, the federal party made very obvious attempts not to show more support to one conservative provincial party over the other. As a result, when PC leader Alison Redford was scheduled to address the convention, the party arranged to give Wildrose leader Danielle Smith her own "turn" the next evening (personal interview). The presence of two conservative options at the provincial level in Alberta mirrors the issues that provincial parties faced during the 1990s and early 2000s when there were two federal conservative parties. Given that conservative cooperation is ideologically, and not organizationally motivated, multiple conservative options can actually limit cooperation in some instances, as there is no clear "partner" to choose.

Second, the issuing of this memo demonstrates that parties think about multilevel politics and campaign integration. The simple fact that a two and a half page memo was crafted and distributed confirms that parties take these issues seriously. Finally, it 
also reveals that parties, especially those in government, seek to find a balance in regards to multi-level campaign integration. The need to work with other parties after the election results are tallied necessitates that parties in government not go too far when endorsing their multi-level counterpart. Despite the warning, the federal Conservatives did often become the story during the 2011 provincial election in Ontario as illustrated above.

While there are limits, and even sometimes risks associated with multi-level campaigning, there are clear benefits as well. As noted in Chapter 5, sitting members of the legislature often use provincial or federal elections as a testing ground for their own elections. New Democrat MP, Paul Dewar, for instance, went door-to-door campaigning with Ottawa Centre NDP candidate Jennifer Mckenzie during the 2014 provincial election. While Dewar certainly wanted to see his fellow NDP colleague elected, he also wanted to get a sense of the mood in the riding and which tactics might work best. Acknowledging the political benefits associated with helping his provincial counterpart, Dewar stated: "We are trying to look towards 2015 and what kind of issues are resonating with people, what kind of arguments work, because sometimes it translates federally" (CBC, 2014a).

\section{Campaign Professionals}

Recall that Chapter 3 provided an assessment of common and shared personnel in federal and provincial parties. Beyond candidates, members, activists, and elected officials, important human resources to be shared between federal and provincial parties are the paid party professionals who work on campaigns. These "wartime generals" 
(Cross, 2004: 122) include pollsters, campaign managers, strategists, and communications specialists. When turning our attention to these and similar individuals, we find that in all three parties, key party professionals migrate from one level to the other during elections. Although in no way exhaustive, some recent examples will provide further insight into this dynamic.

Considering the Liberals, Robert Silver was a senior policy advisor to Ontario Liberal Premier Dalton McGuinty from 2003 to 2005. After leaving this position, Silver acted as Gerard Kennedy's National Policy Director during the 2006 federal Liberal Leadership Campaign. What's more, Kennedy was a sitting Liberal MLA in Ontario when he sought the federal party's leadership. After his defeat, Kennedy went on to be an advisor to federal Liberal leader Stéphane Dion and was appointed to the federal Liberal shadow cabinet. More recently, Warren Kinsella, a long time Liberal advisor during the Chrétien era, was recruited by Dalton McGuinty to serve in the provincial war room during the provincial election. Paul Martin's chief of staff, Tim Murphy, is a former president of the provincial Liberals, and recently served on the 2014 provincial Liberal campaign team.

Likewise, Michael Marzolini, chairman and founder of Pollara, served as the chief pollster and strategist to Prime Ministers Chrétien and Martin for over 12 years. In addition to his commitment to federal Liberals, Marzolini has provided data and strategies to Liberal candidates in Ontario for the past twenty years. Finally, prominent provincial Liberal Don Guy began his career working for federal Liberal pollster Michael Marzolini at Pollara in the 1990s, including the Jean Chrétien win in 1993. Guy 
has since served as Premier Dalton McGuinty's chief of staff and campaign director for the past three elections (Diebel, 2011).

Wynne's closer relationship with the federal Liberals did not end with campaign support. When creating her campaign team she turned to established and experienced party officials at the federal level. David Herle (a former adviser to prime minister Paul Martin) and Tim Murphy (Martin's former chief of staff) were both recruited to serve as managing campaign co-chairs for the 2014 provincial election. Likewise, Pat Sorbara, who previously worked on federal Liberal leader Michael Ignatieff's 2011 campaign, was appointed as campaign director (Benzie, 2013). Surrounding herself with experienced federal party professionals, it is not surprising that Wynne was able to attract considerable campaign support from high profile federal Liberals such as current party leader Justin Trudeau and former Prime Minister Paul Martin.

It is also worth highlighting the fact that the linkages among central party professionals extend beyond general election campaigns. Take, for example, Justin Trudeau's leadership bid for the federal Liberal Party. In the lead up to the leadership election Trudeau began cultivating a team of experts, many of whom had experience with the provincial Liberals in Ontario. One report described Trudeau's inner circle as drawing "heavily from Queen's Park" (Delacourt, 2012). Gerald Butts, for instance, served as the principal secretary to Dalton McGuinty before joining Trudeau's leadership campaign. Likewise, Katie Telford, Trudeau's campaign co-chair, also has connections to the provincial Liberals as she served as the chief of staff to the minister 
of education in the Liberal government. Both of these long time Liberals are now embedded within the federal party's central campaign team. ${ }^{61}$

Similar connections can also be found between the federal Conservatives and the PCs in Ontario. In both the 2006 and 2008 federal election campaigns, Mark Spiro led the Conservative Party War Room, specializing in Target Seat Management. Here Spiro was in charge of assessing the electoral fortunes of each riding and creating a strategy to target potential swing seats that the Conservatives could win. In this role, Spiro and his team would have had contact with counterparts at the provincial level wherever targeted seats were identified. More recently, Spiro transitioned from federal to provincial politics and served as the campaign manager for the winning candidate in the Ontario Progressive Conservative Party leadership contest, Tim Hudak. He subsequently acted as Hudak's Campaign Manager for the 2011 provincial election.

Another example of a multi-level Conservative Party professional is Leslie Noble. Noble has served as a strategic advisor on a considerable number of election campaigns as well as leadership campaigns, both federally and provincially including her role as campaign manager for Mike Harris in 1995 and 1999. More recently, Noble has worked as a consultant for the federal Conservatives during their time in office.

Guy Giorno, Harper's former Chief of Staff also served as Chief of Staff to Ontario Premier Mike Harris. Giorno remained close to his provincial roots while acting as the federal Conservative campaign chair during the 2011 election. During this time he

\footnotetext{
${ }^{61}$ This, of course, just begins to touch upon the campaign personnel with multi-level linkages. Ignatieff's entourage contained Brian Bohunicky, Mario Laguë, and Jim Pimblett, all of who had extensive provincial experience (Steele, 2009).
} 
met with his Ontario counterparts to share his experience and knowledge from the last three federal campaigns (Taber, 2011b). Moreover, it is easy to see Giorno's influence at the provincial level. Adopting the language that was used in the federal campaigns against Liberal leaders such as Stéphane Dion, the major tagline of the PC campaign was "Ontario can't afford four more years of Dalton McGuinty."

Other key Conservative professionals like Tom Long have an extensive history with federal and provincial politics. At the provincial level, Long served as the president of the Progressive Conservative Party of Ontario, campaign co-chair of Mike Harris's 1995 and 1999 campaigns, and Tim Hudak’s 2014 campaign advisor. Federally, Long worked for Prime Minister Brian Mulroney, co-chaired the founding convention of the Canadian Alliance, and sought the leadership of the Alliance.

Finally, it is no surprise to see party professionals in the NDP working federally and provincially given that the party's integrated organizational structure incentivizes coordination and cooperation. Michael Balagus is currently acting as the chief of staff to provincial NDP leader, Andrea Horwath (Brennan, 2014). However, once the federal election is called, he will be tasked with running the federal NDPs Ontario campaign. A long serving advisor, he has a long history with the NDP in other provinces as well. In particular, he spent many years as chief of staff to Manitoba NDP Premier Greg Selinger and to former premier Gary Doer.

Scott Piatkowski, Vice-President of the Ontario New Democratic Party, served on the NDP's Candidate Search Committee for the 2006, 2008, and 2011 federal elections as well as the 2007 provincial election. Likewise, Brian Topp has also worked 
at both levels, including his time as campaign director for the federal NDP in 2006 and 2008. Other individuals like Gerald Caplan, have a long history of working with the party at both levels. Caplan, who served as NDP federal secretary and national campaign manager, also served as advisor and senior strategist to both Donald MacDonald and Stephen Lewis in Ontario.

The federal NDP's primary concern in the lead up to the 2011 election was its ability to secure candidates for each of the country's 308 ridings. After the surprising 2011 election results, however, the party has a new concern: finding campaign professionals to run these individual campaigns to ensure that the 2011 gains are not lost (personal interview). As one NDP MP explained, the party has "trees without roots" in many ridings where the party won a seat in the previous election. As a result of these gains, the federal party is seeking help from its provincial counterparts in regions where it now has an incumbent to ensure that they have access to properly trained and experienced individuals to run the campaigns for the upcoming 2015 election (personal interview). It is expected that many of the local campaign managers in the 2015 election will therefore be borrowed from the provincial parties.

Furthermore, there may be a horizontal dimension to party integration. Close attention to party professionals in recent election campaigns suggests that provincial parties of the same name lend support to one another as well. During the 2013 British Columbia provincial election, for example, a number of Ontario Liberal Party strategists such as Don Guy and Laura Miller migrated west and helped to run the BC Liberal campaign office and leaders tour (Bailey and Howlett, 2014). The recent 2015 provincial NDP victory in Alberta is another telling example. As one news story suggested, the 
NDP "borrowed a chunk of brain power from outside the province" (Clark, 2015). Provincial BC strategist Gerry Scott, and federal campaign organizers Brian Topp and Anne McGrath were among the numerous the federal and provincial outsiders who were brought in to help run the provincial campaign. The Progressive Conservatives in Ontario have sent campaign workers and shared their election expertise and tactics with their counterparts in New Brunswick and Manitoba on a number of occasions in recent years (personal interview). The extent of such cross-provincial collaboration and cooperation, however, is completely unknown and any evidence we have is largely anecdotal and impressionistic.

While the exact extent may be difficult to quantify, it should be very clear that there is a considerable degree of commonality between the party professionals who run provincial and federal election campaigns within the same party. These individuals move seamlessly between the federal and provincial parties, working on elections at either level. Moreover, like other types of party personnel, these party professionals do so in a consistent manner that does not cross partisan lines. My research has not uncovered a single case of a high level and prominent party professional switching parties when working on campaigns at the federal and provincial levels ${ }^{62}$.

In fact, in Flanagan's account of his time with the Canadian Alliance, he notes that it was especially difficult to find an advertising agency because those firms "with interest and experience were already aligned with the Liberals or Progressive Conservatives" (2007: 88). Movement between parties is not seen as an acceptable practice when it comes to campaign professionals as these individuals put considerable

${ }^{62}$ The exception is in parties like the BC Liberals. 
efforts to establish and maintain trust within the party. Once aligned with a party, movement to another party - even if it is at another level - is therefore uncommon.

While cross-party migration of party professionals has undoubtedly occurred, it is very rare. As Koop (2011) notes, split-level party volunteers at the constituency level are often viewed with suspicion and can sometimes be left out of the loop. One activist, for example, described the notion of split-level volunteers as follows: "to me, that's like having a spy in your midst" (Koop, 2011: 76). Another noted that split-level volunteers are welcome, however they are not put in positions "where they'll carry secrets" (Koop, 2011:76).

Conversations with MPs reveal similar feelings. Many noted that they would be skeptical of any staffer or campaign organizer who had a history with another party and even if they were brought on board, "they wouldn't be put on the first tier" (personal interview). Central party professionals, like their amateur and volunteer counterparts at the local level, therefore benefit from a consistent party affiliation across the multiple levels as this allows them to move up the ranks without concern that they may one day defect.

\section{Professional Services and Networks}

Chapter 5 noted that federal and provincial parties often share riding-level data with one another during election campaigns. It is worth considering whether the parties are using the same tools and software to gather this data or whether these tools remain largely distinct. Likewise, do federal and provincial parties typically hire the same public relations or polling firms? The following section explores the extent to which 
federal and provincial parties rely on the same professional services. While information is somewhat limited, as parties often keep their internal contracts hidden, in the following section these relationships are examined further.

Table 8.2 shows the percentage of constituency associations that use the same professional services (such as accountants) as their multi-level counterpart in the riding. While not overwhelming, more than one-in-five Conservative associations use the same professional services as its multi-level counterpart. This figure rises to two-in-three constituency associations when considering the New Democrats. Like previous aspects of integration, however, this should not be surprising. Given that federal and provincial associations are often physically housed together, it makes sense for efficiency purposes that the same professional services be utilized at each level. What is somewhat surprising is the low level of commonality between the services used by Liberal parties. Nearly nine-in-ten Liberal associations use services that are distinct from what are used by their multi-level counterpart.

Table 8.2: Shared Professional Services by Party

\begin{tabular}{llll}
\hline & $\begin{array}{l}\text { Association shares } \\
\text { professional services with } \\
\text { multi-level counterpart }\end{array}$ & $\begin{array}{l}\text { Association does not share } \\
\text { professional services with } \\
\text { multi-level counterpart }\end{array}$ & Total \\
\hline Liberal & $13 \%(14)$ & $87 \%(99)$ & 113 \\
Conservative & $21 \%(20)$ & $79 \%(75)$ & 95 \\
NDP & $67 \%(43)$ & $33 \%(21)$ & 64 \\
Total & $28 \%(77)$ & $72 \%(195)$ & 272 \\
\hline
\end{tabular}

"Does Your Local Association and the Federal Association in the Same Riding use the Same Professional Services?"

Commonality in the professional services used by the central party campaigns is far more common than what we find at the constituency level. The Federal 
Conservatives, for example, have used Responsive Marketing Group (RMG) for fundraising and get-out-the-vote purposes for a number of years. RMG has also provided similar services for a number of provincial Conservative parties including the Ontario PCs (McGregor, 2013). Election documents show that 94 federal Conservative candidates hired RMG during the 2011 provincial election and that the Ontario Progressive Conservatives have spent more than \$2 million in recent elections to hire RMG for mobilization efforts (Leslie, 2012).

Chapter 5 discussed the use of party databases such as CIMS. In many cases both federal and provincial Conservative parties use the same software during election campaigns (Galloway, 2010). ${ }^{63}$ Flanagan, for instance, recounts that:

Our relationship with RMG linked nicely with our development of CIMS. RMG was already familiar with a CIMS-style system because of the work they had done with the Ontario PCs, and CIMS provided a receptacle for the hundreds of thousands of records generated by RMG's large-scale calling programs (Flanagan, 2007: 86).

While RMG may be the most cited example of shared professional linkages between the Ontario PCs and their federal counterparts, there are numerous others. Both parties hired RackNine, an Alberta voter contact firm, for their 2011 election campaigns to compliment the work being done by RMG. Interestingly, RackNine has also been contracted by conservative parties in other provinces (Maher, 2013), evidence that professional linkages between parties is not simply limited to the province of Ontario.

\footnotetext{
${ }^{63}$ CIMS has its roots at the provincial level and was based on the Trackright system created by the Ontario PCs.
} 
Both federal and provincial Conservatives also receive services from Campaign Research, a polling and strategy firm. In 2011 alone the company worked on 39 local federal Conservative campaigns, receiving more than $\$ 390,000$ (CBC, 2012b). The company happens to be co-owned by Ontario PC party president, Richard Ciano (Rider, 2014). Furthermore, Ciano is the former National Vice President and National Councilor of the Conservative Party of Canada. The overlapping web of professional networks and organizations between federal and provincial Conservatives clearly has a human element to it as well.

The Conservatives have also collaborated with their provincial counterparts on the development of the Conservative Campaign University. While this was initially designed as a training program for federal candidates and party officials, "the curriculum was developed and prepared by party professionals in the Ontario PC party" (Esselment, 2010: 882). Using video conferencing technology, the "University" is able to connect Conservatives at both levels all across the country in real time. This and similar training exercises have been tremendously useful for the parties, especially those that find themselves with limited resources or have recently suffered an electoral setback. Being able to draw upon the expertise and experience of the federal party, a party that has won the last three consecutive elections, is a tremendous resource for provincial conservative parties. In fact, during the lead up to most provincial elections, the regional federal Conservative campaign manager is sent to help train staff and share campaign experience (personal interview).

The Manning Centre for Democracy offers additional training for federal and provincial conservatives (candidates, legislators, and other staff as well). In 2014, for 
example, the Centre held its sixth annual Manning Networking Conference in which conservatives from all over the country - both federally and provincially - attended. The 2014 conference brought together high profile provincial politicians such as Tim Hudak and Danielle Smith with federal politicians such as Jason Kenny, Jim Prentice, and James Moore. The networking conference has been referred to as being "like Woodstock for Canadian conservatives" (Manning Centre, 2014). This provides an institutionalized (although non-party based) opportunity for routine communication between key personnel at both levels.

Finally, another structural connection can be found in the "liaison" between the federal and provincial Conservative parties in Ontario. Dr. Kellie Leitch, the 2006 Ontario Federal Conservative Campaign Chair, also served as the federal-provincial liaison between the two caucuses. According to Esselment (2010: 882), "Dr. Leitch visited the Ontario PC caucus to update them on federal campaign preparedness and how provincial members could be of assistance" once per month. Not only did Leitch request help in identifying possible federal candidates, but she also helped broker an informal agreement not to poach candidates from each other (see Chapter 5).

Although not as extensive, similar professional linkages can also be found within the federal and provincial Liberal parties in terms of advertising, party software, and voter identification. During the 2014 provincial election campaign, for instance, the Ontario Liberal Party converted and began using the federal Liberalist database. According to the Liberal campaign director, this technological change allowed the party to more effectively target potential Liberal voters in key swing ridings (Morrow, 2014). While the federal and provincial parties had shared this software in the past, the 
provincial Liberals in Ontario migrated away from utilizing Liberalist in previous elections only to switch back in the lead up to the 2014 election.

By using this software the provincial Liberals not only benefit from the federal infrastructure, but also the federal party benefits from the data collection activities that the provincial party necessarily conducted in the course of the campaign. As outlined in Chapter 4, pooling this data from both federal and provincial elections is tremendously valuable for the federal and provincial parties running modern, professionalized, and targeted election campaigns. Federal Liberal Party insiders were very pleased to see the provincial party once again using the Liberalist software as the Conservatives have been ahead of the other parties in voter surveillance and targeting (personal interviews).

Federal and provincial Liberal parties in Ontario have also used the company for marketing and voter identification purposes (Esselment, 2010: 886). While the federal Liberals often utilize Red Leaf Communications, during the 2008 election the party hired the Element Agency for some advertising purposes, a firm that lists provincial Liberal parties as previous clients (Marketing, 2008).

The federal and provincial New Democrats have often relied on the same advertising firms to develop and produce television advertisements. The party used marketing firm Now Communications during the 2004 and 2006 federal elections based on previous work that the firm had done in provincial campaigns including Ontario (Marketing, 2008). More recently the federal party has switched to Zig marketing, although it is unclear whether the provincial parties will follow. 
At the local level, the interconnected structure of NDP constituency associations results in high levels of shared professional services such as accountants. The fact that the local associations are often physically housed together and are directed by the same riding president incentivizes the use of the same professionals and services for both branches of the party. It is therefore unsurprising that two-in-three NDP associations report using the same professional services as their multi-level counterpart (more than three times the percentage of the next leading party - see Table $8.2)$.

Similar to how the Conservatives use the Manning Centre, both the provincial and federal New Democrats rely on the Broadbent Institute as an activist think tank to conduct research for the party and to train party volunteers for upcoming elections (Radwanski, 2015b). While the Institute is not officially connected to the NDP, its close ties to the party make it a de facto party resource. Partnering with the Broadbent Institute, for example, the NDP has recently begun sending "potential campaign staff" on training placements with 270 Strategies, a company staffed by many individuals who worked on previous Obama campaigns (McGregor, 2014).

Unlike the Manning Centre, however, the Broadbent Institute does not have a 'networking' conference. Thus, while the Institute can train young activists for both levels of the party, it does not provide an opportunity for existing party elites at both levels to meet with one another, create new contacts, and to socialize. This, of course, is less consequential for the organizationally integrated NDP as the party has a number of other venues for this kind of networking. Chapter 5, for example, noted the high levels of multi-level social events that the NDP coordinates. The organizationally 
connected nature of the party means that the party does not need external programs and opportunities for networking since this linkage and communication occurs naturally within the party.

\section{Conclusions}

One of the most important findings of this chapter is that multi-level campaign integration is not confined to the party on the ground (i.e., local constituency associations). Consistent with Esselment (2010) this chapter has demonstrated that parties and party officials in central office engage in integration during election campaigns as well. Whether it is through common fundraising, shared party professionals, campaign support and endorsements, or joint professional services, federal and provincial political parties in Ontario have a lot in common during campaigns and routinely collaborate with one another during the course of the election.

The evidence suggests that while integration is to be expected during campaigns, the level of cooperation can vary across parties and can sometimes depend on the individuals who are involved at each level. ${ }^{64}$ During McGuinty's tenure as provincial Liberal Party leader, the level of integration between the federal and provincial Liberal Party was somewhat suppressed. Campaign officials in the provincial party did not view federal endorsements as overly beneficial and instead focused on their own campaign, somewhat in isolation of their federal counterparts. While this view did not prevent local associations from engaging in multi-level cooperation, there was a distinct absence

\footnotetext{
${ }^{64}$ While difficult to quantify, personality appears to have the ability to trump almost everything else. It can trump interconnected organizational structures, shared ideology, and electoral gains. Two individuals who cannot work together can bring multi-level cooperation and strategic coordination to a halt.
} 
during the province wide campaign. One news report, for example, described the 1999 provincial Liberal campaign as having a "notable absence of high-profile federal Liberals" (Coutts, 1999).

Despite the lack of public support, McGuinty has said that his campaign benefited from the federal Liberals' local infrastructure during the 1999 election. Once the federal and provincial riding boundaries became synchronized, the provincial party began using federal party phone lists and sign locations. This further demonstrates the disconnect between the central and local aspects of multi-level campaigning within the Liberal Party: cooperation at the grassroots tends to be the norm while it is far less certain at the centre. The provincial Liberals were happy to use federal Liberal data and resources at the local level but not seek endorsements or campaign cooperation at the more province-wide level.

As Wynne took over the provincial Liberal Party, however, a dramatic sea change was evident. Wynne hired experienced federal party personnel to run her 2014 campaign, secured endorsements from former Liberal prime ministers, and teamed up with federal Liberal leader Justin Trudeau on the campaign trail. In fact, the Liberals not only worked together during the general election but also coordinated with one another for the by-elections in the months prior. This approach was in stark contrast to previous elections and was largely the result of the individuals involved. Federally, Trudeau has been working to create a more collaborative atmosphere where federal-provincial relations are encouraged. 
More than just the different personalities involved, this change in Liberal multilevel coordination might also be the result of a contagion effect, or very least a response to the other parties. Party officials at multiple levels inside the Liberal Party each noted the success that the Conservatives have been having with their coordinated campaign efforts and how the Liberals needed to respond. One Liberal MP, for example, noted that "Liberals have been forced to huddle together" as a result of the aggressive approach the Conservatives have been taking to multi-level politics (personal interview).

Moreover, this sense of unity appears to be growing. After the federal Conservatives began campaigning against Wynne as soon as the 2014 provincial campaign began, a greater sense of unity was solidified among Liberals regardless of jurisdiction. In fact, many provincial Liberals were upset by this federal 'intrusion' and have promised their support in the next federal election in order to combat the Conservatives.

The province wide campaign differs from local integration in other ways as well. When considering campaign integration, the Conservatives appear to be the most integrated and cooperative of the three parties. Despite the lack of any formal organizational ties, the federal Conservatives provided a considerable amount of support to the provincial PCs during the 2011 and 2014 elections. The federal Conservatives even let the Ontario PCs borrow a campaign bus during the 2011 election. Even when compared to the organizationally integrated and unified NDP, the Conservatives seem to be more united when it comes to election campaigning. The Conservatives have set up networking conferences so that federal and provincial politicians can meet and socialize, they have established joint training programs for candidates and elected officials, they 
rely on the same software for voter identification and tracking, they employ the same marketing and get-out-the-vote firms, and high profile cabinet ministers routinely provide their support and endorsements for their counterparts during the campaign.

As detailed in Chapter 3, a number of high profile federal Conservative minsters also sat in caucus in the provincial legislature. During this time Jim Flaherty, John Baird, and Tony Clement were colleagues of Ontario PC leader Time Hudak. This, of course, only begins to scratch the surface of the human connections between the federal and provincial realms: the 2011 provincial Conservative candidate in Glengarry Prescott Russell, Marilissa Gosselin, is married to the federal party's communications director, Fred DeLorey (Radia, 2011). Likewise, recently deceased federal Conservative Minister Jim Flaherty was married to provincial Progressive Conservative MPP Christine Elliot. The late Senator Doug Finley, who was responsible for the federal Conservative campaigns of 2006 and 2008, mentored Tim Hudak's campaign Manager, Mark Spiro. The human linkages and networks between the two parties go on and on. Given their close personal relationships, it should come as no surprise that the federal and provincial Conservative parties have campaigned for each other during recent elections.

While these kinds of connections and relationships are undoubtedly present in all of the parties, the Conservatives have been able to transform these relationships into productive elements of campaigning. In the absence of organizational incentives to integration, the Conservatives appear to rely on a system of personal networks and social capital that encourages and facilitates coordination and cooperation across levels during election campaigns. The memo issued by the federal Conservatives is telling in this regard ("we may all make efforts as individuals on private time to assist"). It is not the 
Conservative Party that is offering its support to the PCs in Ontario but individual (albeit high profile) members. As an organization and party, the Conservatives have little to offer the PCs in Ontario. As a network of active and influential individuals, however, the federal Conservatives offer a tremendous amount of support for their provincial cousins. 


\section{CHAPTER 9: Integration in the Electorate: Common Voters and Shared Partisanship}

\section{Introduction}

The previous chapters have explored how a wide range of individuals, and institutions or groups typically respond to the multi-level nature of Canadian politics. For the most part, the pattern has been clear: where possible the majority of individuals involved with party politics will participate both federally and provincially and they will do so in a consistent manner that does not cross partisan lines. In general, party life is much more unified and coherent than the current portrayal suggests. Crucially left out of the discussion so far, however, have been the voters that parties compete for during election campaigns.

Although parties perform a wide range of functions (see, for example, King, 1969; Meisel and Mendelsohn, 2000), their distinguishing feature is that they nominate candidates in order to contest elections. This function is what separates political parties from other political organizations such as interest and advocacy groups. The electoral activities of parties that were the focus of Chapters 5 and 8 are therefore among the most essential components of what the party does. Despite all of the linkages that have been documented, an important question still remains: do federal and provincial parties attract partisans who are attached to and vote for the party at both levels or do voters embrace split or single level attachments?

A number of theories of party identification and voter behaviour in multi-level systems raise questions about how well voters can act as an integrating link between federal and provincial parties. This is especially true in highly decentralized states such 
as Canada where the federal and provincial realms are seen to be in a constant state of conflict with one another. According to Reif and Schmitt (1980), for example, there are considerable differences between the various elections that occur in multi-level states. Examining the differences between national and supranational (European Parliament) elections, the authors found that parties in government at the national level tended to "underperform" at the European level. These elections, according to Reif and Schmitt should not be viewed as distinct European elections but instead as a "second order election" that offers voters little additional stimulus or incentive compared to the national election in their country (the "first order election").

In general, the second order election thesis suggests that voters will care less about elections that do not have a stake in forming the national government in their country. This thesis has been extended beyond the supranational level and is said to apply to the sub-state, regional, and municipal levels as well. Indeed, voters in state, land, and provincial elections are believed to be less interested in politics, turnout at lower rates, vote for non-mainstream parties, and respond to stimuli that pertain primarily to the federal level (Norris, 1997; Reif and Schmitt, 1980; Reif, 1997; Van der Eijk et al., 1996).

The possibility of Canadian provincial elections being considered second order is not unreasonable to imagine and evidence suggests that this does occur in other federations. In Germany, for example, Land elections have historically been opportunities for citizens give their verdict on the functioning of the parties at the federal level, rather than focusing on the sub-state level (Hough and Jeffery, 2006: 8). Morton (1997: 11-12) suggests that a similar pattern can be seen in the Canadian case: 
"Ontarians visit the sins of federal governments on their provincial parties". If Morton is correct in his assessment, provincial voting behaviour is not necessarily a result of provincial factors and determinants but is instead a result of factors that are related to the federal level. This, of course, would support the second order election thesis which suggests that sub-state and regional factors are less crucial in the decision making process, even when making decisions about the sub-state level.

In addition to the second order election thesis, other theories also question whether there is meaningful integration in the electorate. It has long been hypothesized that Canadians, and Ontarians in particular, prefer to "balance" their vote across multiple jurisdictions. That is, Canadian voters prefer to have alternating governing parties at the federal and provincial levels, only infrequently allowing the same party to control both federal and provincial levels of power. After witnessing the Liberals dominate federal politics for decades while the party had little success in the provinces, Underhill suggested that:

By some instinctive sub-conscious mental process the Canadian people have apparently decided that, since freedom depends on a balance of power, they will balance the monopolistic power of the Liberal government in Ottawa by setting up the effective countervailing power not in Ottawa but in the provincial capitals (as cited in Smiley, 1976: 86).

The sentiment of Underhill is echoed by Wrong who notes that "many Canadian voters chose to counter the power of the national administration not by electing a strong federal opposition but by voting against the Liberal Party in provincial elections" (1957: 
255). Others have gone further, not only arguing that Canadians prefer this balance but that it is the ideal scenario for the health of the federation.

The federation always worked best when opposite parties inhabited Queen's Park and Parliament Hill. Frost and St. Laurent; Davis and Trudeau; even Peterson and Mulroney, at least on constitutional matters. Things always seemed to deteriorate, however, when identical parties were in both ministers' offices. John Diefenbaker had a testy relationship with Leslie Frost; Bill Davis's relations with Brian Mulroney were far less cordial than with Pierre Trudeau. And there were the epic confrontations between Mitch Hepburn and Mackenzie King (Ibbitson, 2001: 151).

If true, the second order election thesis and the balance theory would mean that very little integration takes place between federal and provincial parties in the electorate. According to both theories, partisan attachments and voting intentions (either because of a lack of interest or a desire to balance political power) are expected to be different at each level of government. As a result, sharing a common base of support in the electorate may be unlikely, even for the most ideologically and organizationally integrated of political parties.

Despite both of these theories being prominent in the Canadian political science tradition, there is very little empirical evidence to support either theory in the Canadian case. Cutler (2008b), for example, provides compelling evidence to suggest that provincial elections in Canada, or at very least Ontario, do not fit neatly into the second order election thesis. Given the considerable authority and influence provincial governments have in Canada, it is not the case that these elections have "less at stake" than their federal counterparts. As a result, voters in Ontario do not behave as the second order election thesis would suggest; they do not turnout to vote considerably less, they 
do not pay less attention, and they do not turn to fringe parties at a higher rate. Perhaps most importantly, Cutler demonstrates that it is provincial campaign effects, and not federal considerations, that influence provincial vote choice. As such, Cutler concludes that "Two first order elections coexist in Canada" (2008b: 502). LeDuc and Pammett (2012: 1) reach similar conclusions in their comparison of multi-level voting behaviour in Canada, Germany, and the United Kingdom, noting that the concept of second order elections "finds little support in Canada at either the provincial or local levels of governance".

Recent survey data provides additional evidence that voters do not think of provincial elections as second order or necessarily less important than their federal counterparts. In a pre-election survey for the 2011 provincial election in Ontario, respondents were asked to rate the importance of elections at different government levels on a scale from 0 to 10 (where 0 means the election is 'not important at all', and 10 means that the election is 'extremely important'). The results reveal that both the federal and provincial elections were ranked almost equally high: 7.73 for the Ontario election and 8.03 for the federal election. ${ }^{65}$ In this regard, Ontario voters defy the second order election thesis, as they do not view the provincial election as being significantly

\footnotetext{
${ }^{65}$ The application of the second order election thesis can be extended to membership and activism more broadly and does not have to be theoretically bound to voters. As such, it may also be worth considering party members. Do citizens, not just narrowly defined as voters, treat provincial politics as second order? If provincial parties are second order, we should find a marked difference between activism and membership rates among federal and provincial parties. In particular, fewer individuals should belong to, volunteer for, and participate in provincial parties. When considering the health and vibrancy of the party, provincial parties do not appear to be notably weaker than their federal counterparts. The average federal constituency association, for instance, only mobilizes an average of 4 more party members to attend routine party meetings and functions. Similarly, the data reveal that federal parties do not attract significantly more members or volunteers. From an activism point of view, members do not treat provincial politics as less meaningful or "second order".
} 
less important or having less at stake. Thus, it may be the case that voters provide a meaningful linkage for federal and provincial parties after all.

Likewise, as long as the balance theory has been proclaimed, there has been an equally long history of research (Perlin and Peppin, 1971; Scarrow, 1962; Wilson and Hoffman, 1970) demonstrating that the balance theory does not adequately explain federal-provincial voting patterns. ${ }^{66}$ Wilson and Hoffman (1970), for example, find that a majority of voters in their sample had no desire to balance power between the federal and provincial governments.

Despite evidence refuting these two particular theories, there are a variety of important structural and institutional reasons why voters in a federal system might hold dual loyalties and vote for/support a different political party at each order of government. First, there are a number of provincial parties, both historic and modern, that do not have a clear or viable counterpart at the federal level. These parties include the Parti Québécois, Social Credit, Cooperative Commonwealth Federation, Wildrose, and Saskatchewan Party. Voters who routinely support these parties at the provincial level, for instance, must choose a different party to vote for federally. While for some the choice may be relatively easy (i.e., a provincial PQ voter choosing to support the BQ federally), for others the choice is less obvious. Moreover, even when the choice is obvious in the current political environment, it might not have always been so clear

\footnotetext{
${ }^{66}$ A recent article by Erikson and Filippov (2001) suggests that these conclusions may be premature. The authors present aggregate data that provides preliminary evidence supporting the balance theory and call for future research on the subject.
} 
historically. Those voting for the PQ, for instance, did not have a federal counterpart for decades until the BQ emerged in the 1990s.

Likewise, there are federal parties, such as the Reform and Canadian Alliance, which have no direct provincial counterpart. Similarly, there are no 'Conservative' parties as such at the provincial level in Quebec, British Columbia, or Saskatchewan. These voters too must affiliate themselves with a different party at the provincial level if they wish to participate at both levels. A lack of federal-provincial party system convergence is therefore a potentially important explanation when considering why voters might cast their ballots in an inconsistent manner. This is especially relevant in the post 1993 political landscape in which federal and provincial party systems have drifted further away from each other (Carty, Cross, and Young, 2000; Stewart and Carty, 2002). Ontario, of course, is the major exception to this general trend as the party systems at the federal and provincial level mirror one another.

Second, as Blake (1982: 693) notes, some federal parties, such as the Liberals in Alberta or the Conservatives in Quebec, tend to "have very weak provincial counterparts". The Liberal Party in Alberta, for instance, was only able to capture five of 87 seats in the 2012 provincial election and only one seat in the 2015 election. Therefore, it is not surprising that when a provincial wing of a federal party performs poorly or fails to run a full slate of candidates, its federal supporters might vote for another party. In other words, even when the same parties exist at both levels, there may be very practical reasons not to vote in a consistent manner at both levels. 
Finally, there are reasons for inconsistent voting that extend beyond the structural factors of party system and patterns of electoral strength. Federal and provincial parties, even when they exist at both levels, share a name, and are both electorally viable options, may have substantive ideological differences nonetheless. That is, there may be considerable variation in their policies, ideologies, and priorities that have the ability to create a substantial rift between the federal and provincial parties. And indeed, policy disputes between federal and provincial parties of the same label are not uncommon. Disputes can arise due to jurisdictional conflicts, the fact that federal and provincial parties have different audiences, the need for the federal government to balance local and national interests, or as a result of the diversity of personalities involved.

A recent example of this kind of tension can be seen in Danny Williams' Anything But Conservative (ABC) campaign and his government's equalization payment policy dispute with the Harper Conservative government. Despite both parties sharing the Conservative label, Williams and the Progressive Conservative Party of Newfoundland and Labrador engaged in an unusually public and very heated confrontation with the Conservative Party of Canada during the lead up to the 2008 federal election. The "ABC" campaign against the party's federal counterpart was extremely successful. So much so that federal party organizers in the province described the dispute as "crippling" their ability to attract volunteers and candidates in the lead up to the election and during the campaign (CBC, 2008a). Ultimately, the federal party lost each of the three seats it had won in the previous election and was completely shut out of the province (CBC, 2008b). 
Even when parties are not in active and bitter policy disputes like the one outlined above, they may simply have different policy outlooks, despite sharing a party label. The Liberal Party in British Columbia, for instance, has more in common with the federal Conservatives when it comes to policy than it does with the federal Liberal Party. For sophisticated voters interested in policy, these differences can result in voting for one party federally and a completely different party provincially. In addition to structural differences in the party system (Cross, 2015), a lack of ideological consistency across levels is therefore another important consideration when exploring federalprovincial vote consistency and potential reasons for inconsistent voting.

Notwithstanding these valid reasons for split-level or inconsistent voting behaviour, there is evidence to suggest that the vast majority of Canadians cast their ballots in a consistent manner. Despite this, Esselment notes that the "bulk" of academics interested in Canadian voting behaviour continue to "focus their attention on the minority of Canadians who vote inconsistently" (2009: 110). While understanding what drives inconsistency is certainly interesting from a scholarly point of view, the consistency of voting behaviour should not be lost or underestimated.

The purpose of this chapter is to assess the extent to which voters in Ontario cast their ballots consistently across multiple jurisdictions and to explore the characteristics of voters who vote for the same party across multiple levels. Shared partisanship in the electorate, like overlapping party members, activists, and other party personnel, can represent an important linkage between federal and provincial parties. If consistent multi-level voting is found, it would mean that parties at the federal and provincial levels share a common base of support and can count on the same individuals to vote for 
them during their respective elections and that voters view them consistently. Given that parties of the Canadian variety are office seeking, sharing common voters has significant implications. It would suggest that the two parties would be likely to develop relatively similar policies, use similar campaign tactics, and so on.

The first section of this chapter applies the concept of electoral volatility (typically reserved for elections at a single level) and applies it to the multi-level context of Canadian elections. Adopting this particular approach will provide an account of how stable the party system is when moving from one level of government to another. Low volatility highlights a stable multi-level party system while high volatility reveals a provincial specific alignment. There are, however, a number of limitations with this approach and aggregate level data in general. Perhaps most importantly, aggregate data can miss a lot of movement at the individual level of the voter.

While this is an important limitation, the electoral volatility approach does have one substantial advantage. Namely, this method is based on actual election results and therefore does not rely on survey respondents to recall who they have previously voted for at multiple different levels over the course of a number of years. Thus, while we should be careful when interpreting the findings and drawing conclusions, we can be confident that this does reflect actual voting behaviour.

Given the limitations, aggregate data cannot be the only source of information for an analysis of multi-level voting patterns. As a result, this discussion is followed by an examination of individual voters and their voting intentions. Drawing on Canadian Election Study (CES) data from 2000-2011, this next section of the chapter explores the 
extent to which individual voters in Ontario cast their ballot in a consistent multi-level manner. In other words, this section answers the following question: to what extent do federal parties and their provincial cousins mobilize the same voters to turn out and vote for them? Additionally, the analysis of individual voters ends with an exploration of panel data from three recent federal elections in order to examine multi-level voter stability over time.

Finally, the chapter ends with an analysis of survey data from the 2011 provincial election. Given that a federal election had just been conducted less than six months prior, this particular survey allows us to drill down further into the consistency of voters in Ontario. Here it is worth considering party attachments beyond voting. Given that there are a number of reasons that an individual might vote inconsistently (i.e., strategic voting in a SMP system), feelings of closeness and attachment to provincial parties and their federal counterparts are useful to examine. The purpose of this final section is to create a profile of the voters who are the most likely to vote in a consistent manner. Conducting a binary logistic regression, the results demonstrate that a number of key variables are significantly related to multi-level vote consistency. In particular, those individuals with partisan attachments are considerably more likely to vote for the same party at both levels than their counterparts without psychological attachments to any of the parties.

\section{Aggregate Level Data: Cross-Jurisdictional Electoral Volatility}

There is a substantial body of scholarly literature that examines electoral volatility in contemporary western democracies (Bartolini and Mair, 1990; Caramani, 
2006; Dalton, 1984; Dalton and Wattenberg 2000; Sikk, 2005). Electoral volatility refers to the net changes of party support within the party system that result from individual vote transfers from one party to another. While the term volatility may have a negative connotation, it should be acknowledged that electoral volatility is not necessarily a problem nor is it inherently harmful for democracy. In fact, a number of authors have suggested that some volatility is actually needed for democracy to function in a healthy and effective manner (Drummond 2006; Lane and Ersson, 2007). Extreme levels of volatility, however, point to potentially problematic and systemic changes occurring in a society. Likewise, high volatility, when considered from a multi-level perspective, may have consequences for national unity and federal stability.

Although the volatility literature tends to focus on national elections, recent work has begun to consider the implications for multi-level systems. Drawing on this literature, Caramani (2006) has applied the Pedersen Index of electoral volatility to the national elections in Europe and those of the European Union. A similar approach can be applied to Canada's federal structure in order to determine how volatile elections are when moving from federal to provincial elections. In other words, this method will allow us to determine the degree to which the party vote in federal elections overlaps with provincial electoral behaviour in Ontario. A low differential between the two orders of elections demonstrates the absence of an Ontario specific alignment whereas a high differential illustrates the presence of an Ontario specific alignment. While this technique only provides an analysis of aggregate trends, it can serve as a useful compliment to the analysis of individual voting behaviour and party attachment that is discussed later in the chapter. 
To calculate the Pederson Index, each federal election is "paired" with a unique provincial election. The index is constructed by totalling the differences between the percentage of votes in each election pair (summing is done in absolute terms, disregarding the signs). The sum of these differences is then divided by two given that a switch from one party to another would otherwise be counted twice (Caramani, 2006; Duncan and Duncan, 1955; Pederson 1979). Doing this calculation provides an easily interpreted score that ranges between 0 (no net change) and 100 (a complete change).

When applying this method to the Ontario case, considerable stability at the aggregate level is evident. Over the past four pairs of elections there has been very little electoral volatility when comparing federal and provincial election results. Mean party system volatility is 7.2 percent for the decade worth of elections between 2003-2014 in Ontario. In other words, the net change from going from a provincial election to a federal one is rather minimal. The low volatility highlights the congruent nature of federal and provincial party systems in the province.

Not only do the same three parties continuously capture 100 percent of the legislative at both levels in Ontario, their share of the vote does not fluctuate considerably. However, since the focus of party integration is more on parties than the party system as a whole, we need a measure that examines the change in support for individual parties. Indeed, the Pederson Index has often been criticized because it cannot identify the parties that voters switch to and from. It tells us a great deal about the stability of the system but very little about the actors and parties involved. To complement the Pederson Index we can use a relatively simple dissimilarity score (Johnston, 2013). This index is similar to that of the Pederson Index as it simply pairs 
the party vote in a federal election with the party vote in the closest provincial election to determine how close the vote shares mirror each other at different levels. While this does not provide individual data at the voter level, it does allow us to focus on individual parties.

Dissimilarity between voting in federal and provincial elections has long been established in the Canadian literature (see, for example, Dawson, 1947). It is not uncommon, for example, for federal and provincial parties of the same name to receive wildly different levels of support in proximate elections. This, however, is not the case with recent elections in Ontario. At the party level, the data reveal similar trends to that of the party system.

Table 9.1 demonstrates the dissimilarity score for each major party for the past four pairs of federal and provincial elections. Average NDP dissimilarity is 3 percent over the past decade. While only slightly higher, average Conservative and Liberal volatility is 5.9 percent and 5.3 percent respectively. With the exception of the unusual results of the 2011 federal election (i.e., the federal Liberal collapse) and the 2014 provincial election (i.e., provincial PCs' poor showing), the dissimilarity scores are remarkably low for the period 2003-2014. In fact, excluding the 2011-2014 Conservative and Liberal election pairs, the remaining 10 dissimilarity scores never reach double digits.

At least at the aggregate level, voter behaviour in Ontario appears to be stable and consistent when examining the last decade of electoral behaviour in the province. When considering both the party system as a whole (electoral volatility) and the 
individual parties that make up the system (dissimilarity scores), voters at the aggregate level have not adopted a provincial -or Ontario - specific alignment. Instead, parties at both levels have received similar levels of support in the province over the past 10 years.

Table 9.1: Federal-Provincial Electoral Dissimilarity (2003-2014) by Party

\begin{tabular}{llll}
\hline Election Pair & $\begin{array}{l}\text { Liberal } \\
\text { Vote (\%) }\end{array}$ & $\begin{array}{l}\text { Conservative } \\
\text { Vote }(\%)\end{array}$ & $\begin{array}{l}\text { NDP } \\
\text { Vote (\%) }\end{array}$ \\
\hline 2011 Federal & 25.3 & 44.4 & 25.6 \\
2014 Provincial & 38.7 & 31.25 & 23.75 \\
Dissimilarity Score & $\mathbf{1 3 . 4}$ & $\mathbf{1 3 . 2}$ & $\mathbf{1 . 9}$ \\
& & & \\
2008 Federal & 33.8 & 39.2 & 18.2 \\
2011 Provincial & 37.6 & 35.4 & 22.7 \\
Dissimilarity Score & $\mathbf{3 . 8}$ & $\mathbf{3 . 8}$ & $\mathbf{4 . 5}$ \\
& & & \\
2006 Federal & 39.9 & 35.1 & 19.4 \\
2007 Provincial & 42.2 & 31.6 & 16.8 \\
Dissimilarity Score & $\mathbf{2 . 3}$ & $\mathbf{3 . 5}$ & $\mathbf{2 . 6}$ \\
& & & \\
2004 Federal & 44.7 & 31.5 & 18.1 \\
2003 Provincial & 46.4 & 34.6 & 14.7 \\
Dissimilarity Score & $\mathbf{1 . 7}$ & $\mathbf{3 . 1}$ & $\mathbf{3 . 4}$ \\
\hline
\end{tabular}

The exception is the 2011/2014 results which have a considerably higher vote differential for the Liberals and Conservatives. This can be explained by the collapse of the Liberals in the 2011 federal election (down more than eight points from the previous federal election). In addition to the federal Liberal collapse, the federal Conservatives were able to make considerable gains (up five points from the previous election). While this change of fortunes was occurring at the federal level, the provincial support for the parties remained relatively consistent with earlier elections.

Given the limitations of aggregate data, however, the analysis provided above needs to be complemented with individual level data. It may be the case, for example, that there is a great deal of movement at the individual level (i.e., lots of split-level or 
inconsistent voters) that is lost when only examining the larger picture at the aggregate level.

\section{Individual Level Data: Federal and Provincial Vote Intentions}

While interesting, having similar levels of aggregate support does not tell us a great deal about whether individual voters link federal and provincial parties together. Indeed, aggregate data that focuses on "net" change can mask the potential for a great deal of federal-provincial movement among voters. For federal and provincial parties to be linked together through the electorate suggests that the same individual voters must be voting for each party. As Chapter 2 examined consistent federal-provincial activities and memberships among party personnel, this section highlights the voter side of this equation.

Based on a sample of decided voters from the six most recent Canadian Election Studies (2000-2011), Table 9.2 highlights the extent to which voters in Ontario hold consistent dual voting intentions. Consistent with the findings presented in earlier chapters, Table 9.2 demonstrates that the majority of decided voters in recent federal elections have voting intentions that are consistent across the federal and provincial levels. This is true regardless of political party.

Perhaps as a result of being the only political party on the right of the spectrum, the Conservatives enjoy the highest levels of consistent voting intention among respondents in the province. In fact, while the percentage of consistent voters does not necessarily appear to vary considerably (a 10\% gap between the Conservatives and NDP 
and a $6 \%$ gap between the Liberals and Conservatives) federal Conservative voters are significantly more likely to be consistent than either the Liberals or the New Democrats.

This is the first concrete empirical ${ }^{67}$ indicator of integration in which the Conservatives have achieved higher levels of multi-level consistency than the NDP. While the Conservatives appeared to offer more multi-level electoral support and endorsements (see Chapter 5) the difference in this provision of support only approached significance. Calculating odds ratios, however, reveals that Conservative voters are 1.8 times more likely to be consistent than their New Democrat counterparts and 1.4 times more likely than Liberal voters. The difference between the Liberals and the New Democrats does not differ significantly in this regard.

Table 9.2: Federal and Provincial Vote Intentions (2000-2011)

\begin{tabular}{llll}
\hline & $\begin{array}{l}\text { Federal Liberal } \\
\text { Voters }\end{array}$ & $\begin{array}{l}\text { Federal NDP } \\
\text { Voters }\end{array}$ & $\begin{array}{l}\text { Federal Conservative } \\
\text { Voters }\end{array}$ \\
\hline Ontario Liberal & $\mathbf{7 6 \% ( 7 5 3 )}$ & $20 \%(82)$ & $14 \%(129)$ \\
Ontario NDP & $8 \%(80)$ & $\mathbf{7 2 \% ( 3 0 0 )}$ & $3 \%(30)$ \\
Ontario Conservative & $15 \%(145)$ & $7 \%(29)$ & $\mathbf{8 2 \% ( 7 6 6 )}$ \\
Total $(\mathrm{N})$ & 978 & 411 & 925 \\
\hline
\end{tabular}

Note: Compiled from Canadian Election Studies (2000-2011). Decided voters only based on the following two questions: "If a provincial election were held today... which party would you vote for?" and "If a federal election were held today which party would you vote for?"

Figures 9.1 and 9.2 combine the data from the previous table and visually demonstrate the consistent nature of Ontario voting habits. Figure 9.1 reveals that the majority of decided voters in Ontario held vote intentions for the same party both federally and provincially. This ranges from a high of 82 percent in 2006 to a low of 63 percent in 2000. The lower levels of consistent multi-level voting intentions during the

\footnotetext{
${ }^{67}$ The previous chapter demonstrates considerable linkages between Conservative parties during election campaigns as they share common services and professionals. This, however, is difficult to quantify and we should therefore be cautious when comparing across parties.
} 
2000 election, however, are hardly surprising given the incongruent nature of federal and provincial party systems at the time. As the party systems in the province have realigned, vote consistency has increased by more than 10 percentage points.

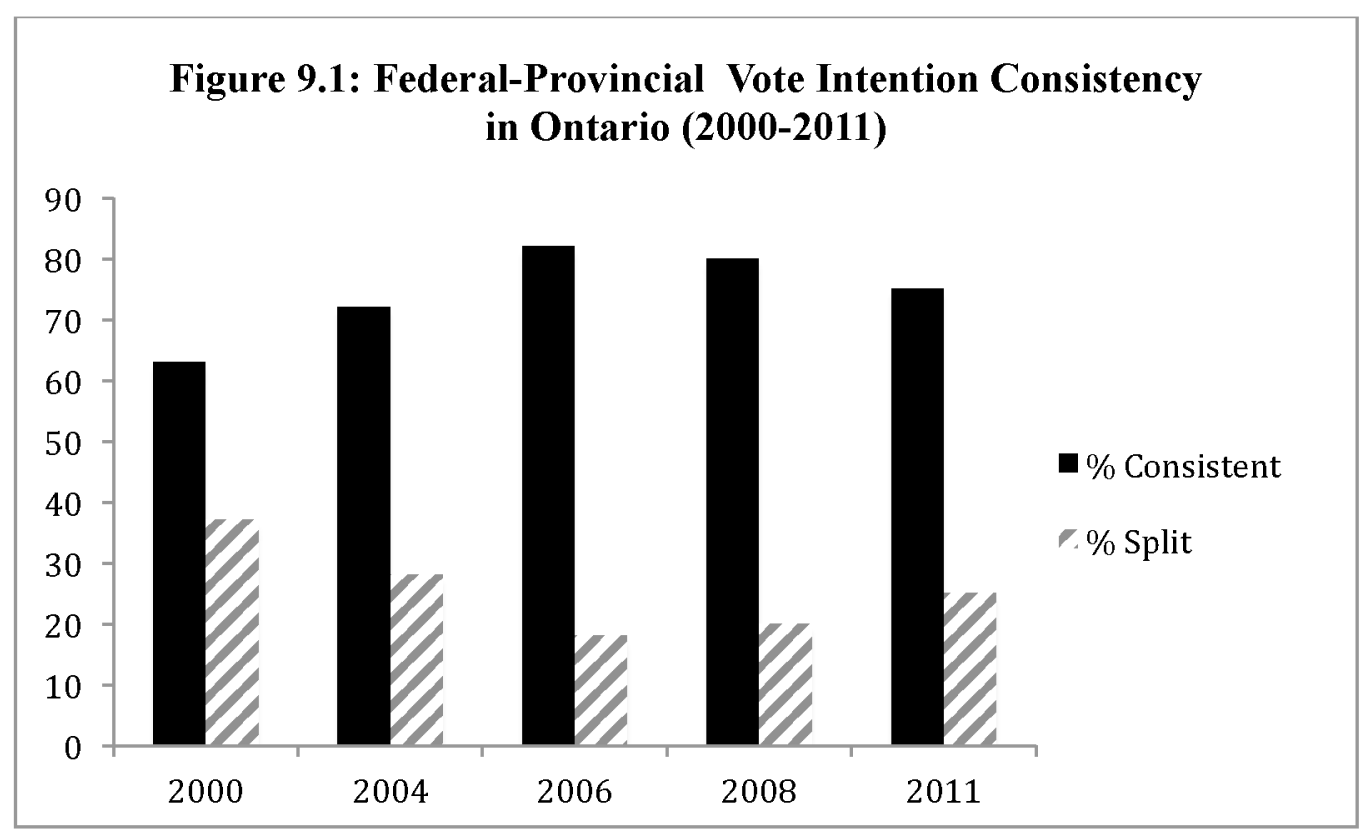

Source: Compiled from Canadian Election Studies (2000-2011). Decided voters only.

Figure 9.2 provides a party-by-party comparison of multi-level voting intentions (2000-2011). Between 2000 and 2008, the percentage of consistent Liberal voters in the province rose from 64 percent to 87 percent: more than 20 percent in just four elections. What's more, despite the party's poor electoral showing in the 2011 federal election, the percentage of consistent Liberal voters did not drop below 2004 levels ${ }^{68}$ Consistent with the aggregate trends, the data obtained from individual voters demonstrates a great deal of federal-provincial consistency.

\footnotetext{
${ }^{68}$ It is worth noting that 17.5 percent of reported provincial Liberal party supporters abstained from voting in the 2011 federal election.
} 


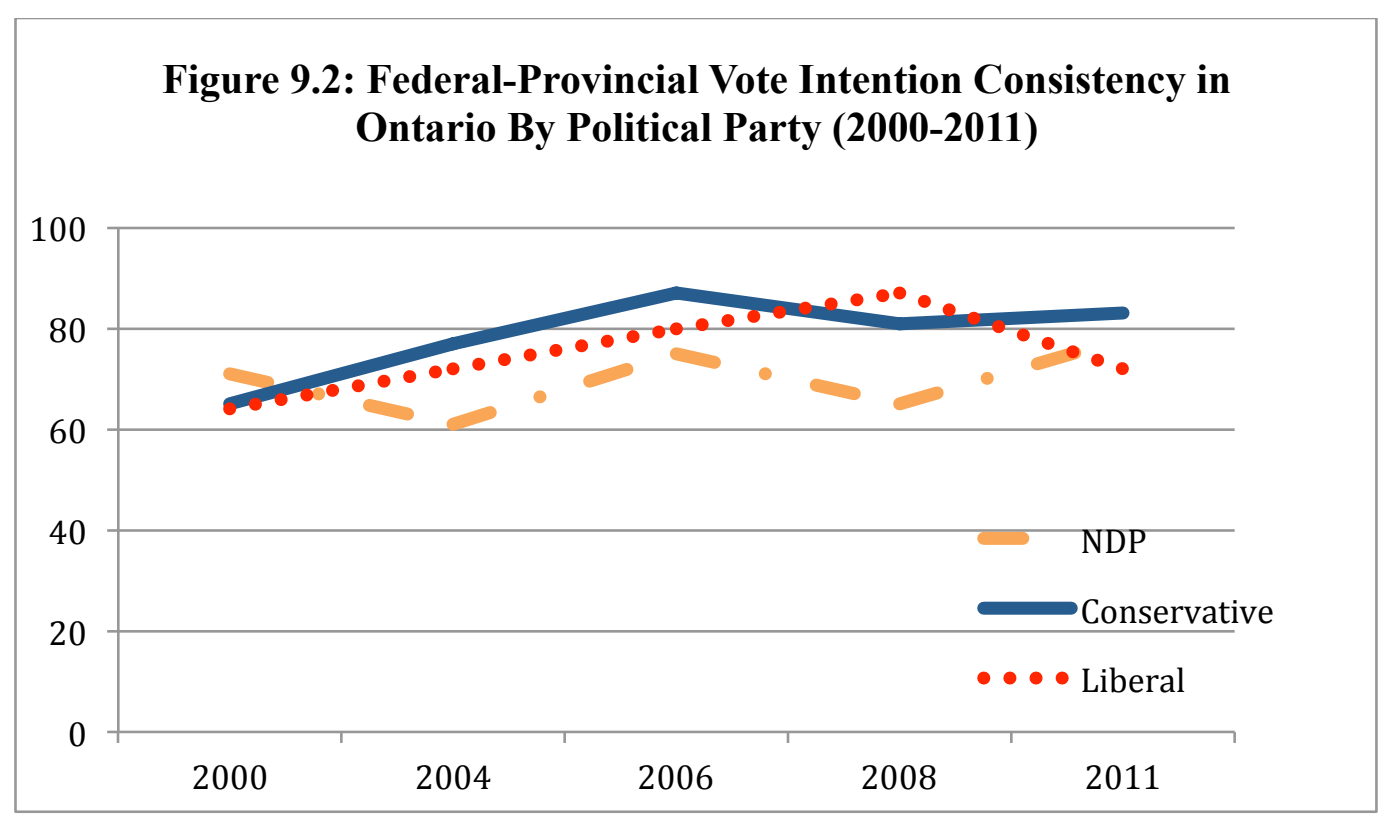

Source: Compiled from Canadian Election Studies (2000-2011). Decided voters only.

Recent Canadian Election Studies also provide an opportunity to add a time dimension to the examination of multi-level vote consistency. The 2004, 2006, and 2008 election studies contain a panel component, and therefore tracked the same individual voters across multiple elections. Using two questions from these surveys ("If a provincial election were held today... which party would you vote for?" and "If a federal election were held today which party would you vote for?"), the consistency of reported vote intention across time can be assessed for individual respondents. Given that each election survey contains two vote intention questions (one federal and one provincial), there are a total of six opportunities to vote for the same party in the course of the panel (three federal and three provincial).

Table 9.3 provides the breakdown of voters and the number of times they reported an intention to vote for a particular party ranging from one (would only vote for 
a particular party in a single election) to six (would vote for the same party in all six elections).

Table 9.3: Vote Intention Across Six Elections (Column Percentages) by Party

\begin{tabular}{llll}
\hline & Liberal & Conservative & NDP \\
\hline Vote for the party once & $16 \%(51)$ & $14 \%(44)$ & $21 \%(44)$ \\
Vote for the party twice & $15 \%(48)$ & $18 \%(55)$ & $19 \%(40)$ \\
Vote for the party three times & $16 \%(51)$ & $15 \%(48)$ & $11 \%(23)$ \\
Vote for the party four times & $15 \%(47)$ & $9 \%(28)$ & $13 \%(27)$ \\
Vote for the party five times & $10 \%(32)$ & $8 \%(24)$ & $13 \%(26)$ \\
Vote for the party six times & $\mathbf{2 7 \% ( 8 6 )}$ & $\mathbf{3 7 \% ( 1 1 6 )}$ & $\mathbf{2 2 \% ( 4 6 )}$ \\
\hline
\end{tabular}

A plurality of voters for each party reported a consistent vote intention across each of the six elections. More than a third of those voters who responded with a vote intention of Conservative reported the same vote intention across all six elections. This rises to nearly one half ( $45 \%$ ) when considering consistent vote choice for five of the six elections. The Liberals and New Democrats achieve lower levels of consistency, with approximately 10 percent fewer voters reporting a consistent vote choice across all six federal and provincial elections.

The level of consistent vote choice for four of the six elections, however, appears to be quite stable across the three parties (Liberals $=52 \%$; Conservatives $=54 \%$; NDP $=$ 48\%). Overall, while adding the time element reduces consistency in vote choice, the analysis demonstrates that a considerable number of individuals hold consistent voting attachments that span both jurisdiction and time.

\section{The 2011 Ontario Provincial Election}

In addition to the data provided by the Canadian Election Studies (CES) detailed above, surveys of provincial voting behaviour (while typically very rare) can provide 
additional insight into the voting behaviour of Canadians. Conducted as part of the Making Electoral Democracy Work project (MEDW), the final section of this chapter draws upon data from a pre and post election survey of voters in the 2011 Ontario election. This particular dataset provides a broad set of questions relevant for studying integration among voters - knowledge, interest, attachment, etc. This dataset also provides a unique opportunity to examine voters through a provincial lens rather than a federal one. Indeed, the last large-scale survey of Ontario provincial voters is more than a decade old, conducted in 2003 .

While the CES data provides an excellent opportunity to examine vote intention from a multi-level perspective, there are no consistent questions about party attachment at the federal and provincial levels. While attachment to the federal parties is always asked, it has been rare for a CES to ask about partisanship at the provincial level. Table 9.4 provides the responses to the question of multi-level partisan attachment. Respondents were asked if they felt close to any particular political party at both the federal and provincial levels. As the data reveal, the vast majority of respondents who feel close to a political party hold consistent party attachments at both levels.

Table 9.4: Multi-level Party Attachment by Party (Which Party do you Feel Closest to?)

\begin{tabular}{llll}
\hline & Federal & Federal & Federal Liberal \\
& Conservative & NDP & \\
\hline Ontario PC & $\mathbf{9 5 \% ( 1 6 9 )}$ & 0 & 0 \\
Ontario NDP & $0.6 \%(1)$ & $\mathbf{9 8 \%}(\mathbf{8 8})$ & $3 \%(4)$ \\
Ontario Liberal & $4.5 \%(8)$ & $2.2 \%(2)$ & $\mathbf{9 6 \%}(\mathbf{1 1 5})$ \\
Total & 178 & 90 & 119 \\
\hline
\end{tabular}

Note: only those individuals who reported feeling close to a particular party.

Shared partisanship, however, does not always translate into consistent multilevel voting behaviour. The difference between party attachment (Table 9.4) and vote 
intention (Table 9.2) demonstrates that there are more consistent identifiers than there are consistent voters. This is particularly relevant for the NDP since its voters are often asked to switch their vote to the Liberals in order to prevent the Conservatives from forming the government. During the 2014 Ontario election, for example, the Liberals targeted NDP voters by raising concerns about a Tim Hudak majority: "On Thursday a split vote will only help Hudak's chances. Polls show only Kathleen Wynne can stop him now. Please consider voting for your local Liberal candidate." Similar appeals are routinely made during federal elections as well, calling on NDP supporters to vote strategically rather than sincerely. The success of such tactics may help explain why consistent voting behaviour among NDP voters is more than 20 percent lower than consistent party attachment.

In addition to knowing the extent of consistent federal-provincial voting, it may be worth exploring which types of individuals are the most likely to engage in consistent voting across multiple jurisdictions. Table 9.5 provides the results of a binary logistic regression. The dependent variable for the analysis is a binary dummy variable for whether or not an individual reported a consistent vote choice across the federal and provincial levels in the most recent elections. This combines actual provincial vote choice with federal voting intention to create a consistency variable.

Included in the model are three broad types of potential explanatory variables derived from the voting behaviour literature. First, a number of socioeconomic and demographic variables such as age, gender, education, and income were included (Berelson et al. 1954; Lazarsfeld et al. 1944). Next, political interest variables were included (Nevitte et al., 2000). This includes interest in politics generally, whether the 
respondent watched the televised leaders debate, self-reported likelihood to vote, and the use of online tools to help with vote choice (i.e., Vote Compass ${ }^{69}$ ). Finally, the model includes an indication of party attachment, as respondents were asked if they felt close to any particular political party (not necessarily voted for) (Campbell et al. 1960; Lau and Redlawsk, 2001).

While exploratory, these and similar variables have been shown to have significant predictive power in terms of vote choice more generally and as such they may offer insight into multi-level voter consistency as well. In particular, we would expect to find highly educated and sophisticated voters to vote less consistently as they are more equipped to navigate the complexities of multi-level electoral politics (different policy jurisdictions, multiple parties with slightly different labels, different campaigns, etc.).

Variables in each of the three categories are significantly related to consistent multi-level vote choice in Ontario. Of the sociological and demographic variables, education is significantly negatively related to consistent voting in Ontario. In general, the more educated a voter is, the less likely she is to vote consistently. This suggests that higher levels of knowledge and sophistication may be able to allow voters to better differentiate between the parties at each level and therefore make more nuanced voting decisions rather than relying on party labels as voting cues. It may also be the case that these voters have the necessary skills that are required to engage in strategic voting.

\footnotetext{
${ }^{69}$ Vote compass in an online educational tool developed by political scientists. After answering a short series of questions about a number of political issues, respondents are situated into the political landscape. In doing so, respondents are able to compare their own views on issues with that of the major political parties. This, and similar tools, are not only expected to help individuals decide how to vote but to promote democratic engagement and electoral/civic literacy.
} 
Given their knowledge and sophistication, these voters are equipped to make strategic decisions that while lowering their level of voting consistency maximize their influence in the election.

Table 9.5: Profile of Consistent Federal-Provincial Voters (Binary Logistic Regression)

\begin{tabular}{lccc}
\hline & Beta & ExpB & $p$ \\
\hline Age & -.005 & .995 & .498 \\
Gender & -.182 & .833 & .342 \\
Education & -.125 & .882 & $.014^{*}$ \\
Income & -.016 & .984 & .544 \\
Likely to vote & .234 & 1.264 & $.013^{*}$ \\
Political interest & .044 & 1.045 & .277 \\
Used vote compass & .546 & 1.727 & $.048^{*}$ \\
Watched debate & .181 & 1.199 & .371 \\
Party attachment & 1.357 & 3.884 & $.000^{* *}$ \\
Constant & .310 & 1.363 & .743 \\
Nagelkerke's pseudo $\mathrm{R}^{2}$ & .175 & & \\
\hline
\end{tabular}

${ }^{* *} \mathrm{p}<.01 ; * \mathrm{p}<.05$

Federalism is often said to raise the informational costs of voting (Smith, 2004) by adding additional electoral arenas and increasing the number of relevant parties. Additionally, voters in a multi-level environment such as Canada need to understand the constitutional division of powers and be able to comprehend complex jurisdictional issues where authority may be informally exercised or shared. In general, then, highly educated voters are better equipped to make informed voting decisions that move beyond party labels and partisan cues.

In a similar fashion, that those voters who used the vote compass are more likely to vote consistently suggests that voters who are less politically sophisticated (and require help from online voting tools) may be less capable of navigating the complexity of multi-level politics. If this is the case, cognitive cues from party labels likely act as 
information shortcuts for these voters and similar labels at each level likely prompt consistent voting. When told to vote one way federally, these individuals are more likely to vote the same way provincially.

Finally, and not surprisingly, the party attachment variable is highly significant. Those voters who feel particularly close to a provincial political party (any party) are nearly four times more likely to vote consistently than voters who do not feel attachment to any of the parties. The psychological attachment to a political party at one level likely encourages simultaneous affiliation at the other level, resulting in higher levels of consistent multi-level voting among these partisans.

\section{Conclusions}

This chapter has demonstrated another important human linkage that federal and provincial parties share in the province of Ontario that is often excluded from the analysis: voters. While scholars tend to focus on the minority of voters who engage in inconsistent multi-level electoral behaviour, this chapter has focused on the high levels of consistency that exists within all of the major parties. Despite a number of reasons for inconsistent voting (different policy jurisdictions, truncated parties, informational costs, etc.), this is not the norm in Ontario. Indeed, an examination of eight elections over the past decade reveals that a clear majority of federal voters participate in elections at multiple levels and do so by voting consistently across jurisdictions. In this sense, parties are able to deliver a significant base of support to their multi-level counterpart in upcoming elections. 
Given this shared base in the electorate, it is not surprising that parties cooperate during election campaigns and use similar professional services and campaign tactics after all it is the same individual voters who are being targeted. This also speaks to the benefits of information sharing across levels. Because the voters for both parties are largely the same, parties that cooperate in a multi-level fashion can benefit greatly by sharing their information to create robust datasets that capture a greater proportion of the electorate and allow for better voter tracking and targeting.

When considering the narrower question of whether integration falls along ideological or organizational lines, neither seems to be appropriate when considering voters. Regardless of the level of ideological consistency or organizational connectedness two parties share, a majority of voters in Ontario hold consistent party attachments and vote intentions that span the provincial and federal arenas. However, the pressures of the electoral system and the incentives to vote strategically are particularly challenging for the New Democrats. While the party maintains a considerable degree of multi-level electoral support, many voters who identify with the party at both levels do not ultimately vote for the party at both levels. Strategic voting can also mask the true level of multi-level support for the other parties as well. This is particularly relevant for the Liberals, as many NDP voters who vote strategically cast their ballot for a Liberal candidate. 


\section{CHAPTER 10: Conclusion}

\section{Introduction}

The previous chapters marshalled a wide range of data from a variety of sources to explore multi-level party linkages in Ontario in what is perhaps the most comprehensive examination of party integration in the Canadian context. Using a unique dataset of 273 federal and provincial constituency associations; interviews of Members of Parliament, campaign professionals, party elites, and riding association presidents; analysis of existing surveys of members, candidates, and voters; content analysis of party platforms; an examination of MP careers; and a careful exploration of media reports, the preceding chapters have been able to offer the most expansive and detailed examination of party linkages in Canada's largest province to date.

This study has done so by not only examining party rules and constitutions as is common practice but also by exploring often ignored aspects of integration such as party ideology, party behaviour, and party personnel. Moreover, it has done so at multiple levels in an attempt to address the national bias that is so common in party research. It has therefore offered a much more in depth analysis than is typically presented on the subject. It has also expanded the number of parties in the analysis to include all of the major parties in the province, including the New Democrats - a party that is often assumed to have multi-level linkages and is therefore excluded from the analysis. Moreover, this is among the first analysis of its kind to examine the newly formed Conservative Party of Canada and the relationship it has with its organizationally separate and distinct provincial cousin, the Progressive Conservative Party of Ontario. 
Emphasizing the informal, the human, and the local aspects of vertical party integration, this study has demonstrated the considerable linkages that exist between the major federal and provincial parties in Ontario. In doing so, it has been able to build upon and empirically test a number of findings and theories derived from earlier small $n$ case studies on the subject of party integration in Canada. Consistent with Koop (2011), Jacek et al. (1972), and Esselment (2010), the central finding is that Canadian parties both at the grassroots level and the central or province-wide level - cooperate in a coordinated multi-level fashion both inside and outside of election campaigns. Far from inhabiting "two political worlds", political parties in Ontario exhibit a number of important integrating linkages: they jointly coordinate campaign labour and volunteers; they share voter and activist data; they campaign for one another and provide endorsements; and they even exert moderate influence on each other in the candidate selection process.

Beginning with party personnel, Chapter 3 demonstrated that a majority of individuals of the party on the ground belong and contribute to political parties at both levels. This includes 70 percent of party members, 76 percent of activists, and 86 percent of constituency association presidents. The more active and committed an individual is, the more it seems they are likely to be engaged with politics in a multilevel manner (activists are more engaged than average members, and association presidents more so than activists). What's more, the vast majority of these individuals are consistent in their multi-level activities, belonging to the same political party both provincially and federally. 
Chapters 5 and 6 examined the election and inter-election activities of local constituency associations. While a modest number of associations get involved in their counterpart's candidate selection process, a majority of associations share volunteers and campaign teams with their counterpart during elections (90 and 74\% respectively). Moreover, a majority of ridings coordinated multi-level campaign endorsements during the 2011 elections. This coordination appears to be, at least in part, the result of precise targeting of certain swing ridings that could be won by the party with the help of their counterpart (i.e., having a cabinet minister introduce the local candidate). While having a cabinet minister from another level introduce a local candidate may not seem like it would yield a significant result, many seats are won and lost as the result of less than five percent of the vote (Carty and Eagles, 2005). Any advantage in securing the support of additional voters, especially any low cost activity that might enhance the profile of the local candidate and her standing by a few percent, is well worth it for the party.

When considering the inter-election period, Chapter 6 demonstrated that parties remain, albeit to a slightly lesser extent, connected to one another when they are not fighting elections. Those individuals who sustain the party when there are no election campaigns to wage are largely the same at both levels. More than seven-in-ten association presidents, for example, report that the members who attend their meetings are mostly the same as those who attend their multi-level counterpart's party meetings. Additionally, more than 70 percent of associations hold joint multi-level social events throughout the year and 60 percent of associations do the same for the purpose of policy discussions. 
Combining the evidence from Chapters 5 and 6, Chapter 7 concluded that fully two-in-three constituency associations live in what Koop (2011) calls an "interconnected political world". Perhaps more importantly, as few as one-in-ten constituency associations can be classified as living in "two political worlds". Empirically speaking, then, the notion that parties live in their own political world in isolation is simply not reflected in the reality of the day-to-day operations of constituency associations and their grassroots membership.

Chapter 8 revealed that this cooperative and coordinated relationship between federal and provincial parties is not limited to the grassroots. While difficult to quantify, parties at the province-wide level also work to cultivate strong multi-level relationships with their counterparts in other jurisdictions. Whether it is the federal and provincial Liberals using the same Liberalist software to coordinate voter targeting and surveillance, the Conservatives' shared use of Responsive Marketing Group (RMG) for fundraising and get-out-the-vote purposes, or the NDP's use of the Broadbent Institute to train staff and candidates for provincial and federal elections, the connections run deep at the central party level as well. This is in addition to the considerable level of overlapping individual campaign professionals that migrate seamlessly between the federal and provincial realms.

Finally, Chapter 9 uncovered the considerable number of shared voters that federal and provincial parties attract. Overall, a majority of decided voters hold voting intentions that are consistent across both levels. Despite the various reasons for inconsistent voting behaviour (different electoral stimuli, different issues, different parties/leaders, etc.), federal and provincial parties of the same name tend to draw upon 
the same individuals for electoral support. Moreover, panel data revealed that a plurality of voters hold consistent multi-level vote intentions across time as well. This, of course, should only reinforce the importance of parties' commitment to working together during election campaigns through the sharing of resources and organizing of campaign endorsements.

Taken as a whole, it should be clear that political parties in Ontario are far more integrated and connected than is typically portrayed and political life in the province is far from bifurcated. Indeed, the majority of individuals active in party politics live in cohesive and interconnected worlds. And the parties themselves engage in a number of coordinated and cooperative activities both during and in between election campaigns that create strong linkages that span the two orders of government.

An important question addressed throughout the previous chapters is "why"? Why do parties bother to engage in this multi-level cooperative behaviour? What benefits does it offer? While answers to this question are found throughout each of the previous chapters, it is worth highlighting perhaps the most common benefit that political parties experience as a result of their multi-level activities: the potential for improved election results.

Take, for example, the electoral district of Oakville. The Conservatives have held the riding federally since 2008 while the Liberals have held the riding provincially since 2003. When it comes time to campaign in 2015 , the federal Liberal candidate will be a relatively unknown quantity and will likely have a difficult time raising funds and competing against the Conservative incumbent (personal interview). The provincial 
Liberal MPP (Kevin Flynn), however, is a member of Wynne's cabinet, has a history with the riding, and is an experienced and tested campaigner. Having Flynn attend fundraising events and introduce the federal Liberal candidate at campaign events will not only ensure that there is a crowd (as voters will more easily recognize Flynn in the riding) but will also help raise money and media attention.

Indeed, many individuals who would not attend a federal Liberal rally/fundraising event in the riding may be swayed by the opportunity to speak with a provincial cabinet minister. Ensuring that events have large crowds of supporters is good optics and few things are more embarrassing for a candidate than to host a sparsely attended campaign event, especially if the media picks this up. The ability to draw upon both federal and provincial members and supporters of the party in a riding helps to ensure that campaign events have a sense of excitement and vibrancy.

Building on the Oakville example, it might seem as though Flynn would gain little in return for his support. What benefit does Flynn get from attending federal campaign events and raising money for the federal association/candidate? Providing election support like this results in a number of benefits for his own electoral fortunes: it allows campaign professionals on his team to gain additional experience; it allows Flynn to remain connected to the voters in the riding; and if successful, it ensures that he has an ally in the riding as opposed to a foe. The latter is of considerable importance as a federal Liberal MP in the riding would be able to offer the same kind of electoral support that Flynn would be providing. Furthermore, it provides voters with a sense that these individuals are committed to cooperation. 
While provincial Liberals, Conservatives, and New Democrats have a desire to help their federal counterparts win office, politics is a business, and the provision of multi-level support is hardly altruistic. Indeed, in all my discussions with party personnel of various kinds (MPs, association presidents, national executive members, etc.), the notion of reciprocity was front and centre when discussing multi-level relations. The lending of campaign personnel, the provision of an endorsement, the sharing of party data, with all of these activities there is a clear expectation that this support will be returned at the next opportunity. Trudeau, for example, was on the campaign trail for Wynne at every opportunity during the 2014 provincial election and he even participated in a number of provincial Liberal by-election campaigns (see Chapter 8). Federal party insiders have a very clear expectation that Wynne and her incumbents (especially those in cabinet) will provide the same support for the federal Liberals in 2015 (personal interviews).

Although there are many reasons that parties find it mutually beneficial to work closely with their multi-level partner, electoral benefits are the most commonly cited, most obviously identifiable, and most immediate in consequence. There are, however, other reasons noted throughout the previous chapters such as competitive responses to other parties in the system, personal relationships, and a shared commitment to certain policy objectives. None, however, are as central as the potential electoral benefits.

\section{Towards an Explanation of Vertical Integration}

One of the fundamental conclusions of this thesis is that integration between federal and provincial parties is the norm rather than an exception in Ontario. As the 
previous chapters have made clear, however, political parties in Ontario do not enjoy uniform levels of integration. In terms of the personnel they share, the endorsements they extend to one another during the campaign, the resources they provide, the activities they engage in, and the voters that they share, there are clear differences at the party level. Chapter 2 highlighted two competing explanations for divergent levels of integration: an organizational hypothesis and an ideological hypothesis. While these possible explanations have been discussed throughout the various chapters, this section combines the findings and evaluates each of these hypotheses in greater depth.

The organizational hypothesis suggests that integration is a function of formal party structures: those parties with formally interconnected organizations will exhibit the highest levels of integration. Recall that if the organizational hypothesis is correct, we should find highly integrated New Democratic parties, weakly integrated Conservative parties, and moderately integrated Liberal parties. The ideological hypothesis, by contrast, suggests that integration is a function of consistent and salient party ideology that bridges the two jurisdictions. Thus, if the ideological hypothesis is correct we should find a different pattern of results. We would expect to find highly integrated New Democratic parties, moderately integrated Conservative parties, and weakly integrated Liberal parties.

As the previous chapters demonstrate, however, neither of these patterns is wholly confirmed. A party's organizational design, for example, cannot explain the similarities between the Liberals and Conservatives in terms of common party personnel and campaign behaviour. If the organizational hypothesis were correct, we would expect the Liberals to be more integrated than the Conservatives (see Figure 2.1). Instead, we 
find that for most indicators, there is no meaningful difference between these two parties. Despite the fact that the Liberals are semi-integrated, they are unable to attract more membership, activist, or legislator overlap than the Conservatives do with a truncated and organizationally distinct party structure. Similarly, the Liberals are not able, in many ways, to create a more cooperative or collaborative local relationship despite formal organizational relationships at the constituency level (i.e., ex-officio rules for riding executive presidents). This suggests that a party's organizational design is important, but only to a degree.

To be sure, organization does matter. We can look within a single party to examine the potential impact of organizational design on the level of integration between party personnel. While the Liberal Party in Ontario has adopted a semiintegrated organization, it has more integrated organizations in certain provinces. In New Brunswick, for instance, the party shares a headquarters, uses the same membership forms, and maintains a close organizational relationship (Esselment, 2010:96). While the party has not adopted a joint membership structure per se, prospective members in New Brunswick have the option of joining at a single level or both simultaneously. As a result of these organizational differences, federal Liberal party members in New Brunswick are considerably more likely to belong to the provincial party when compared to their counterparts in Ontario. Cross and Young's survey of party members reveals that 98 percent of federal Liberal party members in New Brunswick belong to the provincial Liberal Party compared to 68 percent of federal Liberal Party members in Ontario. 
Like organization, ideological differences between the parties do not offer a complete explanation either. If they did, we would expect to find more comparable levels of integration between the New Democrats and the Conservatives since both parties have internally coherent ideologies that are consistent across jurisdictions (see Figure 2.5). However, the evidence demonstrates a significant gap between these two parties. Despite both parties embracing ideological politics, these parties do not attract similar levels of shared party personnel. Likewise, we would expect the Conservatives to be significantly more integrated than the Liberals. As the above discussion highlights, however, this is not the case.

Nonetheless, a recent example can demonstrate the importance of ideology in discouraging cooperation when the ideology is discordant. During the 2014 provincial election, the Ontario NDP was perceived to be moving towards the centre of the political spectrum. As a result, many volunteers and long-time party members felt somewhat alienated from the party's new policy positions (Ferguson, 2014; Mallen, 2014). According to a number of federal NDP MPs, this had a noticeable impact on multi-level cooperation during the election as many long-term volunteers and organizers who had previously worked for both levels decided to focus their attention on federal politics (personal interviews). Beyond volunteers, this conflict over policy also dissuaded some prominent federal New Democrats from participating in the election as well (personal interview).

What all of this suggests is that integration is most likely a factor of both ideology and organization. To make sense of these findings the explanation provided here draws on the new institutionalism literature and approaches (Hall and Taylor, 1996; 
Thelen and Steinmo, 1992). As Detterbeck (2012: 45) notes, "Whatever the nuances between the institutionalist schools, they all agree on the central premise that institutions 'suggest' certain courses of action and rule out others". In the case of integration, vertically connected party structures 'suggest' that federal and provincial parties work together. At the same time, these interconnected structures rule out the possibility that there will be absolutely no integration between the two levels.

Institutionalist approaches, however, are not completely deterministic. A more complete explanation of integration must also take into account some degree of agency and other motivations on behalf of the party personnel who populate federal and provincial parties. The new institutionalism literature has long since recognized the role of ideas (Beland, 2009), discourse (Schmidt, 2008), and norms (Camic and Gross, 2001) in shaping institutions and the opportunities available to individuals. As Blyth (2001: 4) notes, ideas and ideology "allow agents to challenge existing institutional arrangements and the patterns of distribution that they enshrine". Thus, even when organizational structures "suggest" otherwise, ideology can allow individual actors to overcome organizational truncation and act in a unified and integrated manner. The explanation of party integration provided here therefore combines traditional structural approaches with that of political agency, emphasizing the role of ideas and ideology.

Ultimately the NDP's combination of interconnected organizational structures and a coherent ideology creates strong incentives and opportunities for integration. The party ensures overlap through party structure (i.e., unified membership) but also mobilizes the same individuals to be engaged and participate at both levels through shared and consistent ideology even when integration is not organizationally mandated. 
Combined, the organizational design and coherent ideology accounts for the high levels of integration between New Democratic parties.

The Liberals on the other hand, have a semi-integrated organizational structure and a less coherent brokerage ideology, which ultimately provides fewer incentives for integration. The party has a number of modest organizational incentives but cannot rely on ideology to mobilize party personnel to become active at both levels. Since the party's ideology lacks consistency, individuals interested in policy at one level are not automatically directed to their party counterpart at the other. As a result, the Liberals achieve moderate levels of integration but remain considerably less integrated than the NDP.

By contrast, the Conservatives are able to make up for a lack of organizational incentives through their coherent and consistent ideology. Given that membership is often ideologically motivated (Young and Cross, 2002a), consistent ideology provides an avenue for integration between Conservative parties even in the absence of formal organizational paths. Individuals interested in policy at one level are automatically directed to the party's multi-level counterpart as a result of shared ideology. Rather than organizational interconnectedness, it is shared and consistent ideology that creates a sense of unity between these parties. This sense of solidarity fosters the creation of new norms of cooperation and reciprocity among individuals of both parties despite the lack of rules and procedures dictating this kind of behaviour. The end result is that the Conservatives achieve similar levels of integration as the Liberals despite their considerable organizational differences. 


\section{Implications for Ontario Politics and Beyond}

Although unique in many ways, the results presented here have a number of implications for parties competing in other multi-level states and the remaining Canadian provinces. The informal nature of party integration in Ontario - linkages found in party behaviour rather than codified in party statutes - extends well beyond the Canadian case and provides a new avenue for researching multi-level politics in Europe. While an examination of party constitutions clearly demonstrates that political parties in European federations are considerably more integrated than their Canadian counterparts (Thorlakson, 2009), this does not account for informal means of integration. It is therefore worth considering whether parties in other provinces and multi-level states go beyond what is outlined in their internal rules or whether forms of informal vertical party integration are somehow unique to Ontario.

All of this suggests that formal organizations should not be our only focal point when studying the relationships between political parties. To be sure, organizational structures do matter. It is no coincidence that federal and provincial New Democratic parties are the most organizationally connected and also engage in the most integrating activities. The Conservatives, however, clearly demonstrate that two parties that are organizationally separate from one another can still achieve relatively high levels of integration. Despite formal organizational truncation, Conservative parties at the federal and provincial level in Ontario engage in informal integration, cooperating during election campaigns and freely sharing resources such as party personnel. While this behaviour is not specified in party statutes it is no less meaningful or real. 
Thus, in addition to studying formal means of integration through examinations of party statues and constitutions it is important to also consider informal means of integration through an examination of actual party behaviour. While information and data on actual party behaviour is certainly more difficult to obtain, it provides a much more rich and complete understanding of party integration - much more so than a straightforward examination of party rules and constitutions.

The evidence presented in the previous chapters should also caution against treating political parties as a single coherent unit. As a number of authors have suggested (Carty, 2002; Eldersveld, 1964; Katz and Mair, 1993;), parties are comprised of different 'faces' and competing 'units'. We should therefore be careful when making claims about the political party as a whole. The chapters focussing on the constituency level, for example, demonstrate that integration can take place at the local level even when there is less coordination or cooperation at other levels.

The stratarchical bargain that defines Canadian parties (Carty 2002; 2004; Carty and Cross 2006) provides local riding associations with the freedom and autonomy to forge their own networks and connections. Parties at the constituency level have chosen to use this freedom to create meaningful local connections with their multi-level counterpart. To say that Canadian parties have opted out of integration is therefore not completely accurate. While some faces such as the party in central office are less integrated, party politics on the ground is much more unified and integrated.

Although vertical integration is typically viewed as a party phenomenon, the analysis in Chapters 5 and 6 raise a number of new questions for integration scholars to 
consider. When controlling for party (and therefore the level of formal organizational connectedness in this case), the results of the multivariate analysis reveal other potentially important explanatory variables. That parties are more integrated in districts where they are electorally successful and have an incumbent suggests that there are nonparty based determinants to integration.

Finally, while the focus of this thesis has been multi-level linkages, the preceding chapters have also contributed to the study of party organizations more broadly especially their local units. As the last surveys of constituency associations appear to be nearly two decades old (see, for example, Carty, 1991; Cross, 1996), we did not have a great deal of reliable information concerning the democratic activities of grassroots associations or their health and vibrancy. In this regard, this thesis has contributed to filling this gap by providing much needed data on the membership and activism of local parties, their inter-election activities, and their local campaign behaviour. In doing so, it has shed light on an often overlooked, yet fundamental, aspect of party life in Canada. Although focused on a single province, we now have empirical evidence pertaining to the number of party members and volunteers local associations have, the number of meetings that they hold each year, and so on.

The academic and scholarly implications of this study should be clear: party politics is not defined by two political worlds and our assumptions about the multi-level nature of Canadian parties are out-dated and overly simplistic. This study, however, has clear democratic implications that extend beyond the debates in the specialized integration literature. Party integration has consequences for national unity and brokerage politics, democratic participation, and the professionalization of party politics. 
It is worth reflecting on these broader implications for Canadian parties and politics more generally.

\section{National Unity and Brokerage Politics}

One of the primary functions of political parties is to integrate citizens into the political system (King, 1969). Through political socialization, parties are expected to engender psychological attachments with citizens that create a long lasting relationship between the citizen and state. Kircheimer (1966: 188-189), for instance, wrote that parties are "channels for integrating individuals and groups into the existing political order." In Canada, the existing political entity is a multi-level entity. Integrating citizens therefore involves creating attachments at multiple levels within the polity. As Meisel and Mendelsohn (2000: 164) write, Canadian parties are expected to forge "national cohesion". Likewise, Meisel (1963: 370) argued that "the chief and most important latent functions of the political parties and the party system are to foster and develop a sense of national unity and national being". While parties in other countries are often expected to articulate conflict, Canadian parties are expected to mediate disputes and be agents of national unity.

The two political worlds view of Canadian party politics suggests that our parties cannot be agents of integration beyond their own single level and jurisdiction. The separation of federal and provincial party organizations into discrete realms means that Canadian parties are inherently single level actors are cannot encourage citizens to create attachments with Canada as a multi-level state: the Liberal party of Ontario can integrate citizens at the provincial level but it is up to the federal Liberal party to do the 
same at the national level. In fact, when parties are separate like this, they may inspire animosity and hostility towards the political order, deterring citizens from creating attachments with the other level.

The evidence presented here, however, demonstrates that this is not the case. Rather than antagonistic and separate, political parties can engage citizens and incentivize multi-level commitments and participation. And for the majority of individuals involved with politics (be they activists, members, voters, volunteers, etc.), this seems to be working. A majority of people who are engaged with party politics take a multi-level approach and belong to and volunteer for parties at both orders of government. This helps to foster feelings of attachment and closeness to both levels of the polity, strengthening national unity. In many ways this study reveals that parties in Ontario act as agents of national unity on a regular basis, fostering commitment and attachments among their members not only to their "own" level, but to the multi-level political system as a whole. This is multi-level attachment is the result of holding joint social events, multi-level policy discussions, and so on. Indeed, Canadian parties are far more successful integrating agents than they are given credit.

Central to the question of national unity is the practice of brokerage politics. However, it is unclear whether brokerage and integration are fully compatible. Brokerage, as a means of managing conflict (especially regional conflict) seems to be, on the surface, consistent with integration. After all, multi-level party integration suggests a positive and collaborative relationship between federal and provincial parties. Additionally, as detailed above, integration promotes national solidarity and attachments to politics at multiple levels. In this regard, the two concepts seem very compatible. 
Nonetheless, the actual practice of brokerage and integration are very different. Perhaps most importantly, brokerage requires an incredibly flexible ideology. Party leaders need the ability to manoeuvre quickly and freely in order to compromise between competing and often conflicting demands. Carty (2013a: 11), for example, writes that "as consensus-seeking organizations, brokerage parties are characterized as determined to eschew ideological agendas and programmatic politics". As we have seen, however, integration is more common in ideologically coherent, rather than ideologically flexible, parties. Whereas brokerage parties are supported by "electoral success" rather than any "social or ideological coherence" (Carty, 2013a: 16), integrated parties often rely on ideological coherence to incentivize multi-level membership and activism. The flexible ideology required to practice brokerage is unlikely to be consistent across levels.

Furthermore, strongly integrated parties are less likely to be able to practice brokerage for reasons that extend beyond ideology. Building consensus and brokering between competing interests requires that individual provinces do not drive the process. As national unity is the priority, some provinces and regions will need to compromise, perhaps more than others. Such an approach to politics is made more complicated when clear linkages (human or organizational) connect federal and provincial parties. When key campaign staff, party organizers, or even elected officials have strong ties to a particular provincial party, the ability to engage in brokerage may be compromised.

In fact, it was during the pan-Canadian brokerage heyday of the federal Liberals during the 1960s that we really began to see the cracks in Liberal integration. During this time provincial organizations in Canada's two largest provinces pushed for their 
own organizational independence. It is therefore unsurprising that we have not seen former provincial Liberal premiers working at the forefront of federal politics for a number of decades. In order to practice brokerage, the federal Liberals have had to distance themselves, to some degree, from their provincial counterparts. Thus, while both integration and brokerage seem compatible and can coexist, there are a number of reasons to suggest that they cannot be maximized within the same party. Parties can either promote national unity and solidarity through brokerage or they can do so through the creation of vertical linkages, however, they are unlikely to do both simultaneously.

\section{Political Participation}

High levels of integration also have democratic implications for political participation. Federalism is often proclaimed as having the ability to enhance the democratic practice as it opens up more avenues for participation and more entry points into politics. Smith (2010: 23), for example, writes that federalism "offers many access points of participation - national, provincial/territorial, municipal, and Aboriginal." Two electoral arenas with political parties at both levels should therefore allow citizens more opportunities to become engaged with their politics: more election campaigns to volunteer for, more local executives to seek a leadership role on, more meetings to attend, more parties to join, and so on.

Although it may seem counterintuitive, high levels of party integration may actually limit the participation of ordinary citizens, especially at a grassroots and local level. This is especially true for split-level identifiers (those who affiliate with different parties at each level). While in theory split level activists should have just as many 
opportunities to participate at multiple levels as consistent identifiers (simply volunteering for a different party at each level), the reality is not so simple and straightforward. When parties and party systems are integrated, split-level participation is not encouraged. Indeed, whether it is an advertising agency, a local party president, or a party volunteer, it is consistent multi-level behaviour that is rewarded.

Interviews with a variety of campaign personnel highlight the importance of trust and how this is tied to consistent multi-level behaviour and activism. Split-level activists are often not put in leadership roles, not given important tasks, and not trusted with sensitive party information. This, of course, may discourage multi-level participation among those who do not identify with a particular party consistently across levels. Rather than creating additional spaces for participation, under these circumstances participation may actually be diminished. Without the ability to be placed in a position of leadership, many would-be activists may opt for a different form of participation rather than engaging in party politics.

It is not just split-level identifiers who are limited in their potential participation either. With 106 ridings at each level, we might think that there are over 200 local executives to fill in Ontario alone. The practice of federalism should therefore create a myriad of new opportunities for local activists to be engaged in party democracy and take on positions of leadership. This, however, is not necessarily the case. In the NDP, for example, federalism has not resulted in twice as many leadership positions at the local level. Given the integrated nature of the party's local apparatus, many executives have considerable overlap and it is not uncommon for the local president to be the president of both the federal and provincial association. When this is the case, when the 
same individuals occupy positions both federally and provincially, additional opportunities for participation are not created. In other words, there is no net benefit of additional participatory spaces and opportunities.

While there may be more avenues available in the other parties where integration is not institutionalized to the same degree, the data show that it is largely the same individuals who participate at both levels. What this suggests is that there is a local political class in Canada who occupy positions of party leadership both federally and provincially. In many ways, the interconnected multi-level nature of integrated political parties can undermine the democratic promises of federalism, at least as it relates to participation.

\section{Professionalization and Micro Targeting}

The practice of integration of federal and provincial parties appears to be hastening the professionalization of party life in Canada. Campaign managers, pollsters, advisers, and a variety of other campaign and party professionals working for integrated parties are not bound to a single electoral cycle with limited opportunities to practice their craft. Consider those individuals working at the federal level. When and where political life is truncated, these individuals may only be needed once every few years to run a campaign. As a result, other employment is necessary. Multi-level political life, however, creates additional opportunities across the country. Where politics is integrated, these individuals can move seamlessly between federal and provincial politics (and along different provinces), working on campaigns almost continuously. As a result, a professionalized political class can emerge more quickly. Interviews confirm 
this trend as many party professionals use campaigns at different levels as a means of fostering new relationships, gaining experience, and learning new techniques to stay current.

Along these lines, the tactics of parties are not only professionalized but also increasingly sophisticated as a result of federal-provincial integration. Party software now contains an incredible amount of personal data about voters and activists. Liberalist, for example, tracks donations, vote history, vote intention, past party activism, and so on. The ability to combine federal and provincial data allows parties to grow their databases at a much faster pace. Cooperation, combined with increasingly sophisticated campaign techniques is allowing for an unprecedented level of voter surveillance, targeting, and analytics. Without multi-level cooperation in the collection of voter information, the data that Canadian parties have access to would be considerably smaller and less reliable.

The democratic implications of these campaign techniques are numerous. While voter surveillance in Canada is not nearly as sophisticated or prevalent as it is in the United States, where reports suggest there were at least 76 "different tracking programs on barackobama.com" (Benett, 2013: 51), concerns over privacy, data breaches, and the nonconsensual capture and use of personal data are nonetheless valid. There have been a number of recent cases in which individual parties and even the government have engaged in questionable behaviour with the use of personal data (see, for example, the 2011 robo-calls scandal or Cheryl Gallant sending birthday cards from data found in passport applications). These concerns are heightened when parties at multiple levels 
begin sharing data as more actors become involved and the likelihood of a breach increases.

Similarly, concerns that micro targeting can undermine the principles of panCanadianism and national politics are equally valid. While it may be more effective and efficient from a party resource perspective, micro targeting is problematic democratically. This is because unique messages are tailored for different groups, and only certain segments of the population are engaged with during the campaign. This, of course, has implications for the quality of democracy as ignoring large groups of voters can cause alienation, disillusionment, and antipathy. While parties would, and do, engage in micro targeting and voter surveillance of this kind without integration, the relationships and networks between federal and provincial parties facilitates sophisticated data collection and usage. The implications of party integration therefore extend far beyond party organization and have consequences for national unity, political participation, and voter surveillance.

\section{Future Party Integration Research}

It is worth ending with a brief discussion about potential avenues for future party integration research (both as it relates to the Canadian case and more broadly). While this in depth examination of party integration in Ontario has made a number of advancements (both empirically and theoretically), our understanding of party integration remains incomplete. In particular, there are a number of important new questions that arise from this work and require attention. In light of this, three 
recommendations for future research on the subject of multi-level party linkages are offered.

First, further examinations of non-party based determinants of integration are warranted. While this analysis included electoral success, urban/rural location, incumbency, party, and position in cabinet, future research would benefit from considering other constituency level factors such as the geographical size of the riding or population of the electoral district. ${ }^{70}$ Likewise, while the analysis here focused on parties competing in single member districts, future studies might also explore the factors that are important and relevant in more proportional electoral systems. Given that it has been hypothesized that the type of federal arrangement influences how parties organize (i.e., Chhibber and Kollman, 2004), it should not be surprising that other institutional factors could also play a role in shaping the opportunities and challenges that political parties face when organizing for multi-level politics.

Second, analysis of party integration in Canada needs to be expanded beyond the province of Ontario. To be sure, this case provides a unique opportunity to explore the role of organization and ideology on party integration. Much of the existing Canadian scholarship on the subject, however, has also focused on this single province (i.e., Esselment, 2010; Jacek et al. 1972). Even work that takes a more comparative approach to include other provinces tends to focus much of the analysis and commentary on Ontario (Dyck, 1991; Koop, 2011). Given the congruence of both federal-provincial party systems and electoral boundaries in the province, the findings presented about

\footnotetext{
${ }^{70}$ This is a limitation of the current study. That not all associations provided their location means that inclusion of these kids of variables was not practical.
} 
integration in Ontario may not be fully representative of the experiences of parties in other provinces.

As a result, an empirical examination of party integration in other provinces is needed. While this would entail a large-scale data collection exercise, such a crossprovincial examination would allow for a much more rich and in-depth exploration of party integration in Canada. Moreover, given that this thesis has demonstrated that integration can occur even in the absence of interconnected party structures, it is very possible that integration occurs in an informal fashion in other provinces that have very different party systems. How, for example, do the federal Conservatives react to having multiple 'conservative' options available in Alberta? How does the practice of informal integration play out when there is more than one option? The answer is not obvious, and we have little more than news reports to go on. While Ontario is interesting for its own reasons, the situations in other provinces raise new questions that deserve attention from party and federalism scholars alike.

Finally, it is also worth considering party integration from a horizontal perspective in addition to our vertical conception. Horizontal integration refers to the organizational connections and collaborations between parties of the same name in different provinces. While the geographic size of Canada undoubtedly poses obstacles for horizontal integration, the absence of any systematic attempt to study party linkages between parties in the provinces is an obvious omission in the literature. Is such horizontal integration impossible in a geographically vast country like Canada with its numerous regional political cultures and ideological differences? Are some provincial 
parties more closely connected than others, and if so, what accounts for this? These questions have yet to be explored in a serious manner in the literature.

Thus, despite the considerable contribution that this study has made to our understanding of the intersection of federalism and political parties, many questions still remain and further research is required before a complete picture of integration, especially in other jurisdictions, is fully realized. 


\section{References}

Archer, Keith and Alan Whitehorn. 1997. Political Activists: The New Democrats in Convention. Toronto: Oxford University Press.

Associated Press. 2014. "Liberal Candidate in Toronto Byelections gets shot of Star Power from Ont. Premier," CTV News, June 28. Retrieved from http://www.ctvne ws.ca/politics/liberal-candidate-in-toronto-byelection-gets-shot-of-star-powerfrom-ont-premier-1.1890963 (Accessed June 20, 2015).

Bailey, Ian and Karen Howlett. 2014. "BC Liberal Executive Caught up in Ontario Scandal," The Globe and Mail, April 3. Retrieved from http://www.theglobeandm ail.com/news/british-columbia/bc-liberal-executive-caught-up-in-ontarioscandal/article17807705/ (Accessed June 20, 2015).

Bakvis, Herman. 1989. "Regional Politics and Policy in the Mulroney Cabinet, 1984-88: Towards a Theory of the Regional Minister System in Canada," Canadian Public Policy 15(2): 121-134.

. 1991. Regional Ministers: Power and Influence in the Canadian Cabinet. Toronto: University of Toronto Press.

. 1994. "Political Parties, Party Government and Intrastate Federalism in Canada." In Parties and Federalism in Australia and Canada ed. Campbell Sherman. Canberra: Federalism Research Centre.

Bardi, Luciano and E. Calossi. 2009. "Models of Party Organization and Europarties." In Activating the Citizen. Dilemmas of Participation in Europe and Canada, ed. Joan DeBardeleben and Jon H. Pammett. Basingstoke: Palgrave.

Barrie, Doreen and Roger Gibbins. 1989. "Parliamentary Careers in the Canadian Federal State," Canadian Journal of Political Science 22 (1): 137-45.

Barratt, Mark. 2004. "Understanding the Meaning of Collaboration in the Supply Chain," Supply Chain Management: An International Journal 9: 30-42.

Bartolini, Stefano and Peter Mair. 1990. Identity, Competition and Electoral Availability. The Stability of European Electorates 1885-1985. Cambridge: Cambridge University Press.

Béland, Daniel. 2009. "Ideas, Institutions, and Policy Change," Journal of European Public Policy 16(5): 701-718.

Bélanger, Éric. 2003. "Issue Ownership by Canadian Political Parties 1953-2001." Canadian Journal of Political Science 36(3): 539-558. 
Bennett, Colin. 2013. "What Political Parties Know About You," Policy Options: 50-53.

Benoit, Kenneth and Michael Laver, 2007. "Estimating Party Policy Positions: Comparing Expert Surveys and Hand-Coded Content Analysis," Electoral Studies 26(1): 90-107.

Benzie, Robert. 2007. "John Tory Turns to Harper for Help in Keeping Job,” Toronto Star, December 6. Retrieved from http://www.thestar.com/news/2007/12/06/ john tory turns to harper for help in keeping job.html (Accessed June 20, 2015).

. 2009. "Tories say party lists misused - by Tories," The Toronto Star, May 15. Retrieved from http://www.thestar.com/news/ontario/2009/05/15/tories_say party lists misused by tories.html (Accessed June 20, 2015).

Berelson, Bernard R., Paul F. Lazarsfeld, and William N. McPhee. 1954. Voting: A Study of Opinion Formation in a Presidential Campaign. Chicago: The University of Chicago Press.

Biezen, Ingrid van, Peter Mair, and Thomas Poguntke. 2012. "Going, going,...gone? The Decline of Party Membership in Contemporary Europe," European Journal of Political Research 51(1): 24-56.

Black, Edwin. 1972. "Federal Strains within a Canadian Party." In Party Politics in Canada, ed. H.G. Thorburn. Scarborough: Prentice-Hall. . 1989. "Federal Strains Within a Canadian Party." Federalism in Canada: Selected Readings, ed. Garth Stevenson. Toronto: McClelland and Stewart.

Blake, Donald. 1982. "The Consistency of Inconsistency: Party Identification in Federal and Provincial Politics," Canadian Journal of Political Science 15 (4): 691-710.

.1985. Two Political Worlds: Parties and Voting in British Columbia. Vancouver: University of British Columbia Press.

, Kenneth Carty and Lynda Erickson. 1991. Grassroots Politicians: Party Activists in British Columbia. Vancouver: University of British Columbia Press.

Blais, André. 2010. “Making electoral democracy work.” Electoral Studies 29(1): 169170.

Bledsoe, T., and M. Herring. 1990. "Victims of Circumstances: Women in Pursuit of Political Office," American Political Science Review 84(1): 213-23.

Blyth, Mark. 2001. "The Transformation of the Swedish Model: Economic Ideas, Distributional Conflict, and Institutional Change," World Politics 54: 1-26. 
Bradbury, Jonathan. 2006. "British Political Parties and Devolution: Adapting to Multilevel Politics in Scotland and Wales." In Devolution and Electoral Politics, ed. Dan Hough and Charlie Jeffery. Manchester: Manchester University Press.

Bradley, Anthony, J. and Mark P. McDonald. 2011. "All Organizations are Social, But few are Social Organizations," Harvard Business Review. Retrieved from https://hbr.org/2011/10/all-organizations-are-social-b (Accessed June 20, 2015).

Brennan, Richard. 2013. "Secret Document Spells out Tories' Campaign," Toronto Star, November 11. Available at http://www.thestar.com/news/queenspark/2013/11/11/ secret_document_spells_out_tories_campaign.html (Accessed June 20, 2015).

Bryden, Joan. 2014. "Federal NDP Staffers Split with Union that Urged Strategic Voting in Ontario," The Globe and Mail, July 3. Retrieved from http://www.theglobe andmail.com/news/politics/federal-ndp-staffers-split-with-union-that-urgedstrategic-voting-in-ontario/article19438907/ (Accessed June 20, 2015).

Budge, Ian. 2001. "Validating Party Policy Placements," British Journal of Political Science 31(1): 210-223.

Burgess, Mark. 2015. "Alberta Tory Ridings Transferred Money To Secure Fort Mac In 2014 Byelection After EDA Lacked Funds," The Hill Times, March 16. Retrieved from http://www.hilltimes.com/news/news/2015/03/16/alberta-tory-ridingstransferred-money-to-secure-fort-mac-in-2014-byelection-after/41398 (Accessed June 20, 2015).

Cairns, Alan. 1988. "The Living Canadian Constitution" In Constitution, Government and Society in Canada: Selected Essays by Alan C. Cairns, ed. D.E. Williams. McClelland and Stewart.

Camic, Charles and Neil Gross. 2001. "The New Sociology of Ideas." In The Blackwell Companion to Sociology, ed. J. Blau. Cambridge: Blackwell.

Campbell, Angus, Philip E. Converse, Warren E. Miller, and Donald E. Stokes. 1960. The American Voter. New York: Wiley.

Campbell, Will. 2014. "Federal NDP, Liberals see Different Lessons from Ontario Vote for Toronto Byelection," The Globe and Mail, June 21. Retrieved from http://www.theglobeandmail.com/news/politics/federal-ndp-liberals-see-differentlessons-from-ontario-vote-for-toronto-byelection/article19282353/ (Accessed June 20, 2015).

Canadian Press. 2015. "Eve Adams Confirms she will seek Liberal Nomination in Toronto Riding of Eglington-Lawrence," National Post, February 11. Retrieved from http://news.nationalpost.com/news/canada/canadian-politics/eve-adams- 
confirms-she-will-seek-liberal-nomination-in-toronto-riding-of-eglinton-lawrence (Accessed June 20, 2015).

Caramani, Daniele. 2006. "Is There a European Electorate and What Does It Look Like? Evidence from Electoral Volatility Measures, 1976-2004," West European Politics 29(1): 1-27.

Carroll, S. 1985. "Political Elites and Sex Differences in Political Ambition: A Reconsideration," Journal of Politics 47 (4): 1231-1243.

Carty, Kenneth. 1988. "Three Canadian Party Systems: An Interpretation of the Development of National Politics," In Party Politics in Canada $8^{\text {th }}$ edition, eds. George Throburn and Alan Whitehorn. Toronto: Prentice-Hall. 1991. Canadian Political Parties in the Constituencies. Dundurn Press. . 2002. "The Politics of Tecumseh Corners: Canadian Political Parties as Franchise Organizations," The Canadian Journal of Political Science 35(4): 723745 .

. 2004. "Parties as franchise systems: the stratarchical organizational imperative," Party Politics 10:15-24.

. 2013a. "Has Brokerage Politics Ended? Canadian Parties in the New Century," In Parties, Elections, and the Future of Canadian Politics, eds. Royce Koop and Amanda Bittner. Vancouver: UBC Press, 2013.

. 2013b. "Are Political Parties Meant to be Internally Democratic?," In The Challenges of Intra-party Democracy. Oxford: Oxford University Press.

and Munroe Eagles. 2005. Politics is Local: National Politics at the Grassroots. Oxford: Oxford University Press.

and Cross, William. 2006. "Can Stratarchically Organized Parties be Democratic? The Canadian case," Journal of Elections, Public Opinion and Parties 16(2): 93-114.

and Lisa Young. 2000. Rebuilding Canadian Party Politics. Vancouver: University of British Columbia Press.

Clark, Peter B., and James Q. Wilson. 1961. "Incentive Systems: A Theory of Organizations," Administrative Science Quarterly 6(2): 129-66.

CBC. 2006a. "NDP Dumps Buzz Hargrove," CBC News. February 12. Retrieved from http://www.cbc.ca/news/canada/ndp-dumps-buzz-hargrove-1.620335 (Accessed June 20, 2015). 
. 2006b. "PMs Comments Draw Fire," CBC News. Retrieved from

http://www.cbc.ca/canada/toronto/story/2006/05/05/tomcguintyharper20060505.ht $\underline{\mathrm{ml}}$ (Accessed June 20, 2015).

. 2008a. "'Anything but Conservative' Campaign Hurting N.L. Tories," $C B C$

News, September 2. Retrieved from http:/www.cbc.ca/n

ews/canada/newfoundland-labrador/anything-but-conservative-campaign-hurting-

n-1-tories-source-1.694946 (Accessed June 20, 2015).

. 2008b. "Goose Egg: Conservative Vote Collapses in N.L.," CBC News,

October 14. Retrieved from http://www.cbc.ca/news/canada/newfoundlandlabrador/goose-egg-conservative-vote-collapses-in-n-1-1.731366 (Accessed June 20, 2015).

. 2011a. "McGuinty has no Plans to Campaign for Ignatieff," $C B C$ News. March 26. Retrieved from http://www.cbc.ca/news/canada/ottawa/mcguinty-has-noplans-to-campaign-for-ignatieff-1.980940 (Accessed June 20, 2015).

. 2011b. "NDP MP Accused of Improper Ontario Campaigning," CBC News, September 27. Retrieved from http://www.cbc.ca/news/canada/ndp-mp-accusedof-improper-ontario-campaigning-1.1001832 (Accessed June 20, 2015).

. 2012a. "NDP Coming to Quebec for Next Election," CBC News. August 17. Retrieved from http://www.cbc.ca/news/canada/montreal/ndp-coming-to-quebecfor-next-election-1.1183826 (Accessed June 20, 2015).

. 2012b. "Who's Who in the Election Prone Calls Controversy," CBC News. February 29. Retrieved from http://www.cbc.ca/news/canada/who-s-who-in-theelection-phone-calls-controversy-1.1128163 (Accessed June 20, 2015).

. 2014a. "Federal MPs Taking Active Role In Ontario Campaign," CBC News. Retrieved from http://www.cbc.ca/news/canada/toronto/ontario-votes2014/federal-mps-taking-active-role-in-ontario-campaign-1.2650157 (Accessed June 20, 2015).

. 2014b. "Feds Swipe at Kathleen Wynne as Ontario Campaign Kicks Off," $C B C$ News. May 3. Retrieved from http://www.cbc.ca/news/politics/feds-swipe-atkathleen-wynne-as-ontario-campaign-kicks-off-1.2630642 (Accessed June 20, 2015).

. 2014c. "Tom Mulcair Wades into Ontario Election Fray to Support NDP," $C B C$ News. June 4. Retrieved from http://www.cbc.ca/news/canada/toronto/ontariovotes-2014/tom-mulcair-wades-into-ontario-election-fray-to-support-ndp1.2665387 (Accessed June 20, 2015). 
. 2014d. "Clement Keeps up Federal Pressure on Wynne," CBC News, May 6.

Retrieved from http://www.cbc.ca/news/canada/toronto/ontario-votes-

2014/ontario-votes-clement-keeps-up-federal-pressure-on-wynne-1.2634190

(Accessed June 20, 2015).

Chhibber, Pradeep and Ken Kollman. 2004. The formation of national party systems: federalism and party competition in Canada, Great Britain, India and the United States. Princeton: Princeton University Press.

Clark, Campbell. 2015. "NDP in Alberta: This is the Campaign that Jack Built," The Globe and Mail, May 8. Retrieved from http://www.theglobeandmail.com/news /politics/this-is-the-campaign-that-jack-built/article24326067/ (Accessed June 20, 2015).

Clarkson, Stephen. 2005. The Big Red Machine: How the Liberal Party Dominates Canadian Politics. Vancouver: University of British Columbia Press.

Clarke, Harold D., Jane Jenson, Lawrence LeDuc, and Jon H. Pammett. 1979. Political Choice in Canada. Toronto: McGraw-Hill Ryerson.

Toronto: McGraw-Hill Ryerson. . 1980. Political Choice in Canada. Abridged edition. and Marianne Stewart. 1987. "Partisan Inconsistency and Partisan Change in Federal States: The Case of Canada," American Journal of Political Science 31: $383-407$.

, Allan Kornberg, Faron Ellis and Jon Rapkin .1999. "Not For Fame or Fortune: A Note on Membership and Activity in the Canadian Reform Party," Party Politics 6: 75-93.

City News. 2013. "Wynne, Trudeau Join Campaign Trail as Byelection Nears," November 23. Retrieved from http://www.citynews.ca/2013/11/23/wynne-trudeaujoin-campaign-trail-as-byelection-nears/(Accessed June 20, 2015).

Cole, Alexandrea. 2005. "Old Right or New Right? The Ideological Positioning of Parties of the Far Right," European Journal of Political Research 44(2): 203-230

Conservative Party of Canada. 2011. "Conservative Party of Canada Constitution," Amended June 11, 2011.

Constantini, E. 1990. "Political Women and Political Ambition: Closing the Gender Gap," American Journal of Political Science 34:741-70.

Coletto, David 2010. "A Matter of Quality? Candidates in Canadian Constituency Elections." Unpublished PhD thesis, University of Calgary. 
Coutts, Jane. 1999. "Federal Grit No-Shows No Problem: McGuinty. Lack Of Obvious Input From Ottawa Doesn't Mean Absence Of Support For His Campaign, He Says," The Globe and Mail. June 3.

Cross, William. 1996. Grassroots Participation in Canadian Political Parties: An Examination of Leadership Selection, Candidate Nomination, Policy Development and Election Campaigning. Doctoral dissertation, University of Western Ontario. . 2004. Political Parties. Vancouver: University of British Columbia Press. .2006. Candidate Nomination in Canada's Political Parties," In The Canadian General Election of 2006, eds. Jon Pammett and Christopher Dornan. Toronto: Dundurn Press. . 2007. "Policy Study and Development in Canada's Political Parties," In Policy Analysis in Canada: The State of the Art, eds. Laurent Dobuzinskis, Michael Howlett and David Laycock. Toronto: University of Toronto Press.

. 2008. "Democratic Norms and Party Candidate Selection: Taking Contextual Factors into Account," Party Politics 14(5): 596-619.

. 2015. "Canada: A Challenging Landscape for Political Parties and Civil Society in a Fragmented Polity." In Federalism, Political Parties and Civil Society, eds. Klaus Detterbeck and Wolfgang Renzsch. Oxford: Oxford University Press.

and Lisa Young. 2004. The Contours of Party Membership in Canada. Party Politics 10(4): 427-444.

and Lisa Young. 2002. "Policy Attitudes of Party Members in Canada: Evidence of Ideological Politics." Canadian Journal of Political Science 35 (4): 859-80

and Lisa Young. 2011, 'Explaining Local Campaign Intensity: the Canadian General Election of 2008', Canadian Journal of Political Science 44(3): 553-571.

and Lisa Young. 2013. "Candidate Recruitment in Canada: The Role of Political Parties," In Parties, Elections, and the Future of Canadian Politics, eds. Royce Koop and Amada Bittner. Vancouver: University of British Columbia Press. and Dick Katz (eds.). 2013. The Challenges of Intra-party Democracy. Oxford: Oxford University Press.

, Jonathan Malloy, Tamara Small and Laura Stephenson. 2015. Fighting for Votes: Parties, the Media, and Voters in an Ontario Election. Vancouver: University of British Columbia Press. 
Cross, Rob and Laurence Prusak. 2002. "The People Who Make Organizations Go - or Stop," Harvard Business Review, June 1.

Cullen, Nathan. 2011. "BC NDP MLAs Endorse Nathan Cullen for Leader.” Retrieved from http://www.nathancullen.ca/en/media/bc-ndp-mlas-endorse-nathan-cullenfor-leader (Accessed June 20, 2015).

Cutler, Fred. 2004. "Government Responsibility and Electoral Accountability in Federations," Publius 34(2): 19-38. . 2008a. "Whodunnit? Voters and Responsibility in Canadian Federalism. Canadian Journal of Political Science 41(3): 627-654.

. 2008b. "One voter, two first-order elections?," Electoral Studies 27(3): 492504.

Daily Exchange, 2011. "Ontario NDP Leader Welcomes Local NDP Candidates to her Team," August 12. Retrieved from http://www.exchangemagazine.com/morni ngpost/2011/week32/Friday/081205.htm (Accessed June 20, 2015).

Dalton, Russell J. 1984. "Cognitive Mobilization and Partisan Dealignment in Advanced Industrial Democracies," Journal of Politics 46(2):264-284. and Martin P. Wattenberg. 2000. Parties without Partisans. Political Change in Advanced Industrial Democracies. New York: Oxford University Press.

Dawson, R. MacGregor. 1947. The Government of Canada. Toronto: University of Toronto Press.

Delacourt, Susan. 2012. “Justin Trudeau's Inner Circle Draws Heavily On Help Of Long-Time Friends," Toronto Star, September 26. Retrieved from http://www.the star.com/news/canada/2012/09/26/justin_trudeaus_inner_circle_draws_heavily_on help of longtime friends.html (Accessed June 20, 2015).

. 2014. "Christine Innes Fighting Back Against Trudeau," The Toronto Star, April 3. Retrieved from http://www.thestar.com/news/canada/2014/04/03/ christine innes fighting back against trudeau.html (Accessed June 20, 2015).

Denver, David and Gordon Hands. 2004. "Lobour's Targeted Constituency Campaigning” Nationally Directed or Locally Produced? Electoral Studies 23: $709-726$.

Justin Fisher and Ian MacAllister. 2003. "Constituency Campaigning in Britain 1992-2001: Centralization and Modernization," Party Politics 9(5): 541539. 
Deschouwer, Kris. 2003. "Political Parties in Multi-layered Systems," European Urban and Regional Studies 10 (3) 213-26.

. 2006. "Political Parties as Multi-level Organizations." In Handbook of Party

Politics, eds. Rick Katz and W. Crotty. London: Sage.

Detterbeck, Klaus. 2011. "Party Careers in Federal Systems. Vertical Linkages within Austrian, German, Canadian and Australian Parties," Regional and Federal Studies 21 (2): 245-70.

. 2012. Multi-Level Party Politics in Western Europe. Basingstoke: Palgrave.

Dewar, Paul. 2012. "Nova Scotia MLA Maurice Smith Endorses Paul Dewar for Leader of the NDP." Retrieved from http://pauldewar.ca/content/nova-scotia-mlamaurice-smith-endorses-paul-dewar-leader-ndp (Accessed June 20, 2015).

Diebel, Linda. 2011. "Meet Don Guy, the 'Godfather of Queen's Park,"” Toronto Star, December 3. Retrieved from http://www.thestar.com/news/canada/2011/12 /03/meet don guy the godfather of queens park.html (Accessed June 20, 2015).

Docherty, David. 1997. Mr. Smith Goes to Ottawa: Life in the House of Commons. Vancouver: University of British Columbia Press. 2005. Legislatures. Vancouver: University of British Columbia Press.

Donovan, Todd and Jeffrey A. Karp. 2006. "Popular Support for Direct Democracy," Party Politics 12(5): 671-688.

Downs, Anthony. 1957. An Economic Theory of Democracy. New York: Harper and Row.

Drummond, Andrew J. 2006. "Electoral Volatility and Party Decline in Western Democracies: 1970- 1995," Political Studies 54(3): 628-647.

Duverger, Maurice. 1954. Political Parties: Their Organization and Activity in the Modern State. New York: Wiley.

Dyck, Rand. 1991. "Links between Federal and Provincial Parties and Party Systems," In Representation, Integration, and Political Parties in Canada, ed. Herman Bakvis. Toronto: Dundurn Press. . 1996. "Relations Between Federal and Provincial Parties," In Canadian Parties in Transition, eds. Brian Tanguay and Alian Gagnon. Scarborough: Nelson. 
Eagles, Munroe and Annika Hagley. 2010. "Constituency Campaigning in Canada," In Election, ed. Heather McIvor. Peterborough: Emond Montgomery Press.

Elections Canada. 2011. "Financial Reports of Political Parties" Retrieved from http://www.elections.ca/content.aspx?section=pol\&dir=limits\&document=index \&1 ang $=\mathrm{e}$ (Accessed June 20, 2015).

Elections Ontario. 2011. “2011 Political Party Campaign Returns” Retrieved from http://www.elections.on.ca/en-CA/Tools/FinancialStatementsandContributions /FilingStatus/2011PoliticalPartyCampaignReturns.htm (Accessed June 20, 2015).

Eldersveld, S. J. 1964, Political Parties: A Behavioural Analysis. Chicago: Rand McNally.

Elder, L. 2004. "Why Women Don't Run: Explaining Women's Underrepresentation in America's Political Institutions," Women and Politics 26(2): 27-56.

Erk, Jan. 2008 Explaining Federalism: State, Society And Congruence In Austria, Belgium, Canada, Germany And Switzerland. London: Routledge. and Wilfred Swenden. 2010 eds. New Firections in Federalism Studies. London: Routledge.

Erickson, Lynda. 1997. “Might More Women Make a Difference? Gender, Party and Ideology Among Canada's Parliamentary Candidates." Canadian Journal of Political Science 30(4): 663-88.

and David Laycock. 2002. "Post-materialism Versus the Welfare State? Opinion Among English Canadian Social Democrats," Party Politics 8(3): 301-325.

Erickson, Robert and Mikhail Filippov. 2001. "Electoral Balancing in Federal and Subnational Elections: The Case of Canada," Constitutional Political Economy 12: 313-331.

Esselment, Anna. 2008. "Fighting Elections: An Example of Cross-Level Political Party Integration in Canada," Paper for presentation at the Canadian Political Science Association. June 6. . 2009. "Family Matters: The Role of Partisanship in Federal-Provincial Relations in Canada." Doctoral dissertation, The University of Western Ontario, London, Ontario. . 2010. "Fighting Elections: Cross-Level Political Party Integration in Ontario," Canadian Journal of Political Science 43(4): 871-892. 
. 2013. "A Little Help from My Friends: The Partisanship Factor and Intergovernmental Negotiations in Canada," Publius: The Journal of Federalism 43: $701-27$

Fabre, Elodie. 2007. Party Organisation In A Multi-Level Setting: Spain And The United Kingdom. Unpublished PhD thesis, Catholic University of Leuven, Belgium.

. 2008. "Party Organization in a Multi-level System: Party Organizational

Change in Spain and the UK," Regional and Federal Studies 18(4): 309-329.

. 2009. "Measuring Party Organization: The Vertical Dimension of the Multilevel Organization of State-Wide Parties in Spain and the UK," Party Politics 17 (3): 343-63.

Fekete, Jason. 2015. "Conservative MPs Take Sides In Ontario PC Leadership Race," Ottawa Citizen January 2. Retrieved from http://ottawacitizen.com/news/politics/ conservative-mps-take-sides-in-ontario-pc leadership-race (Accessed June 20, 2015).

Ferguson, Rob. 2014. "NDP Aasn't Ready for Election, Defeated Veterans say," The Toronto Star, June 19. Retrieved from http://www.thestar.com/news/queenspark /2014/06/19/ndp_went too far_right and wasnt ready for_election_defeated ve terans say.html (Accessed June 20, 2015).

Flanagan, Tom. 2007. Harper's Team: Behind the Scenes in the Conservative Rise to Power. Montreal-Kingston: McGill-Queen's University Press. . 2010. "Campaign Strategy: Triage and the Concentration of Resources," In Election, ed. Heather McIvor. Peterborough: Emond Montgomery Press.

Fischer, Jorn, and Klaus Stolz. 2010. "Patterns of Ministerial Careers across Territorial Levels in Germany." Paper presented at the annual meeting of the Canadian Political Science Association, Montreal.

Filippov, M., P. C. Ordeshook and O. Shvetsova. 2004. Designing Federalism. A Theory Of Self-Sustainable Federal Institutions. Cambridge: Cambridge University Press.

Fournier, Patrick, Fred Cutler, Stuart Soroka, and Dietlind Stolle. 2011. The 2011 Canadian Election Study [dataset]. Retrieved from http://ces-eec.org/ pagesE/surveys.html

Funke, Alice. 2014. "Conservative Software Project Went Into Production in 2013, Financial Statements Show," Pundits Guide July 3. Retrieved from http://www. punditsguide.ca/2014/07/conservative-software-project-went-into-production-in2013-financial-statements-show/ (Accessed June 20, 2015). 
Galloway, Gloria. 2005. "Younger Blood Flows in Tory war room." The Globe and Mail November 21, A5.

. 2010. "Tory Campaign College Offers Lesson in Favours," The Globe and Mail, August 19. Retrieved from http://www.theglobeandmail.com/news/politics/ tory-campaign-college-offers-lesson-in-favours/article1377739/ (Accessed June 20, 2015).

. 2011. "Despite Hopes for hat Trick, Harper Strikes Conciliatory tone with McGuinty; Letting Bygones be Bygones, PM Congratulates Ontario Liberal". The Globe and Mail. October 7. Retrieved from http://www.theglobeandmail .com/news/politics/ottawa-notebook/despite-hopes-for-hat-trick-harper-strikesconciliatory-tone-with-mcguinty/article618125/ (Accessed June 20, 2015).

Gagnon, Alain-G. 2009. Contemporary Canadian Federalism. Toronto: University of Toronto.

Gauja, Anika. 2012. The Politics of Party Policy: From Members to Legislators. Basingstoke, United Kingdom: Palgrave Macmillan.

Gélineau, Francois and Éric Bélanger. 2005. "Electoral Accountability in a Federal System: National and Provincial Economic Voting in Canada." Publius 35(3): 407- 424.

Government of Canada. 2013. "Members of the House of Commons." Parliament of Canada. Retrieved from http://www.parl.gc.ca/Parlinfo/Lists/Members.aspx? Language $=\mathrm{E} \&$ Current $=$ True. . (Accessed June 20, 2015).

Government of Ontario. 2013. "Past and Present MPPs." Legislative Assembly of Ontario. Available at http://www.ontla.on.ca/web/members/members all.do?locale=en. (Accessed June 20, 2015). . 1990. Election Finances Act. Section 20.

Hall, P. A. and C. R. Taylor. 1996. "Political Science And The Three New Institutionalisms," Political Studies 44: 936-57.

Herbert, Chantal. 2014. “Ontario Election Foreshadows 2015 Federal Race," Guelph Mercury, June 11. Retrieved from http://www.guelphmercury.com/opinionstory/4569592-ontario-election-foreshadows-2015-federal-race/ (Accessed June 20, 2015).

Hix, Simon and Michael Marsh. 2011. "Second-Order Effects plus Pan-European Political Swings: An Analysis of European Parliament Elections across Time," Electoral Studies 30: 4-15. 
Hofferth, Sandra. L. and Iceland, John. 1998. "Social Capital in Rural and Urban Communities," Rural Sociology 63: 574-598.

Hooghe, Liesbet and Gary Marks. 2003. "Unraveling the Central State, but How? Types of Multi-level Governance." American Political Science Review 97 (2): 233-43.

, and Gary Marks. 2001. Multi-Level Governance and European Integration. Lanham, MD: Rowman \& Littlefield.

Hopkin, Jonathan, and Jonathan Bradbury. 2006. "British Statewide Parties and Multilevel Politics," Publius 36(1): 135-152.

Hough, Dan and Charlie Jeffery. 2006. Devolution and Electoral Politics. Manchester: Manchester University Press.

Ibbitson, John. 2001. Loyal No More: Ontario's Struggle for a Separate Destiny. Toronto: Harper Collins.

Jacek, Henry, John McDonough, Ronald Shumzu, and Patrick Smith. 1972.

"Congruence of Federal-Provincial Campaign Activity in Party Organizations:

The Influence of Recruitment Patterns in 3 Hamilton Ridings," Canadian Journal of Political Science 5(2): 190-205.

Jick, Todd. 1979. "Mixing Qualitative and Quantitative Methods: Triangulation in Action," Administrative Science Quarterly 24: 602-611.

Johnston, Ronald John, and Pattie, Charles. 2006. Putting Voters in Their Place: Geography and Elections in Great Britain. Oxford: Oxford University Press.

Johnston, Richard. 2013. "The Electorate With A Janus-Face: Federal-Provincial Discrepancies In Canadian Electoral History," Paper Presented At The Annual Canadian Political Science Association, May 2013.

Kaplowitz, Michael, Timothy Hadlock and Ralph Levine. 2004. “A Comparison of Web and Mail Survey Response Rates," Public Opinion Quarterly. 68(1): 94-101.

Katz, Richard. 2013. "Should we Believe that Improved Intra-party Democracy Would Arrest Party Decline?" In The Challenges of Intra-party Democracy, eds. William Cross and Richard Katz. Oxford: Oxford University Press.

and Peter Mair. 1993. "The evolution of party organization in Europe: the three faces of party organization," The American Review of Politics 14: 593-617. . 1995. "Changing Models of Party Organization and Party Democracy: The Emergence of the Cartel Party," Party Politics 1(1): 5-28. 
Keating, Michael, and Alex Wilson. 2010. "Renegotiating the State of Autonomies: Statute Reform and Multi-level Politics in Spain," West European Politics 32(3): 536-558.

King, Anthony. 1969. "Political parties in Western Democracies: Some Sceptical Reflections," Polity, 2(2): 111-141.

Kirchheimer, Otto. 1966. "The Transformation of the Western European Party Systems," In Political Parties and Political Development, eds. Joseph LaPalombara and Myron Weiner. Princeton, NJ: Princeton University Press.

Koop, Royce. 2010. "Professionalism, Sociability, and the Liberal Party in the Constituencies," Canadian Journal of Political Science 43(4): 893-913. . 2011. Grass Roots Liberals: Organizing for Local and National Politics. Vancouver: University of British Columbia Press.

. 2012. "Party Constituency Associations and the Service, Policy, and Symbolic Responsiveness of Canadian Members of Parliament," Canadian Journal of Political Science 45(2): 359-378.

and Campbell Sharman. 2015. "National Party Structure in Parliamentary Federations" Subcontracting electoral Mobilisation in Canada and Australia," Commonwealth and Comparative Politics Online first.

Knopff, Rainer and Anthony Sayers. 2005.“Canada,” In Constitutional Origins, Structure, and Change in Federal Countries, eds. John Kincaid and G. Alan Tarr. Montreal and Kingston: McGill-Queen's University Press.

Krackhardt, David and Jeffry R. Hanson. 1993. "Informal Networks: The Company Behind the Chart," Harvard Business Review, July 1.

Ladrech, Robert. 2002. "Europeanization and Political Parties: Towards a Framework for Analysis," Party Politics 8(4): 389-403.

Ladurantaye, Steve. 2011. "PM's Aide Commissions Ontario Riding Poll that's Much More to his Liking." The Globe and Mail. September 27. Retrieved from http://www.theglobeandmail.com/news/politics/ottawa-notebook/pms-aidecommissions-ontario-riding-poll-thats-much-more-to-his-liking/article617756/ (Accessed June 20, 2015).

Lane, Jan-Erik and Svante Ersson. 2007. "Party System Instability in Europe: Persistent Differences in Volatility between West and East," Democratization 14(1):92-110. 
Lazarsfeld, Paul F., Bernard Berelson, and Hazel Gaudet. 1944. The People's Choice: How the Voter Makes Up His Mind in a Presidential Campaign. New York: Columbia University Press.

Lau, Richard R. and David P. Redlawsk. 2001. "Advantages and Disadvantages of Cognitive Heuristics in Political Decision Making," American Journal of Political Science 45(4): 951-971.

Lawless, Jennifer and Richard Fox. 2010. It Still Takes A Candidate: Why Women Don't Run For Office. Cambridge, MA: Cambridge University Press.

LeDuc, Lawrence. 2001. "Democratizing party leadership selection," Party Politics 7(3): 323-341. and Jon Pammett. 2012. "Multilevel Patterns of Electoral Participation in Canada and Europe," Paper for presentation at the annual American Political Science Association.

Leslie, Keith. 2013. "Robocalls Also Made During Ontario Election, say Liberal, NDP Candidates," Toronto Star, March 1. Retrieved from http://www.thestar.com/ news/canada/2012/03/01/robocalls also made during ontario election say liber al_ndp_candidates.html (Accessed June 20, 2015).

Liberal Party of Canada. 2010. Model Constitution for Federal Liberal Electoral District Association.

Liberal Party of Ontario. 2012. "Constitution of the Ontario Liberal Party." As Amended September 29, 2012.

Mair, Peter and Ingrid van Biezen. 2001. "Party membership in twenty European democracies, 1980-2000," Party Politics 7(1): 5-21.

Mallen, Sean. 2014. "Ontario Election: Traditional NDP Supporters Disgruntled by New Policies," Global News, May 20. Retrieved from http://globalnews.ca/news/134 2879/ontario-election-traditional-ndp-supporters-disgruntled-by-new-policies/ (Accessed June 20, 2015).

Maher, Stephen. 2013. "Conservatives Admit they were Behind Last Week's Robocalls," National Post, February 5. Retrieved from http://news.nationalpo st.com/news/canada/canadian-politics/conservatives-admit-they-were-behind-lastweeks-saskatchewan-robocalls-after-voice-analysis-links-them (Accessed June 20, 2015).

Manning Centre. 2014. Manning Networking Conference" Available at http://mnc2014.ca/ (Accessed June 20, 2015). 
Marketing, 2008. "Zig, Element Agency Back up NDP, Liberals," Marketing Magazine, September 9. Retrieved from http://www.marketingmag.ca/brands/zig-elementagency-back-up-ndp-liberals-17545 (Accessed June 20, 2015).

Marks, Gary. 1993. "Structural Policy and Multilevel Governance in the EC." In The State of the European Community, ed. Alan Cafruny and Glenda Rosenthal. Boulder, CO: Lynne Rienner, 391-411.

, Liesbet Hooghe and Arjan Schakel. 2008. "Patterns of Regional Authority," Regional and Federal Studies 18(2-3): 167-181.

Martin, Lawrence. 2011. Harperland: The Politics of Control. Toronto: Penguin Canada.

Mays, Nicholas and Catherine Pope. 2000. "Assessing Quality in Qualitative Research." British Medical Journal 320: 50-52.

McGregor, Glen. 2013. "Tory Call Centre Company Under Control of U.S Investment Firm," Ottawa Citizen, December 13. Retrieved from http://ottawacitizen .com/news/tory-call-centre-company-under-control-of-u-s-investment-firm (Accessed June 20, 2015).

. 2014. "If the 2011 Vote was the Twitter Election then 2015 will be the big Data Election," The National Post, October 17. Retrieved from http://news.nati onalpost.com/2014/10/17/if-the-2011-vote-was-the-twitter-election-then-2015will-be-the-big-data-election/ (Accessed June 20, 2015).

. 2014. "The Big Data Election: Political Parties Building Detailed Voter Records," Ottawa Citizen October 18. Retrieved from http://ottawacitizen .com/news/politics/the-big-data-election-political-parties-building-detailed-voterrecords (Accessed June 20, 2015).

McMahon, Tasmin. 2011. "PM's Chief of Staff Latest to Jump into Ontario Election." The National Post, September 28. Available at http://news.nationalpost .com/news/canada/canadian-politics/pms-chief-of-staff-latest-to-jump-intoontario-election (Accessed June 20, 2015).

Meisel, John. 1963. “The Stalled Omnibus: Canadian Parties in the 1960s.” Social Research 30 (3): 367-390.

and Matthew Mendelsohn. 2000. "Meteor? Phoenix? Chameleon? The Decline and Transformation of Party in Canada." In Party Politics in Canada $8^{\text {th }}$ edition, eds. George Thorburn and Alan Whitehorn. Toronto: Prentice-Hall.

Moon, David, and Oivind Bratberg. 2010. "Conceptualizing the Multi-level Party: Two Complementary Approaches," Politics 30(1): 52-60. 
Morton, Desmond. 1997. "Sic Permanent: Ontario People and Their Politics." In The Government and Politics of Ontario, edited by Graham White. Toronto: University of Toronto Press.

Naumetz, Tim. 2014. "NDP MP says Tories, Libs going after NDP Mailings to Influence Ontario Election, Grit Calls Claim 'Absolute Paranoid Fantasy,"' Hill Times, June 4. Retrieved from http://www.hilltimes.com/news/politics/2014/06 /04/ndp-mp-says-tories-libs-ganging-up-on-ndp-mailings-now-to-try-to-influenceontario/38709 (Accessed June 20, 2015).

New Democratic Party of Canada. 2011. "Constitution of the New Democratic Party of Canada." Effective June 2011.

. 2013. "Constitution of the New Democratic Party of Canada." Effective April 2013.

New Democratic Party of Ontario. 2013. "Constitution of the New Democratic Party of Ontario."

Newman, James, Stephen Shaffer and David Breaux. 2004. "Motives for Involvement among Grassroots Party Activists in the Modern South," In Southern Political Party Activists eds., John Clark and Charles Prysby. Kentucky: University of Kentucky Press.

Nevitte, Neil, Blais, Andre, Gidengil, Elisabeth and Nadeau, Richard. 2000. Unsteady State: The 1997 Canadian Federal Election. Don Mills, Ontario: Oxford University Press.

Noel, Sid. 2007. "Leaders' Entourages, Parties, and Patronage." In Canadian Parties in Transition, ed. Alain-G. Gagnon and A. Brian Tanguay. 3rd ed. Peterborough ON: Broadview Press.

Norris, Pippa. 1997. "Second-order elections revisited," European Journal of Political Research 31, 109-115.

. 2002. Democratic Phoenix: Reinventing Political Activism. New York:

Cambridge University Press.

. 2005. "The impact of the Internet on political activism: Evidence from

Europe," International Journal of Electronic Government Research. 1(1): 20-39.

Northern Life. 2015. "Chrétien Endorse Thibeault in Sudbury Byelection,” January 28. Retrieved from http://www.northernlife.ca/news/localNews/2015/01/28-chretiensupports-thibeault-sudbury.aspx (Accessed June 20, 2015). 
Ontario Women's Liberal Commission. 2009. “Constitution of the Ontario Women's Liberal Commission.”

Ontario Young Liberals. 2014. "Constitution of the Ontario Young Liberals." August 17, 2014.

Paikin, Steve. 2008. "McGuinty Refuses to Support Dion," TVO, September 8. Retrieved from http://theagenda.tvo.org/blog/agenda-blog/mcguinty-refusessupport-dion (Accessed June 20, 2015).

Pedersen, Mogens N. 1979. "The Dynamics of European Party Systems: Changing Patterns of Electoral Volatility," European Journal of Political Research 7(1):126.

Pelizzo, Riccardo. 2003. "Party Positions or Party Direction? An Analysis of Party Manifesto Data," West European Politics 26(2): 67-89.

Perlin, George and P. Peppin. 1971. Variations in Party Support in Federal and Provincial Elections: Some Hypotheses," Canadian Journal of Political Science 4(2): 280-86.

. 1980. The Tory Syndrome: Leadership Politics in the Progressive Conservative Party. Montreal: McGill-Queen's University Press. 1988. Party Democracy in Canada: The Politics of National Party Conventions. Scarborough: Prentice-Hall.

Picard, Andre. 1989. "Quebec NDP opts for Autonomy," The Globe and Mail. May 1. A 2 .

Pilet, Jean-Benoit and William Cross. 2014. Leadership Selection in Contemporary Parliamentary Democracies: A Comparative Study. London: Routledge.

Poguntke, Thomas, Nicholas Aylott, Robert Ladrech and Kurt Richard Luther. 2007. "The Europeanisation of national party organisations: A conceptual analysis," European Journal of Political Research 46 (6): 747-71.

Progressive Conservative Party of Ontario. 2013. "Constitution," Amended September, 2013.

Putnam, Robert and Robert Leonardi and Rafaella Nanetti. 1993. Making Democracy Work: Civic Traditions in Modern Italy. Princeton, NJ: Princeton University Press.

Radia, Andy. 2011. "Federal Tories Involvement In Ontario Election Could Hurt Hudak: Pollster," Yahoo News, October 5. Retrieved from https://ca.news.yahoo 
.com/blogs/canada-politics/federal-tories-involvement-ontario-election-could-hurttim-173918513.html (Accessed June 20, 2015).

. 2014. "Win for Ontario Liberals Could Spell Challenges for Justin Trudeau next Federal Election," Yahoo News. June 13. Retrieved from https:/ca.news.yahoo.com/blogs/canada-politics/justin-trudeau-affect-ontarioelection-ontario-election-affect-194039927.html (Accessed June 20, 2015).

Radwanski, Adam. 2015a. "Kathleen Wynne's Controversies are a Weight on Trudeau's Liberals," The Globe and Mail, June 8. Retrieved from http://www.theg lobeandmail.com/news/national/kathleen-wynnes-controversies-are-a-weight-ontrudeaus-liberals/article24833733/ (Accessed June 20, 2015).

. 2015b. "As The Federal Election Year Begins, How Are The Tories, NDP And Liberals Preparing For The Campaign?," The Globe and Mail, January 2. Retrieved from http://www.theglobeandmail.com/news/politics/as-the-federalelection-year-begins-how-are-the-tories-ndp-and-liberals-preparing-for-thecampaign/article22282273/ (Accessed June 20, 2015).

Rana, Abbas. 2014. "Federal Tories not Worried about Ontario Election Results, vow not to Repeat Hudak's Campaign Mistakes," Hill Times, June 23. Retrieved from http://www.hilltimes.com/news/news/2014/06/23/federal-tories-not-worriedabout-ontario-election-results-vow-not-to-repeat-hudaks/38888 (Accessed June 20, 2015).

Ranney, Austin. 1981. "Candidate Selection," In Democracy at the Polls, eds. David Butler, Howard Penniman and Austin Ranney. Washington, DC: American Enterprise Institute.

Rayside, David. 1978. "Federalism and the Party System: Provincial and Federal Liberals in the Province of Quebec," Canadian Journal of Political Science 11(3): 499-528.

Reform Party of Canada. 1987. "Constitution of Reform Party of Canada," Adopted October 30, 1987.

Reif, K., H. Schmitt. 1980. "Nine second-order national elections: a conceptual framework for the analysis of European election results," European Journal of Political Research 8, 3-44.

. 1997. "European elections as member-state second-order elections revisited," European Journal of Political Research 31, 115-124.

Rider, David. 2014. “Kick Kouvalis was John Tory's Ford Whisperer," Toronto Star, November 3. Retrieved from http://www.thestar.com/news/city hall/toronto2014 
election/2014/11/03/nick kouvalis was john torys ford whisperer.html (Accessed June 20, 2015).

Riker, William. 1964. Federalism: Operation, Origin, Significance. Boston, MA: Little Brown.

Rocher, Francois. 2009. "The Quebec-Canada Dynamic or the Negation of the Ideal Federalism," In Contemporary Canadian Federalism, ed. Alain-G. Gagnon. Toronto: University of Toronto.

Samara. 2012. "By Invitation Only: Canadian's Perceptions of Political Parties". Retrieved from http://www.samaracanada.com/research/current-research/byinvitation-only (Accessed June 20, 2015).

Sartori, Giovanni. 1976. Parties and Party Systems: A Framework for Analysis. Cambridge: Cambridge University Press.

Sayers, Anthony. 1999. Parties, Candidates, and Constituency Campaigns in Canadian Elections. Vancouver: University of British Columbia Press.

Savoie, Donald. 1999. Governing from the Centre. Toronto: University of Toronto Press. 2008. Court Government and the Collapse of Accountability in Canada and the United Kingdom. Toronto: University of Toronto Press.

Scarrow, Howard. 1962. Canada Votes; A Handbook Of Federal And Provincial Election Data. New Orleans: Hauser Press.

. 1964. "Nomination and Local Party Organization in Canada: A Case Study," Western Political Quarterly 17 (1): 55-62.

Scarrow, Susan. 1999. Parties and the Expansion of Direct Democracy: Who Benefits? Party Politics 5(3): 341-62.

and B. Gezgor. 2010. "Declining Memberships, Changing Members? European political party members in a new era," Party Politics 16(6): 823-843.

Schattschneider, E. E. 1942. Party Government. New York: Rinehart.

Schmidt, Viven. 2008. "Discursive Institutionalism: The Explanatory Power of Ideas and Discourse," Annual Review of Political Science 11: 303-326.

Schmitz, Judith M., Robert Frankel and David J. Frayer. 1995. "Vertical Integration without Ownership: Strategic Alliances Offer a Managerial Alternative," Journal of Marketing: Theory and Practice Summer: 23-30. 
Schwartz, Mildred. 1990. The Party Network: The Robust Organization of Illinois Republicans. Madison: University of Wisconsin Press.

Seigfried, Andre. 1966. The Race Question in Canada. London: Eveleigh.

Seyd, Patrick, and Paul Whiteley. 1992. Labour's Grass Roots: The Politics of Party Membership. Oxford: Clarendon Press. Membership.

. 1999. "New Parties/New Politics? A Case Study of the British Labour Party," Party Politics 5(3): 383-405.

Sikk, Allan. 2005. "How Unstable? Volatility and the Genuinely New Parties in Eastern Europe," European Journal of Political Research 44(3):391-412.

Smiley, Donald V. 1976. Canada in Question: Federalism in the Seventies. Toronto: McGraw-Hill Ryerson.

. 1987. Canada In Question: Federalism In The Eighties, 3rd ed. (Toronto: McGraw-Hill Ryerson).

1987. The federal condition in Canada. Toronto: McGraw-Hill Ryerson.

Smith, Jennifer. 2004. Federalism. Vancouver: University of British Columbia Press.

Steele, Andrew. 2009. "Changes in Ottawa," The Globe and Mail, November 17. Retrieved from $h t t p: / / w w w . t h e g l o b e a n d m a i l . c o m / n e w s / p o l i t i c s / s e c o n d-$ reading/changes-in-ottawa/article 792977 (Accessed June 20, 2015).

Stewart, David and Ian Stewart. 1997. "Fission and Federalism: The Disaggregation of Canadian Party Activists," Publius 27(3): 99-111. and Keith Archer. 2000. Quasi-Democracy? Parties and Leadership Selection in Alberta. Vancouver: University of British Columbia Press.

and Kenneth Carty. 2002. "Leadership Politics as Party Building: The Conservatives in 1998" In Political Parties, Representation and Electoral Democracy in Canada, W. Cross ed. Oxford: Oxford University Press. and Kenneth Carty. 2006. "Many Political Worlds? Provincial Parties and Party Systems," In Provinces: Canadian Provincial Politics, ed. Christopher Dunn. Peterborough ON: Broadview Press.

Stolle, Dietlind, Marc Hooghe and Michele Micheletti. 2005. "Politics in the SuperMarket-- A Three Nation Pilot Survey on Political Consumerism as a Form of Political Participation," International Review of Political Science 26(3): 245-269. 
Stolz, Klaus. 2003. "Moving up, Moving Down: Political Careers Across Territorial Levels," European Journal of Political Research 42 (2): 223-48.

Taber, Jane. 2011a. "Barbecue Backlash and Prayers for Jack; The Conservatives are Rushing to Toronto Mayor Rob Ford's Fefence, and Jack Layton Speaks of the Power of Prayer," The Globe and Mail, August 4. Retrieved from http://www.theglobeandmail.com/news/politics/ottawa-notebook/barbec ue-backlash-and-prayers-for-jack/article616395/ (Accessed June 20, 2015).

. 2011b. "Ties that Bind Federal, Ontario Tories run Strong, Deep." The Globe and Mail, June 17. Retrieved from http://www.theglobeandmail.com/n ews/politics/ottawa-notebook/ties-that-bind-federal-ontario-tories-run-strongdeep/article615266/ (Accessed June 20, 2015).

and Bill Curry. 2011. "Tory Provincial Election Rule Number one: Don't Become the Story," The Globe and Mail, August 2011. Retrieved from http://www.theglobeandmail.com/news/politics/ottawa-notebook/tory-pro vincial-election-rule-number-one-dont-become-the-story/article616521 (Accessed June 20, 2015).

Tanguay, A.B. 1992. "Canadian Party Ideologies in the Electronic Age." In Canadian Political Party Systems: A Reader, ed. R.K. Carty. Toronto: Broadview Press.

The Toronto Star. 2003. "Liberal Party Membership Roll Swells To 531,536 As Vote Nears," July 25, A6.

Thelen, K. and S. Steinmo. 1992. "Historical Institutionalism in Comparative Politics," In Structuring Politics, eds. Steinmo, S., K. Thelen and F. Longstreth. Cambridge: Cambridge University Press.

Thorlakson, Lori. 2006. Party Systems in Multi-level Contexts. In Devolution and Electoral Politics, ed. Dan Hough and Charlie Jeffery. Manchester: Manchester University Press.

. 2009. "Patterns of Party Integration, Influence and Autonomy in Seven Federations," Party Politics 15(2): 157-177.

2011. "Measuring Vertical Integration in Parties with Multi-level Systems data," Party Politics 19: 713-734.

Truman, David. 1951. The Governmental Process. New York: Knopf.

Turner, Garth. 2007. "Nowhere to Hide," Garth Turner Commentaries. Retrieved from http://www.garth.ca/2007/10/12/nowhere-to-hide/ (Accessed June 20, 2015). 
Underhill, F. H. 1957. "Canadian Liberal Democracy in 1955," In Press and Party in Canada: Issues of Freedom, eds. Ferguson, G., and Underhill, F. H. Toronto: Ryerson.

van der Eijk, C., Franklin, M.N., Marsh, M., 1996. "What Voters Teach us about Europe-wide Elections: What Europe wide Elections teach us about Voters," Electoral Studies 15, 149-166.

Volkens, Andrea, Pola Lehmann, Nocolas Merz, Sven Regel and Annika Werner. 2013. "The Manifesto Data Collection. Manifesto Project." (MRG/CMP/MARPOR) Berlin: Wissenschaftszentrum Berlin für Sozialforschung (WZB).

von dem Berge, Benjamin, and Thomas Poguntke. 2013. "The Influence Of Europarties on Central and Eastern European Partner Parties: A Theoretical and Analytical Model," European Political Science Review 5(2): 311-334.

Walton, Dawn. 2012. "Alberta PC Party Considering Severing Voting Ties with Conservative MPs," The Globe and Mail, November 8. Retrieved from http://www.theglobeandmail.com/news/politics/albertas-pc-party-consideringsevering-voting-ties-with-conservative-mps/article5132897/ (Accessed June 20, 2015).

Ware, Alan. 1996. Political Parties and Party Systems. Oxford: Oxford University Press.

Waters, Rosanne. 2009. "The Relationship Between Provincial and Federal Political Parties: A Perspective from the Ontario Legislature". Paper for presentation at the annual Canadian Political Science Association.

Werner, Kevin. 2014. "Trudeau Looks to Provincial Libs to Help out in Election," Hamilton News. August 14.

Wesley, Jared. 2011. Code Politics: Campaigns and Cultures on the Canadian Prairies. Vancouver: University of British Columbia Press.

Whitaker, R. 1977. The Government Party: Organizing and Financing the Liberal Party of Canada 1930-58. Toronto: University of Toronto Press.

White, Graham. 2005. Cabinets and First Ministers. Vancouver: University of British Columbia Press.

Whiteley, Paul. F. 2010. "Is the Party Over? The Decline of Party Activism and Membership Across the Democratic World," Party Politics 17(1): 21-44.

Wilson, J., and Hoffman, D. 1970. "The Liberal Party in Contemporary Ontario Politics," Canadian Journal of Political Science 3: 177-204. 
Wingrove, Josh and Steven Chase. 2014. "Eve Adams Could Learn Political Fate this Week," The Globe and Mail April 7. Retrieved from http://www.theglobeandmail .com/news/politics/mp-could-learn-fate-this-week/article17869106/ (Accessed June 20, 2015).

Woolstencroft, Peter, and Faron Ellis. 2008. "Stephen Harper and the Conservatives Campaign on Their Record." In The Canadian General Election of 2008, eds. Chrisopher Dornan and Jon Pammett. Toronto: Dundurn.

Wolinetz, Steven B. and R. Ken Carty 2006. "Disconnected Competition in Canada," In Devolution and Electoral Politics, eds. Dan Hough and Charlie Jeffery Manchester: Manchester University Press, 2006.

Wrong, Denis. 1957. "The Pattern of Party Voting in Canada," Public Opinion Quarterly 19: 252-264.

Young, Lisa. 2013. "Party Members and Intra-party Democracy," In The Challenges of Intra-party Democracy, eds. William Cross and Richard Katz. Oxford: Oxford University Press.

and William Cross. 2002a. "The Rise of Plebiscitary Democracy in Canada," Party Politics 8: 673-99.

. 2002b. "Incentives to Membership in Canadian Political Parties," Political Research Quarterly 55 (3): 547-69.

Anthony Sayers, and Harold Jansen. 2007. "Altering the Political Landscape: State Funding and Party Finance," In Canadian Parties in Transition, eds. AlainG. Gagnon and Brian Tanguay. Toronto: University of Toronto Press. 


\section{Appendix 1: Survey Instrument}

2013 Riding Association Survey Project

These are some questions about your activities as an active individual within the provincial Progressive Conservative Party

1. For how many years have you served as President of your riding Association?

2. In what year did you join the Provincial Progressive Conservative Party?

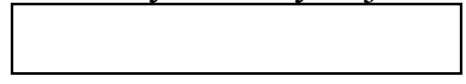

3. Have you ever belonged to a different provincial party?
$\mathrm{O}$ Yes
O No

4. If yes, which ones? (Please check all that apply)

Ontario New Democratic Party

Ontario Liberal Party

Ontario Green Party

Other Ontario party

5. Which party currently holds the seat in your riding at the FEDERAL level

$\begin{array}{ll}\bigcirc & \text { Federal Conservative Party } \\ \bigcirc & \text { Federal Liberal Party } \\ \bigcirc & \text { Federal New Democratic Party } \\ \bigcirc & \text { Federal Green Party } \\ & \text { Don't know }\end{array}$

6. Which party currently holds the seat in your riding at the PROVINCIAL level

O Ontario Progressive Conservative Party

Ontario Liberal Party

O Ontario New Democratic Party

O Ontario Green Party

o Don't know

7. Do you currently hold a membership in a federal political party?

$\mathrm{O}$ Yes

O No

8. If yes, which one?

Federal Conservative Party

O Federal Liberal Party

O Federal New Democratic Party 


\section{O Federal Green Party \\ Other Federal party}

9. In the past year have you attended a federal Conservative Party riding association meeting?
$\mathrm{O}$ Yes
O No

10. If yes, how would you describe the people in attendance compared to those that attend the provincial Progressive Conservative riding association meetings in the same constituency?
O All the same
O Mostly the same
O Mostly different
O Completely different

11. In the 2011 Federal election, for which party did you cast your ballot?
O Federal Conservative Party
○ Federal Liberal Party
O Federal New Democratic Party
Federal Green Party
O Did not vote

12. How often do you volunteer/work on provincial election campaigns?

$\begin{array}{ll}\bigcirc & \text { Every provincial election } \\ \bigcirc & \text { Most provincial elections } \\ \bigcirc & \text { Some provincial elections } \\ \bigcirc & \text { Never }\end{array}$

13. How often do you volunteer/work on federal election campaigns?
$\mathrm{O}$ Every federal election
O Most federal elections
O Some federal elections
O Never

14. For which party do you volunteer? (Please check all that apply)
O Federal Conservative Party
O Federal Liberal Party
O Federal New Democratic Party
- Federal Green Party
O Other federal party

15. To which level of politics do you devote more of your time and attention?

$\begin{array}{ll}\bigcirc & \text { Federal } \\ \bigcirc & \text { Provincial } \\ & \text { Both the Same }\end{array}$




\section{O Don't know}

16. Have you ever held party office in a Federal Conservative Party riding association? If yes, for how many years?

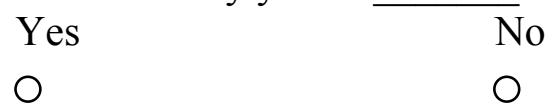

17. Have you ever held party office in the provincial Progressive Conservative Party beyond the local level? If yes, for how many years?

$\begin{array}{ll}\text { Yes } & \text { No } \\ 0 & 0\end{array}$

18. Have you ever held party office in the federal Conservative Party beyond the local level? If yes, for how many years?

Yes

$\mathrm{O}$

\section{No}

$\mathrm{O}$

19. Where would you place the Ontario Progressive Conservative Party on the left right scale, where 10 means "right" and 0 means "left"?

$0 \ldots \ldots \ldots 1 \ldots \ldots \ldots .2 \ldots \ldots \ldots .3 \ldots \ldots \ldots 4 \ldots \ldots \ldots 5 \ldots \ldots \ldots 6 \ldots \ldots . . \ldots \ldots \ldots . . \ldots \ldots \ldots . . \ldots \ldots \ldots 10$

20. Where would you place the Federal Conservative Party on the left right scale, where 10 means "right" and 0 means "left"?

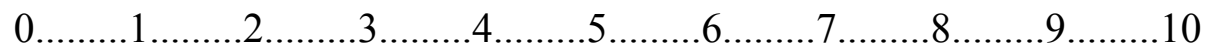

21. Where would you place yourself on the left right scale, where 10 means "right" and 0 means "left"?

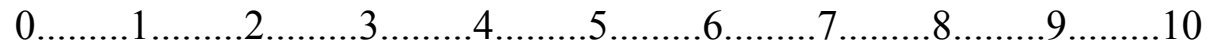

22. The Federal Conservative Party holds too much influence over provincial Progressive Conservative Party affairs.

O Strongly Agree

O Agree

Neither Agree nor Disagree

O Disagree

O Strongly Disagree

\section{These next questions relate to the riding association and your thoughts as the president of a provincial Progressive Conservative Party association.}

23. On a scale from 0 to 10 , where 10 means "the same" and 0 means "different", where would you place the Ontario Progressive Conservative Party and the Federal Conservative Party in terms of shared goals and interests? 


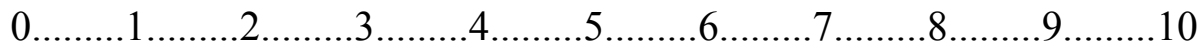

24. On a scale from 0 to 10 , where 10 means "very integrated" and 0 means "not at all integrated", how organizationally integrated is your constituency association with the Federal Conservative Party association in the same riding?

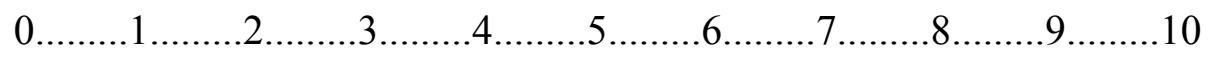

25. How often does your provincial riding association engage in joint fundraising with the federal Conservative Party association in the same riding?

$\begin{array}{ll}\bigcirc & \text { Very Frequently } \\ \bigcirc & \text { Frequently } \\ \bigcirc & \text { Occasionally } \\ \bigcirc & \text { Rarely } \\ \bigcirc & \text { Very Rarely } \\ \bigcirc & \text { Never }\end{array}$

26. How often does your provincial riding association meet with the federal Conservative Party association in the same riding?
O Very Frequently
O Frequently
O Occasionally
O Rarely
O Very Rarely
O Never

27. How often does your provincial riding association host joint social events with the federal Conservative Party association in the same riding?
○ Very Frequently
O Frequently
O Occasionally
O Rarely
○ Very Rarely
O Never

28. How often does your provincial riding association hold joint policy discussions with the federal Conservative Party association in the same riding?
O Very Frequently
O Frequently
O Occasionally
O Rarely
O Very Rarely
O Never

29. Does your local party association and the federal Conservative Party association in the same riding share lists of members, activists, or supporters?
O Yes
O No 
30. Does your local association and the federal Conservative Party association in the same riding coordinate volunteers jointly?

O Yes

○ No

31. Does your local association and the federal Conservative Party association in the same riding use the same professional services (accountants, advertising, etc.)?

$\mathrm{O}$ Yes

○ No

32. During the 2011 Provincial election campaign, did any of the following campaign in your constituency?

Federal Conservative Party leader

Federal Conservative Party MP from your riding (if you have one)

Any other Federal Conservative Party MP

Any other prominent federal Conservative Party figures

Federal leader of a different political party

Federal MP from a different political party

Yes No

O $\mathrm{O}$

0

0

0

00

33. During the 2011 Federal election campaign, did any of the following campaign in your constituency?

Provincial Progressive Conservative Party Leader

Provincial Progressive Conservative Party MLA (if you have one)

Any other Provincial Progressive Conservative Party MLA

Any other prominent provincial Conservative Party figures

Provincial leader of a different political party

Provincial MLA from a different political party

34. Thinking about the 2011 federal election, how do you think the results of that campaign impacted your provincial constituency campaign?
O Helped
O Had no impact
○ Hurt

35. In your opinion, which of the following statements best describes the relationship between the provincial Progressive Conservative Party and the Federal Conservative Party?

OThe provincial party is an organizational component of the federal party.

OA party of the same name exists at the federal level, but it is not organizationally linked to the provincial party.

O The provincial party collaborates with a party at the federal level, but the two are not organizationally linked. 
36. In your opinion, to what extent does the federal Conservative Party influence the provincial Progressive Conservative Party's actions in the following areas:

Content of party platform and policy
Highly Influential
O Somewhat influential
O Not very Influential
Not at all Influential
O Don't know

Choice of candidates for provincial elections
○ Highly Influential
O Somewhat influential
Not very Influential
O Not at all Influential
Don't know

37. In recent elections the provincial and federal party compete for campaign funding from the same donors

$\begin{array}{ll}\bigcirc & \text { Strongly Agree } \\ \bigcirc & \text { Agree } \\ \bigcirc & \text { Neither Agree nor Disagree } \\ \bigcirc & \text { Disagree } \\ \bigcirc & \text { Strongly Disagree }\end{array}$

38. In recent elections the provincial party has significant disagreement with the federal Conservative Party over major policy issues

$\begin{array}{ll}\bigcirc & \text { Strongly Agree } \\ \bigcirc & \text { Agree } \\ \bigcirc & \text { Neither Agree nor Disagree } \\ \bigcirc & \text { Disagree } \\ \bigcirc & \text { Strongly Disagree }\end{array}$

39. Most party members in this association are also members of the federal Conservative Party.

$\begin{array}{ll}\bigcirc & \text { Strongly Agree } \\ \bigcirc & \text { Agree } \\ \bigcirc & \text { Neither Agree nor Disagree } \\ \bigcirc & \text { Disagree } \\ \bigcirc & \text { Strongly Disagree }\end{array}$

40. Most volunteers in this association also volunteer for the federal Conservative Party.

O Strongly Agree

Agree 


$\begin{array}{ll}\bigcirc & \text { Neither Agree nor Disagree } \\ \bigcirc & \text { Disagree } \\ \bigcirc & \text { Strongly Disagree }\end{array}$

41. Most members that sit on the executive in this association have also served on the local executive of the federal Conservative Party.

$\begin{array}{ll}\bigcirc & \text { Strongly Agree } \\ 0 & \text { Agree } \\ 0 & \text { Neither Agree nor Disagree } \\ \bigcirc & \text { Disagree } \\ 0 & \text { Strongly Disagree }\end{array}$

42. Most campaign teams (office manager, campaign manager, etc.) in this association have also served on campaign teams for the federal Conservative Party in the same riding.

$\begin{array}{ll}\bigcirc & \text { Strongly Agree } \\ \bigcirc & \text { Agree } \\ \bigcirc & \text { Neither Agree nor Disagree } \\ \bigcirc & \text { Disagree } \\ \bigcirc & \text { Strongly Disagree }\end{array}$

\section{Finally, here are some questions about your riding.}

43. Which of the following best describes the riding in which you serve as president?

P Primary rural

O Small urban area

○ Primarily suburban

P Part of a large urban centre

44. In what place did the candidate for the provincial Progressive Conservative Party in your constituency finish in the 2011 election?

$\begin{array}{ll}0 & \text { First } \\ 0 & \text { Second } \\ 0 & \text { Third } \\ 0 & \text { Fourth }\end{array}$

45. In what place did the candidate for the provincial Progressive Conservative Party in your constituency finish in the 2007 election?

$\begin{array}{ll}0 & \text { First } \\ 0 & \text { Second } \\ 0 & \text { Third } \\ 0 & \text { Fourth }\end{array}$

46. How many members does your constituency have?

47. How often does your constituency association hold meetings?

48. How many people attend an average meeting? 
49. How many volunteers did you have in the 2011 election?

50. Please select your constituency. 


\section{Appendix 2: Survey Invitation}

\section{Carleton \\ U N I V E R S I T Y \\ Canada's Capital University}

Title of research project: The Impact of Organizational Design on Party Integration: An examination of formal and informal linkages between federal political parties and their counterparts in Ontario

Dear Mr.

My name is Scott Pruysers and I am a Doctoral candidate in the Department of Political Science at Carleton University working under the supervision of Dr. William Cross. I am writing to solicit your participation in a comparative study of federal-provincial party relations in Canada.

I am hoping that you will agree to participate in an online survey of Riding Association Presidents from all major political parties in Ontario. The purpose of the survey is to better understand the relationship between federal and provincial parties in Canada. In general, I am interested in decisions relating to campaign coordination, levels of activism, and cooperation. I am sure from your leadership position within the party that you will be a good source of information in this regard.

Carleton University's Research Ethics Board requires that you be informed that your participation in this project is voluntary. Should you agree to participate, you have the right to decline to answer any question in this study and may withdraw your participation at any time during the survey process. The information gathered from the survey will be used solely for the purposes of writing an academic study and responses will never be attributed directly to you. Instead, responses will be attributed to "Party Activists" or "Riding Association Presidents". Further, no data will be released in a form that allows for identification of who did and did not participate in the study. Should you have any questions regarding these issues, you may contact:

Professor Andy Adler, Chair

Research Ethics Board

Carleton University Research Office

Carleton University

1125 Colonel By Drive

Ottawa, Ontario K1S 5B6

Tel: 613-520-2517 E-mail: ethics@carleton.ca 
I hope that you will be available to participate in the survey. Please visit the following link to be directed to the survey.

\section{$<$ SURVEYLINK $>$}

Thank you for considering this request. 


\section{Appendix 3: Survey Reminder Invitation}

Dear Riding Association President,

About one week ago, we requested your participation in a study of Constituency Association Presidents in Ontario. It is important that you complete the questionnaire so that your experiences and views are included in this study. Remember that your answers will be treated confidentially and no data will be released in a way that allows it to be identified with any particular respondent.

If you have already completed the questionnaire, thank you very much for your participation. If you have not yet done so, please visit the following link today to complete the survey.

We very much appreciate your help with this important research project.

Sincerely,

Scott Pruysers

Doctoral Candidate

Department of Political Science

Carleton University

Ottawa ON K1S 5B6, Canada 


\section{Appendix 4: Survey Consent Form}

\section{Carleton \\ Canada's Capital University}

Title of research project: The Impact of Organizational Design on Party Integration: An examination of formal and informal linkages between federal political parties and their counterparts in Ontario

Welcome to the Ontario 2013 Riding Association Survey Project. The project is designed to gather information about political activists and electoral riding associations in Ontario. We very much appreciate your willingness to participate in this project. Your participation in this project is of course completely voluntary. Your answers to the survey questions are completely confidential. Data from the survey will be used only for purposes of academic publishing (scholarly journal articles and book chapters). Data will be used for completion of my $\mathrm{PhD}$ thesis and will be securely stored for future use in other academic projects. No data will be released in a form that allows for identification of who did and did not participate in the study nor will any responses be attributed to a particular respondent. In that way, your privacy will be fully protected.

The survey data are being collected on a server in the province of Ontario operated by Fluid Surveys. After all of the data are collected, they will be securely transferred to a server at Carleton University and deleted from the Fluid Surveys server. The data will only be available to the researchers working on this project. Please be advised that this project has been approved by the Carleton University Research Ethics Board and fully complies with standard academic research ethics practices. Thank for your time and your participation.

If you have any questions please contact Scott Pruysers (spruyser@connect.carleton.ca) from the Department of Political Science at Carleton University. Any concerns about your participation in this study can be addressed to:

Professor Andy Adler, Chair

Research Ethics Board

Carleton University Research Office

Carleton University

1125 Colonel By Drive

Ottawa, Ontario K1S 5B6

Tel: 613-520-2517 E-mail: ethics@carleton.ca

By clicking "yes" you agree to participate in this project. You may of course withdraw from participating at any time prior to submitting your completed survey. Would you like to proceed? 
Appendix 5: Interview Invitation

\section{Carleton \\ U N I V E R I T Y \\ Canada's Capital University}

Title of research project: The Impact of Organizational Design on Party Integration: An examination of formal and informal linkages between federal political parties and their counterparts in Ontario

Dear

My name is Scott Pruysers and I am a Doctoral candidate in the Department of Political Science at Carleton University working under the supervision of Dr. William Cross. I am writing to solicit your participation in a comparative study of federal-provincial party relations in Canada.

I am hoping that you will agree to be interviewed for this project. The purpose of the interview is to discuss recent election campaigns for the purpose of better understanding the strategic decisions the party took both before and during the campaign. In general, I am interested in decisions relating to campaign coordination and the allocation of resources, especially between parties at the provincial and federal levels in Canada. I am sure from your leadership position within the party that you will be a good source of information in this regard.

Carleton University's Research Ethics Board requires that you be informed that your participation in this project is voluntary. Should you agree to participate, you have the right to withdraw your participation up to one month after our interview and to have any record of information you have provided destroyed and not used in this study. Furthermore, you may decline to answer any questions you wish throughout the interview. The information gathered from the interview will be used solely for the purposes of writing an academic study and responses will never be attributed directly to you. Instead, responses will be attributed to "Party Insiders" or "Campaign Officials". Finally, no recording, other than written notes, which shall be stored in my locked office, will be kept of the interview. Should you have any questions regarding these issues, you may contact:

Professor Andy Adler, Chair

Research Ethics Board

1125 Colonel By Drive

Ottawa, Ontario K1S 5B6

Tel: 613-520-2517 E-mail: ethics@carleton.ca

I hope that you will be available for an interview, either in person or via telephone. Please contact me by email (spruyser@connect.carleton.ca) to arrange a time. 


\section{Appendix 6: Interview Consent Form}

\section{Carleton \\ U N I V E R S I T Y \\ Canada's Capital University}

Title of research project: The Impact of Organizational Design on Party Integration: An examination of formal and informal linkages between federal political parties and their counterparts in Ontario

I, ___ volunteer to participate in a study on federal-provincial party relations in Canada. The purpose of the interview, which will last no longer than 90 minutes, is to discuss recent election campaigns for purposes of better understanding the strategic decisions the party took both before and during the campaign. In general, I an interested in decisions relating to campaign coordination and the allocation of resources, especially between parties at the provincial and federal levels in Canada. The purpose of this study is to understand the ways in which parties at the provincial level coordinate and cooperate with their counterparts at the federal level and vice versa and the extent to which the same individuals are involved at both levels of politics.

Carleton University's Research Ethics Board requires that you be informed that your participation in this project is voluntary. Should you agree to participate, you have the right to withdraw your participation up to one month after our interview and to have any record of information you have provided destroyed and not used in this study.

Furthermore, you may decline to answer any questions you wish throughout the interview. The information gathered from the interview will be used solely for the purposes of writing an academic study and responses will never be attributed directly to you. Instead, responses will be attributed to "Party Insiders" or "Campaign Officials". Finally, no recording, other than written notes, which shall be stored in my locked office, will be kept of the interview. In order to benefit from this research, findings will be made available to the political parties that participated.

Please be advised that this project has been approved by the Carleton University Research Ethics Board and fully complies with standard academic research ethics practices. Thank for your time and your participation.

If you have any questions please contact Scott Pruysers (spruyser@connect.carleton.ca) from the Department of Political Science at Carleton University. Any concerns about your participation in this study can be addressed to:

Professor Andy Adler, Chair

Research Ethics Board

Carleton University Research Office

Carleton University

1125 Colonel By Drive 
Ottawa, Ontario K1S 5B6

Tel: 613-520-2517 E-mail: ethics@carleton.ca

Signature of participant

Date

Signature of researcher

Date 
Appendix 7: List of Interviews

\begin{tabular}{lll}
\hline Date & Party & Role \\
\hline March 2015 & Liberal & Central Party Executive Member (federal) \\
February 2015 & Liberal & Member of Parliament (federal) \\
March 2015 & Liberal & Member of the Provincial Parliament (provincial) \\
April 2013 & Liberal & Central Campaign Professional (provincial) \\
June 2013 & Liberal & Riding Association President (provincial) \\
June 2013 & Liberal & Riding Association President (federal) \\
March 2015 & Liberal & Central Party Executive (provincial) \\
March 2015 & NDP & Member of Parliament (federal) \\
April 2015 & NDP & Member of Parliament (federal) \\
April 2013 & NDP & Central Campaign Professional (provincial) \\
June 2013 & NDP & Riding Association President (federal) \\
June 2013 & NDP & Riding Association President (federal) \\
June 2013 & NDP & Riding Association President (provincial) \\
March 2015 & Conservative & Member of the Provincial Parliament (provincial) \\
March 2015 & Conservative & Central Party Executive (federal) \\
April 2013 & Conservative & Riding Association President (federal) \\
March 2015 & Conservative & Campaign official (federal) \\
\hline
\end{tabular}




\section{Appendix 8: Comparative Manifesto Left-Right Coding}

To calculate a party's position on the left-right scale, the percentage of quasi-sentences devoted to right wing issues is subtracted from the percentage of quasi-sentences devoted to left wing issues. Right and left wing issues are classified into 13 categories each. The following table contains the left-right coding scheme.

Left-Right CMP Coding

\begin{tabular}{ll}
\hline Right wing categories & Left wing categories \\
\hline Military (positive) & Decolonization \\
Freedom, human rights & Military (negative) \\
Constitutionalism (positive) & Peace \\
Effective authority & Internationalism (positive) \\
Free enterprise & Democracy \\
Economic incentives & Regulate capital \\
Protectionism (negative) & Economic planning \\
Economic orthodoxy & Protectionism (positive) \\
Social services limitation & Controlled economy \\
National way of life (positive) & Nationalization \\
Traditional morality (positive) & Social services expansion \\
Law and order & Education expansion \\
Social harmony & Labour rights (positive) \\
\hline
\end{tabular}

Source: adapted from Budge et al., 2001. 
Appendix 9: McKay-Hunter BBQ Invitation

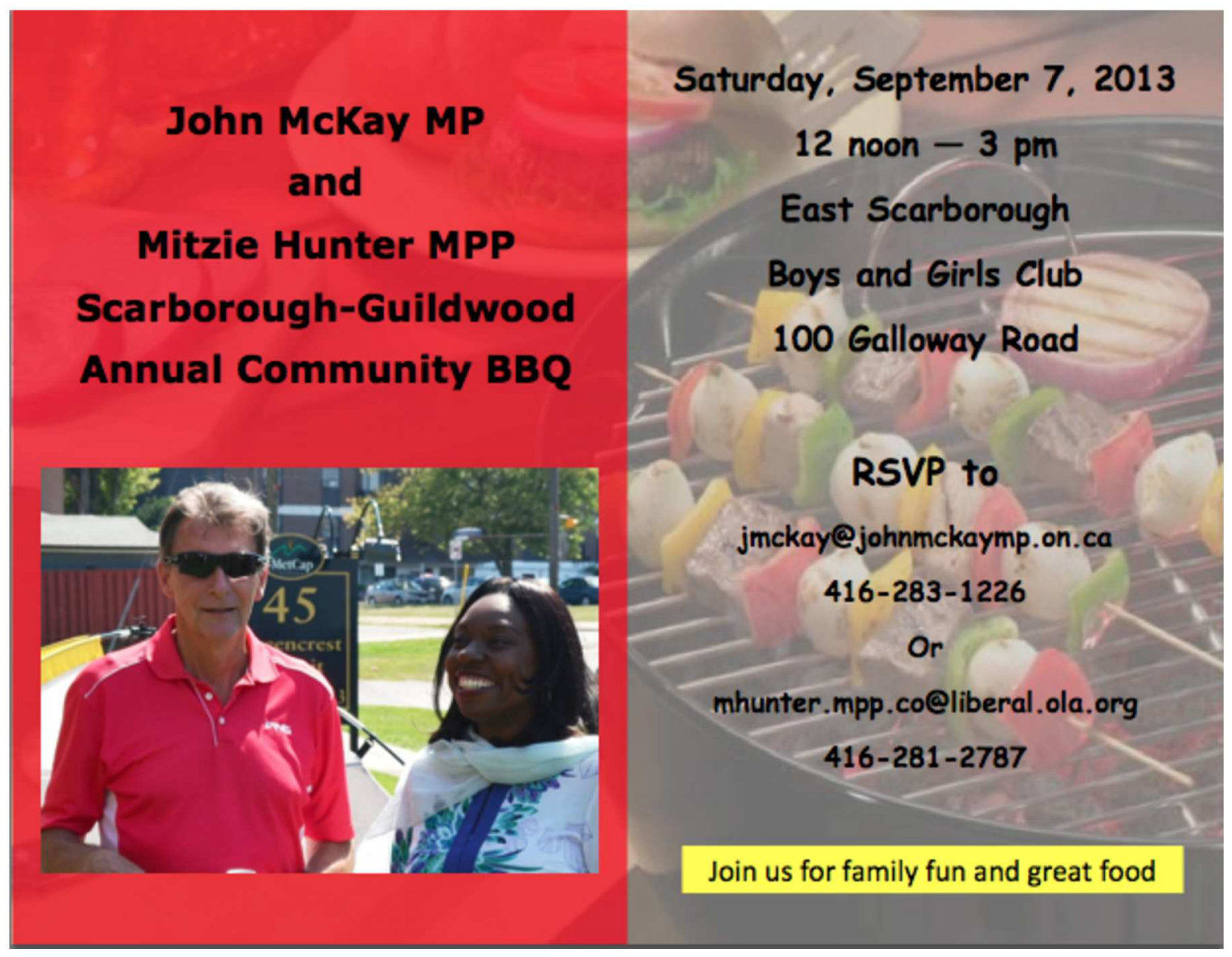




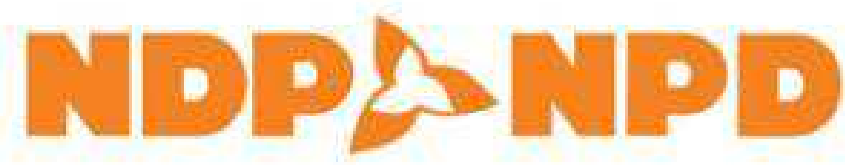

\section{Prosents eur anamal \\ Midsummer Madness}

The must attend exent of this summer

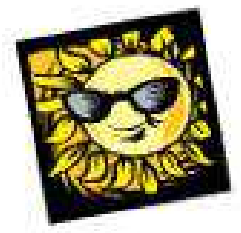

Join MPP Teresa Armstrong \& MP Irene Mathyswen

Thursday, August 7 at $5 \mathrm{pm}$

3M PICNIC AREA

CARKE ROAD (lust north of Oxtord)

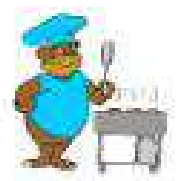

Fundraising B.B.Q, sales table,

$\&$ silent auction

Detuxe sausage, hamburgers, fibeof and vegetariant, savds and desserts

Contact: Margoc Laird: 519-451-0099

Pavkion on sile in case of rain

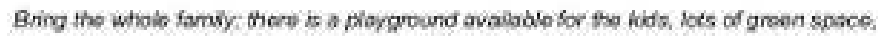
pionic tables avalabile. You may wish to bring lawn chairs for a more condortable sit. 
Appendix 11: Annual Joint BBQ Bruce Stanton, M.P and Garfield Dunlop, M.P.P

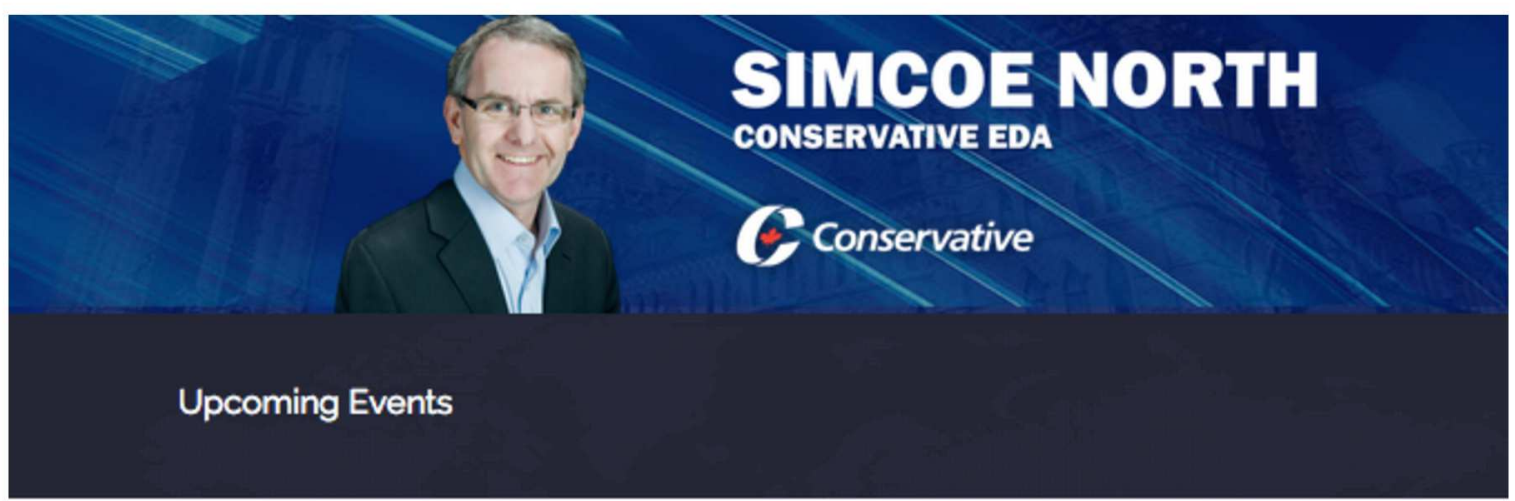

* All Events

Annual Joint BBQ Bruce Stanton, M.P. and Garfield Dunlop, M.P.P

July 11 (4.00 am - 5:00 pm

Coldwater Curling Club

- google calendar

- ICAL EXPORT

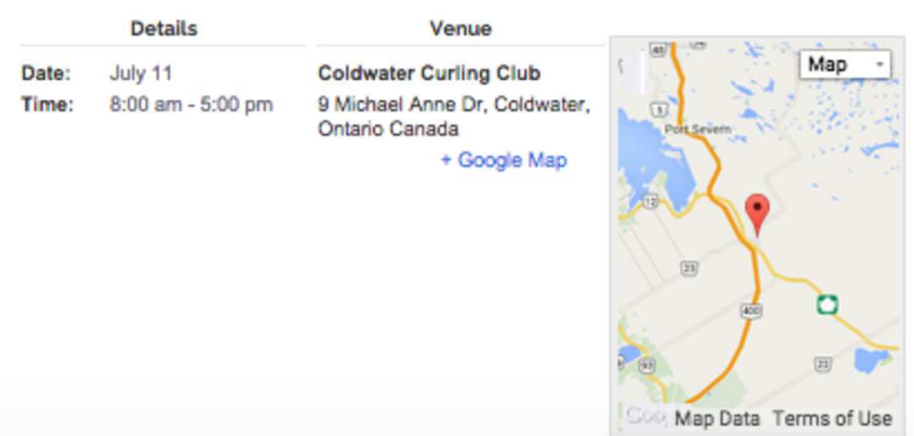




\section{Appendix 12: Tim and Dean's West Niagara BBQ}

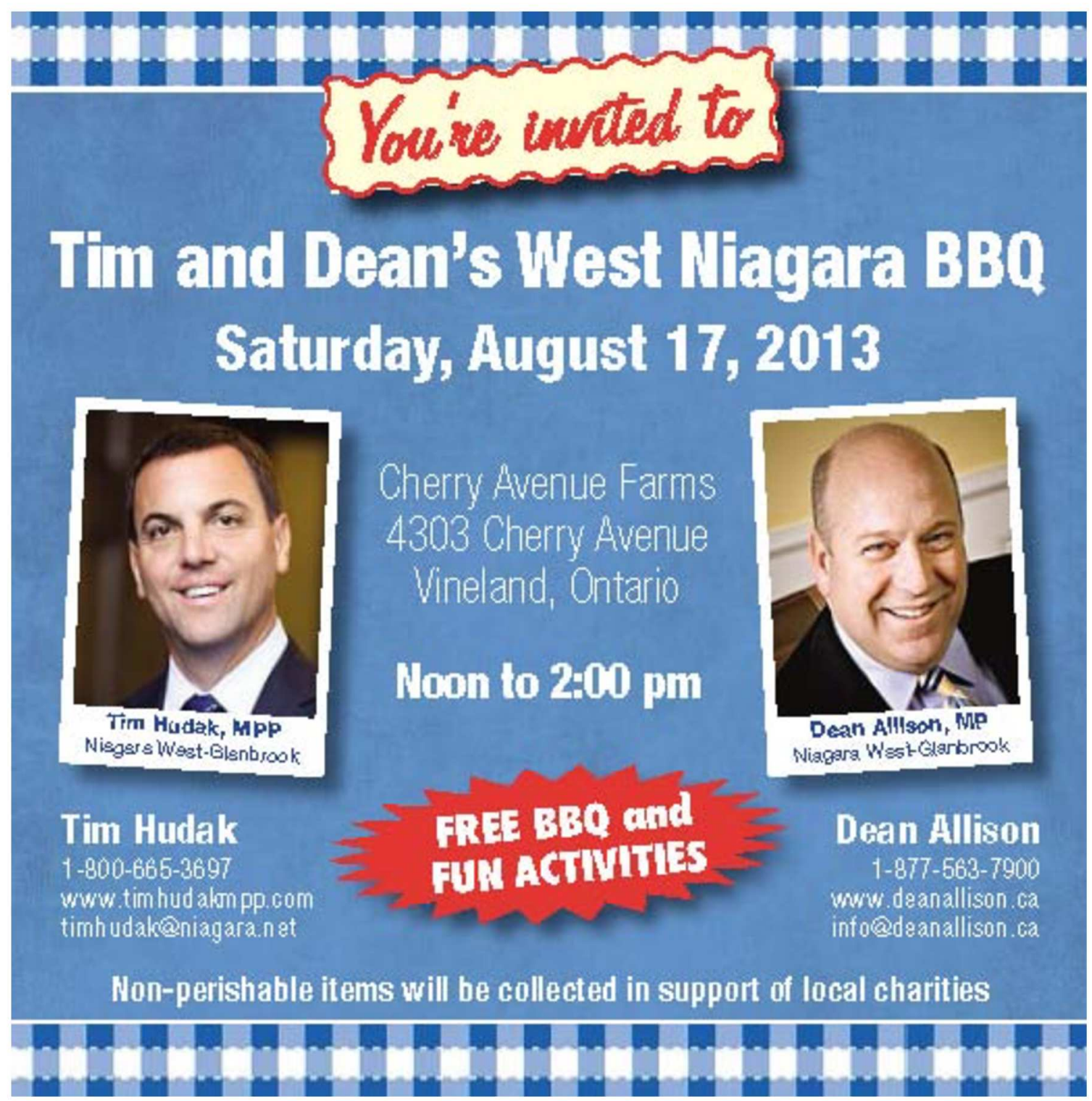




\section{Appendix 13: Provincial PC Announcement for Federal MP Peter Van Loan Event}

\section{ONIARIOPPC}

\section{Upcoming Event}

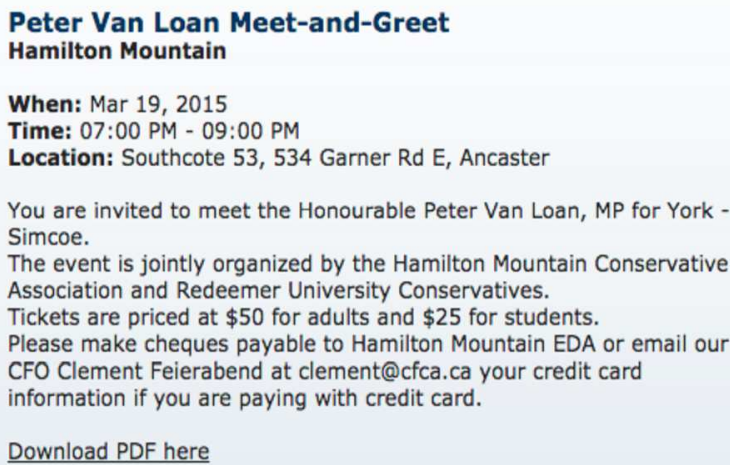

You are invited to meet the Honourable Peter Van Loan, MP for York Simcoe.

The event is jointly organized by the Hamilton Mountain Conservative Association and Redeemer University Conservatives.

Tickets are priced at $\$ 50$ for adults and $\$ 25$ for students.

Please make cheques payable to Hamilton Mountain EDA or email our CFO Clement Feierabend at clement@cfca.ca your credit card information if you are paying with credit card.

Download PDF here

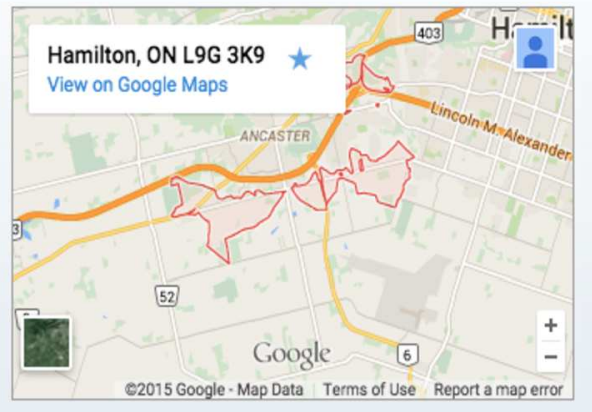

